ORPHEUS

\title{
Powers of \\ Divergence
}

An Experimental Approach

to Music Performance

INSTITUTE 
Powers of Divergence:

An Experimental Approach to Music Performance 


\section{POWERS OF \\ DIVERGENCE:}

AN EXPERIMENTAL

APPROACH TO MUSIC

PERFORMANCE

Lucia D'Errico

Leuven University Press 


\section{Table of Contents}

7 Preface

9 Acknowledgments

11 Specific Terminology

13 Introduction

\section{BOOK I}

Description

of the Practice:

37

47

49

55

58

61

65

67

70

74

79

84

88

93

96

101

108

111

118

121

129

133

136

161

167 Appendix 2: List of Musical Examples

179 Closing Remarks

181

184 References

191 Biographical Note

Appendix 1: Techniques of Minoration
1. The Problem of Resemblance

2. Beyond Improvisation

3. A Series of Anamorphic Glances

4. On Methodology

5. Phonographic Writing

6. The Phantasmic Image of the Musical Work

7. The Vectors of the Body

8. The Musical Work as a "Manifold"

9. A Peripheral Instrument

10. Modes of Exposition 


\section{BOOK II}

Derivatives

Derivative I: On Three Different (Musical) Eyes

Derivative II: The Phonocentric Vision of Music

Derivative III: An Eye That Sees Itself

Derivative IV: The Joyous Power of Simulacra

Derivative V: How to Defy Perspective through Perspective

Derivative VI: Automaton

Derivative VII: How to Produce a Phantasm? Part I: Gian Lorenzo Bernini

Derivative VIII: How to Produce a Phantasm? Part II: Francis Bacon

Derivative IX: How to Produce a Phantasm? Part III: Salvatore Sciarrino

Derivative X: How to Produce a Phantasm? Part IV: Carmelo Bene
First Glance

\section{BOOK III}

Five Glances

upon the

Unspeakable Body 33 37 47 49 55 58 61 65 67 70 74 79 84 88

Second Glance 93 96 101 108 111 118 121

Third Glance 129 133 136

Fourth Glance 161 167 179

Fifth Glance 181 



\section{Preface}

This book is an integral part of the five-year research programme Experimentation versus Interpretation: Exploring New Paths in Music Performance in the Twenty-First Century or MusicExperiment21, funded by the European Research Council, hosted at the Orpheus Institute, Ghent, Belgium, and led by Paulo de Assis. The programme has explored and developed notions of "experimentation" in order to propose new performance practices of Western notated art music.

The research project of which this book is the outcome proposes a move beyond commonly accepted codes and conventions of musical interpretation. Crucially, the project is founded on a strong creative and practical component, presenting a new approach to the performance of Western notated art music. In this new approach, corresponding to an artistic practice supported by reflections and research, the performance of past musical works is not regarded in its reiterative, reconstructive, or reproductive function. This new practice instead insists on performance as a locus of experimentation, where "what we know" about a given musical work is problematised. The performative moment becomes both a creative and a critical act, through which new epistemic and aesthetic properties of the musical work emerge.

This new practice insists on the unbridgeable divergence between codification (score) and materiality (sounds, gestures). Rather than being minimised, this divergence is amplified, so that performance happens through sounds and gestures unrecognisable as belonging to the original work as an interpreter would approach it. Instead of relying on the culturally constructed system through which symbolic categories are biunivocally connected to material events, this practice exposes the arbitrariness of such a system, together with the boundaries of its epistemic implications.

The activity of interpreters and executants focuses on the balance between objectivity (the instructions contained in the score, the "facts" accumulated around the musical work, etc.) and subjectivity (the performer's freedom, his or her expressivity, etc.). This new practice goes beyond both objectivity and subjectivity, embracing an experimental approach to music performance that challenges traditional notions of interpretation. Whereas execution and interpretation relate to an ideal and aprioristic sonic image of the musical work (as Platonic copies), the performance practice proposed here posits itself as a production of simulacra: thus performance becomes a sonic "image" that relates to what is different from it (the score) by means of difference, and not by attempting to construct a (supposed) identity. In this process, internal resemblance is negated, together with the idea of composition as origin and performance as its telos. 



\section{Acknowledgments}

The three-and-a-half-year experience with MusicExperiment21 and with my trajectory in artistic research, leading to the writing of this book, allowed me to interweave an array of expertise and interests (ranging from performance to composition, improvisation, visual arts, and post-structural philosophy) that in my previous activity as a freelance guitarist were left unrelated. This experience gave me the opportunity to understand their common potentialities and their capacity to mutually enhance one another, and to foster possibilities that were latent in me, both as an artist and as a researcher. The change brought forth by this project concerns not only my everyday work but also a complete transformation of my way of thinking about my own profession and creativity.

For this, and for much more, I am deeply thankful to MusicExperiment21's Principal Investigator, Paulo de Assis, to the Director of the Orpheus Institute, Peter Dejans, to my promoter at Leuven University, David Burn, to the Orpheus Institute's Director of Research, Jonathan Impett, to my colleagues and team members, Heloísa Amaral, Paolo Giudici, Juan Parra Cancino, and Michael Schwab, and to the whole Orpheus Institute, its researchers, administrative personnel, doctoral students, and guest researchers. I would further like to thank Zsuzsa Baross, William Brooks, Edward Campbell, Marcel Cobussen, Roberto Dani, David Davies, Matteo D'Errico, Andreas Dorschel, Règis Dragonetti, Wolfgang Ernst, Carl van Eyndhoven, Marlene Monteiro Freitas, GAME Ensemble (Sara Baldini, Hanna Kölbel, Benjamin Maneyrol, Carlo Prampolini, and Hannah Reardon-Smith), the late Bob Gilmore, Arnaud Hendrickx, Gunnar Hindrichs, Ensemble Interface (Marieke Berendsen, Bettina Berger, Anna D’Errico, Niels Hap, Agnieszka Koprowska-Born, Christophe Mathias, and Andrea Nagy), Daniel Leech-Wilkinson, Jo Liekens, Tiziano Manca, Vincent Meelberg, John Rink, Fabrizio Saiu, David Savat, Trio Scordatura (Alfrun Schmid and Elisabeth Smalt), Kathleen Snyers, Richard Taruskin, Luk Vaes, and Heike Vermeire. Special thanks go to Edward Crooks and Justin Christensen for their invaluable work of copy-editing.

Finally, thanks to my friends and family for their support. Each of you knows his or her special place in this adventure. 



\section{Specific Terminology}

The nature of this project led to a partial redefinition of some musical terms that have been consolidated by convention and tradition. A new terminology, albeit provisional, has been necessary; it includes the following terms:

Divergent performances: the main artistic outputs of this research project. Divergent performances are constituted by sounds and gestures that are unrecognisable as belonging to the score they refer to, and in this they diverge from the traditional paradigms of musical execution and interpretation.

Primary work: the musical work as codified by its score(s) and the performative traditions around it, taken as a departure point for the divergent performances. Soundtrack: a sonic object constituted by a phonographic fixation of sounds that is meant to be played back through speakers or headphones in a variety of situations (during a performance, as a recording, etc.).

Sonic image: a soundtrack providing a blueprint of the sequence of events that lays out the conditions for the divergent performances. It can be used as a preliminary material, or included as part of the divergent performance itself. In some cases, divergent performance and sonic image can coincide.

Being-heard-ness: the characteristic of sound when apprehended through perceptual and cultural a priori systems of parameterisation, and therefore partly deprived of its material incommensurability. 



\section{Introduction}

\section{BEYOND INTERPRETATION}

In approaching this introductory text, I am struck by the difficulty of a beginning. When painter Emilio Vedova was teaching at the Accademia di Belle Arti in Venice and one of his pupils would be paralysed in front of the empty canvas, he would dip a brush in the paint and lash it against the white surface. Was the pupil facing the void, and was Vedova's gesture interrupting such a void? Massimo Recalcati (2011) suggests the opposite. This gesture looks for a void, it tries to scar the overabundance of images that crowd the canvas, intimidating the pupil and preventing him or her from beginning. What the brushstroke breaks is not a void, but an array of prefigured knowledges, experiences, commonplaces, memories, modes of thinking, clichés, rules, and vetoes. "The cumbersome presence of dead signs is never a contingent experience. The white canvas is always full of dead knowledges, of inert elements, of monumental ideals" (ibid., translation and emphasis mine).

A creative act must always start in medias res, from the middle, as a break that looks for its void. The project that this book presents is in the field of artistic research, and thus includes a fundamental creative component. It takes as its field of creativity the performance of Western notated art music. What, then, is the empty, or rather the overfull, "canvas" for a performer approaching a piece of written music? What is the middle that his or her creative act starts from?

For the moment, I would like to remain on the literal level of the phrase the performance of written music. "Written music" brings with itself the past, the already codified elements, the stratification of former practices; its "performance" is the reiteration of its life - its future and simultaneously its completion. Thus, the middle I want to and must start from is the-generally overlooked-preposition of. The performance of written music.

The canvas of the of, devoid of actual materiality and at the same time burdened with the virtual inertia of the past, is the place of a crucial transformation. Through it, the codified scores of the Western tradition are turned in a dimension that differs from them, both materially and operationally-that is to say, in the dimension of sound and gesture. Two different levels are put into correspondence; the performance of written music is thus a matter of semiotics, of representation. How does a system of signs allow a certain sonic and gestural materiality to take place? How is the correspondence between the notated sign and its material enactment constructed through performance? What dictates a resemblance between a score and its performance, given that their inscription occurs through materials and modalities that show no conformity with each 


\title{
Introduction
}

other (the first through immaterial symbols and on material visual media; the second in vibratory, haptic, and n-dimensional spatial materialities)?

As a team member of the research programme MusicExperiment21 (musicexperiment21.eu), of which my own project is part, I have been engaged in the development of notions of "experimentation" with the aim of constituting and theorising new performance practices in the context of Western notated art music. One of the fundamental points of this programme was the move away from musical interpretation, regarded as the still dominant paradigm in the performative attitude towards past musical works. Whereas many performers in this musical context consider interpretation as the only possibility for describing their activity, MusicExperiment21 underlines the epochal nature of such a concept and term, and the partiality of the view it offers on musical works:

\begin{abstract}
Rooted in positivist thinking ..., "musical interpretation" has often been used to signify the way in which notation should be interpreted-pointing to a text-based understanding of the musical work. Predicated upon the existence of a fixed source text (the score), which preserves an idealised concept of the authorised "musical work," and on a performer bringing the musical experience itself into renewed existence, the concept of "interpretation" implies a centripetal approach from the performer towards the supposed "essence" of the artwork itself and it is strongly related to other time-bound concepts, such as Werktreue, "authenticity," “composer's intention," and, crucially, to certain editorial practices, particularly the Urtext. (Assis 2012)
\end{abstract}

The work done by MusicExperiment 21 therefore has aimed at challenging traditional modes of thinking, both about the nature of musical works and about the practice of their performance. On the one hand, it has problematised the ontological character appointed to musical works by some musico-philosophical traditions (see Assis 2018, chapter 1). On the other hand, it has redefined the locus of performance as a place of experimentation, where instead of replicating the past through a set of inherited modalities and tools, "what we know" about a particular musical work is reshaped and constituted anew. Crucially departing from both applied musicology and performance studies, MusicExperiment21 situates itself within the field of artistic research, where knowledge production is inseparable from the constitution and reconfiguration of material practices and objects.

Throughout the project, a large part of MusicExperiment21's activity has been directed towards reshaping the mode of thinking about "musical works" and "performance" that the notion of interpretation carries. Conversely, the specific aim of my project is to focus on the above mentioned "of." Whereas the team's research work has been mainly directed towards challenging the fixity of such categories, and instead moving towards the formulation of a dynamic theory for them, my choice was to observe musical works and their performance as relatively stable and unproblematised. The problematisation that I focus on in my research approach happens rather in the transferral from one form of inscription to the other, in the moment in which the symbolic dimension of the score shapes the incommensurably material one of the performance. At a later stage 


\section{Introduction}

of the research, from the circumscribed perspective of the "of," partial redefinitions of what a musical work is and what performance is have also emerged.

\section{TOWARD AN EXPERIMENTAL/DIVERGENT PERFORMANCE PRACTICE}

In an essay on the history of the terminology of music performance commissioned by MusicExperiment21, musicologist Hermann Danuser $(2015,187)$ remarks that "interpretation' is based on texts and leads to texts: first, on the composer's musical text and books on musical performance ... and second, assuming that the work has been recorded, on the sonic text of a work." I would take this remark even further, by adding that it is not only in cases in which a work has been recorded that interpretation leads to sonic texts. The materiality of the performative act in interpretation is shaped by a form of textuality that makes a text out of it. In other words, from the point of view of the transformation happening in the decisive "of," it matters little whether the sonic inscription is recorded and fixed onto a phonographic medium or it takes place in the fleeting moment of the live performance. The textuality of the score is directly transferred into a sonic and gestural enactment that reflects-and is in turntext. In his essay "Beyond the Interpretation of Music," musicologist Laurence Dreyfus comments critically on interpretation. As he states, "Interpretation aspires to reproduce the composer's spirit in a looking-glass, or ... to be 'a mirror which, held before an object, reflects it in its unclouded purity and truth"” (Dreyfus 2007, 263, emphasis mine). Before getting lost in suppositions about what a composer's spirit might be and where it might be possible to locate itif at all-a more basic question arises, How can a sound sequence mirror something that has nothing to do with sounds? Or, from the opposite end, What kind of reduction does a symbolic structure ask to be operated upon a material event in order for it to resemble itself, and according to which mediational apparatus?

In the text-based regime of interpretation, performance is therefore always vicarious. Critically, the overarching goal of my research project is to detach the performance of written music from its text, and to treat it as an independent kind of "writing": one that does not try to reproduce, to represent, or to mirror anything, but that instead creates its own rules according to the materials and modalities in and through which it takes place, constructing its own world.

It is vital to pay attention to a small but decisive detail. What I want to detach from the textuality of written music is by no means "performance"-it is "performance of." My creative activity therefore places a fundamental distance between itself and two pre-existing modalities. In the first place, it does not want to pose itself as a form of "performance" independent of a text. The practice in this direction already has a long history. It is far longer than that of musical textuality - if we remember that the fixation of sound sequences into a reproducible codification could become a habit and a mode of thinking only after the birth of the concept of composition due to the invention of music notation. Moreover, post-notational practice paths have already been abundantly traced by a multiplicity of experiences that have put the emphasis on 


\section{Introduction}

the "onstage" situation of music, diminishing the prominence of textual codification, as for example in experimental music. ${ }^{1}$ In the second place, even if my artistic activity, as we shall see, entails elements of composition, it is fundamentally different from compositional processes. My musical activity rejects any form of symbolic codification of sounds. One of the claims of this research is that there is a form of sonic materiality that makes text of itself, which strongly implies its own notational codification and makes possible the production of a "resemblance" between text and sound. My aim is therefore also the production of a kind of materiality in performance that puts semiotic categories into crisis, jeopardising the very existence of a musical text. Moreover, my musical practice is not directed towards the constitution of new musical "repertoire." In contrast, by referring to a pre-existing repertoire and by destabilising it, this practice aims at taking away, subtracting repertoire.

Again, we are back at the middle. My activity inhabits the space between the fleetingness of performance-as-event and the stratification into music-as-text. The "performance of" (written music) points to a referent (the notated musical work) and at the same time obliterates it, overwhelming it with the incommensurable materiality that is the fabric of performance. The new performances that I have been "writing" as artistic outputs of this project do not resemble the work that they depart from, as they question the whole apparatus that has made such a resemblance a possibility. If they resemble something of the work, they do so in a divergent way. They might not contain any single semiotic unit of the work's score: any pitch, pattern, rhythm, colour, instrumental idiom, harmony, reference to tone system, or stylistic element. My task has been to depart from the original work as much as possible, but only to the point where "something" of it is retained. When I say "something," I choose this word carefully. The indeterminacy that it entails is not an unpleasant drawback of the process; rather, it is the only condition for success when renouncing semiotic categories.

\section{Research Strategies, Perspectives, AND limits}

In the variety of examples, musical experiences, different disciplines, concepts, and references that are addressed in this book, it is important to keep in mind that the point of view is always very particular, and the focus extremely concentrated. Each musical activity (composition, improvisation, analysis, etc.) is always described not only as observed from the perspective of the performer, but also, even more specifically, by a performer who regards her activity through the infinitesimal locus of the "of." I will proceed to introduce five main topics that have structured the research trajectory, and that emerge throughout the book. They are (1) the role of semiotics, (2) beyond authority and tradition, (3) the use of visual examples, (4) a "baroque regime" for the performance of written music, and (5) bodies and organisms.

1 In this sense it is interesting to note Morag J. Grant's (2003) remark that experimental music operates a shift from a symbolic mode of signification to an indexical one, "presenting" itself instead of "representing." 


\section{Introduction}

(1) The role of semiotics

The performance of written music can be seen as a problem of semiotics. Some clarification is needed about what I mean by this, and which kind of musical semiotics is relevant to my project. Despite innumerable exceptions, music does not "represent" anything; it does not possess a "signified," as in verbal languages, or a "referent," as in the visual arts. Several studies have been done on what the "signified" of music might be, ${ }^{2}$ but to establish this correspondence is beyond the scope of this research. The relevant semiotic aspect that concerns me is not so much the relation between what Saussurean semiotics calls the "signifier" and the "signified," but rather, what happens within the dimension of the "signifier" or sound-image. In his Course in General Linguistics, Ferdinand de Saussure ([1983] 2013, 76) states that the "sound pattern" that constitutes the signifier "is not actually a sound; for a sound is something physical. A sound pattern is the hearer's psychological impression of a sound, as given to him by the evidence of his senses. This sound pattern may be called a 'material' element only in that it is the representation of our sensory impressions." The signifier then is not properly material; it is not "physical." As the notational codification of sounds entails a material dimension (pencil and paper, print, music editing software, digital audio workstation, etc.) but is independent from it in that it is symbolic, so musical sound is indeed based on physical sound and is nevertheless symbolic and potentially abstract. It was not until Jacques Derrida's time that the cruciality of the intrinsic notational dimension of speech was pointed out, together with Saussure's limits in considering the phonic substance as privileged in relation to its supposedly degraded "notation" into physical writing.

Saussure continuously reminds his readers of the difficulty in distancing the study of verbal language from all the "transparencies" built by its wide usage. With Jacques Lacan, I would add that whereas language is commonly understood as a "tool" to be used by subjects for practical means, conversely, language "uses" or, even better, constitutes subjects. In this respect, it is vital to clear the ground of the commonplace notion of music notation as a simple "tool"-mnemonic, organisational, compositional. Not only has notation built a new way of thinking about music and about sound, its wide (or exclusive) use by interpreters also imposes a huge series of "transparencies" about what happens to sound when thought (and performed) through notation. When Igor Stravinsky (1947, 122) advocates for a kind of performer who, when reading a score, would "[put] into effect ... an explicit will that contains nothing beyond what it specifically commands," he is inhabiting precisely such a transparency: for what is commanded on paper has nothing whatsoever to do with sound. Whenever there is representation (or, more simply, "one thing stands for another"), there is no possibility for the neutrality wished for by Stravinsky. In representational processes we have to keep in mind that "what represents" cannot be identical to "what it represents." The system of transferral between the represented and the representing, especially when deemed "neutral" or "transparent," is far from being so-quite the opposite, it is a way of constituting reality.

2 See in particular the work of Eero Tarasti $(1994,2015)$. 


\section{Introduction}

The point is precisely this: to understand what kind of reality musical interpretation constitutes, and to propose a different one. The specificity of each reality is a very important aspect of my research. It is impossible to outline a general semiology of music performance, not even in the very limited scope of notated music in the Western tradition. As Gilles Deleuze and Félix Guattari widely discuss in the fifth plateau of $A$ Thousand Plateaus $(1987,111-48)$, one general semiology does not exist, there are only specific semiotics, or "regimes of signs" (ibid.). Moreover, each of these semiotics is not abstract and pure, but can combine with others in every possible kind of situation-from the macroscale of political regimes and historical epochs, to the micro-scale of pathologies, family situations, and fleeting and incidental moments in communication. Nevertheless, it is also true that some of these semiotics might happen to adhere more consistently to given epochs, contributing to their constitution and definition. The same can be said for musical semiotics. Interpretation is indeed time-bound (as the above cited studies by Danuser and Dreyfus underline), but it is also constitutive of a musical episteme, one that is still dominant but that should not prevent one from looking for other regimes, other realities, and other new epistemes through creative practice.

(2) Beyond authority and tradition

In the essay discussed above, Laurence Dreyfus (2007) suggests that in musical interpretation the presence of an authority is fundamental. Authority is invoked by the interpreter facing a text to even out arbitrariness and provide orientation in indecision. He lists a series of authorities that regulate the boundaries of performance in the regime of interpretation:
(1) the composer who creates the work; (2) the musical text which is commonly a stand-in for the composer himself; (3) the teachers and music directors who transmit the authority of the composer or the text; and (4) superior, usually older musicians whom one emulates.... (5) performers' traditions, as in the assertion that this is the way we have always done it; (6) musicological rectitude ...; (7) musical structure (as defined by music theorists and analysts); and something called (8) musical common sense. All these authorities conspire to validate interpretations, to assure us that we are doing the right thing, and to help pass on interpretative practices to the next generation. (Dreyfus 2007, 254)

Authority plays a prominent role in interpretation. Yet, the aspect on which I would like to draw attention is not the need for an upheaval of or a rebellion against authority - which, incidentally, usually leads to the instauration of a different authority. Rather, the important aspect is that the need for authority is not an accidental or cosmetic dimension of musical interpretation. The establishment of authority in music performance is of course a cultural and historical construct. Dreyfus even suggests that "to play a piece of music without caring for any agent of authority would mean that we would no longer be interpreting at all but approaching music via other, conceptual frames" (ibid.). Yet, there is a deeper side to this matter, concerning the nature of music notation and its operational modalities. The need for authority is merely a side effect of 


\section{Introduction}

the arbitrariness of the symbolic system, through which sounds are codified in the Western tradition.

I refer again to verbal languages and to Saussure's reflections, in particular to what he wrote on the topic of the arbitrariness of the sign. Most evident in alphabetic writing, the sign has liberated itself from its relation to speech. This way of working is unlinked from physicality: it is algorithmic. However, whenever words have to relate to speech and to its physical enactment, arbitrariness generates the following paradox: on the one hand, "the arbitrary convention ... allows free choice" (Saussure [1983] 2013, 86); on the other hand, this choice can be fixed and regulated only by the passage of time. Here shines the doubleedged sword of music notation: it consents to detach a musical sequence from an immanent, physical, sounding practice; but whenever this sequence must be turned again into physical sound, it cannot dispense with the continuity of tradition. In Saussure's words, "It is because the linguistic sign is arbitrary that it knows no other law than that of tradition, and because it is founded upon tradition that it can be arbitrary" (ibid.). The rethinking of a relation between performance and written music different from interpretation must therefore also address the role of tradition. Or, vice versa and most importantly, a music performer willing to dispense with the burden and with the epistemic implications of the continuity of tradition cannot escape the redefinition of his or her own practice in terms radically different from execution or interpretation.

The objection might be raised that many musical works have been generated in a specific epistemic landscape, one that is inextricably linked to the notion and practice of interpretation. In this respect, interpretation would be what the score itself asks to be done with it. All the same, this should not prevent an artist from relating to the musical work in a different way from what the musical work "thinks" itself to be. A new vision of what a musical work is hovers in the background of this book. Such a vision has been deeply influenced by MusicExperiment21's new image of the musical work as an assemblage, 3 a complex aesthetic-epistemic network of things, forces, intensities, and signs, which entails a historical, cultural, material, symbolic, and psychological dimension. In the view of my project, the musical work as codified by its score(s) ceases to be either a set of instructions or an ontologically defined entity. It becomes a reservoir of forces, a dynamic system able to affect times, places, and epistemes different from those in which it was generated. As an assemblage, the musical work contains the potential energy to reappear in material instances able to reshape it, time after time.

(3) The use of visual examples

The example of verbal language, of the relationship between the symbolic dimension of writing and the phonetic dimension of speech, has been extremely relevant throughout my research. But even more relevant-I would say seminal - has been a constant reflection on how a similar correspondence

3 On the notion of musical work as assemblage, see the chapter on "Assemblage Theory for Music" in Assis (2018). 


\section{Introduction}

between codification and materiality, representation and physicality, takes place in visual art. What has been said above about the existence of several "regimes of signs," each constitutive of a different reality, can also be said for visual representation. Moreover, visual art has an advantage over verbal and musical languages: it entails a spatial, sometimes even projectional dimension that gives more clarity and apprehensiveness to the processes of representation. It has therefore been a useful comparative tool for understanding the processes at play in the relationship between the symbolic codification of the score and the materiality of performance. In this comparison, I am not attempting a correspondence between visual art and music, maintaining their analogy as representational processes-evidently, musical composition cannot claim a "referent" in the real world as visual art might. Once more, it is important to keep in mind the horizon of my research, the "of" connecting/separating musical works and their performance. The visual paradigm is relevant for my own research for the very strong role that the word "of" plays in it. As much as visual art relates to the representation "of" reality, music performance relates to the representation "of" musical works.

In visual art, every new way of conceiving space, every shift in the representational paradigm, every new relationship enacted between the material (canvas, paint, marble, etc.) and the symbolic and mental, is not only the consequence of a technical innovation. Every visual regime constitutes a different world, with strong epistemic implications, whose understanding, albeit not immediate and easy, is nonetheless more physical and accessible than what happens in sonic worlds, where the fleetingness of materials is all too often mistaken for a closeness to immateriality-a-signification, a supposedly prelinguistic or "spiritual" domain. These reflections on different modes of representation in the visual arts have become increasingly important for me in thinking critically about different regimes in the performance of written music. I began to delineate a parallel between musical interpretation and linear perspective, especially in the historical moment when this representational technique came to coincide so strongly with the epistemic paradigm of Western culture as to substitute itself for the "visual reality" of things. This technique, which entails a whole epistemic paradigm of rational viewing and measuring of things and distances, was initiated in the time of Giotto and culminated in the experiments of Filippo Brunelleschi. It is still now widely deemed to represent "reality as it is," as the role of photography shows-photographic devices function with linear projection and they still define life-likeness in today's relationship to images. In a similar way, musical interpretation and execution have obscured their own arbitrary value, coming to coincide with the portrayal of musical works "as they are." Through this reflection, it is not my aim to negate the creative impact, the strength, the beauty, or the value of either linear perspective or musical interpretation. Nor do I want to overlook the enormous space for creativity that both models give to artists, whether they are painters, sculptors, or performers. What I want to underline is how the flattening out of the material dimension in favour of the mental dimension, which both linear perspective and musical interpretation operate, is at the same time their precondition, their strong 


\section{Introduction}

point, and their limit. Just as linear perspective is one possibility of seeing the world, interpretation is one possible type of relation to written music.

The reflection on the visual examples, guided and corroborated by my artistic practice and by observations on operative ways of interpretation, has led to what will probably be for the reader the most controversial claim of this book. This claim is that, in order to be able to interpret or to execute a score, the performer must believe in the existence of an original sound prior to performance. In such a vision, which after Derrida $(1997,11)$ I have called "phonocentric," sound is metaphysically present before the performer begins the first note. This sound might be regarded either as a transcendental entity present in the mind of the composer, supposedly in dialogue with itself, or as located in a given historical time, considered as situated, detectable, and reconstructable. Even when, at the level of composition, the techniques employed overtly expose the role of notation as independent from the "transcription" of pre-existing sounds (I could mention for example Renaissance counterpoint and serial music), the phonocentric vision is restated over and over because notation asks to be transcoded into sound. Conversely, the creative process constitutive of my research project counters such a vision, proposing a different relationship between codification and materiality.

(4) A new regime for music performance: the baroque

Even before the emergence of the ideas reflected on above, which occurred throughout and alongside my artistic process, the starting goal of my research project was to produce a "baroque regime" in the performance of written music. I have already hinted towards the spatial and projectional tools provided by the observation of representational mechanisms in the visual arts. For reasons that I could understand and articulate only through the progress of my research and artistic practice, there is something in the representational approach of some Baroque artists-specifically that of Gian Lorenzo Bernini-that suggests a possibility for a different approach to music performance. Why was Bernini's approach so dissimilar to that, for example, of Michelangelo? What kinds of different epistemic implications are their works expressing? In many instances, Bernini and Michelangelo operated on the same kind of assemblage: iconography-mythology-body-mineral-supports-sculptural-space-architectural-space-urban-space. Where then does the difference lie in their ways of approaching the assemblage, of "machining" its components, of redistributing its parts?

The deeper I got into these questions, the more I realised that what I named the "baroque regime" exceeded the Baroque as a-however dubious-historical category. Gilles Deleuze opens The Fold: Leibniz and the Baroque ([1993] 2006,3) with the following sentence: "The Baroque refers not to an essence but rather to an operative function, to a trait." Similarly, the "baroque" I was looking for was an operative function, which could guide me towards a new regime for the performance of written music. What this baroque function produces is the liberation of divergence as a positive and absolute power, pointing towards a locus where semiotic categorisations subside. 


\section{Introduction}

As a trait, as a function, the baroque is transhistorical. Not all "Baroque" artists, in a historical sense, are "baroque" in an operative one; vice versa, not all operatively baroque artists are historically Baroque. I have looked for baroque instances throughout history, and have adopted four artistic experiences as models for my own practice: that of sculptor, architect, urbanist, painter, and scenographer Gian Lorenzo Bernini (1598-1680); that of painter Francis Bacon (1909-92); that of composer Salvatore Sciarrino (b. 1947); and that of actor, theatre director, film-maker, and writer Carmelo Bene (1937-2002). Through the plurality of their experiences, through the differences in their fields, and through the diversification of fields that characterises the work of some of them, I could identify four fundamental characteristics of the "baroque trait" that I have been looking for. I will list and describe them briefly here, as a memorandum to aid the reader to recognise their emergence throughout the book.

1 The poetics of the double: "The baroque dreamed of an eye that would view itself to infinity." This is how Christine Buci-Glucksmann (2013, xv) introduces her book on baroque vision. According to her, the baroque is based on a split between the Eye and the Gaze, an infinite reverberation between the act of seeing and the act of being looked at, generating the vertigo of the Lacanian I saw myself seeing myself. The baroque is a way of seeing that observes a way of seeing. It encapsulates the principles of humanistic visuality, and at the same time takes distance from them.

2 Anamorphosis: This word emerged during the seventeenth century ${ }^{4}$ to describe a particular projectional and pictorial technique. Anamorphosis consists of stretching an image on a surface so that what the image represents can be "understood" only when the viewer positions him- or herself facing the surface at a specific angle (figure 1). From the frontal, conventional viewpoint, the image appears therefore confused and disorganised; when the correct viewpoint is detected, the correct image appears, but its character has something phantasmic to it. It seems to exceed the bidimensionality of the surface of the canvas, to float and move with the micro-fluctuations of the eye of the observer. The distortion of appearance, and the importance of the point of view in affecting the work of art, is another characteristic of the baroque regime.

\footnotetext{
4 According to Jurgis Baltrušaitis $(1977,1)$, the technique of anamorphosis was already in use among painters before that time.
} 


\section{Introduction}

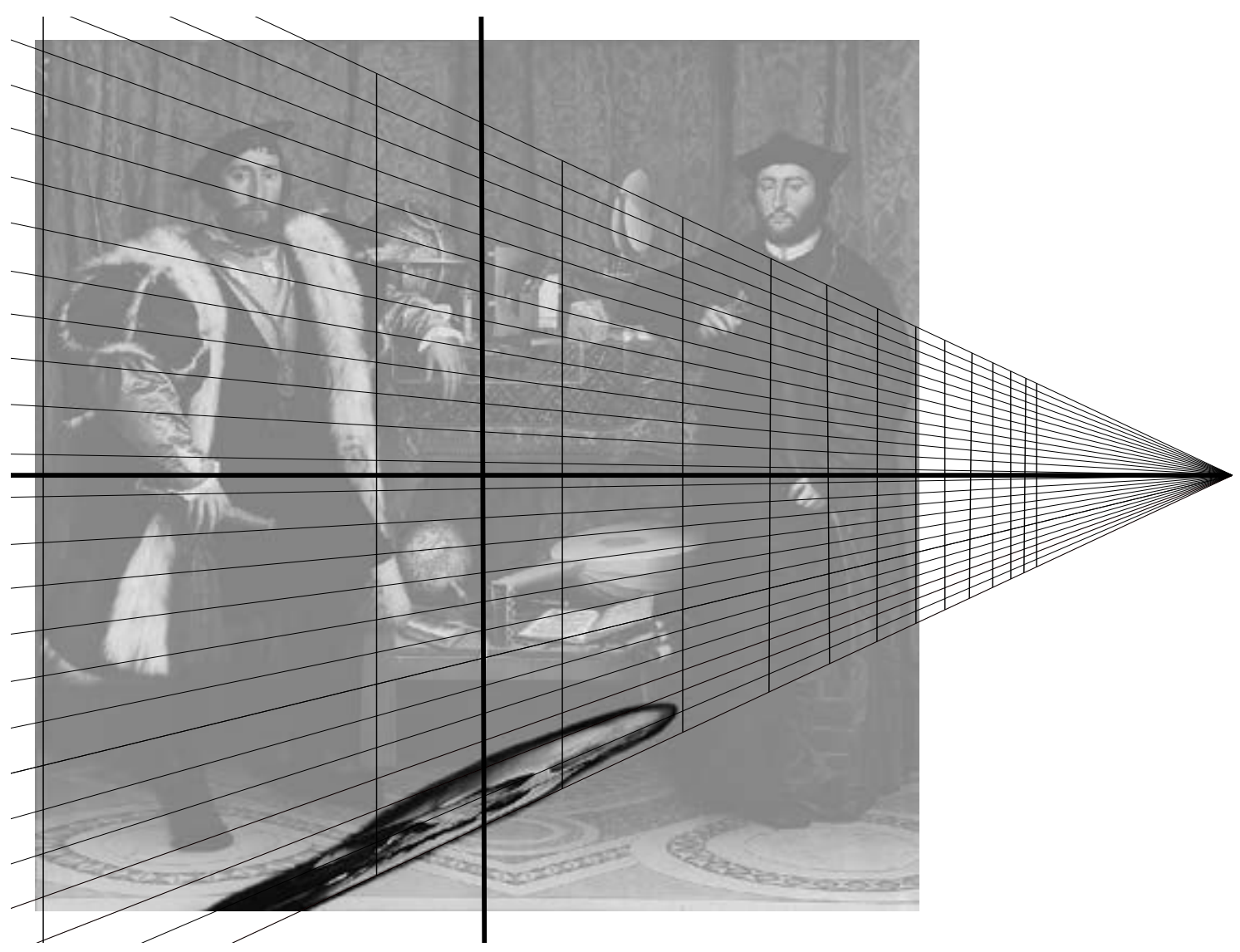

Figure 1.a

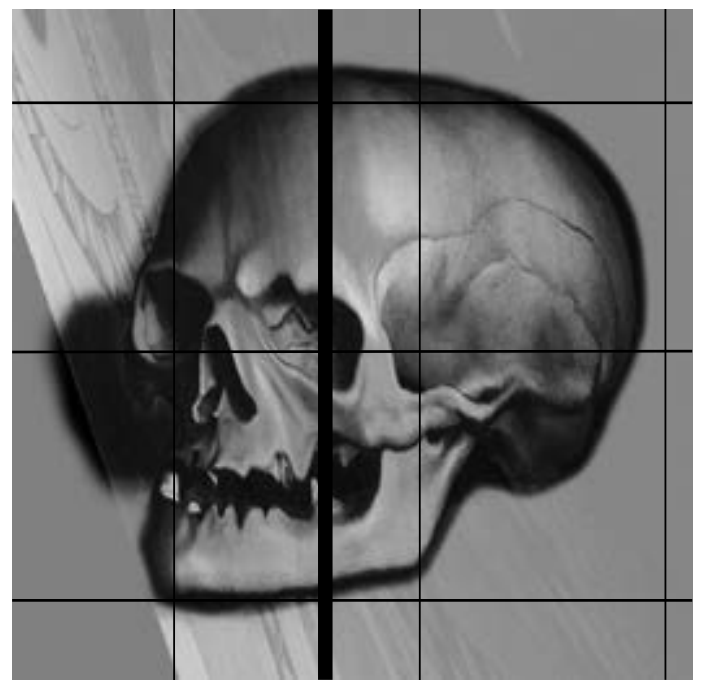

Figure 1.b 


\section{Introduction}

3 The incommensurability of matter: Baroque art starts from a vision of matter that is in continuous vibration, variation, and transformation. "Matter ... offers an infinitely porous, spongy, or cavernous texture without emptiness, caverns endlessly contained in other caverns: no matter how small, each body contains a world pierced with irregular passages, surrounded and penetrated by an increasingly vaporous fluid" (Deleuze [1993] 2006, 5). Through an excess of materiality, the baroque creates a friction with the clarity of the symbolic order, to the point where semiotic categories falter and recognise themselves as insufficient.

4 The displacement of the centre: After the Copernican revolution, and most importantly, the Keplerian one, the Baroque man and artist lost his position as the privileged subject at the centre of the world. In response to this changed episteme, a new vision of matter, of space, of the subject, and of the relationship between the three emerges. First of all, the Earth, formerly thought of as the immobile centre of the planetary system, was displaced from that position. Moreover, in Kepler's delineation of the Earth's orbit as an elliptical trajectory, the planet circles around a double centre: a gravitational one and an empty one, configuring the Earth's motion as unceasing negotiation between attraction and fall.

\section{(5) Bodies and organisms}

The more I have investigated the limits of interpretation, the more other limits have become apparent. In the above-mentioned text from $A$ Thousand Plateaus, Deleuze and Guattari $(1987,134)$ individuate three principal "strata binding human beings," which trace the limit that "separates us from the plane of consistency and the abstract machine, where there is no longer any regime of signs." In the new baroque regime, pursuing the flight towards a plane where semiotics subsides through the positive power of divergence, I have had to take into account not only the first stratum, "signifiance and interpretation," and the second one, "subjectification and subjection," but also a third stratum, probably the most difficult to dismantle: that of the "organism."

That the body of the performer is strongly involved in his or her musical activity is evident, albeit neglected by a long tradition of text-based musicology and music analysis. What is less evident is that a body also has its own semiology. There is a part of the body that makes text. The body is often taken for a preconscious, prelinguistic, a-semantic wild terrain. I will dedicate a specific section of this book to addressing this topic, and to arguing that there are-at least- two bodies: an extensive one (the anatomical body, the body of instrumental interfaces, the organism) and an intensive one (the "body without organs" of Artaud and Deleuze and Guattari; the "body that beats" of Barthes/Schumann). 


\section{Introduction}

\section{Outcomes AND METHODOLOGY}

An integral part of this book is the artistic output of the research, consisting of eleven "divergent performances" that I have produced, which depart from various musical works from the past.. These performances are not to be considered an a posteriori extension of the discourse presented in this book. Rather, the theoretical reflections have been developed and explored interchangeably with the artistic process, in a recursive relationship. On the one hand, verbalisation has clarified and articulated processes that were vague and implicit in the practice; on the other hand, the ongoing artistic work has redirected or consolidated the theoretical progress.

Without the constitution of the artistic part, the point made by the verbal reflection would remain insufficient. This musical practice is therefore also, and most prominently, a critical act. The "divergent performances" might be regarded as "critical studies" on performance, on interpretation, and on the musical pieces they take as their starting point. In an autonomous aesthetic framework they might be regarded as compositions. Yet, crucially, on an aesthetic-epistemic level, they constitute spaces of experimentation. In such spaces, the critique of traditional modes of thinking does not take place primarily through verbal articulation, but more immediately in and through the materials and operational ways specific to artistic production. Critique becomes constitution; the principal object of this musical practice is thus the creative/critical posture of the artistic researcher, enabling the search for ways out of the pregiven codes and territories of musical hermeneutics.

The function of the artistic output has thus been to constitute, through a practical and creative act, (1) a critique of a specific performative activity (interpretation), (2) a reflection on a set of pieces of written music, and, most importantly, (3) a proposition for a new form of practice. In the making of this practice I have never considered myself as a composer, but crucially instead as a performer with a professional background in the interpretation of classical and contemporary Western music. The fact of having been, and still being, an interpreter of written music has been fundamental, because interpretation is still present as a suspended activity. Interpretation is used, as a preliminary act, offstage. In my critique of interpretation, I benefit from having inhabited the role of the interpreter, and thus having become acquainted with the representational and reproductive mechanisms there implied. Nonetheless, what I already could do as an interpreter is neither the object of this research, nor its tool. This rather sets the pre-established territory for a practice that aims at going beyond it.

In other words, I have operated the "baroque" move of double observation. As an interpreter, I have observed a set of pieces from the past; as an artistic researcher, I have observed such observation, generating a distance from it. This attitude is not aimed at expressing or finding what "is inside my own mind" (therefore, I do not take a subjective approach), nor at exploring what might have been "inside someone else's mind" (a composer, another inter-

5 For multimedia documentation of the artistic output of this project, see www.orpheusinstituut.be/en/powersofdivergence. 


\section{Introduction}

preter, etc.- - therefore, I also do not take an objective approach). The aim has been rather to understand what my mind is inside of. What are the limits that interpretation imposes upon my way of thinking about written music? Is it possible to expand such limits, and if so how?

Throughout the artistic process, a methodology also has been delineated, divided into two aspects: the first, which will be explained in $\$ 4$, concerns the establishment of a tripartite approach for the relationship to the scores and to the creation of the new "divergent performances"; the second aspect, reported in Appendix I-Techniques of Minoration, lists a series of specifically musical problems that have been encountered through the research, and explains how I have faced them and connected them to theoretical observations.

\section{FRAMEWORK OF REFERENCES}

Because this bookis not concerned eitherwith "musical works" orwith "performance," the reader will encounter hardly any references to musicology, music analysis, or performance studies. Some examples of compositional activities will be discussed. Salvatore Sciarrino will be one of the subjects of four portraits of the already mentioned "baroque artists." In addition, various observations will be made on how John Cage and Brian Ferneyhough — taken as examples of two diametrically opposed compositional attitudes-generate a rethinking of the "of" between musical work and performance, from the point of view of the score and of the musical work. Certain authors will be cited from the fields of music philosophy and music semiotics. Among them, I cite Theodor W. Adorno, for the distinction made in his writings posthumously published as Towards a Theory of Musical Reproduction (2006) between the "mensural," "idiomatic," and "neumic" dimensions of music performance. Jean-Jacques Nattiez's observations will support and argue for the necessity of an interpreter to construct meaning out of any kind of score-even one that at the textual level exposes itself as devoid of meaning. Some passages from Eero Tarasti will be quoted in relation to what I have named the "phonocentric" vision of music.

A brief reference will be made to media theory, in relation to the epistemic differences between the symbolic codification of music through notation, and its fixation through phonographic media. Observations by Wolfgang Ernst and Vincenzo Caporaletti will be reported.

The largest frame of reference, though, is not specifically musical. This project is about the limits of representation, the semiotic implications of musical writing on the materiality of performance, the search for a trajectory beyond the bounds of signification, interpretation, subjectification, and organisation. I needed to find a theoretical framework that would support the reflection on semiotics and language, but at the same time would not remain circumscribed within their limits. Besides this, such a framework would also need to go beyond the limits of subjective and phenomenological approaches. This is because the subject-object divide did not allow me to explore the problems of my research. Its limits had to be explored at the fringes of paradox. 


\section{Introduction}

Post-structural philosophy provided such a framework, bypassing both structuralism and phenomenology. As I am not a philosopher, I have made a partial - I would say practical —use of post-structuralist theories. The study I have made on them is always specific, and must always be brought back to my artistic practice. Yet, it is not the case that philosophy has explained what art cannot; rather, I have made art with philosophy. The two have accompanied each other, changing their course and mutually disclosing each other's content.

In this framework, I have referred to Jacques Derrida, on two specific points. The first is his concept of "phonocentrism" and his critique of the "metaphysics of presence" exposed in Of Grammatology (1997). The second point regards his comments on interpretation in theatre, which can be found in his writings about Artaud (Derrida [1978] 2005).

My second major reference is Jacques Lacan. His relevant concepts for this project are the mirror stage; the imaginary nature of the "I"; his observations about the gaze, perspective, and anamorphosis contained in Seminar XI: The Four Fundamental Concepts of Psychoanalysis (see Lacan [1981] 1998); and his reflections on the baroque and on the Keplerian revolution in Seminar XX: On Feminine Sexuality, the Limits of Love and Knowledge (see Lacan 1998).

Derrida and Lacan have covered a function that I would call diagnostic - that is, they have helped frame the situation of musical interpretation that was my starting landscape, and helped identify its implications and problems. The philosophy of Gilles Deleuze, alone or with Félix Guattari, has had a more creative function. Whereas for Derrida and Lacan the limits between the world of language and the a-semiotic dimension remain in the last resort insuperable, Deleuze and Guattari open the possibility for a line of flight as an absolutely positive form of divergence towards an a-semiotic plane of consistency. While Lacan defines the Real — the dimension that escapes language—as a lack, an unreachable limit, Deleuze and Guattari see it as a creative process: not the unrepresentable but the non-representational.

Deleuze's thought is particularly relevant for explaining the irreducibly dynamic nature of the "of." His is a process philosophy, focusing on becoming instead of on being. Moreover, he has always been very attentive to the constitutional power of art, to its capacity to shatter pre-given systems of representation. It is not a coincidence that three of the artists that I have adopted as models for the "baroque trait" also played an important role for Deleuze: first, Francis Bacon, to whom Deleuze dedicated the entirety of the monograph Francis Bacon: The Logic of Sensation (2003); second, Carmelo Bene, whose theatre Deleuze wrote about in the short essay "One Less Manifesto" (1997). Finally, Gian Lorenzo Bernini, whose name appears throughout the pages of Deleuze's book on the Baroque, The Fold ([1993] 2006). Deleuze's reading of their experiences constantly accompanied my own reflections about them.

It is important to mention two other Deleuzian concepts that have been crucial in the development of this project. The first is the rehabilitation of the notion of simulacrum, in opposition to the Platonic theory of Ideas, which is exposed in the first appendix of The Logic of Sense ([1990] 2004). The second is the concept of minoration, which appeared for the first time in Kafka: Towards 


\section{Introduction}

a Minor Literature (Deleuze and Guattari 1986) and was extensively used in the essay on Carmelo Bene cited above.

Philosophy has also been very relevant for my reflections about the body. In that respect I must mention the importance of Roland Barthes's essays on Schumann's music (from The Responsibility of Forms, see Barthes 1985a, 1985b), Brian Massumi's text "The Autonomy of Affect" (1995), and the concept of body without organs invented by Antonin Artaud and further developed by Deleuze and Guattari.

Finally, I have to mention several further references regarding my reflections on visual art. As do the thinkers discussed above, the three main authors I refer to in this book observe visual art through philosophy. An important text that reflects on the epochality of linear perspective is Pavel Florensky's "Reverse Perspective" (2002). Fundamental to my own definition of the "baroque trait" have been the studies on Baroque art by Yves Bonnefoy (Rome 1630, 2000) and Christine Buci-Glucksmann (The Madness of Vision, 2013). Also, for an overview of the history and implications of anamorphosis, I have referred to Anamorphic Art by Jurgis Baltrušaitis (1977).

\section{STRUCTURE}

This book was written in an experimental style, which allows for different reading paths (see table of contents). On the basis of practical artistic activity, Powers of Divergence conveys in written form the process of mutual affection between artistic practice and theoretical reflection. The existence of different layers in the content, each having their own discourse and requiring a different language, has led me to conceive of the manuscript as three distinct books:

Book $I$ is a description of the artistic process made in chronological order. It is divided into ten parts. Each part corresponds to one of the case studies, constituted through "divergent performances" of existing musical works.

Book II contains theoretical reflections, ranging from semiotics to philosophy, visual arts, theatre, and music composition. It is divided into ten "derivatives." Each derivative relates to a specific point in the trajectory of the artistic practice, underlying the "rate of change" happening at that point, as suggested by the mathematical sense of the word "derivative."

Book III contains reflections on the materiality of the body as part of the performance of written music. It is divided into five parts called "Five Glances upon the Unspeakable Body."

These three books are not presented separately, but rather are intertwined to produce a "fourth" book. This fourth book, coinciding with the linear order of the chapters, constitutes more of a "proposed sequence" of reading, accounting for the deep-rooted link between praxis and theory (see table of contents).

Appendix 1 is an extensive account on the methodologies developed through this artistic research project, listing a series of specifically musical problems encountered during the research, and explaining how I have faced them.

Appendix 2 is a short technical description of the case studies mentioned in Book I. 


\section{Introduction}

\section{SYNOPSIS}

Book I

$\mathbb{S}$ 1. "The Problem of Resemblance" starts with various reflections on the representative mechanisms of the performance of written music (how the symbolic dimension of the score is transferred into sounds and gestures). The case study presented is of Nicola Vicentino's madrigal Madonna il poco dolce.

$\mathbb{S}$ 2. "Beyond Improvisation" deals with the relations between my new practice and practices of improvisation, emphasising the kinds of representative mechanisms that are at play in the latter. The case study presented is of Giulio Caccini's song Amarilli mia bella.

$\int 3$. "A Series of Anamorphic Glances" introduces the concepts of anamorphosis and of multiple outputs applied to performance. Both concepts emphasise the emergence of new epistemic and aesthetic properties of the musical work in my new practice. The case study presented is of Sigismondo d'India's song Piange Madonna.

S 4. "On Methodology" exposes a tripartite methodology of my new approach to written music and to performance.

$\$$ 5. "Phonographic Writing" reflects on the implications of the use of phonographic inscription as a form of writing radically different from symbolic codification, with a brief incursion into media theory. The case study presented is of Ludwig van Beethoven's Diabelli Variations no. 8.

S 6. "The Phantasmic Image of the Musical Work" reports on a collaborative experience with an architect-researcher, thereby exposing a phantasmic image of the musical work. The case study presented is of Robert de Visée's Prelude from the Suite in D minor.

$\$$ 7. "The Vectors of the Body" reports on a didactic and collaborative experience of composed improvisation. The case study presented is of Giulio Caccini's song Amarilli mia bella.

S 8. "The Musical Work as "Manifold" briefly introduces the notion of a musical work as a "manifold" or assemblage. The case study presented is of Robert Schumann's Kreisleriana no. 4.

S 9. "A Peripheral Instrument" deals with my relationship with a physical instrument (specifically the acoustic guitar). The case studies presented are of Athanasius Kircher's Antidotum Tarantulae and a duet from Claudio Monteverdi's L'incoronazione di Poppea. 


\section{Introduction}

S 10. "Modes of Exposition" contains a reflection on different modes of exposition of the artistic output, and on how each of them enables a different balance between aesthetic and epistemic fruition.

\section{Book II}

"Derivative I" reflects on some regimes of visual representation, individuating a parallel number of regimes in the performance of written music.

"Derivative II," through reflections on the theories of Derrida and Lacan, exposes the theory of the "phonocentric vision of music," proposing a move beyond it.

"Derivative III" proposes and describes the "baroque regime" as a possibility for music performance.

"Derivative IV" explains the concept of simulacra as a positive force, and the importance of the "point of view" thereby implied.

"Derivative V" reflects on some past compositional experiences that have addressed the material dimension of performance in an innovative way starting from the symbolic codification of the score.

"Derivative VI" explains how the baroque regime aims at breaking through the semiotic limits imposed by language and perception.

"Derivative VII" is a portrait of the sculptor, architect, urbanist, painter, and scenographer Gian Lorenzo Bernini (1598-1680).

“Derivative VIII" is a portrait of painter Francis Bacon (1909-92).

"Derivative IX" is a portrait of composer Salvatore Sciarrino (b. 1947).

"Derivative X" is a portrait of the actor, theatre director, film-maker, and writer Carmelo Bene (1937-2002). 


\section{Introduction}

Book III

In the "first glance" I introduce the concept of body without organs, as theorised by Deleuze and Guattari, and discuss its relevance for the performance of written music.

The "second glance" exposes Barthes's concept of somatheme, which appeared in his article "Rasch" (1985b) on Schumann's piano music.

The "third glance" reflects on the exploration of the limits of the body as representation in the artistic experience of Antonin Artaud.

The "fourth glance" is about the intensive body, as theorised through the concept of affect by Brian Massumi.

The "fifth glance" is a final recapitulation in the form of a textual collage, centred on the statue of Ludovica Albertoni by Gian Lorenzo Bernini. 



\section{The Problem of Resemblance}

In his interviews with Daniel Sylvester, painter Francis Bacon tries to put into words the difference between "paint which conveys directly and paint which conveys through illustration" (Sylvester [1975] 1999, 18). It is difficult to provide a clear-cut distinction between these two modes, but, as Bacon phrases it, the first "comes across directly onto the nervous system" while the second "tells you the story in a long diatribe through the brain" (ibid.). It is all the more difficult to tell the one from the other because, according to Bacon, the type of painting that he calls "pure illustration," which he also called "figurative" (ibid., 28), can indeed still affect the nervous system directly, as happens for him with some of Velásquez's works. In any case, Bacon attempts in his works to overcome the moment of "illustration," in order to "bring... the force of the image over very much more strongly than if one just sat down and illustrated the appearance" (ibid. 126).

What happens in the process Bacon called "illustration" or "figurative" painting? In it, there seems to be a relation between "paint" and a "story" that, to take place, has to undergo a "long diatribe through the brain." The process appears therefore to entail three dimensions: (1) the materiality and the action of paint, (2) something to be conveyed (a "story," a thing, an image?), and (3) a modality of accomplishing the connection between the previous two points. Bacon does not question the first two dimensions. He still wants to convey images; he still operates on and through paint. The decisive difference between his painting and "illustration" takes place in the third dimension, how the connection is made. It is crucial that this connection happens at a different speed, and that the speed also concerns how the body of the painter/spectator is affected (coming "directly onto the nervous system").

Usually, when comparisons are made between painters and musicians, the musical figure who is taken into account is a composer-the creator, the inventor of a musical form. I would like to reflect on another, more intriguing comparison: between a painter and a performer of written music, an "interpreter." A painter works directly with the materiality of paint, as a performer works with the materiality of sounds and gestures. In contrast, even when confronted with forms of materiality (paper, print, instruments, computers, etc.), composers in the Western tradition work mainly with mental, symbolic objects-predominantly, with notation. Moreover, painters "convey" images provided by visual perception, through an act of decodification of visible reality, and of recodification into the media and inscriptions of art. In their work, something stands for something else; in a word, they deal with representation, deciding whether to comply with the norm representation dictates (figuration and illustration), to defy it (abstraction), or to modulate between its ever-present power and the possibility of eluding it (as Bacon did). But in all cases a complex set of rules defining 


\section{The Problem of Resemblance}

representation is present, preceding and presiding over the artistic act. In a similar way, an interpreter approaches a musical "work"-a pre-given sequence of musical relations and instructions. He or she decodes a given reality-the score, the historical and analytical givens accumulated about and around that work. He or she recodes, into a sonic and gestural inscription.

In the activity of the performance of written music, we can retrace three dimensions similar to those cited above about Bacon's painting: (1) the materiality and the action of performance; (2) something to be conveyed (a "work," a sonic sequence, a piece of written music); (3) a modality of accomplishing the connection between the two. The third dimension is expressed by the simple preposition of, which both connects and separates "performance" and "written music"; it is the least noticeable and yet is the most crucial.

Traditional interpreters always have to comply with a complex set of rules defining this of, which determines how they produce the connection of resemblance between a work and its performance. Unlike painters, interpreters never "defy" the musical work, they cannot look for abstraction. The space for creativity and diversity in interpretation can be regarded as a balance between the first two dimensions: either greater faithfulness to the score and to its "facts" (objectivity), or greater liberty to the performative moment, to its unpredictability, and to the expressivity of the performer (subjectivity). Does objectivity coalesce with subjectivity, or are they in contrast? How far can a performer go in subjective choices before effacing the resemblance between performance and the musical work? All these questions, whose answers give rise indeed to innumerable different interpretations through the creativity of composers and performers, leave the dimension of the "of" untouched, unquestioned, and unalterable.

At the base of my artistic research project is a conviction similar to Bacon's, that through the performance of written music it is possible to bring about the "force" of a given musical work "much more strongly than if one just sat down and illustrated the appearance" (Sylvester [1975] 1999, 18). If the moment that is comparable to illustration, in the case of performance, is interpretation, from the start the objective of my practice has been to produce a resemblance to a given piece of notated music, which I will call the "primary work," without passing through the set of rules inherited through the interpretational tradition. This implied a starting set of premises.

In the first place, the "matter" of performance (sounds, gestures) should not be moulded ahead of time by the pre-given semiotic units of its score. In other words, the new performance should relate to the primary work without-potentially-containing any element of its score. Something should be retained of the work; at the same time, though, resemblance should be suggested through sounds, musical shapes, and gestures unrecognisable as pertaining to the work as a traditional interpreter would approach it. Second, it was necessary somehow to fix the sonic and gestural sequence of the new performance. In doing so, the risk was that, instead of fundamentally altering the interpretational "of," it would simply re-emerge at a different stage, to be shifted somewhere else. From the start, it was very clear that the task was inher- 


\section{The Problem of Resemblance}

ently different from "recomposing" a musical work from the past, insofar as a new composition might have asked to be in turn executed or interpreted.

The first primary work addressed in my research was the madrigal Madonna il poco dolce (1555) by Nicola Vicentino (1511-72). I decided not to take possession of the musical code devised by Vicentino but to manipulate it. Rather, I tried to relate to the musical work by means of externality, being alert to the sonic, affective, and aesthetic impact that it had on me. Through all these means I was looking for a common ground, a "greatest common divisor" between Vicentino's composition and my living experience of it. My own subjective experience-as performer and as listener-and the objectivity of the score were to be mobilised towards each other, so that the sounding and gestural event of the performance would emerge as a third dimension, independent from both subject and object, but generated through their mutual affection. Through a distortion of the "of," the relations between the two sides of subjectivity and objectivity started to mutate. They began to contaminate each other, and crucially to exchange something of their functions.

The first step was to approach the primary work as an interpreter would: reading the score, listening to existing recordings, and performing the piece myself. I was observing the primary work, not only its codified score but also the way in which the relations contained in it would be transferred, through traditional execution and interpretation, into the material dimension of performance. Such are the internal relations that constitute the "identity" of a given work, which makes it possible for us to recognise it each time it is performed as "the same again," independent from the differences between renditions. I observed the rules of interpretation, with the goal to move beyond them.

After this phase, I started planning the conditions for a new performance. I tried to work out a graphic scheme, a notated score, a series of instructions; yet, all these modalities seemed to contradict the starting premise of my research. Through a new symbolic codification, the interpretational "of" would re-emerge at a different position, and remain intact. It was fundamental to renounce pre-given semiotic units- the categories that are expressed by the conventions of notation, but also by a visual diagram relying on such conventions - and instead to utilise a medium able to imprint not only a linear temporal sequence but also the actual materiality of the vibratory event: phonographic inscription. I therefore produced a "performance" that was recorded, edited, and processed into an electronic soundtrack. On the "surface" of the digital audio workstation, I could operate as a painter would on a canvas. The electronic medium was not my "instrument," a chosen field of expertise; nor was it yet another means through which I was trying to "re-present" my own live performance. It was a support structure for incision, a plane against which to lean the micro-variations of sonic utterances, a performative tool. On it, a structure could be defined, while at the same time events beyond my own will could be fixed and reworked, while the sonic acts that complied too much with interpretation could be deleted or distorted. Through recording and processing, I could experiment with different relations to the score, imprinting some of its elements and re-elaborating them through operations that have something of 


\section{The Problem of Resemblance}

the graphic and the haptic. In the making of this "divergent performance," my memory of the previously interpreted primary work was still operative, but in mutation, turning itself into a non-memory, an active forgetting. The materiality of sound/gesture was obliterating the symbolic dimension of the score.

Through the material inscription, I could capture what trait of the primary work affected my "nervous system" - the physical and at the same time imaginative sensation of resemblance-at the fastest possible speed, without passing through the "long diatribe" of the decodification of signs and information (in the score), and recodification into new signs and information (in performance). At that moment I could not articulate where the fundamental difference lay, nor what had happened structurally to the elements codified in the score, what was left and what had been subtracted, what had been changed and how. Importantly, though, I had accomplished a result that could provide further reflection, and I had discovered in the phonographic inscription of my own performance a tool for constitution and experimentation. 


\section{Derivative I: On Three Different (Musical) Eyes}

A parallel with representational processes that are easier to apprehend can provide insight into the performance of written music. In what follows, I will describe two possible representational worlds in the visual arts, connecting them to two modalities of music performance. Additionally, I will propose a third world, the one that my research project wants to constitute.

(1) Monofocal (linear) perspective. In this projectional technique-systematised and elevated to a dominant visual paradigm during the Renaissancespace is regarded from an unmoving eye, coinciding with a fixed focus. Such vision establishes a relationship of identity between the viewer and the viewed, between subject and object; yet it also establishes a separation between them by means of sight. Filippo Brunelleschi's famous experiment using mirrors and perspective enacts almost tangibly the processes at play in this representational mechanism. After painting a panel with the perspectival image of the Florentine baptistery, Brunelleschi drilled a hole in the spot of the vanishing point. Facing the real baptistery, viewers were invited to look through the hole and to insert a mirror between them and the visible object, so that the reflected panel could show its perfect conformity with reality "as it is" (figure 2). Through Euclid's geometric optics, the conformity between what is perceived as real and what is represented is guaranteed. The infinite variability of the visible becomes completely codifiable from a fixed projection point. In this respect, the "eye" becomes also an "I," a wholeness with which a subject identifies and that it projects into the world it is looking at, but that at the same time allows each subject to separate itself from that world. It is an autopsic glance-in an etymological sense, the "I look upon myself." Recognising him- or herself in reality, the painter dissects and partitions as an anatomist would do.

In perspectival representation, reality is regarded as absolute presence that can be directly transferred, according to the monofocal visual grid, onto the artistic medium. There is absolute stability and correspondence between the visible and the possibility of codifying it. The visible is the absolute signified, where the infinite and arbitrary chain of signs finds its end.

It is important to underline the reductionist move implied in this experiment. Human vision is generated by two eyes that experience the visual as three dimensional, and therefore it is not coherently reducible to the surface of one retina. The plurality of the foci develops sight in a spatial duration without a relationship to a two-dimensional space. In his writings about perspective, philosopher Pavel Florensky comments on the fact that such a representational device has come to coincide so forcefully with cultural assumptions of what "visible reality" is that its artificiality is no longer noticed. He remarks how "the second eye, competing with the first, destroys the oneness, and consequently the absolute- 
Derivative I: On Three Different (Musical) Eyes

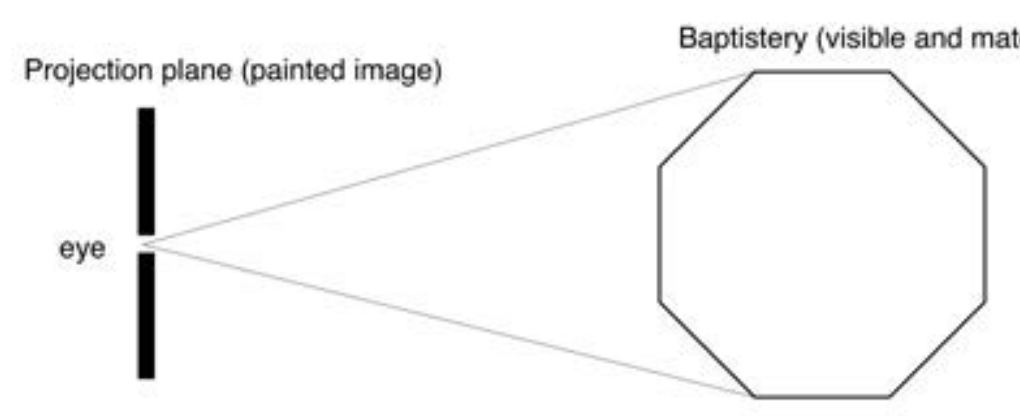

Reflection: painting = mirrored image

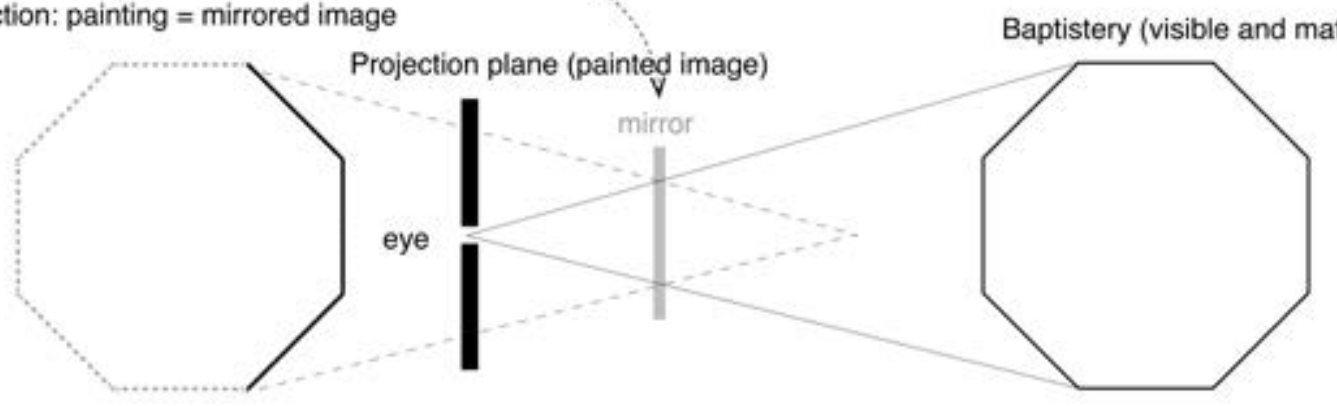

Projection plane (painted image)

Baptistery (visible and material)

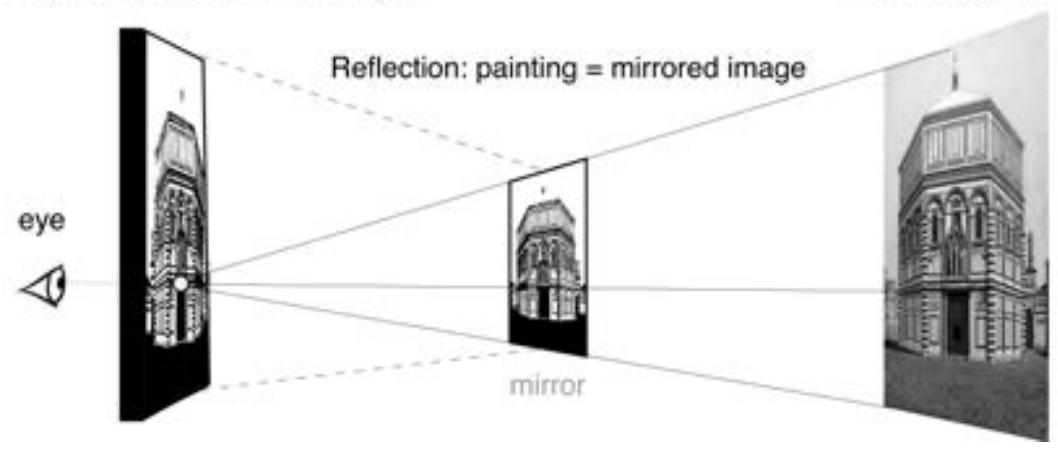

Figure 2. 
ness, of the point of view.... Essentially, the whole world is related not even to the observing artist, but only to his right eye, conceived, what's more, as a single point, its optical centre" (Florensky 2002, 262). To attain the spatial stability of monofocal perspective, Brunelleschi eliminates one eye from vision. Thus, the represented image can attain a punctual visual consistency, coinciding with a singular moment, a frozen reality and immutable presence, which is therefore totally apprehensible.

(2) Reverse perspective. The reproduction of a depth of field on a two-dimensional surface, which is essential for perspective, is not envisioned in Byzantine and Orthodox art. There is no attempt to represent depth in the pictorial space, because all the depth is brought in front of and outside it, in the distance between the image and the viewer. The clearest example of this visual operation is reverse perspective (figure 3 ), where the projection point does not coincide with the position of the viewer, but is located on the opposite side of the viewing plane. It is not a subject that pierces a space with the linear weapon (both pointed and punctual) of the "I-eye"; rather, it is an imaginary glance beyond the painting that looks at the viewer. As he or she looks, the viewer-still the subject of the action of looking-is at the same time subjected to the glance of the image. Moreover, non-planimetric techniques of projection unfold the space of vision as a time of vision: on the two-dimensional surface of the pictorial medium, the eye(s) wander(s) in an n-dimensional space. Here, identification is broken, since the viewer's glance does not coincide with a fixed point. The viewer is rather encountered by image and space, affected by them. The subjectobject relationship, unproblematic in the case of monofocal perspective, cannot work in this instance.

Moreover, reverse perspective does not simply interchange the functions of subject-object. The viewer is subjected to the image, but such subjection is initiated by the act of looking. Thus, whereas in monofocal perspective the glance (situating itself in the only position envisioned for it) aligns with the linearity of the subject-object relationship, in reverse perspective a recursive causality is engendered that bypasses it. One looks, and therefore is looked at. Hence, the space of vision is not simply the projection plane as a mirroring of the visual function of the subject. It is the space of relationality between viewer and viewed, what is outside and beyond the visible.

To outline an application of these visual examples for the relationship between sign (score) and sound (performance), I will first delineate the terms involved. The infinite and ungraspable dimension perceived as "real" and "visible" that is transferred on the projection plane in painting becomes in music performance the dimension of the audible, the physicality of sound, too complex to conform to any kind of codification. The projection plane functions as the dimension of the codifiable: a surface on which some elements of reality are coded and transferred in order to be decoded by means of convention. The centre or centres of projection refer to the agents involved in musical production (listener, composer, performer). 
Derivative I: On Three Different (Musical) Eyes

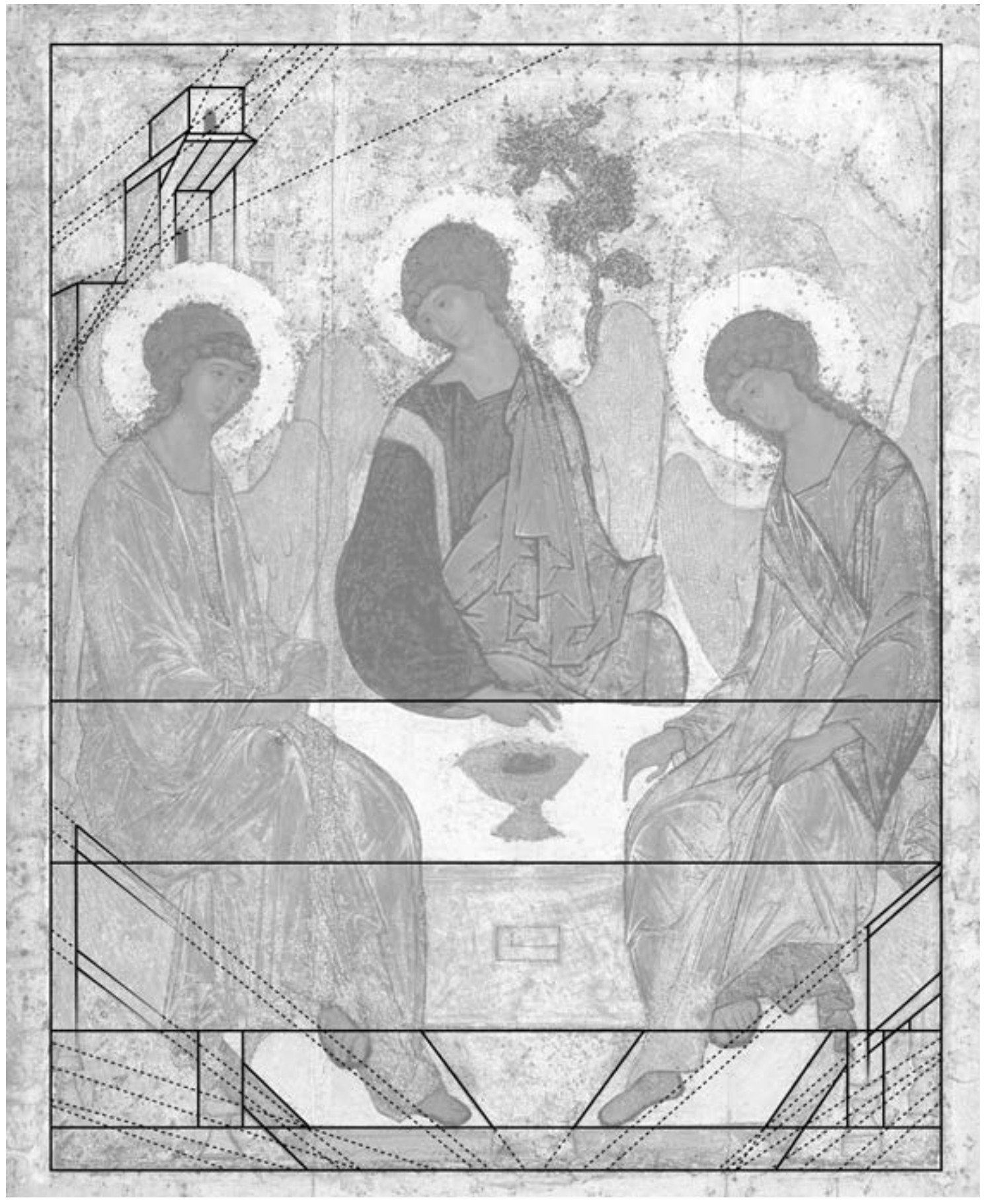

Figure 3 . 
(1) In traditional interpretation, the space defined by the score-performer relationship can be compared to monofocal representation. In it, the infinite variability of the real (audible) is actually made visible, and thus codifiable and projectable onto the plane of the score. The mirroring relationship between score and sound sees the performer as redundant, in that the performer has to insert him- or herself perfectly in the line of identity between score and sonic reality. Utilising the model of Brunelleschi, if the score is the painting and the sonic result is the "real," then the performer has the function of the mirroring surface. He or she is there to guarantee identity between score and sonic result, but is actually superfluous, since the projection point is potentially already occupied by the expectation of the listener, which is in turn inserted into an identity line with the codifiable and the audible (figure 4). Whether it stands for a set of instructions or for an actual representation of the sonic result, the score already encompasses all the possibilities of its faithful accomplishment. The best that the performer can do is to become as translucent as possible. He or she is a medium, a mediator.

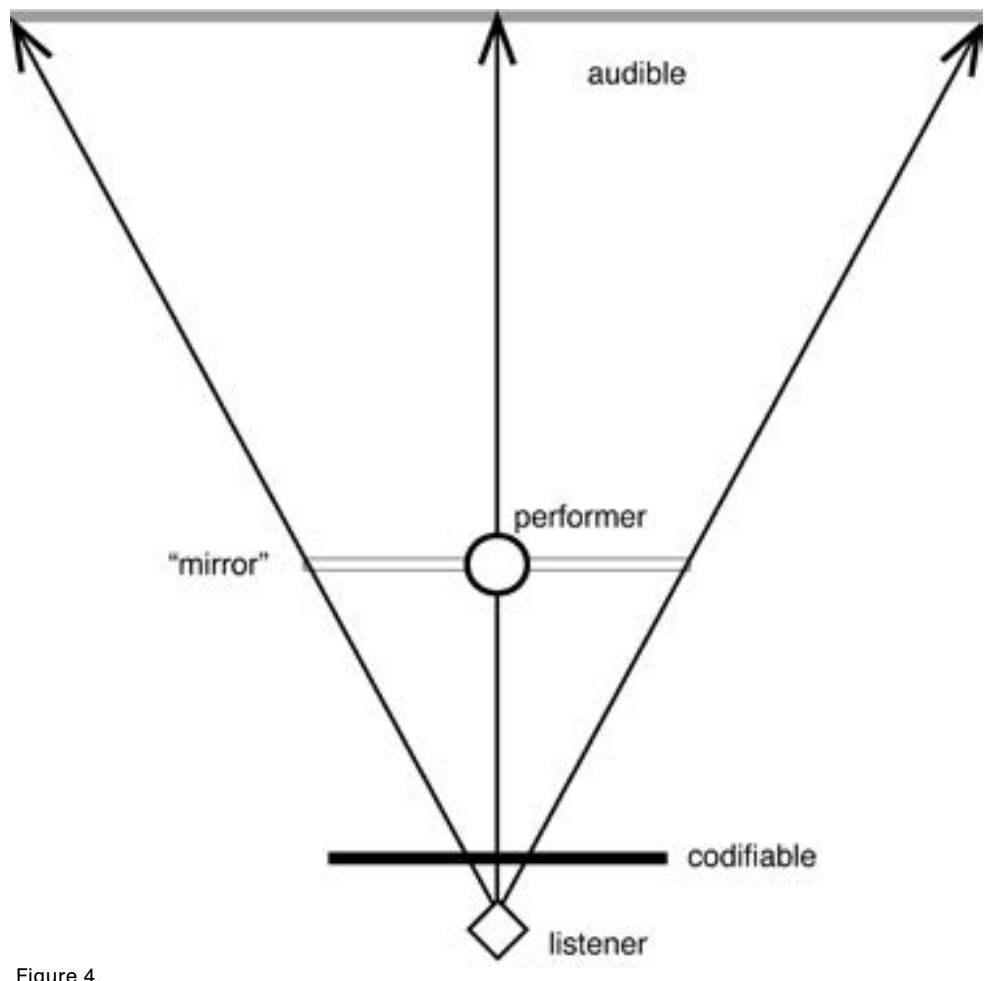

(2) The correspondent of reverse perspective would regard the codifiable (plane of vision) as testimony. An invisible dimension is projected onto the plane, which in itself defines both the limits of the auditory experience and its codifiable surface. This visual model can be compared to music that uses 
as its support either electronic generation or phonographic fixation (or both in combination). The score (plane of vision) corresponds to the limits of the codifiable - in this case, the soundtrack, tape, or digital patch (figure 5). Such a dimension does not seek to include the invisible (the source of the audible), but rather to recreate it as space of relationality between the soundtrack as score and the subject of the act of listening as subjected to it. As Pierre Schaeffer comments about the acousmatic musical work he defined as the "sound object," "the relationship between subject and object is already inscribed within [the work]" (Schaeffer quoted in Nattiez 1990, 98). Such a mode of sonic production does not see the performer as redundant, but he or she remains outside and beyond the locus of musical fruition.

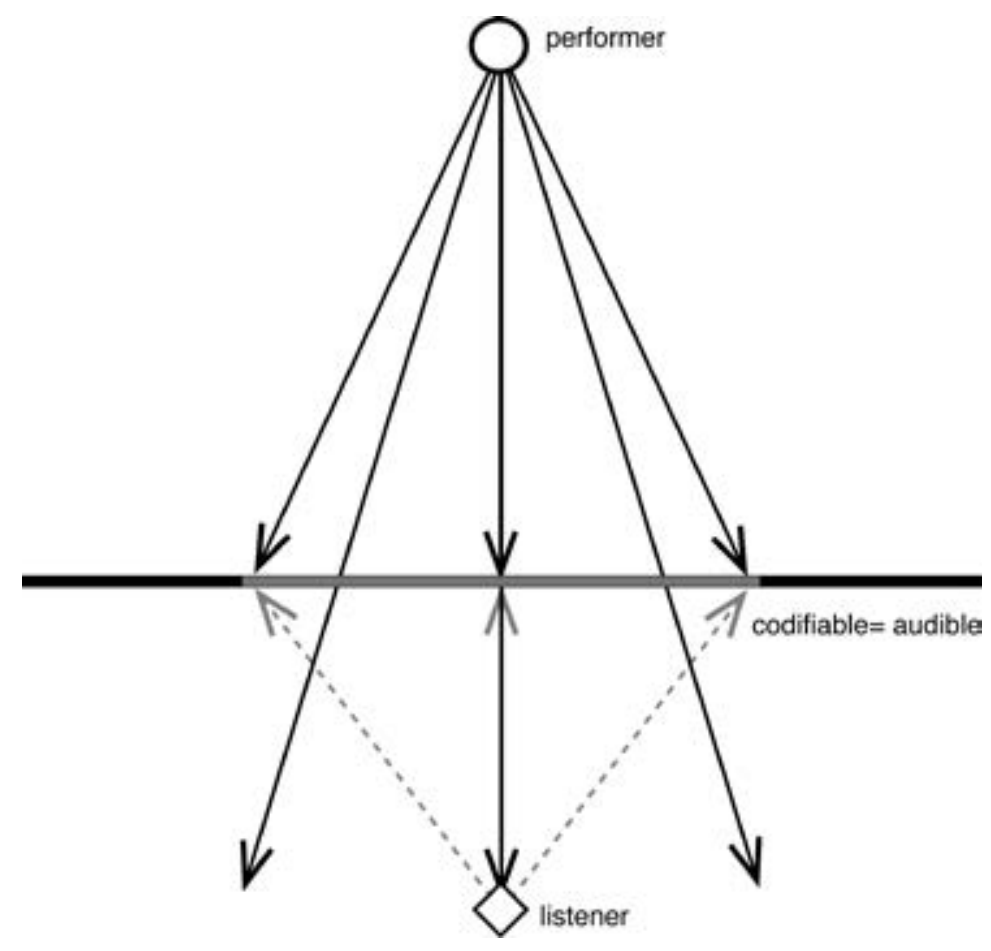

Figure 5 .

A score that is not strictly normative but that allows the reintegration of practices of improvisation or the irruption of unpredictable elements would suggest a dimension that apparently escapes both models; however, it is actually engendered in the first and liable to end up in the second. The performer is still the guarantor of a relation of identity between the instructions contained in the score and the audible result. Moreover, any experience that retains the primacy of an authority upon it - such as would cling to an artist who first performed a work, or collaborated with the composer, or made a first or notable 
recording, and so on - is capable of becoming a testimony of the original will of the composer, reinstating thus the "reverse perspective" model.

Despite their substantial differences, these two models of music performance-"monofocal" and "reverse perspective"-share an important aspect. Regarded from the point of view of the performer, sound precedes inscription. Both modalities stem from a performative approach that considers the dimension of sound in absolute proximity to the presence of a musical idea, be it either completely visualised through notation or "witnessed" through sound's direct projection onto an electronic or phonographic medium.

To unsettle the perfect and ideal alignment of score-sound-listener that entraps the performer into a condition of repetition and surplus, the performer should maintain a relationship with the codifiable that differs from the audible. This implies that the listener too would need to be unsettled from this linear relationship of identity. The question then is, Is it possible to remain inside a perspectival space and at the same time manage to displace the fixed focus that engenders an autopsic vision of (what is perceived as) reality? Since we are referring to notated music, which envisions a score in need of being decoded and transformed into sound, we cannot dispense with the metaphor of perspective. Nevertheless, the performer and the listener need to be kept on the same side of the codifiable but out of the line of identification between the audible, the codifiable, and the agent. This implies a definition of a space that is similar to the monofocal perspective model, but with some radical differences. Some of the elements in the picture need to be repositioned.

(3) A baroque model. This approach to written music able to operate such a displacement resembles a mode of spatial depiction that includes perspective but at the same time defeats it: accepting its limitations, but at the same time trying to retrieve the "invisible" space, the nothing behind the canvas that Byzantine art designated as the only space of (unrepresentable) presence. The new regime of music performance that my research project proposes points to its own outside, in the acknowledgment that the codifiable is incapable of encompassing the infinite plurality of the audible. Yet, it also renounces the annotation of this outside "directly, through a stenography," as Yves Bonnefoy (2000, 44, translation mine) claims Byzantine art did, and as the unmediated projection of sound waves upon an electronic medium implies. Unrepresentability is postulated, not because the medium is deficient (as maintained by a vision of notation as necessarily degraded transcription of presence, see Derivative II), but because ultimately there is nothing to be represented, and any mode of representation is generated by a fictitious possibility of identity between the codifiable and the audible. Once representation is denied, the sign folds upon itself in a paradoxical excess of negation, by showing the illusory nature of both artistic media and their physical supports. Such a musical regime finds its visual correspondent in the baroque model (figure 6). 


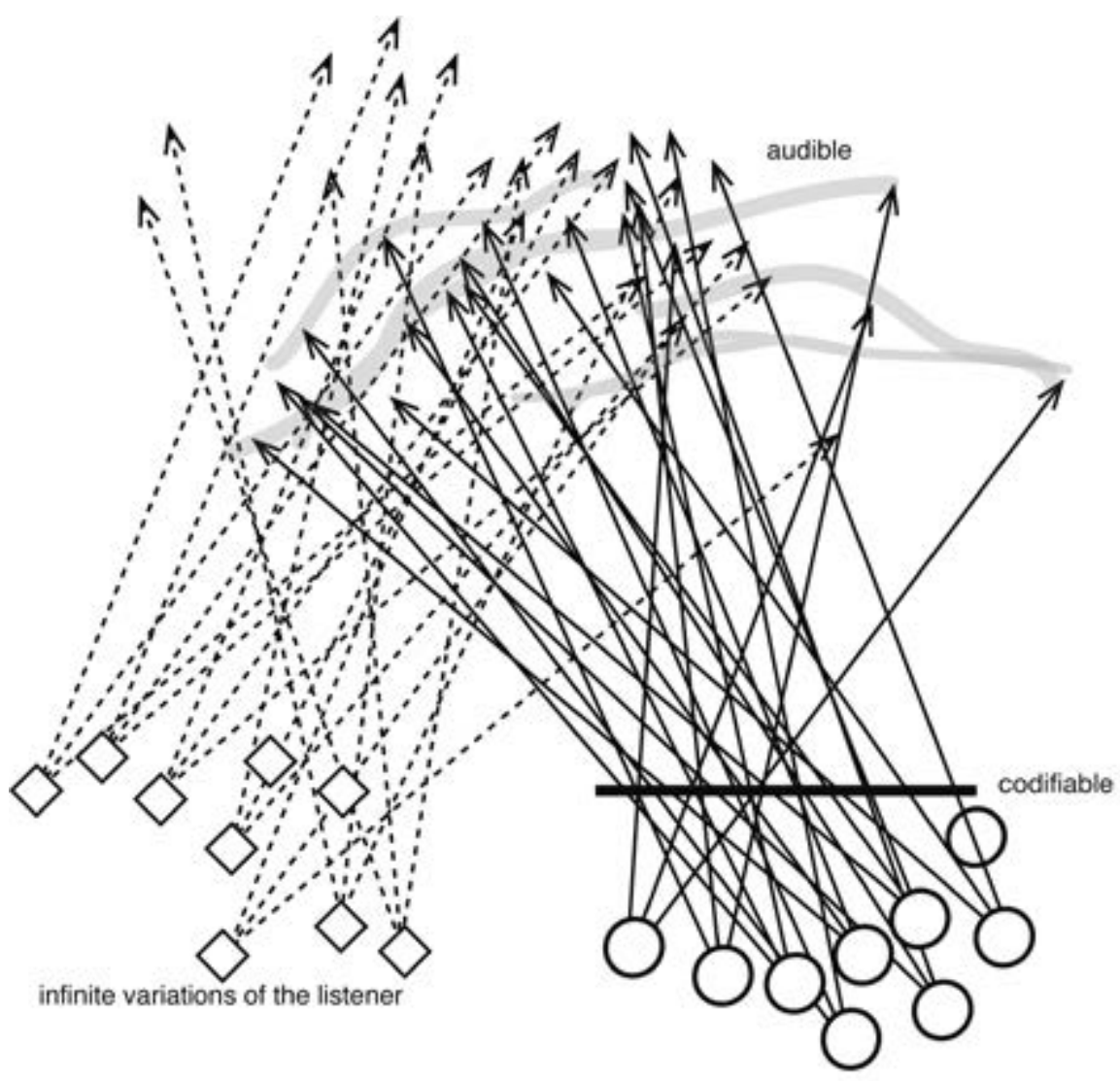

infinite variations of the performer

Figure 6 .

If the baroque accepts the extensive visual constraints of its objects, keeping a reference to a perceived reality and to the representational assumptions of mimesis, such extensive parts are stretched and exploded, forced up to and beyond their own limits. The paramount epitome of the baroque approach to representation is anamorphosis: a technique that "instead of reducing forms to their visible limits, ... projects them outside themselves and distorts them so that when viewed from a certain point they return to normal" (Baltrušaitis 1977, 1). Anamorphosis takes perspective into account, but it "is a continual reminder of the astonishing and artificial elements in perspective... Perspective ceases to be a science of reality and becomes an instrument of producing hallucinations" (ibid., 2). The perspectival version of a reality that can be represented "as it is" by virtue of Euclidean geometric laws can no longer hold up. In this, Baroque art responds to a changed vision of the world. In the place of a locus of hidden meaning to be discovered through the capability of decoding its visible signs, nature becomes for the Baroque man only a decaying sequence of empty 
traces, testifying for the perishability of the world in comparison to the richness and plenitude of "another world."

The distinctions between perspectival, reverse perspective, and baroque models lie also in a different alignment of the relationship between presence and absence. In Byzantine art, presence is unrepresentable - therefore the sign as testimony "makes a sign." It does not represent but it indicates. In perspectival art, signs and the world stand in biunivocal relation: the world can be read, interpreted, the present "thing" is fully represented by its sign in its absence. The baroque mode recapitulates and exceeds the other two models. It points to presence as Byzantine art intends it, but negates the presence that can establish a stable relationship with a sign. Presence is neither representable nor unrepresentable, but non-representational.

Applying the musical terms designated above, the baroque approach entertains a relationship of externality with the codifiable. From a tilted and ever-changing perspective, the performer regards the codifiable anamorphically, distorting it and contaminating it with his or her own point of view. This position engenders a relationship of non-conformity between the sounding dimension (the audible) and the codifiable (the score), and is based on a fundamental divergence. The new sounding result also implicates the relationality between the performer and the score, encompassing it. The instability of the performer, through an infinite variation of his or her position in relation to the score, will produce sound as an excess, not as a mirroring. Ideally, the same excess will potentially also affect the listener, who, instead of searching for recognisability as a parameter for a satisfactory performance, can actively recreate through his or her auditory experience the relationship between the sounding result and the original codification of the piece.

The world depicted by perspectival representation posited the subject at the centre of the universe, epitomised by the monofocal projection point, and the outside world as a spherical emanation from that point. As a repercussion of the Copernican revolution, the human subject is eradicated from its position of privilege. Yet, in Seminar XX, Jacques Lacan $(1998,42)$ notes how "the Copernican revolution is by no means a revolution. If the center of a sphere is assumed, in a discourse that is merely analogical, to constitute the pivotal point ..., the fact of changing this pivotal point, of having it be occupied by the earth or the sun, involves nothing that in itself subverts what the signifier 'center' intrinsically ... preserves." The real revolution takes place not when a centre is substituted for another (the Sun for the Earth), but when a shape of imperfection questions the notion of centre altogether. This happens with the Keplerian introduction of the ellipse into the planetary orbit: "The subversion, if it existed somewhere, at some time, was not that of having changed the point around which it circles ... - it is that of having replaced 'it turns' with "it falls" (ibid., 42-43). The trajectory of the ellipse defines the planetary orbit as perpetual renegotiation between an established, fixed centre and a falling movement towards an empty, unknown centre. 
The change from a single focal point to the introduction of an empty centre that doubles the gravitational one is decisive for explaining the change for a baroque paradigm in the performance of written music. Despite so many significant musical experiences during the twentieth century bringing about a subversion of the communicative mechanisms between composer and performer, the performer's vision in relation to written music has remained perfectly spherical. Communication is displaced, but it keeps slipping back into a centre that is repeatedly re-established somewhere else. The performer has been through many a productive Copernican revolution; what conditions would allow a Keplerian revolution to take place?

The image of the ellipse thus introduces a second focus in the trajectory of the performative attitude of the musician. The "perspectival" approach relates the orbit of the performance to a single centre-the sonic result pre-encompassed by the score and considered as a singular moment in time that is historically locatable and liable to be reconstructed-therefore arranging it as a circle or sphere around such a centre. The baroque mode unsettles this idea, not by negating the existence of a centre altogether (is there such a thing as absolute "freedom" from precodified musical systems?) but by widening the performer's orbital horizon to include an "empty centre" as the attractor of a falling gesture. The centre of gravitation (the original score) is still there, it is still decisive in shaping the direction of the performance. But, instead of constituting the sole centre to which every gesture of the performance univocally refers, the centre will be one element in relation to which a recursive negotiation between attraction and departure, balance and fall, before and after, will unceasingly take place. 


\section{2. \\ Beyond Improvisation}

The experience with Vicentino's madrigal was the start of my research on how to produce a resemblance between a primary work and a performance. In the onstage enactment of its performance, I was confronted with the relationship between the phonographically inscribed soundtrack and the live actions of the performers. I decided to play back the soundtrack and to integrate it with semi-improvisatory actions by a viola player and myself on guitar. These live parts were a sort of gestural recapitulation of the sounds of the track. They were constituted by very simple textural actions, and did not need a notational codification to be remembered and performed. This combination proved especially interesting due to the ambiguity generated between live performance and playback. For the next experience, I wanted to achieve a similar result without the aid of a pre-recorded soundtrack. The fundamental problem at this stage was how to simultaneously achieve a certain amount of clarity (the primary work should keep a degree of recognisability, even if the extent of the differences and the principles according to which it had been changed were still enigmatic) and unclarity (such recognisability could not take place through semiotic categories).

While reflecting upon the moulding effect of notation on performance, it became clear that semiotic categories belong not only to notation sensu stricto but to any form of preconstituted component of a musical system-be it the instrumental interface, a pitch system, rhythm, or metric division, even human anatomy, perception, consciousness, or linear temporal organisation. Notation is more than the writing tool that is used to transcribe the semiotic units of sound onto a rhythmic-diastematic score. Without a cultural and mental approach to sound thought a priori as notation, it would not be possible to transfer sound into musical writing, that is, to reduce it into preconstituted semiotic categories. Writing, in its broad sense, can thus be regarded as the established territory of music, the accumulation of stratifications that constitute musical structures, and through which it is possible to conceive of an identity between performance and a given work. But, in the interpretative vision, in which the connection between coding and materiality follows stable rules, where is the "original" sound that performance reproduces? What is the unspoken sonic paradigm that establishes resemblance? In other words, given that symbolic codification and the performative event have no conformity whatsoever with each other, how can a performer think of his or her activity in terms of conformity and identity?

These questions remained suspended as I proceeded in my practice. I decided to "use" a score as the starting material for live improvisation, so that an underlying structure might still be "felt" in a performance that diverged from the text as such. I transformed a score into a visual diagram that could account for a level of the musical text exceeding its semiotic codification. I chose to work on the song Amarilli mia bella (1602) by Giulio Caccini (1551-1618), a piece of music 


\section{Beyond Improvisation}

whose composition displays an extremely forceful rhetorical organisation, ${ }^{1}$ which constituted the main material for the diagram. Soon after that, improvising presented me with operative problems that interfered with the purpose of my research. From this, it emerged that improvisation is likely to present two opposite risks. (1) Excessive semiotic clarity: While improvising it is easy for a performer to fall back into predetermined categories that, operatively speaking, do not differ from those of a fixed textuality. I experienced that preconstructed semiotic categories can operate in improvisation with even greater strength than in the interpretation of written music. In the first place, the anatomical and instrumental interfaces are much more likely to impose their fixity upon the sounding result, moulding it accordingly. Moreover, internalised formal structures, together with the will and habits of the performer, are likely to come to the fore much more forcefully. (2) Excessive unclarity: In the improvisatory situation where the musician tries to abandon such structures in order to open the performative dimension to the unexpected, it is very difficult to adhere to the task of trying to produce a resemblance to a given primary work.

If I wanted to jeopardise the primacy of semiotic structures, which are conveyed not just through notation, this could not be achieved through improvisation alone. When abandoning the territories of notation, a performer enters, willingly or not, other territories, with other codes, stratifications, and constraints. Operatively speaking, improvisation and composition do not differ so much from each other. The problem does not simply lie in the abandonment of text as authority. The problem for my musical practice was rather how to problematise what constitutes musical identity in interpretation altogether. From the perspective of the "of" connecting "performance" and "written music," the practice of improvisation completely shifted the balance of interpretation towards the former. Textuality had been eliminated, but in a "false" way, in that its (supposed) objectivity had been obliterated in favour of the complete (supposed) subjectivity of the performer. Yet, the locus of the "of," through whose transformation I wanted to bypass both subjective and objective approaches, had been eluded.

In my research, I had been asking myself where the sound that an interpreter "reproduces" lies. This unsuccessful experience with improvisation aided my realisation that the interpretation of written music necessarily entails belief in the existence of an original sound, present before performance, and ideally located before/behind the score. For a composition, this is the fictitious sound that originated in the composer's mind, supposedly in dialogue with itself. In approaching a score, the interpreter has to penetrate its depths to discover a hidden dimension that needs to be brought back to life in performance. However strange this might sound, in the case of improvisation, the problem of this "original" is not eliminated; it is just shifted to a different position. If the interpreter imitates a sound fictitiously present in someone else's mind, then the improviser imitates what is fictitiously present in his or her own mind, the sounds produced must necessarily reflect those originating in such a dialogue.

1 For a thorough description of the song's rhetorical structure, see $\$ 7$. 


\section{Derivative II: The Phonocentric Vision of Music}

In his formulation of the concept of the "mirror stage," Jacques Lacan (2006a, 1-6) describes the formation of an "ideal-I" as arising from a psychic response produced through the externalisation of a child's own image, projected outside its body onto a mirror. The crucial point of the theory has two implications. On the one hand, identity emerges through a fundamental alterity - the image in the mirror corresponds to how the child sees the others. On the other hand, the child experiences a visual anticipation of a wholeness of and mastery over its body in discrepancy with its actual experience, which is characterised by vulnerability and fragmentation. From the mirror stage on, the subject finds themselves in a sort of fundamental delay with this anticipated wholeness, in the chase of which their "alienating destination" (Lacan 2006a, 2) is already accomplished. The infant does not "match up" with the image it sees in the mirror, which constitutes both a sort of representation — a gestalt—of the child, and an ideal goal that he or she will also strive to pursue as an adult. Identification is introduced in the life of the subject, but the price it demands is the need to be rebounded against an external and alien image, and-most importantly-its irreconcilability with the direct experience of oneself. We are always someone else, in that the imaginary formation of an "I" as a separate and consistent entity is inherently dependent upon an image that is separate from us.

The role of the mirror as formulated above discloses a vision of identity that, far from granting sameness through a correspondence between internal and external experience, is built not only on the missed conformity between external and internal, but on the very act of separation between inside and outside. Before disengaging its own image from its body, the child is not even aware of the split between the body and its environment-the body of its mother. Identity is thus only the other face of alienness, inseparable from it and yet born at the same time.

From a different perspective, in a passage from Of Grammatology (Derrida 1997, 36), Jacques Derrida employs the metaphor of the mirror to exemplify a vision of the relationship between writing and speech that he defined as "phonocentric." Such vision privileges the phonè, meant as the (supposed) transparency of the acoustic fact and its (supposed) vicinity to presence, over writing. Speech in its phonic substance would be closer to the interiority of the subject, and therefore linked to an idea of sense that exists originally, prior to writing, with no need for a signifier in order to be what it is: intelligible and selfcontained prior to its deterioration into actual notation. The phonocentric linguistic system considers writing, most evidently alphabetic writing, as a representative technique, a degraded double of speech, which in its full and uncorrupted state would be present to itself and to its own significance. Phonocentrism is bound up with logocentrism: from the former ensues the primacy 
of the logos, meant as the internal voice of the conscience able to understand itself and to escape the capture of the sign. In this passage, Derrida reports both Jean-Jacques Rousseau's and Ferdinand de Saussure's annoyance over the inversion of roles between speech and writing. As the latter states, "Whoever says that a certain letter must be pronounced a certain way is mistaking the written image of a sound for the sound itself" (Saussure, quoted in Derrida 1997, 36; see also Saussure [1983] 2013, 34). Derrida comments, "What is intolerable and fascinating is indeed the intimacy intertwining image and thing, graph, i.e., and phonè, to the point where by a mirroring, inverting, and perverting effect, speech seems in its turn the speculum of writing, which "manages to usurp the main role." The phonocentric ideal, therefore, is based on the postulation of the existence of sound itself, a definite entity preceding writing and doubled by a false image that threatens to overthrow the sounding language from its position of primacy. The mirror of writing in this sense would wait to duplicate an organism that is pristinely whole.

In Of Grammatology, Derrida $(1997,91)$ proposes a sort of revolution in the "heliocentric concept of speech," a gesture of departure from a correspondence between signifier and signified that is considered univocal and representative - as formulated by Saussure. With this he also proposes a new conception of writing not as a notation of a pre-existing sound present to itself, but as an autonomous "trace" (ibid., 9), unmotivated and unmoored from any natural link with the signified, and which therefore is unable to refer to a unified presence. In this vision, writing does not simply expose, and at the same time counterfeit, the presence of the signified. Both writing (meant as notation) and speech stem from the "trace," a form of writing that is not to be considered as an antecedent or original. Once the possibility of signification is inaugurated, only the deferral of signs can exist, and in this sense Derrida delineates an idea of language that has always been in a state of writing, the sign of a sign, never referring to the wholeness and presence of the phonè. The idea of a presence outside and prior to writing, and the very opposition between presence and absence (given through signs), can only be constructed and conceived within language.

Lacan himself developed a theory of language, located, according to his register theory, in what he calls the Symbolic; he describes language as having an important similarity to Derrida's idea of language as "trace": language precedes humans-it even makes humans, rather than being made by them. Alterity is an important component of language too, as it was in the formation of the I; but, in the case of language, the autre becomes the capitalised Autre, an alterity that "is de-psychologised, de-anthropised, to coincide with the laws of culture and language themselves" (Di Ciaccia and Recalcati 2000, 39, translation mine). The point here is not to make a comparison between Derridean and Lacanian theories of language, but rather to underline an affinity between their two ways of depicting the illusion of identity at the core of representational processes and a similar and revolutionary decentring move that regards an apparently stable system from an oblique vantage point.

For Lacan, such a stable system is personal identity. An "I" that believes itself to be an "I" in Lacan's view does not belong to a person who has reached a 
healthy stability (hence, "if a man who thinks he is a king is mad, a king who thinks he is a king is no less so" [Lacan 2006b, 139]). On the contrary, the illusion of identification, although necessary and intrinsic to the formation of the subject, is the beginning of an aspiration to unity and stability bound to permanent frustration. In the case of Derrida, the supposedly stable system is the immediate relationship between logos and sense, between the interior voice and its being able to understand itself: "a logos which believes itself to be its own father" (Derrida 1997, 39). Lacan unveils the illusory nature of the image of the "I" by placing a mirror in front of it, and by stating that the mirror is not a mere apparatus that reveals and replicates the image of a system that is complete and stable, but that the premise of the formation of this (illusory) system is the duplication in the mirror. Derrida describes the signifier as having a parallel function on the signified. It is not the sign that duplicates through its shallow image the whole sense of the spoken word; rather, the signifier discloses the signified in turn as a writing, and the two are inextricably bound to each other, simultaneously as each other's offspring. Consequently, there is no such thing as a wholeness of sense in proximity to speech, there is no such sense at all.

That music is centred on sound is difficult to question; as Jean-Jacques Nattiez underlines, "we would not know how to speak of music without referring to sonority, even when the reference is only implied" (Nattiez 1990, 43). Even in the numerous musical examples where silence, gesture, or image take the place of sound, obliterating it while still claiming to be part of a musical piece, the link with the vibratory acoustic phenomenon seems insoluble. At the same time, music does not only exceed sound in cases where some of the visual components implied by the production of phonic substance are isolated in order to refer to it metonymically or symbolically. Music has a deeply embedded visual and spatial dimension, one that is most prominent in notation, but that is already at play in organisational systems that precede notation, such as a pitch system (e.g., a musical scale), or fingering. In the case of written music, the discrepancy between visual and phonic dimensions is all the more evident, constituting the two sides of its allographic nature ${ }^{2}$ (one side being the notated score, while the other is its gestural and sonic enactment in performance). The not so innocent question is then, where do we locate sound in relation to notation? What are the rules that allow us to relate a sign on paper to an acoustic vibration? And what kind of relationship do they have with each other?

In an attempt to circumscribe this problem, Theodor W. Adorno devotes an important part of the reflections contained in his notes posthumously published as Towards a Theory of Musical Reproduction (2006) to the individuation of three levels in the reproduction of a musical text in performance. The first level, which he calls the mensural, "is described as everything that is "unambiguously given through symbols" (Boucquet 2009, 45-46). The second level, the neumic, "represents the structural element that has to be interpolated from the symbols" (ibid., 46). Finally, the level called the idiomatic "stands for the general musical language which is, to a certain extent, preexistent and encompasses

2 For the notion of allographic or non-autographic art, see Goodman ([1968] 1976, 113-15). 
a particular work" (ibid.). Reflecting on the first level-the one coinciding with the written musical text-Adorno (2006, 93) comments: "The mensural is imprecise, i.e. does not reach the music's level. Musical notation is an aidememoire. It does not carry the whole, it is much, much too undifferentiated, and this is something fundamental that still remains-and possibly even increases-the more refined one's notation becomes.... But this imprecision is precisely the measure of the difference between notation and sense."

Notation then would always fall short of "the music's level"; there is a "sense" from which musical writing is detached in its impossibility to portray the complex differentiation of music itself.

Explaining one of the premises behind his theory of musical semiotics, Eero Tarasti describes the relationship between distinct levels of music as follows:

\begin{abstract}
Because musical reality manifests itself in various ways, we have to ask what the relation is between expression and content (signifier and signified) in each mode ... and whether the different musical modes can be translated into each other, thus making possible the continuity of the musical process. The first "translation" occurs in the composer's mind, with the transformation of his or her musical idea into visual notation. Next, the performer translates the score into gestural language and body techniques. Then the listener translates sound phenomena into the "language" of inner experience. (Tarasti 1994, 4)
\end{abstract}

Tarasti explicitly summarises a fundamental vision lying at the core of the theories reported so far: the musical process is considered as originating in an initial "musical idea" that emerges in the mind of the composer and undergoes a series of "translations"-into writing, into performance, into listening experience. According to this vision, "the level of music" is then located in a primordial condition where the mind of the composer is in dialogue with itself. In such a dialogue, sound is present in its mental state and in its fullness, unmediated by any further "translation" into writing — not to mention those others into performance and listening. This is the level of the "sense" that, according to Adorno, is not able to be matched by the portrayal through notated signs, the level that the performer is asked to try to access through their decodification of the written score. And since, as Adorno notes, the "mensural" dimension of the written text is always deficient towards the richness of sound, where the score is insufficient to reconstruct the original sound image, the performer should delve into further levels that, through their coalescence, can contribute to retrieving an image of wholeness. What Adorno names "the neumic" and "the idiomatic" can be added to historical and musicological research, music analysis, organology, the study of treatises on performance practice, biographies of composers, and composers' writings and influences. In short, this original sound would function for the performer like a kernel from which infinite layers emanate: the more layers one can reassemble and put in relation to one another, the closer one will be to the wholeness of "music's level."

In turn, what I propose is a move to decentre what I venture to name-as contradictory as this might sound-the phonocentric vision of music. If sound is still regarded as the centre around which the system of music revolves—a Ptolemaic 
one-I want to operate a sort of Copernican gesture. At the core of the phonocentric vision is the assumption that notation is a vicarious representation of a pre-existing sound, and that such a sound is whole and full of sense in itself. Notation would be the representative mirror image of a sounding organism that is integral and unquestioned-the "sense" made in the imaginative mind of the composer. Notation then can be used as a mirror in the Lacanian sense: by reflecting itself onto notation, sound constitutes itself as meaningful and whole; yet, crucially, such wholeness is only imaginary and contrasts with a fragmentary, unexplainable, and irreducible reality.

Phonocentric vision in performance is perfectly exemplified by the performative attitude that Igor Stravinsky elects as the most commendable, one that regards its "proper function" to be "transmit[ting] music to the listener" (Stravinsky 1947, 120). Aware that the score cannot encompass all the elements needed for its performance-as Adorno states about the mensural aspect of written music-Stravinsky favours a performer endowed with "experience and intuition" (ibid., 123) to realise those elements without betraying the work. In short, this kind of performer, named an "executant," has to be a serviceable mirror: one cannot claim that the image it reflects is the same as the one the composer conceived, but the less distorted the surface, the clearer one can hope the image given back to listeners will be. The phonocentric vision also describes what I have named the "perspectival model" in music performance (see "Derivative I"). To show the perfect correspondence between the Florentine baptistery "as it is" and its perspectival rendition, Brunelleschi interposes a mirror between them that functions in a Lacanian and Derridean way. Instead of being regarded as the interface that generates a mode of vision, the mirror obliterates and substitutes itself for "how things are viewed" altogether: the mirror reflects the world as Brunelleschi believes it is, forgetting that the operating laws of the mirror belong to the mirror itself in the first instance! Perspectival painting, and perspectival music performance, are incapable of, or unwilling to, comprehend (both in the sense of "understand" and of "include") what lies outside their supports other than through the assimilation of a negative image (be it the one in the mirror of writing and notation or in the mirror that reflects light according to Euclidean optics).

The Lacanian mirror that my project wants to place in front of the performance of written music can then be described as follows. There is a series of widely shared assumptions on how a sounding and gestural performance should replicate a written score. Such assumptions are necessary to grant the constitution of the musical subjects-not only the musical work and its consistent identity but also the defined roles of the composer and the performer and the relationships existing between them. Doubly bound by the necessity of such a consistency and the impossibility of carrying it out coherently, my experience as a performer of written music is characterised, on the one hand, by the pursuit of a whole image of the musical work, always anticipating performance through the visual wholeness of the score, and, on the other hand, by the actual experience of the materiality of sound and gesture, marked by fragmentariness and deficiency, and in contrast with the initial image. The continuous post- 
ponement between sign and sound and their failure to match signal the alienating destination already encompassed by the two-sidedness of written music, constituting identity and at the same moment permanently preventing it.

The gesture of using notation as a mirror for the sounding dimension of music is also intended to open a creative reflection upon the fact that musical writing is not simply a notational or mnemonic tool. In the Derridean sense, music is already writing, even in its supposed status of a mere sounding idea in the mind of the composer. It is not the composer's musical imagination that "utilises" and "makes" music notation. Quite the opposite: the composer's imagination is made, constituted, by music notation, or by the proto-notational ways of organising space and time that are employed also in so-called oral musical cultures. ${ }^{3}$ Even the performer's body is already a form of writing; for the moment, the focus is on the reversal of the relationship between sound and sign, and in the raising of consciousness that such reflection calls for on the side of the performer. Once the widespread notion that the performer must "translate" the score into sound reconstructing the phonic image already envisioned by the score is subverted, an increased awareness is required of the performer, as is a different commitment towards his or her own role and towards the musical past itself.

3 It is important to keep in mind the crucial distinction made by Derrida between writing in the narrow sense (notation) and writing as an "entire structure of investigation" (Spivak 1997, lxix), which also applies to cultures that make no use of the written code in the first sense (see Derrida 1997, for example 74). 


\section{Five Glances upon the Unspeakable Body: First Glance}

My reflection on the performance of written music started in the field of representation and semiotics. In traditional interpretation, performance is moulded by the internal proportions of a score, which mediate between the imaginary "original" sound and the material, actual one. By placing the mirror of representation in front of itself (see "Derivative II"), the sign is emancipated from the role of degraded phonè traditionally allotted to it by the "metaphysics of presence" (Derrida 1997, 22). It is thus possible to break with a notion of presence as otherworldly, transcendental, and immaterial. In consequence, the break is also with the notion of an original unmediated sound, either transcendentally present in the mind of a composer in dialogue with itself, or ideally present as an origin in a past conceived as retrievable, reconstructable, and therefore interpretable. Metaphysical presence has been eliminated from a world that is accessible only through signs, not as mediators of reality but as its constitutive foundation.

The world of signs is now regarded as a system of relations that precedes and describes life. The reflections of structuralism and deconstruction underlying this assumption have made it possible to have done with the judgement of god (Artaud). ${ }^{4}$ They have got rid of the primacy of the origin, of a metaphysics that cannot regard the originated if it is not in relation to its self-founding origin. This approach discloses a different relationship to inscription, one in which inscription is considered as an opportunity for creativity and constitution rather than as a normative law. Yet such a vision still regards presence as negation. Once there is awareness that the mechanisms of perception and consciousness tend to superimpose themselves onto the real, once the delusion of the subject that autoptically "sees itself" in the outside world is unmasked, where is presence to be located? Would then "real life" lie outside the limits of the accessible experience, outside the cultural automaton (see "Derivative VI") that generates subjects and objects? According to this vision, there would be no bridge to what is "beyond" the boundaries of linguistic (human) discourse.

However, an attempt can be made at shattering language, at deterritorialising it towards a zone that lies outside the systems of signs. Life is not-or is not only-what is governed by a preceding sign system. Language indeed creates the subject; but beyond language, beyond the subject, even beyond the human, there is a life that emits non-signifying signals, and whose encounter is able to perturb and interfere with language. Artistic reflection and practice can be a privileged means to explore this perturbation, and a place for its enactment.

4 See Artaud ([1976] 1988, 555-74). 
So far, this book has proposed a reversal between physical sound and its (supposed) degradation into image and transcription. If the real sound, present in performance, is no longer consubstantial with its origin, then its relation to the sign and to its (supposed) representation in writing becomes one of radical difference, of total divergence: the difference and the divergence of the Deleuzian simulacrum (see "Derivative IV"). Detached from its representative role, the simulacrum manages to obliterate the imaginary, transcendental, and selfgenerating origin, in that it is able to subsist without any internal relationship with the Platonic Idea and with the One. However, the journey into the dismemberment of representational conventions does not end with the dissolution of the textual unity into sound. The materiality of sound and gesture directly affects and incises, and is in turn affected and incised by another irreducible materiality: that of the body.

A body is not the opposite of a text. Texts and structures have the capacity to proliferate everywhere, in order to rescue subjects from aphasia, from nothingness, from the social and physical death that menaces anyone that falls outside the safe categories of recognisability. The reassuring apparatus of mutual recognition is not simply what is enacted by a text that asks to be reflected in a performance, dictating resemblance through its internal relations. This actually makes the existence of "a text" possible in the first place. A text is something bigger than a piece of writing. It is the micro-scale pattern of the colossal cultural automaton; it is the mechanism that allows, through the generation of predetermined subjects and objects, the transformation of the unfaceable chaos of reality into an oriented world where one can move securely. Therefore, there is a body that "makes text": two eyes, two arms, ten fingers, one heart, two hands. To elude the wielder of the text, one must also withdraw from the territories of the organised body, retreat to the fringes inaccessible to both the height of the mind and the depth of bodily functions, and to skim the wordless terrains of an unordered body.

In the plateau entitled "November 28, 1947: How Do You Make Yourself a Body without Organs?" from A Thousand Plateaus, Gilles Deleuze and Félix Guattari $(1987,149-66)$ propose the existence of three main strata concerning and binding the existence of the human being: the organism, signifiance, and subjectification (ibid., 159). The fundamental act of experimentation that Deleuze and Guattari put forth in the plateau consists of dismantling all three strata. Experimentation involves great risks and difficulties. Dismantling signifiance and subjectification threatens to lead one towards illusion, hallucination, psychosis-in short, the complete loss of social and linguistic reference points. But dismantling an organism is no less challenging: in this enigmatic process, the body would risk possible death.

My research process began by facing the stratum of signifiance in the performance of written music, that is, the way in which a culturally shared code predetermines musical imagination ahead of the material and vibratory "real" of sound, and the gestural and bodily "real" of performance. Through Deleuze and Guattari, my reflection opened up two more strata. These are less evident perhaps, and less liable to be perceived as binding for the flow of intensities, 
even in music. Subjectification is the formation of a self and of selves able to function in social and political contexts. Finally, the organism, the network of anatomic supports and interfaces, is itself a stratum. The body is not a romantically wild terrain prior to structure; it is not the "nature" in our "culture." It can "make a text"; it stratifies.

A musician in pursuit of a "body without organs" must proceed carefully. Not only because, as Deleuze and Guattari warn, the dismantling of strata is a difficult and risky process, but first because one must detect where the strata lie. Subjectification can be seen as the conglomeration of identities around prefigured roles (also seen from the social and political viewpoint) in the field of music performance: the composer, the interpreter, the executant, the performer, the conductor, the instrumentalist, the producer, and so on. But is not "expressivity" already constructed along the trajectory of a subjectivity that needs to find its place in the world? The performer as subject is caught in the mechanism of representation, of interpretation, juxtaposing his or her own subjectivity against an objectivity of which that subjectivity is already part-as one side of a mirror that is unable to see the mirror that generates "the real" side together with the reflected image.

Finally, the body of the performer as organism also has to be rethought. The fact of "having a body" is not enough to depart from the stratum of the text. The presence of the body onstage and its movements have a double function: they support, but at the same time hinder the pure intensity of the "body without organs." A musician must then find what lies "in between" a movement and a gesture, fingering and intensity, preshaped movement and movement that produces a shape and a space, chronological/metronomical time and the tunnel in time that emanates in the infinity of the Now. What is the materiality of a body that resists its commensurability with anatomy, in unceasing friction with the "semiotic body," producing unclassifiable particles of intensity? 


\section{3 . \\ A Series of Anamorphic Glances}

By the time I started operating on the third primary work, I had almost abandoned the thought that improvisation could be productive for my practice. Additionally, I started questioning the role of live instrumental performance altogether. If a musical instrument or even human anatomy are already a form of textuality, how could I problematise the primacy of semiotic clarity over performance by abandoning notation, and yet remain within the-in turn, semiotic-constraints of physical interfaces?

At that point, I decided to concentrate on the potentiality of phonographic inscription. Such a medium also possesses its own representational pitfalls, which must not be overlooked. It is by no means true that recording captures physical sound "as it is," because it is still determined by its digital functioning, and ultimately by a culturally mediated human perception. The point though was not to use phonographic inscription as yet another "representative" technique: I was not recording to "convey" a live performance, but rather treating it as a support where I "kneaded" sound in one of its material manifestations. In phonographic inscription, sound maintains a degree of incommensurability, of ambiguity, of internal variation, as the materials of painting and sculpture do. It was my intention to bring such ambiguity to an extreme, to generate an unbridgeable conflict with the semiotics of sound.

At the same time, with the research team MusicExperiment21, I had been working on the outputs' seriality as a manifest form of differential repetition in relation to a musical work. The research done by the team on a number of case studies, mostly based on iconic musical works from the nineteenth and twentieth centuries (among which were Robert Schumann's Kreisleriana, op. 16, and Ludwig van Beethoven's Diabelli Variations, op. 120), was presented as a series of experiments. Each performance, presentation, lecture-performance, installation, or publication related to the case studies constituted one instantiation in a process seen as a continuum rather than a sequence of self-contained objects. The aim was to emphasise the emergence of new epistemic properties of a musical work throughout a process of experimentation, and not the production of finished aesthetic or scholarly outputs based on such piecesalbeit each instantiation might as well be considered as such. This suggested the introduction of a form of seriality in my practice. I was working with artistic processes that involved my affective response to a primary work, the reconfiguration of its internal relations in my own memory/forgetfulness, the interference of an involuntary dimension fixed through recording: all features radically bound to a singular here-and-now. All this could be more consistently exposed by the production of what I named a "series of anamorphic glances."

With the word "anamorphic," I refer to a projectional technique in visual art aimed at producing distorted images whose recognition from a viewer 


\section{A Series of Anamorphic Glances}

requires either the use of special devices (such as mirrors) or the location of a specific vantage point from which to regard these images (see also "Derivative I"). Anamorphosis describes my operation: seen from a traditional perspective (what in painting would be the frontal view, and what in my case would be interpretation), the new sonic configuration is confused and thus difficult to relate to a known image. But there are specific conditions under which it is possible to relate the image to its referent. In my case, such conditions are not scientifically projectional but more complex. They involve my own experience as a performer, the distance in historical time that separates such experience from the primary work, the moment in which the new sonic configuration is produced, the use of instruments different from those envisioned by the original score, and the innumerable variety of incidents and accidents happening in the memory, in the sensation, and in the body. Each of the renditions in the series brings to the fore one of the possible relations that I, the performer, can entertain with the work. A multiplicity of performances, not only diverging from the primary work but also from each other, could express some of the infinite possibilities of regarding a single object from different perspectives.

This serial approach was the first important new element of my operation on the third primary work, the song Piange Madonna (1609) by Sigismondo d'India (c.1582-1629). Another relevant choice was to use only existing recordings for the preparatory phase, and no score. By this time, it had become clear to me that traditional interpretation already brings with it the semiotic dimension of the score, however great the margin of indeterminacy and ambiguity that physical sound can generate. Even in the case of early Baroque music, where the non-notated (with Adorno one could say "idiomatic" [see Adorno 2006, 67]) dimension is very pervasive (the importance of ornamentation, the improvisational freedom of the continuist, etc.), it is still possible to access the semiotic categories embedded in the score. To use a linguistic metaphor: it is true that French pronunciation diverges much more evidently from its written notation than, for example, Russian or Italian. Nonetheless, if one is acquainted with the idiom, it is perfectly possible, from the sonic substance of spoken French, to infer its symbolic codification.

During this experience, some of the processes underlying the production of resemblance came to the fore. In the first two "glances," I managed to produce the desired degree of resemblance with the primary work; such was not the case with the third. In the third version, the attempt was to "anamorphise" the word Madonna (my lady) and the corresponding melodic profile when sung by the soprano. However, this rendition too closely followed the internal relationship of the elements contained in the first term of the analogy. Concretely, I tried to shape some sounds that could relate to the single phonemes of the word, and to stretch the time span of the original song - a few seconds-over five minutes. On the one hand, the result was more of a "homothetic" scaling) than an anamorphosis; on the other hand, I devised a sort of new code

5 Homothesis is a mathematical transformation in which the original coordinates remain fixed and the distance between any two points is multiplied by the same number. 


\section{A Series of Anamorphic Glances}

through which to "translate" the old one (pitches and phonemes). Even if for a potential listener the result still diverged completely from the original, the action I exerted on a fragment of the primary work was again a "story" told "in a long diatribe through the brain" (Bacon quoted in Sylvester [1975] 1999, 18; see also $\$ 1$ ). From my side (if not from the listener's side) the correspondence remained highly traceable-even predetermined.

Even if the role of live instrumental performance had been set aside during this working phase, I still had to face the necessity of presenting these outputs in front of audiences. Simply projecting a pre-recorded soundtrack during a concert situation was no solution. If the materiality of sound was at this stage the strongest element through which I was emphasising the performative moment as divergent from the score, I could nonetheless not ignore the other great form of materiality in and through which performance takes place-the materiality of the stage situation, its visual and acoustic impact, and the relationship with a performing body, or, eventually, with its absence. The sublimation of the instrumental gesture in pure sound was a promising idea, and in line with my research. All the givens that had defined my "being in the world" as an interpreter would be removed from the stage (not only the musical text, but also the instrument, the instrumentalist-perhaps the anatomical body itself). I was proceeding towards subtraction; but for subtraction to happen it was not sufficient just to project sound or to eliminate the physical presence of the performer.

I made two attempts to stage Piange Madonna: neither was completely satisfactory but they were still interesting for the progress of the work. In the third instantiation, I worked, as in the case of Vicentino's madrigal, by devising a semi-improvisatory instrumental part to be performed live alongside the soundtrack. For the other two instantiations, I worked with live interaction through a midi controller, launching and processing the pre-recorded and edited samples in real time. This option, again, could generate an ambiguity, a gulf between sounds and gestures, allowing the breaking of the one-to-one correspondence between instrumental interfaces and sound generation. 


\section{Derivative III: An Eye That Sees Itself}

In her study The Madness of Vision: On Baroque Aesthetics, Christine BuciGlucksmann asks: "Can the eye see itself without resorting to the remarkable artifice of the mirror ... ? Doesn't the eye retract in the night, a blind spot of disappearance, something that the Greeks call aphanismos: to vanish, to escape the self, to wrest the self from the self, to lose consciousness?" (2013, 24). Born within perspectival visual assumptions, the baroque paradigm manages to turn the mirror of representation against itself. The baroque eye sees itself, yet not in the mirror image: it paradoxically contemplates its own ways of seeing. It observes and accepts the all-too-human limitations of perspectival representation-the limitations to the real set by the visual modalities engendered by Euclidean optics, and expressed by the functioning of the mirror. At the same time, it faces a space of impossibility, a nothing beyond the material support of art as the only space of the real. Such is the abysm generated by self-reflexivity: the eye that looks upon itself, that looks upon itself, that looks upon itself, and so on. Pure presence, the logos in dialogue with itself, is lost, and with it the possibility to put a reassuring end-an end in presence-to the chain of illusory representation. Presence is substituted by baroque nothingness, a place emptied of the ability to signify and yet, precisely because of that, overfull with an excess always saturating the partitions of language and representation.

Buci-Glucksmann further investigates the paradoxical potential of baroque vision. What she calls "the work of the gaze"-juxtaposed with the "eye" in a Lacanian sense-manages to produce "a highly cunning theoretical torsion by which the eye might see itself and analyse itself" (Buci-Glucksmann 2013, 21). Whereas humanism in visual art had enacted the coincidence between the extensive eye/I and the intensive gaze, the baroque separates them anew. The gaze, as Byzantine and Orthodox art expressed, does not possess a fixed locus, but is floating and never in place, never occupying a centre. Such a visual paradigm negates the mechanism so perfectly epitomised by Brunelleschi's mirror. The gaze does not see the body that it inhabits through its reflection as others see it, outside itself. Rather, through the gaze the body is seen by the outside-it expands in its outside. It turns the outside in and the inside out. If the mirroring mechanism of identity inevitably redirects the discourse to the formation of the "I" according to Lacanian theories, "seeingness escapes the only logic of imaginary constraints and the mirror stage as model of the construction of the Ego" (Buci-Glucksmann 2013, 43). The fallaciousness of the imaginary is unmasked, its attempted obliteration of the inconsistency of materiality unveiled. Materiality proliferates uncontrollably, like the pleats of Bernini's statues, like Daphne's sprouting of leaves in the sculpted group of the Galleria Borghese in Rome-organic life beyond human anatomy and in centrifugal escape. 
The objects of representation undergo a subtraction of stable properties, desubstantialised and doubled by another body: intensive, fictitious, unable to be encompassed by its own extensive limitations. The paramount example of such modality is anamorphosis (see "Derivative I"), where the object is not represented according to the rules of perspective, but is strained beyond its own extensive limits (better: the representational limits that are imposed upon its image by Euclidean optical laws). This implies in the first place an unveiling of the frames of representation as illusory: the eye, exposed to its own ways of seeing, recognises them as a construct, as an artefact. The coincidence of reality "as it is" with the visible no longer holds up. Anamorphosis is the projection of forms beyond their bounds, their deformation, their destruction; but it also grants their regeneration in the shape of a phantasmic apparition evoked a posteriori by sight, without complying with the retinal mechanism. "The anamorphic phantom offers us the painter's Gaze as if seeing us, if we position ourselves in the correct view-point. It offers us the painter's Gaze as 'simply the subject as annihilated"' (Buci-Glucksmann 2013, 43). The viewer is not offered a reassuring identification with his or her own way of seeing, but is encountered by the painter's gaze, observed by it, no more the subject of an action (the inside acts on the outside) but subject-ed to an external force (the inside is affected while it affects the outside). That the point of view is not fixed, and that the viewer is invited to wander through a series of ephemeral positions, epitomises the infinite variability of the relationship between viewer and viewed. The anamorphic gaze provides one law-the operating ways of vision-and the infinite series of its variations, of its transgressions, each embodied by one possible viewpoint. On the one hand, it conveys the expressive similarity with the object; on the other hand, it does so through a proliferation of difference and otherness. With its emphasis on multiplicity and variation, the baroque eye therefore produces an infinite plethora of images and simulacra. Paradoxically, such an insistence on the illusory nature of extension generates precisely the opposite: the production of intensities. The emphasis is on the relationality between the space of representation and the viewer: an affective space. The geometric, Euclidean space destroys itself to give way to a space of apparition beyond resemblance.

The insistence on illusion and deception is indeed also a rhetorical device, but most importantly it defines itself as space. Something is realised in, and not through, illusion. If it has to create wonder and amazement, illusion is also exposed as such rather than concealed: "the two experiences, that of presence and that of disillusion ... take place in one instant. Indeed, the baroque gesture ... is meant to signify the presence of the divine in the person: but this excess marks itself with such exterior signs that it denounces itself at the same time ... as simply an image" (Bonnefoy 2000, 41, translation mine). Hallucination does not feign presence, as happened in Brunelleschi's experiment, where the functioning of the human eye was so perfectly superimposed to the operative ways of art that it counterfeited "reality": for the Baroque artist, presence itself is hallucinatory (see Deleuze [1993] 2006, 143). 
In his book on Leibniz and the Baroque, Gilles Deleuze ([1993] 2006, 21) sums up "the basis of perspectivism, which does not mean a dependence in respect to a pregiven or defined subject; to the contrary, a subject will be what comes to the point of view, or rather what remains in the point of view." The point of view implies infinite variation of the object, and therefore of the subject. It is not actually a point, but a site. It is not dependent upon a pre-envisioned subject, but on the contrary, a subject is what comes to occupy it: "The point of view is not what varies with the subject ... it is, to the contrary, the condition in which an eventual subject apprehends a variation (metamorphosis), or: something = $\mathrm{x}$ (anamorphosis).... It is not a variation of truth according to the subject, but the condition in which the truth of a variation appears to the subject" (ibid.). It is a visual and spatial image for the absence of a centre-and, accordingly, of an origin.

Similar to the Baroque artist, the performer in the "baroque paradigm" does not relinquish the extensive qualities reported in the score. He or she observes not only those relations but also the "perspectival" way of relating to them. Traditional interpretation is not negated. Rather, it is considered as one possible "way of seeing," the illusory nature of which is unmasked in order to point, through an excess of materiality, towards a place of impossibility, of a lack of signification. In other words, the internal relations expressed by the score (functioning according to the Euclidean grid of notation) are not straightforwardly transferred into the space of performance. Rather than limiting him- or herself to mirroring the score, the performer retains it as an object that holds a relationship of total exteriority, but is nevertheless able to wield forces upon him or her. The codifiable (score) then will not be taken as a surface capable of envisioning the totality of the sonic result, but rather as an osmotic diaphragm filtering the performer's affects and transferring them onto the sonic result. If in the "reverse perspective" model (see "Derivative I") the positions of the performer and of the composer come to coincide, here the performer partly superimposes his or her task onto that of the composer.

Through this process, performance reactivates potentialities latent in the codified score, unheard of in traditional interpretation. The position of the performer also partly coincides with that of the listener: the performer is affected by the original score and by its perspectival rendition. He or she agrees to be part of the "perspective" mechanism, but in order to strain it, to displace it according to the variation of his or her own point of view. This has nothing to do with the self-conscious postmodern game of manipulating codes that come from the past in the form of debris. It means, in contrast, that the performer renounces historically inherited codes and distils affects that hover over the objective score and the subjective performer as a third, suspended dimension. The performer, as a listener, cannot retrieve the affective understanding of musical techniques and idioms from the past in the same way as audiences did in the time that such techniques and idioms were devised. But he or she can try to imagine and reimagine a new shape for their affective potential, having them filter through ears and bodies that have completely different influences and reactions. This does not altogether mean a plunge into the unknown, insofar 
as unknown is negatively defined by the known. If the future is still regarded in a "perspectival" mode, as a reality in which the subject is free to project his or her own potential, it will still constitute a "past in the future," liable to become past and therefore an object of reproduction. The baroque trajectory is rather a continuous divergence from the already known, an unceasing exploration of infinite tangents of the past and of the known. 


\section{Derivative IV: The Joyous Power of Simulacra}

In the first appendix to The Logic of Sense, Gilles Deleuze ([1990] 2004, 253-79) asks himself what it really means to reverse Platonism. To answer, he underlines the importance of investigating the Platonic theory of Ideas, and its difference to other dialectical procedures. The starting point of Platonism is division and selection. However, it is not a division of a genus into species-one that horizontally compares similarities. It resembles more the choice of a "real lover" from a crowd of suitors. The selection descends to the depths in a vertical chain, from the most authentic down to the least authentic: starting with copies of the "real thing," then copies of the copies, and so on infinitely. In such a lineage, it is impossible to be ranked first. The "participant" in the ranking possesses the object aspired to, but only in a secondary way. What possesses it in a primary way is its foundation, or the "unparticipated," which gives out the object for participation. For example, justice would be the unparticipated, the quality of being just would be the participated object, and the just person would be the participant (the first in rank, yet the second in terms of possession). Following the participant is a whole degrading sequence of pretenders with less and less right to claim vicinity to the unparticipated.

The copy is distinguished from the original, yet is still well founded in its pretence to aspire to it. Copies truly resemble "the thing" they copy because they aspire to the Idea of that thing. There is a further distinction though. On the basis of an essential perversion or deviation, simulacra are false pretenders, images that lay claim to a thing or a quality by means of insinuation. Simulacra are not simply infinitely degraded copies: they miss the internal relationship with the original, that is, resemblance. Copies are "good" because they are endowed with resemblance, which connects them internally and spiritually to the Idea. The simulacrum is situated at a distance so great from the "real thing" that the observer cannot master it. He or she is transformed in turn by this distance, which encompasses the differential point of view, becoming in turn part of the simulacrum. Resemblance is not at the foundation of the simulacrum, it is its effect, produced by deceptive means.

Not only resemblance but also dissimilarity is of a very different nature when it refers either to copies or to simulacra. In the case of copies, we could say that "only that which resembles differs" (Deleuze [1990] 2004, 261), since difference is regarded from the standpoint of a previous similitude. Therefore, a copy can only be degraded when confronted with an original. With simulacra, the case is that "only differences can resemble each other" (ibid.), for similarity becomes the product of a deep disparity. The world is posited as an icon by copies and as a phantasm by simulacra. In both cases, the original is unattainable, but there is a crucial difference in their aspiration to it, depending whether they start from a pre-given resemblance or they try to produce one. 
The aspiration to an original "real thing"-which is unattainable, as at best the second rank can be attained-lies at the core of the "perspectival" approach to written music: traditional interpretation. An interpreter does not question the arbitrariness of the relation of resemblance between sign and materiality. Such arbitrariness is not regarded as an opportunity for creative divergence, but as a riddle that finds its solution in the discovery of the original sound, located either in the (ideally retrievable) historical past or in transcendence. Interpretation posits the musical work as an icon. In interpretation, "only that which resembles differs": the dissimilarity that is unavoidably found between each of the sonic renditions of the same score is based on a previously given and accepted identity. As in the Lacanian mirror phase (see "Derivative II"), identity is at the same time anticipated and never achieved. The pretender to the wholeness and consistency promised by the image of the "ideal-I" always ranks second. In its attempt to be as faithful as possible to the sonic result encompassed and transmitted by the score, performance will never coincide exactly with its imaginary original sounding image. Philology and historical informedness, music analysis, construction or reconstruction of meaning, rhetoric, instrumental technique, and virtuosity are all layers added to the sonic and gestural performance to make it rank as high as possible in the array of pretenders to absolute faithfulness to the original. The problem is that such an original, in its impossibility to be fully achieved, will remain the always anticipated unparticipated.

The baroque approach to the performance of written music explores the positive, joyous, and divergent power of musical simulacra; the power, that is, to deny both original and copy, to make the Same and the Similar subside under the primacy of the false, of the infinitely disguised. The sonic and gestural enactment of the score is then not simply a projection inside a Platonic cave, but a cave within a cave within a cave, a baroque world of "caverns endlessly contained in other caverns" (Deleuze [1993] 2006, 5), in which there is no more depth or height and everything becomes surface effect. A different relationship with resemblance is thus the keystone in this process, but the point is not so much the discrepancy between sounding and gestural performance and the original work. "It matters little whether the system has great external and slight internal difference, or whether the opposite is the case, provided that resemblance be produced on a curve, and that difference, whether great or small, always occupies the center of the thus decentered system" (Deleuze [1990] 2004, 299).

The simulacrum of a musical work could indeed produce such an accurate effect of resemblance that it would actually resonate with each and every extensive part of it. There are musical "interpreters" who manage to twist the perspectival approach from its inside. The code is traversed by a flow of materiality, of forces and intensities; each joint of the notational Euclidean grid is jeopardised at the micro-level (Glenn Gould). My musical practice wants to be more explicit, expanding the simulacrum to a bigger scale and to a more evident and open display, to place the performer at such a distance from the primary work that his or her differential point of view surrounds the work, sweeping it away with its own "ways of seeing"; it wants to overtly show that the arbitrariness that every composer (consciously or not) sets between sound and sign can be appropriated by the performer in the production of radical divergence. 


\section{4 . On Methodology}

The constitution of a divergent performance happens throughout three phases, separated in time. Between each phase, there can also be a significantly long lapse of time, such as weeks or months. The three phases are: (a) a preparatory traditional approach, consisting of reading the original piece's score(s), where possible executing it, and listening to some existing recordings of the piece; (b) recording, editing, and processing an electronic soundtrack functioning as a "sonic image" of the divergent performance; (c) the design of the kind of interaction that onstage performances can have with the "sonic image" constructed in phase (b). Throughout these phases, three different angles of relationship with the primary work are expressed: (1) a relational angle, concerning the kind of affection ${ }^{6}$ that the primary work is able to exert upon the memory and imagination of the performer at a given moment; (2) a compositional angle, dealing with a variablility in the degree of resemblance to the primary work; (3) a semiotic angle, dealing with the problematisation of the musical inscription and of its relation to sound, and therefore concerning the specifically performative dimension. ${ }^{7}$

The scheme in table 1 summarises the three distinct phases in time and how the three angles of relationship are subsumed by them. It is important to note that, on the one hand, the creation of the "sonic image" reinstates a divide between the devising of a structure and its live performance, and therefore the necessity of communication between the two. However, on the other hand, the "compositional" and "performative" angles are carried out at the same time, and not as separate and consequential phases, as would happen in notated music. Even though the new performance consists of two clearly distinct moments (the design of the "sonic image" and its enactment in live performance), they are simultaneously carried out as both compositional and performative operations. The musical composition is directly inscribed into sound in its making. Both composition and sound generation are dealt with as performative practices happening directly in the material dimension. Let us consider two different kinds of analogy. The first analogy is attained when resemblance precedes the moment of performance, dictating it, producing materiality and affecting it directly - in other words, when the internal relations of one element pass directly into another one. The second analogy appears as the result of relations completely different from those internal to the object that one intends to reproduce. Resemblance is produced afterwards, as an effect of a materiality

6 The word "affection" here refers to the force through which work and performer affect each other. No reference is meant to the Baroque Affektenlehre.

7 For the sake of completion, I should also include: (4) a perceptional angle: how do audiences relate to the divergent performances? Is it possible to determine the extent to which the primary work is recognisable behind the deformation operated by the performance? This has been an underlying concern in my practice, but has been theoretically left suspended in the current project. 


\section{On Methodology}

in the process of shaping itself. The preparatory phase can thus be regarded as an observation point on an analogy of the first kind: at the moment the performance is actualised, the original inscription's (the score's) internal relationships pass directly into the new inscription to become its relationships. The first angle of relationship with the primary work coincides with the preparatory listening and executive phase, where the musician detects the identity of the "givens" from which to depart, and which are the relations to be redefined between the score and the sounding result. This preparatory phase complies with the "representational" assumptions of interpretation. In traditional execution and interpretation, however great the margin of difference between a score and its sounding rendition, the resemblance between the two sides is still dictated by the maintenance of internal proportions: the sounds and gestures of the performance follow a sequence that responds to the distribution of the elements contained in the score.

\begin{tabular}{llll}
\hline angles & $\begin{array}{l}\text { angle (1) } \\
\text { (relational) }\end{array}$ & $\begin{array}{l}\text { angle (2) } \\
\text { (compositional) }\end{array}$ & $\begin{array}{l}\text { angle (3) } \\
\text { (semiotic and performative) }\end{array}$ \\
\hline $\begin{array}{l}\text { phases in time } \\
\text { (preparatory) }\end{array}$ & $\begin{array}{l}\text { Listening to the original } \\
\text { piece/executing it in a } \\
\text { traditional way }\end{array}$ & - & - \\
\hline $\begin{array}{l}\text { phase (b) } \\
\text { (sonic image) }\end{array}$ & $\begin{array}{l}\text { What is retained of the } \\
\text { original work? }\end{array}$ & $\begin{array}{l}\text { Shaping the sequence of } \\
\text { events through recording, } \\
\text { editing, and processing }\end{array}$ & $\begin{array}{l}\text { Performing the content of } \\
\text { the sample; where necessary, } \\
\text { designing an explanatory } \\
\text { diagram }\end{array}$ \\
\hline $\begin{array}{l}\text { phase (c) } \\
\text { (live performance) }\end{array}$ & - & $\begin{array}{l}\text { Shaping the sequence } \\
\text { of events through devising } \\
\text { live performances }\end{array}$ & Live performance \\
\hline
\end{tabular}

The second and third angles are significantly intertwined in a performative process that is set up to shape the composition through the course of its making. Through the inscription of sound onto media capable of retaining something of its vibratory status (recording, electronic processing, and live performance), together with sound's infinitesimal inflections and the accidental and idiosyncratic marks of the performer(s), and not according to a rationalistic reduction into semiotic units (which is what happens in notation), the soundtrack is simultaneously a composition and its performance. This saturates the gap between the design of a musical form and its enactment through the physical and sensual phenomenon of sound. 


\section{On Methodology}

This procedure thus explains why traditional musical practices such as interpretation and electronic composition are not rejected in my research. Rather, they are incorporated into a system that decentres them, introducing an external point of view that affects them and becomes their material part. Together with "what is seen" (the primary work), this anamorphic methodology incorporates "how it is seen": it exposes the illusory nature of the superimposition of a mere cultural convention on what is deemed to be the "objectivity" of execution and interpretation.

In the second and third angles, principles that are different from the first analogy are at work. The internal proportions of the score are not kept in performance (not even in a "homotetic" scaling, see $\$ 3$ ). Rather than being linear, the deformation exerted by anamorphosis is vectorial. Through the principle of vectoriality, musical shapes are not considered to be circumscribed by fixed points, such as the fundamental semiotic units of rhythmic-diastematic scores (pitch and duration). The shapes produced through the anamorphic deformation are carriers of an energetic and directional charge.

The use of phonographic fixation has another important advantage. It provides a canvas of experimentation, upon which sound can be imprinted, distorted, dissipated, deteriorated, mixed, or wrought. On it, the deforming power of sound can be addressed directly without having to traverse the culturally pre-shaped paths of the symbolic. Such a medium has allowed me to work with chance and thus to introduce an involuntary dimension in my practice-a dimension that would affect the materiality of sound, imprinting it with a forcefully gestural and vectorial quality. But it has also allowed me to rework this materiality, to rearrange it, to concentrate it. This has made it possible for me to delete the unsatisfactory parts and return to re-elaborate the composition, directly dealing with the principal material of music as if it were a kind of plastic matter, and not a mental or semiotic category.

The introduction of an involuntary component in the procedure implies that the number of discarded examples by far exceeds the number of successful ones. Whenever I started working on a new performance, it was always unpredictable whether the attempt would be valuable for the research. Consequently, it is also not possible to fully explain the choices made, both in terms of instruments or samples used in the process and in terms of why some elements of the primary work are detectable in the divergent performances while others are not. This process presents an aspect of paradox, of irrationality, that makes it possible only to make an attempt towards it. This explains also the choice of serial outputs. The work is left open, not only for myself but for anyone who would like to continue it, and it is infinite and non-finite by definition. This is also why I do not refer to these performances as compositions. They can indeed be regarded as autonomous aesthetic objects, but that is not the reason why I produced them. They are places of experimentation, and as such they are not complete and are never fully "successful." 


\section{Derivative V: How to Defy Perspective through Perspective}

Throughout the history of written music in the Western tradition, performers have repeatedly witnessed the overturning of pre-given musical systems, be they constituted by pitch organisations, conventional sound production and instrumental techniques, stable and clearly perceptible textures, predetermined formal structures and combinations of sounds, the idea of composition as a teleological and narrative formal organism, the vision of the composer as endowing structure and meaning to materials, and so on. In particular, the music of the twentieth century can be read as a continuous renegotiation of pre-existing categories, as a series of expansions but also open subversions of former musical regimes. Throughout the century, composers have largely questioned previous models (instead of reiterating them in new shapes) together with common and commonsensical assumptions about music itself.

Notwithstanding the ongoing renegotiation of the status of "written music" and the role of "performance" in relation to it, from the interpreter's perspective little is required from each new experience other than an extension and a perfecting of his or her performative and hermeneutical skills. If composition has redefined its own relation to significance, to structure, to meaning, to the subject, not much has changed from the point of view of the "of" that connects "written music" to "performance" (see $\$ 1$ ). It is crucial to consider this problem not as a general inquiry into "notated music," but from the singular perspective of the interpreter, from the infinitesimal gap that separates text from material action, a gap in which a whole vision of thought can be implicated independently from the ones implicated in the text.

Through a practical case, Jean-Jacques Nattiez clarifies how an interpreter facing a written text cannot dispense with the construction of meaning, no matter how far the text itself goes into the dissolution of signification. In Music and Discourse, Nattiez (1990, 10-12) reports an example, originally used by Jean Molino, in order to differentiate between the "poietic dimension" and the "esthesic dimension" of the symbolic process. The term poietic refers to the process of creation out of which a symbolic form is constructed, whereas the esthesic dimension is the one in which a receiver is confronted with such a symbolic form. In this example, sentences are created according to the rule " $\mathrm{A}$ is to $\mathrm{B}$ as X is to Y," where the letters are substituted by random terms from the English language. The randomness of the process ensures that, at the poietic level, there is no intention whatsoever to produce any form of meaning, let alone a univocal one. At the same time, Nattiez demonstrates how it is perfectly possible at the esthesic level to deduce some form of meaning from the sentences, even from patently absurd ones such as can be produced through the above-cited formula. 
Meaning will be assigned a posteriori, or even will be constructed out of a meaningless symbolic form. In the case of the performance of written music, this constructed meaning is of course of a very different nature from that of verbal language; though, as reported by Laurence Dreyfus in "Beyond the Interpretation of Music" (2007, 268), the "assertion of meanings," either "metaphysically subjective or historical[ly] verifiable," plays a crucial role in the interpreter's task.

When writing about the esthesic dimension, Nattiez refers to the listening experience of music, but he never explicitly addresses that a symbolic musical form must be turned into material sound before it is possible to listen to it. In the interval in which this transformation takes place-minimal in the apparatus of music production, enormous in its semiotic and epistemic consequencesan imprint happens on the vibratory body of sound, on the physical body of interfaces, on the visible and pulsating body of the performative space, which shapes, conditions, and even constitutes listening. If a listener cannot escape the construction of meaning that starts from symbolic form, it is because someone before him or her has turned sound into a symbolic form, making it subsidiary to notation and completely obliterated by it. And this transformation of sound into a symbolic form was accomplished by the interpreter/mediatorthe invisible, neutral transmitter that assures perfect correspondence between (mental) symbol and (physical) matter.

Later in the book, when referring to Pierre Schaeffer's theories about acousmatic music, Nattiez discusses how electronic sonic inscription problematises the separation between the poietic and the esthesic. The problem of materiality, of its capacity to generate an ambiguity and a dissolution of the symbolic, is close to being touched upon. Yet, Schaeffer himself seems to neglect a point that for me is crucial. For him, in Nattiez's $(1990,98)$ words, "the listener must discover what the composer wants him or her to hear. Schaeffer is, in short, a man obsessed with communication." Schaeffer's critique of his contemporaries who use serial compositional techniques (e.g. Stockhausen, Babbitt, Boulez) refers not to the primacy of semiotic clarity in their musical language but, on the contrary, to his belief that the poietic structures they produce are not made audible enough! In other words, he did not deem it possible to clearly enough perceive as symbolic the sonic materiality produced by serial music. Schaeffer uses the concrete medium of phonographic inscription for goals opposite to the ones that my research is pursuing. For him, phonographic inscription allows the listener to have the same experience as the composer. But, in my view, the irreducible materiality of sound prevents, because of its nature, the sameness of experience, perception, and affection. In contrast, an interpreter faced with symbolic structures in the scores of Stockhausen, Babbitt, or Boulez will always have access to their symbolic clarity, and therefore will be able to knead the sonic matter accordingly. For Schaeffer, serial music is too ambiguous. From the point of view of my research, it is still too semiotically determined, and therefore all too univocal.

The structural thought underlying serialism is important for understanding a fundamental disparity between compositional thinking and performative thinking in Western notated art music. At the level of the text, serialism had 
already exposed the delusion of the "phonocentric ideal" (see "Derivative II"): there is no logos at the origin, there is no sound before writing. Composition is a machinic process, producing structures and affects according to specific rules, that does not constitute a transcription of a sound pre-existing in a supposed romantically pristine and unmediated state. The problem is that, at the performative level, serial music still requires interpretation. And, given that the symbolic dimension is empty and arbitrary, the materiality with which the interpreter replenishes that dimension must be found in an idea of origin.

To move beyond the interpretative regime of the performance of written music, it is important to observe notational practices that have managed to engender an ambiguity between the symbolic and the material only through the means of the symbolic. Some compositional attitudes have faced the emergence of a dimension radically exceeding the musical text through the generation of an irreconcilable discrepancy between score and performance. Such attitudes can be summarised through a polarisation with John Cage and Brian Ferneyhough at opposite ends.

In some of his most ground-breaking works, Cage exposes a-signification in its actual state, by laying bare an involuntary layer of sound beyond, behind, and below the symbolic, where the possibility of articulation itself is hushed, together with the will of music to express itself as such ("No-continuity. No sounds. No harmony. No melody. No counterpoint. No rhythm" [Cage 1961, 132]). The hum of everyday life that the pre- or extra-musical dimensions of sound carry with them (for example, the noise of blood pressure against the ear membrane in the anechoic chamber [see ibid., 51]) testifies to the presence of a phonic substance that has an immediate link to the presence of life. Deprived of the predetermined structures of Western thought, art becomes only an empty frame through which a fragment of life passes, unburdened from the assignment of constituting itself as structure (such as the time frame of a performance or the space frame of a concert hall inside which one is free to "listen" without the imposed mediation of what the composer decides one should listen to). In other words, Cage breaks with the code of music, but reinstates human interiority (be it expressed directly, through the performative act, or through the perceptual act of listening to the non-human environment) as its confined territory.

At the opposite end of the scale, Ferneyhough accumulates signs to be wound up against each other in an excess that annihilates the possibility for signification to be constructed in performance, precisely because the performer's attempt to signify is so extreme and concentrated. Through his hyper-complex use of notational coding, he carries out a radicalisation of the assumptions implicit in notation, one that ultimately leads to the overruling of such assumptions. A performer who tries to approach such extremely detailed and dense scores is faced with the physical impossibility of decoding them into a series of instrumental gestures capable of reflecting what is reported through signs in an intelligible way. The result, through the programmed failure of the fulfilment of the correspondence between coding and decoding, is the emergence of 
a material performative energy that transcends the score itself. Such a conscious use of both the operational ways of the notational medium and the aggregate of common and commonsensical practices and habits around it results in a sort of third dimension: a highly sensual sonic space that produces a similar density and impossibility of decoding and recoding on the level of aural perception. Ferneyhough brings the symbolic code to an extreme intensity, and, by doing so, brings the space of performance outside the physical and, perceptual boundaries of the human, no matter whether he or she is a performer or a listener.

Cage tries to reverse the habits of musicians onstage by constructing a spiritual and extra-musical framework that becomes as relevant to the performance as the symbolic tools that regulate it (the score). He also prevents performers from relying on the phonocentric ideal by setting the notational and physical interfaces as autonomous generators of sounds and not as their representation (for example, in his non-notated pieces, such as cComposed Improvisation No. 1, 1990). Ferneyhough displaces the performers from their relationship to the symbolic by consciously manipulating their habits towards it, and by trusting that such habits, forced into the space of action with such a density and complexity, would explode naturally, which is what happens. Yet, the distance they both decide to maintain to the space of performance forces their operational modalities back into the scenery of interpretation. Thus, they rely on the attitude of a performer who wants to entertain a relationship of identity and meaningfulness with a text, and who cannot refrain from doing so, as Nattiez (1990) demonstrates. In this respect, Cage's experience-apparently the most radical in the search for a rupture with the primacy of text over performance-contains an underlying contradiction. Interpreters relate to his works exactly as works, whereas the composer's aim, as emerges from his writings as much as from his music, was largely to question the principles that led the musical world to fetishise the features that constitute a musical work as such: authoriality, structure, or even the concert ritual. Where Ferneyhough's experience seems to completely neutralise any possibility of departing from the symbolic, through overcoding he consciously manipulates the interpreters' compulsion to fidelity in order to generate a mismatch between the moment of codification (composition and notation) and that of decodification (re-inscription into bodily and instrumental gestures), which generates a third dimension between the two, subtended but not expounded by either of them. Through an insistence on the symbolic Ferneyhough defies the symbolic, deterritorialising it into performance and dissolving it into the incommensurability of sound. In both cases, though, we are left with the problem of signification. Its construction is still there, either surreptitiously re-entering performance right where one was led to believe it eradicated, or programmatically exploited and driven mad by its own limitations. To use the terminology implemented in this book, where the works by John Cage relapse-unwillingly - into the "reverse perspective" model, those by Brian Ferneyhough bring the "perspective" model to the extreme limits of its functionality, until it starts twitching-which, incidentally, is the most creative act of perspectival painting according to Pavel Florensky (2002, 229-31): "violating" perspective while still using it. 


\section{$5 \cdot$ Phonographic Writing}

Regarding phase (c) of my working methodology (the one that concerns the onstage enactment of the divergent performance, see $\$ 4$ ), I experimented with a number of different possibilities. The simplest modality of performance was the playback of the sonic image in front of an audience. Another one was the design of semi-improvised instrumental parts to be performed together with the playback. This modality proved particularly interesting for the split it generated between the source of sound and the presence of the performer(s). The overlapping of live instruments and electronic soundtrack meant the audience could not tell which the actual sound source was and how it connected to the onstage gestures. Finally, another option was the real-time performance and processing of pre-recorded samples through a midi interface.

At this point of my research I was presented with the chance of exploring this relationship in a more complex way. I was asked to design a piece based on one of Ludwig van Beethoven's Diabelli Variations (1819-23) for a performance with a group of six musicians on acoustic instruments. For this, I decided to experiment with another modality.

According to the phonocentric ideal (see "Derivative II"), from the point of view of the performer, music notation has to mediate and guarantee identity between two sounding results: an original one, supposedly imagined by the composer, or performed at his or her own time, and the one entrusted to the performer. This means that both sounding results are considered to be already predetermined by the notational medium. The phonocentric delusion is further corroborated by a mode of thinking about notation that does not take into account its potential to shape sonic imagination even before the physical act of notation takes place. My claim is that sonic ideas themselves are already "thought" through the notational system. This is true not only of compositional practices that overtly expose this autonomous potentiality of notation, such as Renaissance counterpoint or modern serialism or aleatoric music. When any composer starts to write, he or she is not actually, or is not only, reducing sound to an articulable semiotic unity. At the same time, the existence of a semiotic system - be it notation sensu strictu or instrumental and bodily interfaces, and so on-backwardly shapes the composer's thought, anticipating the necessity of conveying it, through signs, into the new sonic result of performance. Without the primacy of the symbolic in the Western mode of thinking about sound, the divide between composition and performance-its "allographic" nature-would not be possible. For my work with an ensemble, I wanted to subvert this order between textuality and sound.

The semiotic units of sound are "what is heard"; yet, they are not, or are not only, an effect of the physical sound on the sense of hearing, but rather its "being-heard-ness." "Being-heard-ness" is radically different to the reality of 


\section{Phonographic Writing}

the sound in the world; similar to linguistic categories, musical semiotic units are not material, but mental. For the performer approaching the score, the "being-heard-ness" of sound subsists prior to sound, and in absence of sound. Or better yet, physical sound and its "being-heard-ness" are made to coincide, in a similar way to the painted representation of the Florentine baptistery and its image in the mirror that are unequivocally assimilated by the perspectival action of Filippo Brunelleschi (see "Derivative I").

In its physical dimension, sound is incommensurable with its reduction into perceivable distinct units. Sound is always a foreign language: if taken as a material event, as a reality, we always lack the a priori understanding that allows us to categorise it into comprehensible, communicable components. When a musician is confronted with phonographic inscription, his or her relationship to a sonic structure is totally different from the one that they would have with its written codification. Such fundamental difference can be explained through what Vincenzo Caporaletti (2014, translation mine) names "neo-auratic codification" (codifica neoauratica). The term "auratic" overtly refers to what Walter Benjamin theorised as the loss of the aura in the work of art in the era of technological reproducibility (see Benjamin 2008). If Caporaletti agrees with Benjamin on the deprivation of the hic et nunc due to technological replication, he also sees in the medium of phonographic recording "the means for the fixing of some significant indicators of the processual/phenomenal qualities, so as to reconstruct ... a new model of 'auraticity' through the technological medium" (Caporaletti 2014, 209, translation mine). The understanding and apprehension of the recorded sound is therefore completely different from that which is embedded in notation. Recording can fix accents and inflections that pertain to sound's immanent nature and that can never be symbolised. In the words of media theorist Wolfgang Ernst $(2013,176)$, the fundamental difference between notation and phonographic fixation "lies in an idealistic, aesthetic, even ideological (cosmic-order) idea of sound as opposed to its physical and physiological 'mediatic' experience (aisthesis)." This difference is more than a matter of practical "tools": it expresses a different way of relating to the world.

In the wake of these reflections, I designed a performative condition that would take place through a sort of "osmotic" relationship with the recorded sonic image. When designing my own piece based on Variation VIII of the Diabelli Variations, I wanted the musicians to produce sound through the “adherence of one's corporality, 'leaning on' the physiological dimension of articulation, ... transforming and personalising the musical text with microvariations" (Caporaletti 2014, 228, translation mine). In contrast, what happens in written music is "[the] forcing [of] one's perception within a visual-mechanistic system, where rhythm issues from the reconstruction of a fragmented sonic idea on the written page in mathematical divisions of notes" (ibid.).

In Variation VIII, I asked the six musicians to organise the performance on the basis of listening to and imitating a soundtrack. In practical terms, the musicians were invited to extract their sonic and gestural performance from the sounds in the recorded sonic image. What I aimed for through the proximity between the recorded sound and the performed sound was an unbridge- 


\section{Phonographic Writing}

able ambiguity between the real, material, and uncodifiable sound and the "being-heard-ness" that each musician would construct after such a sound, as its after-effect and not as its foundation. In the making of the soundtrack, I had worked with ambiguous sound qualities, so that what the musicians listened to was not univocal but contaminated by the irreducible ambivalence of the micro-variations of the physical sound. While trying to adhere as closely as possible to the sound in the track, they would have to choose what of it to retain, that is, how to listen to it. Performing the piece, the musician would also have to perform his or her listening, testing it with the possibility of refining it infinitely, finding him- or herself in the continuous perceptual fluctuation caused by the impossibility of clearly singling out its "being-heard-ness." Moreover, by trying to adhere to the sound through the physical contact with their ear membrane and their body, and not through the negotiations of the brain, the musicians would lose control over their will: thus being affected, provoked, and stirred to produce sound.

The person who in this case takes the role of the traditional "composer" (me) does not state any "intention" nor try to achieve the clarity that alone allows the perpetuation of a faithful performance. I did not ask the group to perform a composition, but to perform a performance. I did this as I wanted to dislodge them from the familiar "of" of interpretation, with its rules and conventions, and to instead short-circuit the "performance of": performance of performance of performance of performance of... As a result of this infinite inward curvature, performers would have to question their own perception, to face the crisis that the physicality of sound always presents us with and that notational codification resolves and domesticates. Notation is always "right," in that it expresses an a priori mental category that sound will try to conform to later on (according to the ways of the interpretational "of"). In contrast, sound is never "right." One can try to channel it into a particular perceptional category, but only by having the perpetual doubt of having lost something in the process. While notation aids and disciplines memory, physical sound can only be forgotten. Isidore of Seville wrote, "unless sounds are held by the memory of man, they perish, because they cannot be written down" (Isidore of Seville [c.635] 1472, 3:15, as translated in Isidore of Seville 2006, 95). It is true, sounds cannot be written down, but they cannot be remembered by man either, except through the deforming duration of forgetfulness.

That this operative methodology starts from a phonographic text might raise some reasonable objections. Not only is the performance dictated by an imitation of a technological reproduction, but performers also have to face a creative impasse that seems even stronger than that which would be forced upon them when needing to interpret a score. At first glance, this would appear perfectly in line with the phonocentric ideal (see "Derivative II"): performance chasing an "original" sound. However, what actually happened in the performance of Variation VIII negates this. The real, physical presence of sound is impossible to retain in one's consciousness. It always exceeds the mental categories of listeners and performers, or even of composers. In the effort of remembering the sounds in the soundtrack, the memory of these sounds fades away. The absence 


\section{Phonographic Writing}

of a clear rhythm or metrical division sees the performers as being lost in a free fluctuation of temporal duration. Time broadens up. Patterns and articulations become lost. The mind of the performer is no longer in communication with itself, but drifts away in the impossible effort to remember a material phonic sequence deprived of the foothold of structure. The possibility of control over the sounding result is forestalled, because such a result will be constructed not in compliance with explicit parameters but with an unpreventable difference to the sonic image.

The practicalities involved in working with an ensemble of six people, and the time constraints of the rehearsals, suggested I use a graphic guide for the performers so they could identify the segments in the sonic image that each of them were meant to perform. My idea was to facilitate the discernment of pitch ranges, and to clarify the assignment of the different sounds for each instrument. Through mere listening this would have been time-consuming; and it was complicated by the fact that the sonic image had been produced by utilising different instruments from those that would be used for the live performance. This operation, which could have been substituted with longer working sessions and a workshop approach to the preparation of the performance, proved not only highly contradictory from a theoretical point of view but also detrimental to the attitude of the performers.

I report here some of the instructions I wrote for using the graphic guide:

$$
\begin{aligned}
& \text {... you can use this graph as guidance; I suggest using it only after familiarising } \\
& \text { yourself with the recording. } \\
& \text { This is not a score. It is a tool that can help you in the performance of this piece of } \\
& \text { music. The other-more important - tool is the audio recording, and the two are } \\
& \text { meant as complementary parts of each other... It is a visual guideline, and not } \\
& \text { meant as a graphical support for improvisation. } \\
& \text { When reading the graph, keep in mind that: } \\
& \text {-the reading order follows that of traditional notation: from left to right, one line } \\
& \text { after the other from top to bottom; } \\
& \text { — the notated space has no precise correspondence with the passing of time.... } \\
& \text { - the notes in boxes... are purely referential, and are just there to remind each } \\
& \text { instrumentalist around which pitches to organise the sounds he or she will produce. }
\end{aligned}
$$

Even if these indications for the kinds of desired approaches to the graphic guide try to be as explicit as possible, and try to state its difference from a prescriptive score (the pitches are indicative, rhythm should not be strict, etc.), they contain a basic contradiction in themselves, in that the guide wants to restore a level of clarity in a process that is meant to unsettle the notion of musical clarity itself.

Even if the process partly worked in the theoretical direction envisioned, some of the musicians in certain moments approached the graphic guide (1) as one approaches graphic scores meant for improvisation, where graphic symbols are treated as an approximation of rhythmic-diastematic notation (for example: a horizontal line is a long note, vertical space on the page corresponds 


\section{Phonographic Writing}

to change in pitch, a wavy line is a trill, etc.). This happened despite this possibility being explicitly mentioned in the instructions, and was probably due to the primacy of the visible on musicians who are used to reading from scores. And some of the musicians approached the guide (2) as a prescriptive score (for example, four equal symbols amount to an equal division of a pulse in four parts).

Most of the musicians also resisted the fact that I relied on the impossibility and ambiguity of the process, and were constantly asking me "what I wanted" and whether what they were doing "was right." Deprived of a statement of intention and significance from my side (in a sense, deprived of the score), the function they usually were called to perform (creating a correspondence between score and materiality) was suspended. In other words, professional musicians who were so well trained in the interpretational "of" were thrown off balance by such a drastic change in the nature of the "of." Not ready to dispense with "written music," they were perplexed by a dimension of sound that-as paradoxical as it may seem-interpreters are never asked to relate to: physical presence independent from its "being-heard-ness." 


\section{Derivative VI: Automaton}

Linear perspective is only possible if the function of sight is assimilated to a spatial mapping, channelling the perceptual visual information into a grid of signifying relations. I want to name this grid the "automaton," the tissue that the human subject-specifically a Cartesian cogito-constructs around the unassimilable real. Such constructed reality is projected onto the real, substituting itself for it, engendering an "identity of thought" (Hurst 2008, 215) -the delusion in which the subject mistakenly believes his or her own thought to be identical to that which is real. The need for coherence-experiencing the outer world as a stable system-is indissoluble from the illusory nature of such coherence. What is experienced as "reality as it is" is actually only a network of facilitations that, in Lacanian terms, corresponds more to the Imaginary (the formation of an illusory identity through the mirror image) than to the Real.

In his essay on reverse perspective, Pavel Florensky (2002) repeatedly suggests how the monofocal perspectival model of representation, far from constituting a single possibility of projecting a three-dimensional space onto a two-dimensional surface, has come to coincide so perfectly with the dominant Weltanschauung in Western culture that it has been elected the only allegedly correct paradigm for visual depiction. Beyond its creative and artificial power, perspective has become "a method for uniting all notions about the world, such that the world is understood as a single, indissoluble and impenetrable net of Kantian and Euclidean relationships, having their focus in the I of the observer of the world, but in such a way that this I is itself inactive and mirror-like, a certain imaginary focus on the world" (ibid., 264). Florensky takes the example of the representation of an eggshell, where it is not possible to lay the shell on a flat surface, other than through an action that would reduce it into a fine powder at the price of obliterating its form (see ibid., 259). Consequently, even if a painter were only to represent the visible surface of reality, this still could not be transferred onto a bidimensional plan by optical means. In this sense, "there can be no passage from reality to a picture, in the sense of resemblances" (ibid., 260). And yet, the predominant outlook of Florensky's contemporaries led them to maintain that perspective was the right way to depict things "as they are." Considering the still authoritative power of photography in portraying "truth" (a technology that does not differ much from perspectival painting, as light is projected upon the surface of the film or digital frame through

8 The use of this term is loosely inspired, on the one hand, by Jacques Lacan's appropriation of Aristotle's term automaton, in contrast with tuché (Lacan [1977] 1998, 52-80), and, on the other hand, by the formulation automa della cultura (automaton of culture) by Carlo Sini $(2014,4)$. 
the single point of the lens focus), representational assumptions about what is "real" have not changed much since the time of Florensky. Commenting on the photograph in relation to painting, Deleuze $(2003,11)$ states, "it is dangerous not simply because it is figurative, but because it claims to reign over vision, and thus to reign over painting." The reduction of the visible to a single fixed point responds to the need to identify a moment in time and in space as the original object of representation. In this respect, monofocal perspective seems to comply to a certain extent with the Derridean logocentric ideal: it creates the illusion of a signified "present" that would place itself at the end of the chain of references from sign to sign. Linear perspective, relying on the automaton, aims at "the restoration of the world that lies at the end" of the surface of inscription (Lacan [1977] 1998, 87).

Through the "perspectival" rendition of a score (see "Derivative I"), that which is performed is the musical counterpart of the automaton. The prefigured knowledge accumulated through and around the musical work is organised into a grid that allows the arrangement of sounds in such a way that they come to coincide with the "reality" of the sonic imagination at the same moment that the composer conceives of a musical piece. This results in there being an attempt to faithfully portray the work in the performance, which the performer does by reflecting his or her knowledge in and through the work. The same mirroring process is originated between the expectations of the audience and the rendition of the piece, so that recognisability becomes a parameter of assessment of a satisfactory performance. The performer and the work thus relate to each other in an autopsic subject-object relationship, the same as is engendered by a monofocal perspective between the viewer and the viewed, whereby through the act of observation, the viewer projects his or her own knowledge upon the external world, which becomes as readable as an open book. As a result, the larger the knowledge that a performer is able to gather through and about a given piece, the deeper the resemblance to the original he or she will manage to attain. All this is not to imply that the expansion of philological knowledge is incapable of providing any form of diversification and thus of increasing creativity in performance. The claim here is less direct but much more radical. Despite philology being neither a good nor a bad practice in itself, it does express a cultural outlook that stands as unambiguous, and has a centrality that needs to be challenged.

Performers who comply with the perspectival model in written music act in a similar way to the Freudian analysts who Lacan criticises for aiming to detect the "real" origin of the trauma. These performers presuppose that "since one cannot apprehend what was never there in the first place, there must have been something present to apprehend, an original event, a first encounter, the positively present 'real thing"' (Hurst 2008, 217). In producing the subject-object autoptic vision, the automaton determines an origin and a telos, that is, the two extremes in what with Derrida we can name the "metaphysics of presence" $(1997,22)$. The origin (in the case of music, the sonic result that precedes and is encompassed by the score) is the cause of the repetition, as it is the antecedent structure of a stable system that allows for the reproduction 
of the same. But the actual experience of reality is ambivalent, paradoxical, "a continuous pouring, overflowing, changing, struggle takes place in the living conception. It is continuously playing, sparkling, pulsating, but never does it founder in the inner contemplation of a thing like a dead schema" (Florensky 2002, 271). To continue from Florensky, the space of the audible and the space of the codifiable have different curvatures, which result in there being no projectional model that can guarantee biunivocal transferral between the two spaces. Consequently, the reassuring coincidence between the sonic and gestural acts of the performer and those imagined in the moment of composition cannot exist in that it is imaginary, and yet such coincidence rules over the traditional modalities of music execution and interpretation, substituting itself for the real.

The argument that every single performance of the kind that I have defined as "perspectival" provides a potential for a substantial diversification of its model-such a model being the score and the sonic result that is embedded in it - and therefore consists of a variation of the original, does not contradict the discourse I am proposing. Were Brunelleschi to paint the Florentine baptistery a thousand times, no doubt each actual object produced by him would be different every time. Nevertheless, what would not change would be the visual assumptions subtended by his operative mode of representation: first, the assumption that the stable system of the automaton can substitute itself for reality; second, and more importantly, the assumption that there is such a thing as a reality that can be portrayed neutrally through Euclidean geometry. According to the perspectival view, notation cannot be a series of conventional signs for what a performer hears, but it instead crucially substitutes what a performer hears altogether. Only by virtue of the imaginary stability of the notational system-combined with all the other systems implied within it, such as tuning, scales, instrumental interfaces, and so on-is it possible to extract a phonic substance out of a written score. What is not directly contained in the score is compensated by the pre-inscribed apparatus of writing-in the broad sense-which is what Adorno (2006, 67) would call the "idiomatic" and the "neumic." As Derrida (1997, 63) notes, "If language were not already ... a writing, no derived 'notation' would be possible," and the same has to be said for music.

Where can the real be met, if it is situated outside the phenomenological barriers of human perception and the structural barriers of human language? The answer provided by Lacan $([1977] 1998,55)$ is that the Real is to be found in "the encounter in so far as it may be missed, in so far as it is essentially the missed encounter," and thus the Real always "eludes us." The event-the trauma whose cause is impossible to be sought by analysts-is what causes the repetitive compulsion that has as its goal the concealment of the impossibility of its repetition. The automaton is therefore a screen that, with its delusional promise to domesticate and create an interface with the outer world, instead prevents access to it. Still, the trauma can be recognised as such and treated only at the level of the automaton. It is therefore necessary to start from the already mediated automaton, since it is impossible to negate it or to try to overcome it. One 
has to acknowledge its function in the first place. Yet, cannot art entertain a creative, productive relationship with the automaton? It is not a matter of finding new solutions to the questions raised by the automaton; it is a question of trying to interrogate it in a different way.

Given that the automaton cannot be dispensed with, its function in my musical practice has to be of a completely different nature to that envisioned by the monofocal perspective paradigm. As in the baroque model suggested earlier (see "Derivative I"), the arrangement of the elements needed for representation must be different from the monofocal perspective. In his book about the painting of Francis Bacon, Deleuze $(2003,86)$ explains that the mistake at the core of the figurative belief is "that the painter works on a white surface," and that he or she can reproduce on the empty canvas an external object that has the function of the "model," or original. Such is not the case. "The painter does not have to cover a blank surface, but rather would have to empty it out, clear it, clean it. He does not paint in order to reproduce on the canvas an object functioning as a model; he paints on images that are already there, in order to produce a canvas whose functioning will reverse the relations between model and copy" (ibid.). Music performance has to start from the same premise. The space of sonic and gestural production is not an empty one, to be filled according to the elements pre-envisioned by the space-time organisation of the notated score, but is a locus already occupied by it, one that has to be cleared, emptied. There is no original model to be reproduced during the performance, but only givens; the performer's task, then, is to "determine, among these givens, which are an obstacle, which are a help, or even the effects of a preparatory work" (ibid., 87). The perspectival model should be criticised not for its faithfulness to reality, but for not being faithful enough (see ibid., 97) — that is, for not being able to account for the inconsistencies and ambivalences of the real in comparison to the stable system of the automaton, which is functional to its assimilation but at the same time destroys and screens it in the impossibility of its repetition. A "figuration" must then be conserved, Deleuze maintains. But it is a figuration of another kind, one that, instead of turning its benevolent face to the representable reality, filters it, turning its back on it and confronting the unrepresentable void of "what eludes us." What happens"-reality "as it is"is indeed something that exceeds sense and the possibility of language, not logocentrically, as something posited before it, but rather as its offspring. In this sense, the "baroque paradigm" for music performance differs radically from the "reverse perspective" model. Both models stand for signs of an overflowing and irreducible presence outside and beyond the locus of representation; but whereas the "reverse perspective" tries to retrieve, stenographically, the plenitude that is impossible to represent through a testimony of the divine glance, the baroque makes $a$ sign of its own representation, pointing to an unassimilable, irreducible presence by means of an excess of its negation. Baroque art unconditionally accepts representational assumptions, but at the same time it points elsewhere, outside itself, accepting and exposing the inadequacy of its own limits to contain the superabundance of the real. As did Francis Bacon (in this sense a great baroque painter), the baroque artist chooses to "aban- 
don [himself or herself] to clichés, to collect them, accumulate them, multiply them, as so many prepictorial givens" (Deleuze 2003, 92), to then reject them as the perishable and illusory simulacra of an irreducible excess.

The possibility of enacting a baroque regime in music performance begins then "from the possibility of neutralising the phonic substance" (Derrida 1997, 62); thus, my musical practice wants to exit music through music, to sever the umbilical cord linking music to a pre-existent sound, and to reverse the function of the materiality of sound in relation to writing. With this practice, there is not a (preceding) origin, but an (emanating) endless divergence, a "loss of the proper, of absolute proximity, of self-presence, in truth the loss of what has never taken place, of a self-presence which has never been given but only dreamed of and always already split, repeated, incapable of appearing to itself except in its own disappearance" (ibid., 112). 


\section{6. \\ The Phantasmic Image of the Musical Work}

In 2015 I participated in a series of seminars where architects were invited to confront their practices and reflections alongside other artistic researchers. ${ }^{9}$ In the course of the presentations and discussions, a specific and productive affinity emerged between their work and the performance of written music, in that architects also make use of a notation-a plan - that retains only an aprioristic and symbolic relationship with the inconsistency and affective potentiality of a building's physical space.

During these seminars, I decided to collaborate on a small project with architect Johan Liekens, whose research presented significant points of contact with my own. His work on design and architecture investigates the relation between architectural plans and their physical enactment, and how such physicality affects the relationality between the building and its users. Similarly to me, he is also in search of a different form of "of" between structure and materiality, one that takes place through the immanent act of building (where part of the project is his own engagement in the physical construction of a house). Through our dialogue, we both expressed an interest in a phantasmic image of the "work," whose exposition would not present the viewer/listener with a finished holistic composition, but with a series of partial "views." Inspired by notions of fragmentation, of simulacrum, and of point of view (see "Derivative IV"), we decided to produce two series of "glances," each upon one single object. In my case, this object was a prelude for Baroque guitar (1686) by Robert de Visée (c.1655-c.1733); in his case, it was a house under construction. The fragments I worked on consisted of six soundtracks, each isolating a single "trait" of the prelude, and designed to be played back automatically in a loop. In parallel, Liekens produced a series of miniature models from iron wire, each of which presented a "trait" of the building and focused on the relation that such a trait engenders between the space and its user (figure 7). The idea was to invite the viewer/listener to reconstruct an imaginary vision of the finished house and an imaginary aural experience of the pre-existing piece of music. Our aim might be described as the production of a "reverse memory": an evocation, a feeble impression, like the one that happens in remembering. Except that, in this case, there is nothing to be remembered. The "original" experience is obliterated by its dissolution into fragments.

9 The series of Joint Doctoral Seminars was organised by the Department of Architecture, Campus Sint-Lucas (KU Leuven), and LUCA Faculty of the Arts (LUCA School of Arts). 


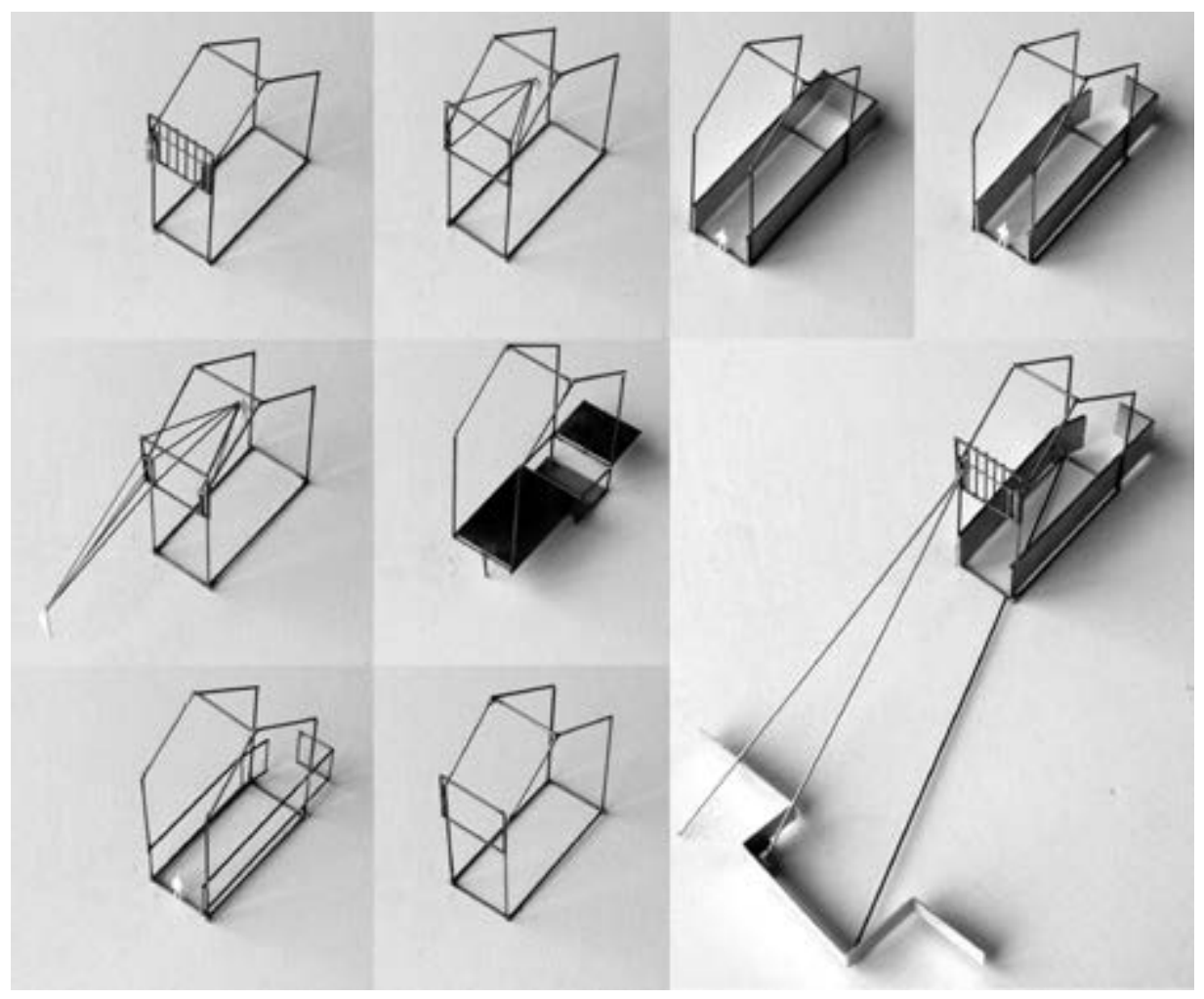

Figure 7 .

Liekens, in dialogue with me, also designed a physical installation for the exposition of a double series of fragments (aural and visual). The result was a cabinet with ten small fissures, through which it was possible for visitors to see one of the models and/or listen to one of the sonic tracks (figure 8). The cabinet materialised the conceptual approach of the musical piece and of the building. Its spatial construction invited listeners and viewers to re-enact, together with the musician and the architect, a process of de-composition of the previously composed work (the missing "original" musical work and building). 


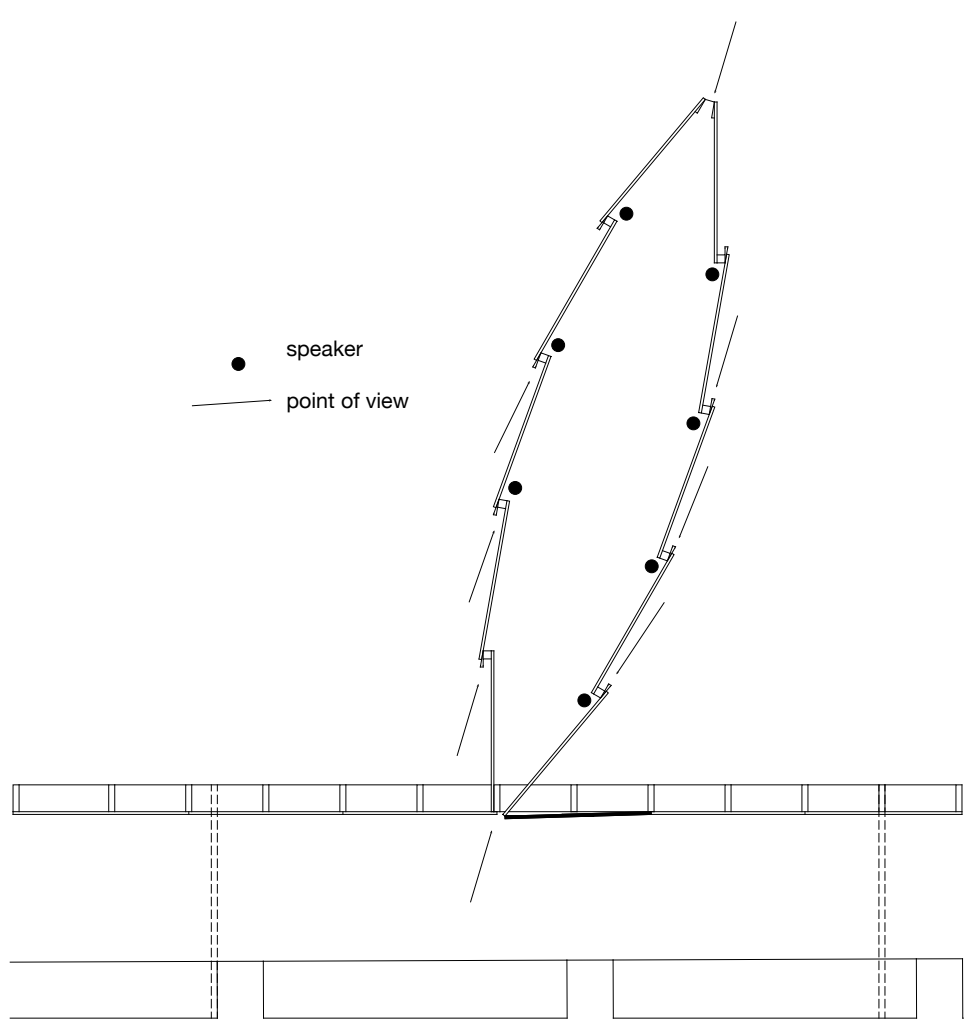

Figure 8.

Whereas my previous performances had been enacted only in concert situations (with the inevitable consequence of fixed temporal linearity and relative spatial stasis), here the physical interaction between the listener and the sound could make more explicit-both for myself and for the audience-the processes of decomposition and isolation applied to the primary work. As an alternative to pre-established occasions for music to be heard (e.g., at a concert, or on a home audio system) and the frontal and detached scenery of the listening experience they generate (e.g., the stage, the recording), the cabinet shaped the act of listening in the form of a tangible, and at the same time imaginative, pathway. The possibility of experiencing the integrity of the piece, as a work of art that recalls the consistency of a living organism and invites listeners to form a sense of identity, however ambiguous, was broken up through an engagement with space as a route into the deconstruction and reconstruction of the musical piece. The reconstructional moment, the mental image that listeners retain of the piece, generates a phantasmic dimension, inconsistent, totally subjective, and irreducible to a tangible and fixed actualisation. Impossible to catch in its integral wholeness, the piece of music exposes itself as a simulacrum, as an object exceeding its own extensive limitations as inscription—on the phonographic 
medium, on memory and perception - to inhabit a locus of forgetfulness. The piece of music, far from being re-membered, is dis-membered in such a way that one cannot but forget it, and retain of it only its imaginative ghost or shadow. In this way, the relationship between the listening subject and the musical object has to be broken. The listening subject will experience the musical object only under the conditions of a series of points of view-in this case, points of hearing-where the subject, occupying such changing locations, becomes as much part of the work of art as the object itself, which results in the two being in an anamorphic relationship with one another. The musical experience, far from relying on the fixed and established midpoints of musical communication (e.g., the composer/work, the performer, the listener), rearranges itself in a continuous intermingling of the roles. The performer therefore is also both a listener to the primary work and its de-composer, the listener performs his or her own pathway of recomposing the primary work in its phantasmic image, and the work acts as an affecter on the performer and listener, (per)forming their perception and reaction.

The practical construction of the installation faced various problems (limited budget, practical knowledge, and space), which made the experience more valid as a work-in-progress than a finished output. Each of the seven fragments was projected through a mono speaker positioned right above one of the fissures through which the architectural model could be seen. The models were not visible directly through the fissures, but through their images that were reflected onto small mirrors, adding ambiguity and intangibility to the viewing experience. A problematic feature of the installation was that whereas it was possible to gain a totally fragmentary experience of the visual aspect, this did not happen for the aural part, because it is impossible to reduce sound projection to a singular site in space. The aural experience therefore was that of a blurred and very soft background sound, as the speakers were within the wooden frame of the cabinet and projecting at a very low volume. Visitors were thus only able to isolate each singular fragment by placing their ear close to the fissure, to listen to it clearly and almost without the interference of the other speakers. Alongside this problem, the spatial and visual aspect of the installation invited the viewers to look through the fissure, but not to place their ear towards it to listen. For that reason, the fragments were not perceived as clearly distinct singular moments. Such a problem might have been solved by the introduction of a second fissure, situated in such a spot that, through the act of looking, the ears of the visitors would automatically be placed very close to the projection point of the speaker.

In conclusion, integrating a divergent performance with an installation proved to be very promising, especially because it enhanced the fragmentariness of the listening experience and allowed one to think differently about how to structure the performance. Yet, to function effectively, it would require further work on the technical issues of the audio projection and on the relationship between the visitors and the visual and physical space. 


\section{Derivative VII: How to Produce a Phantasm? Part I: Gian Lorenzo Bernini}

The Copernican revolution displaced the Earth from the centre of the universe. However, while it did that, it did not question the notion of centre and of periphery. That revolution relied on Kepler: it took the introduction of an imperfect shape (the ellipse) in place of a perfect one (the circle) for the centre to be problematised at all (see "Derivative I"). The baroque artist lives the consequences of this changed episteme. Not only is the humanistic Uomo Vitruviano displaced from his central position: the centre has become double-a planet does not "circle" around an origin, but its movement is a perpetual negotiation between two foci, one of which is empty. Moreover, as Jacques Lacan (1998, 42-43) underlines, when the planet approaches its empty centre, its movement can actually be regarded as a fall.

The world the new artist faces is equally double and displaced. On the one hand, there is the level of appearances, the illusory glories of the mundane that are doomed to decay and end; on the other hand, there is the unrepresentable world of the spirit, invisible yet all the more real. Since the reality of the spirit cannot be portrayed, the baroque artist points to this unrepresentable beyond through a proliferation of signs from the first level, the level of appearances. The proliferation of ornaments, the emphasis on materiality, and the human that is interfered with by a non-human life (e.g., the animal, the organic, the inorganic) are all devices through which the sculptor, architect, urbanist, painter, and scenographer Gian Lorenzo Bernini operates in this sense.

The world of the visible is illusion; its life is decay, as a source of horror and dismay. Whereas Caravaggio chooses to display the tragic realism of human life, Bernini pursues the opposite direction through the active power of imagination to transform the world, to unsettle the veil of straightforward resemblance in order to show its deceitfulness, and to ultimately destroy it. Bernini's nihilism is positive, joyful, and erotic. The imaginative life is exalted through the insistence on the ephemerality of representation. His art incorporates the whole spectrum of the ambiguity of the baroque, which is, on the one hand, disillusion, "the devaluation of life in its heightened forms" (Buci-Glucksmann 2013, 79), and, on the other hand, the positive and creative power of artifice and technique. For him, technique is actually a means for producing ambiguity (here again he diverges from Caravaggio, who displays no ambiguity in the almost obscene details of his paintings in the hallucinatory violence of the trompe l'ail). The marble of the statues can be moulded to become something else: as soft as cloth, as mobile as hair or leaves, as resilient as flesh-while the fact that it is not silk, hair, leaves, or flesh is never disguised (see Argan 2003). Marble is marble, it is a material of art and technique, and the "nature" that art would seek to 
imitate is negated and overruled by artifice. The relation to a deferred world of nature is still present, but its primacy is obliterated; art is severed from reality but still always points towards its referent, in order to shatter it. Underlying the idea of perfect mimesis in art is an attempt to approach the supreme value that nature encompasses; but when such value is lost, then images are just there for the sake of themselves, mere appearance, phantasms. The beauty of nature is not heightened through art in the form of an unachievable-Platonic-ideal.

As Deleuze ([1990] 2004, 293) points out, the simulacrum (see "Derivative IV") is an image that is severed from the object it is supposed to resemble: its power is the "evil power of the false pretender," laying claim to a proximity to qualities and things by means of insinuation. The simulacrum produces the effect of a resemblance, one that is built not through identity but through perversion and difference. In this respect, Bernini's sculptural figures are simulacra of nature: they arouse imagination and fulfil it at once, leaving no time for the observer to reconstruct a reality that would match such imagination. If reality is nullified, it is then impossible to fear it or loathe it. Even with all its dejection, real life is not dramatic, as in Caravaggio, but is instead a source of amazement: "[Bernini] knows how to stumble upon an open tomb without feeling horror for life" (Bonnefoy 2000, 71, translation mine). Bernini's art distances itself from art. Artistic inscription is self-conscious in its falseness and deceitfulness. Art does not look "nature" in the eyes; it looks at itself, through a short circuit, a continuous feedback relay that ultimately is amplified to infinity, producing a vertigo that goes beyond inscription and human life itself. Encapsulating illusion within illusion (very clearly in the double spectacle of the Cappella Cornaro, where two sculpted groups on the sides observe the statue of Saint Teresa [figure 9], but even more subtly and strongly in other instances), vision is driven mad by its own looking upon itself ad infinitum. We see; we know that we see; we are made conscious of the illusory nature of our perception, and therefore we "are seen" by our own perceptual system ("I saw myself seeing myself").

In Bernini's architectural experiences, illusion is again achieved through the creation of two parallel levels: a structural level and an ornamental one. In the church of Sant'Andrea al Quirinale, the spatial perception of the viewer is challenged on many levels (figure 10). The elliptical shape of the floor plan, with the longer side perpendicular to the altar, radically questions the monodirectionality of the Latin cross plan, together with the notion of centre and periphery. Additionally, the internal cupola in gold flattens out the spatial depth, almost reversing it, so that it unceasingly encounters the observer, as in Byzantine golden backgrounds, which negate and invert the perspectival depth that could grant the viewer the possibility to "enter" the pictorial space. But the conventional space of the church is not only tilted: it is deviated, covered, and negated by a proliferation of materiality. The gravitational force lines, the structural elements that until the time of Palladian architecture were able to "speak for themselves" and to expose the might and beauty of their constructional "truth," become hidden, disguised under a flood of decorations. 


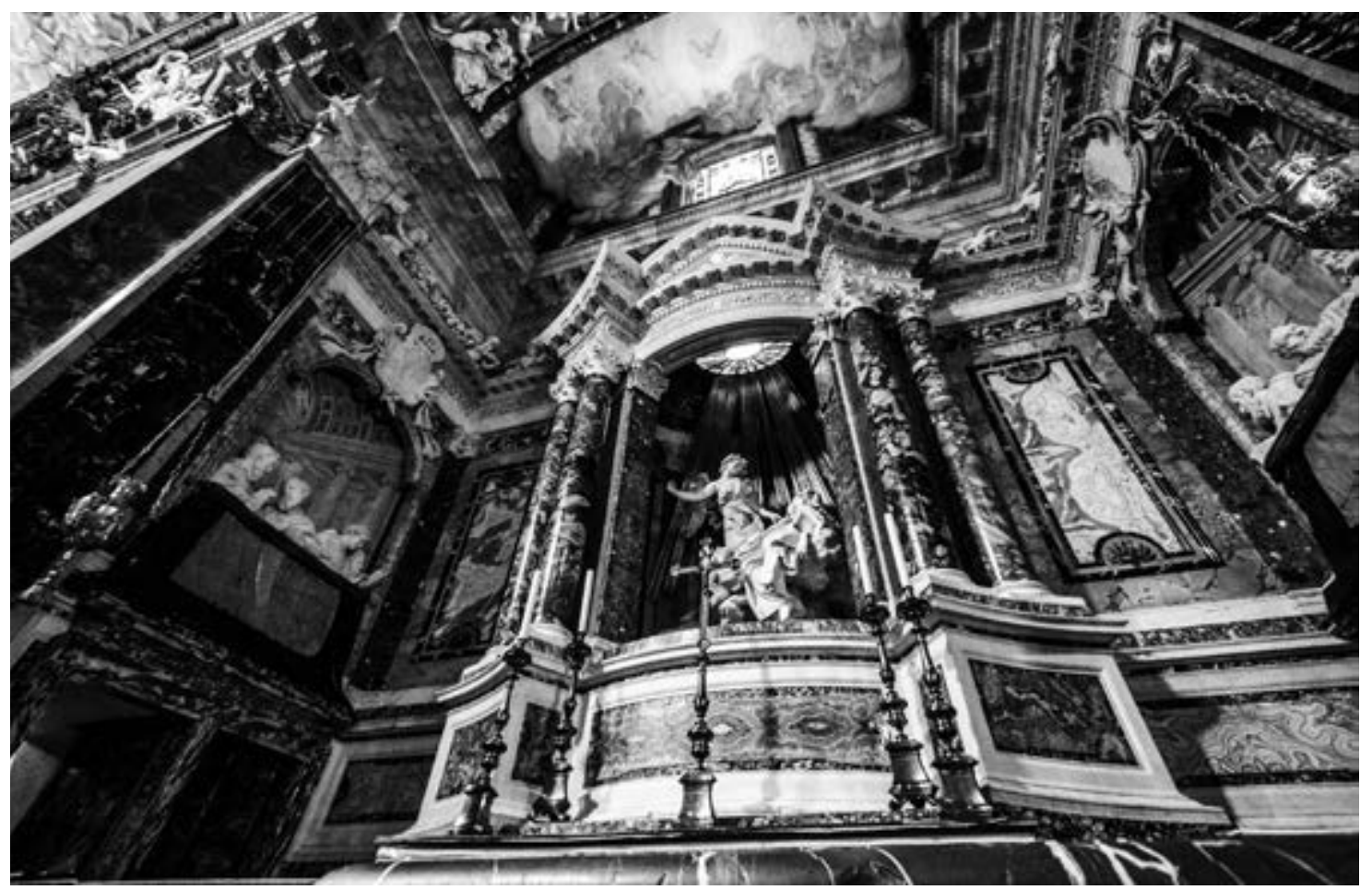

Figure 9.

Baroque ornamentation materialises a drive towards aphasia that, forced to articulate itself through apprehensible structures, nonetheless manages to shatter, confound, and pervert them. The structuring principle is not-and cannot be-negated outright; nevertheless, it can be problematised to such an extent that it begins to emerge as contradictory. Referring to Baroque ornamentation in music, Christine Buci-Glucksmann $(2013,18)$ underlines the existence of "two states of language and sound: an original, 'naked' language; and a second that, according to Roland Barthes, has an 'animating function.' ... By a permanent linguistic gap, by a rupture of continuity, excess or variation generates passion, as in Bernini's theatrical sculptures." Such a "permanent linguistic gap" is what constitutes the underlying principle of baroque excess, the search for a void concealed under and embedded into the impression of horror vacui.

Bernini emphasises the relationality of space, of perception, and of affection. The viewer is caught, through illusion, in the dissolution of the traditional subject-object relationship. The most powerful operation in this respect is San Pietro: this time it is not only a colossal building that becomes its own simulacrum; instead, the whole city of Rome becomes the generator of differential points of view involved in simulacra production. The city is turned inside out by Bernini's operation: it is folded, implicated by the church. San Pietro devel- 
ops not in space but in time, through a series of variations of perspectives and partial openings, as a theatrical play. The church is never to be seen as a whole (the later intervention on the Via della Conciliazione would open up a monodirectional duct towards it, thus expressing a renewed idealistic, "perspectival" vision of the whole city). Under Bernini's reworking, San Pietro becomes a creation of memory and imagination, a phantasmic entity constituted through the virtual reassembling of its infinite views: a scenic machine, producing an action in space that is not just theatrical, but that triggers a material agitation that sets the environment into resonance with itself. The whole city becomes an integral part of the church, becoming "a floating, imaginal space where every frontier wavers between subjective and objective, inside and outside, real and unreal, ... so that it opens onto the non-human point of view of the phantasmatic, . . the invisible" (Buci-Glucksmann 1994, 58). Most importantly then, the viewer also becomes part of the church. As a result, San Pietro is similar to the Deleuzian simulacrum, in that it "includes the differential point of view; and the observer becomes a part of the simulacrum itself, which is transformed and deformed by his point of view" (Deleuze [1990] 2004, 258).

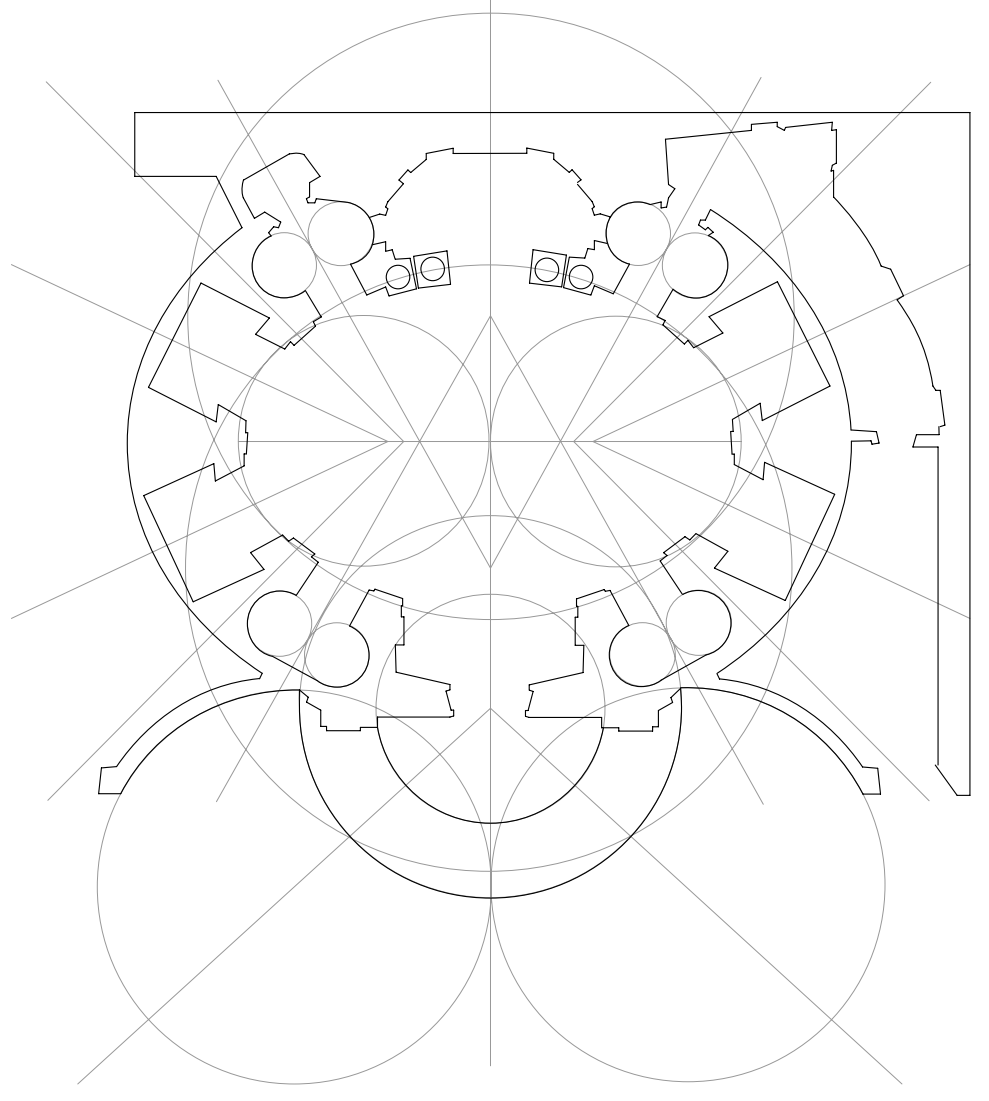

Figure 10 . 
Although he accelerated the decline of humanism, an artist such as Michelangelo remained centred on the human. In his statues, he twisted human anatomy, wrenched limbs, and curled, twirled, and misshaped bodies. But his David remains "the human subject" in all its might: the observer of a reality the human subject creates through the power of its gaze, the contemplator of an outside world that is a direct consequence of its own will. In contrast, the figures in Bernini's sculptures manage to bypass both human anatomy and the Euclidean space where anatomy is inserted. They are immanent to themselves, neither part of a landscape nor the centre of an action. Rather, it is the landscape that emanates from them, as if their motion encompassed its own target, or, better yet, the potentiality to reach it. There are actually no ends and targets in Bernini, but an infinitely unfolding duration. What is outside the scene, what is not represented, does not affirm a separation between the diegetic space and its non-diegetic counterpart (as in Michelangelo's David), but it is rather enhanced as a non-visible space of potentiality. The space of art is an agency that allows the production of another space, that of an invisible presence. The sculptural figures do not occupy a place; they do not act on anything or stand for anything. Their function is to agitate a space, to put it into reverberation with the environment they are set in. Bernini's figures are like vectors: they have a magnitude and a direction, but are not bound to a predetermined point in space. As with any visual object, they might indeed be "rasterised," inserted in a Euclidean grid of fixed spatial coordinates-but only at the cost of negating their intrinsic power of producing a space rather than holding a place. They are sculptural machines, capable of changing the time-space system altogether. This is because one cannot analyse them through measurable time-space categories, as one cannot understand the relativity of an inertial frame of reference without stepping out of it (Galileo). Bernini has managed to strain the human beyond the human: towards the supra-human (e.g., the frozen Saint Longinus, struck as if by a thunder in a divine moment of idiocy and loss of the self; or the Ecstasy of Saint Teresa, whose body is turned into a surface for the heavenly rays to reflect) and towards the sub-human (e.g., Daphne, caught in her becoming-tree; the Damned Soul and the Medusa, their aberrant hair sprouting in becoming-animal). Again, the proliferation of materiality and its irreducible excess accompanies structures and media towards their ecstatic annihilation. 


\section{Five Glances upon the Unspeakable Body: Second Glance}

In "Rasch," his essay on Schumann's Kreisleriana, op. 16, Roland Barthes $(1985 \mathrm{~b}$, 312) expresses the need for a "second semiology" able to account for a zone of Schumann's music that lies inaccessible to the first semiology—where the first semiology deals with the quantifiable and extensive properties of a musical text: "system[s] of notes, scales, tones, chords, and rhythms" (ibid.). This second semiology would address an intensive level of the text that manifests itself through the forces that directly affect the body. Mimicking the structuralist language fashionable in his time (see Assis 2017, 34), Barthes coins a new concept to define the units of this semiology: the "somathemes" or "figures of the body ..., whose texture forms musical signifying" (Barthes 1985b, 307). Barthes's study of the somathemes recognises itself as paradoxical: on the one hand, it is the only enquiry accounting for a dimension of Schumann's music that traditional semiology fails to even see, let alone to approach; on the other hand, Barthes claims not to be able to fully delineate its framework (e.g., his statement: "I do not always manage to name [these figures of the body]" [ibid.]). He attempts to articulate this dimension through the creation of a highly physical, sensual, and sexual discourse by which he follows the micro-acrobatics that the body undergoes when listening to, and more importantly, when performing Schumann's music.

The somathemes can be experienced first of all through the physical gestures of the performer: the hand stretches and contracts, it hits the keyboard, it weaves like a spider, it jumps, it hesitates. Barthes himself was an amateur pianist, rather than a professional music analyst, and exactly through this tentative physical approach he "became alert and vigilant to the transformations of his own body while playing" (Assis 2017, 17). But the somathemes are not only gestures, not only sounds: through gestures and sounds they affect the muscles, the viscera, the pulsation of bodily fluids. The anatomical body is the interface for this para-semiotic transmission, and is fundamental for such a transmission to take place. But anatomy also has limits.

The level of music pertaining to the second semiology is performed and perceived by a "body that beats" (Barthes $1985 \mathrm{~b}, 299$ ), where the anatomical organisation subsides into zones of intensity, fluctuations of forces, processes that are irreducibly differential and unsuited to being fixed into a function, into an organ. The body of the pianist is also — and yet it cannot be only—ten fingers. And, even if Barthes does not explicitly mention it, this interface seems still to belong to the first semiology, a layer that is inseparable from the intensive one, and one that assures its existence; yet, crucially, it does not stand in conformity with it. 


\section{Second Glance}

"Music ... is what struggles with writing" (Barthes 1985b, 308): the two levels of music are mutually dependent and yet in conflict. One level is the cultivated network of signs and meanings, which are unable to account for the desiring and pulsional body; the other level is the language of "blows," deemed by Barthes to be the "sole structural elements of the musical text" (ibid., 310). This second level is transhistorical, and would be independent from semiotic systems, if not for the fact that, time after time, a historically located semiotic system is needed to fix it into a code. The blows, the excess of the body, will always be in friction with writing.

The level of the "blows" exceeds musical hyper-specialisation. Barthes, the amateur pianist, can define himself as "the true Schumaniann pianist" $\left(1985^{\mathrm{a}}\right.$, 295) by virtue of an approach to the text that is unmediated by a body whose pulsionality is dulled by virtuosity, expertise, and training. Furthermore, on this second level the distinction between composer, interpreter, and listener crumbles apart. "On the level of the beats ... each listener executes what he hears" (Barthes 1985b, 303).

Such a level grants one access to zones that are at the same time smaller and bigger than the human subject. The pianist and the listener are thus confronted with their own interior life (interiority here is by no means intended to be spiritual, but to be visceral). Music relays directly to the subhuman world of bodily fluids, of molecules, of temperatures, of speeds, at a site that elicits commonalities with the animal (the body weaves like a spider, it moves like a serpent), the vegetal ("shifting branches" [Barthes 1985b, 311]), the mineral ("a big bang" [302]), the meteorological ("it showers" [300]), and the electromagnetic. But, on the other hand, it also allows access to the supra-human, engendering a non-communicative form of inter-subjective transmission that takes place below the culturally mediated codes of language, through a shared incision into the viscera and into the nervous system.

Writing is then the articulative support that allows the language of the "beats" to become perceptible and apprehensible. Yet, in this need to affix and to clarify, writing radically conflicts with this eminently bodily layer, characterised by ever-mobile fluctuations of potential and by a condition of unceasing becoming. The musician is thus in a permanent process of negotiation between the need for such clarifying support and the necessity to escape its repressive organisation. Consequently, Schumann's music is searching for its own "body without organs," a quest Deleuze and Guattari described in the following passage:

You have to keep enough of the organism for it to reform each dawn; and you have to keep small supplies of signifiance and subjectification, if only to turn them against their own systems when the circumstances demand it, when things, persons, even situations, force you to; and you have to keep small rations of subjectivity in sufficient quantity to enable you to respond to the dominant reality. Mimic the strata. You don't reach the $\mathrm{BwO}$ [body without organs], and its plane of consistency, by wildly destratifying. (Deleuze and Guattari 1987, 160) 


\section{Second Glance}

Deleuze and Guattari warn about the possible risks of dismantling the organism-which in this case can be applied both to the musical textual body and to the body of the performer. The "body without organs" is a permanent limit, a non-locatable margin that one has to experiment with, running two parallel risks: on the one hand, risking falling back under the hegemony of the organised body; on the other hand, risking spoiling everything, getting rid of the medium by "wildly destratifying" and therefore reaching an undifferentiated, pure abstraction, or even death. Experimentation is a tightrope walk between these opposite threats. 


\section{$7 \cdot$ The Vectors of the Body}

In $\$ 2$ I discussed the problems of improvisation in relation to my practice and research. First, the influence of predetermined, interiorised categories risks the possibility of informing the materiality of improvised performance in an even stronger way than a written text can do through interpretation. Second, improvisation displaced my practice too much in the direction of "performance," to the detriment of the "of": it is difficult, if not impossible, to improvise a "performance of" (a musical work). However, the structure of the song Amarilli mia bella, and the work previously done on it, still suggested some potential for improvisational practices.

Also in $\$ 2$ I mentioned the extremely forceful rhetorical structure devised by Caccini, and how I had transformed it into a visual diagram to be used for improvisation. I realised that the potential of Caccini's song exceeded the rhetorical and the structural: using very simple relations within the proto-tonal structure of melody and harmony, Caccini delineated a scenario of extreme physicality, sexuality, and violence. As a result, I wanted to bring to the fore this powerful potential that has usually been blunted by traditional interpretative and executive approaches.

Susan McClary (2007) has already drawn attention to the bodily aspect of this song. In her essay, which argues for the appearance of traits of proto-tonality in the early Baroque, she unfolds the song's rhetorical structure showing how it is almost paradigmatically supported by the underlying modal-tonal apparatus. Using the pitches provided by the musical scale as signals for "crucial nodal information" (ibid., 97), Caccini constructs the song as a bodily space, a scene of desire and violence. The compositional tools that Caccini chooses are extremely self-contained, the minimum necessary to tackle the maximum of expression: in a proto-G minor key, the melody develops almost only within the diapente between D and G; only once does it descend to the diatesseron, and I will explain later how violent a bodily gesture is associated with this movement. The two notes enclosing the melodic range set the limits of the bodily space: the $\mathrm{D}$ is the shining, yet distant, world of the beloved one, Amarilli; the $\mathrm{G}$ is the opaque world of the singing persona, its appearance in the song often coinciding with the words mia, mio (my), and so on. The D-Amarilli, the first element of difference in the harmonic series, is uncompromisingly the G-lover's other, yet at the same time it belongs to its harmonic projection. I report here my own reflections about the rhetorical structure of Amarilli mia bella, integrated with some of McClary's considerations, through which I have divided the song into six sections, each defined as a "vector": 
Vector 1: In the first two phrases, the singing "I" is reaching for Amarilli, trying to "throw" melodic phrases at her and to drag her closer to him. Three times the melody lingers on the $\mathrm{D}$ and then is diluted into a different descending melody, each with its own varied affective nuance: the first time "tortured" (McClary 2007, 99) in the harmonic contour, underlying the singer's sorrow; lightening up on a $\mathrm{C}$ the second time, with the word credi (believe), as if illuminating the lover's sincerity; and finally lingering on the $\mathrm{B} b$, as if to rejoice at Amarilli's beauty the third time.

Vector 2: On the fourth phrase, a stronger gesture is accomplished: the pitches presented at the beginning are sung in a descending scale, from $D$ to G. With the words "d'esser tu l'amor mio" (that you are my love) the singer is trying to materialise his wish to draw closer two worlds previously presented as distant - that of the incredulous beloved and that of the passionate lover.

Vector 3: In the middle section, the repeated A conglomerates into a static membrane that lies between Amarilli and her lover: it is the membrane of suspicion (Amarilli does not believe in the lover's good faith), against which the singer continuously directs his voice in an attempt to undermine the membrane with his sincerity. Supporting this, the verbal text itself becomes corrugated by harsh consonant sounds (“cr-," "pur," “-mor," "pr-," "str-").

Vector 4: Recalling the successful attempt at drawing Amarilli close to himself (in vector 2), the singer starts from a climax (the D pitch) - with the open sound "a" emphasising the pathos of the moment-and then descends and breaks the membrane of doubt of the note A. Yet what happens is the unexpected break not only of the membrane but also of the bodily interiority of the singer himself. The "proto-leading tone" $\mathrm{F} \#$ weakens into a $\mathrm{F}$, and the melody leads towards the diatesseron low D. In a "moment of profound erotic surrender" (McClary 2007, 99), the singer opens his chest to show the inscription of his beloved's name on his own heart. The gesture is one of incredible violence: Amarilli has taken the blade of a dart to lacerate the body of her lover, and now she is contemplating his open chest, where the $\mathrm{D}$ - perhaps the sign of the possibility of similarity and union between lovers-pulsates.

Vector 5: Straight after that, the singer starts approaching again the distant and beautiful Amarilli. The leading tone that opens the way to his own interiority is the starting point of an ascent in three slow and painful fits, the physical effort of which is also underscored by the use of secondary dominants, until he reaches the $\mathrm{D}$ passing through the $\mathrm{C} \#$ as if it were the key to access Amarilli's interiority.

Vector 6: The ending figuration, a sort of melisma carrying the liberating force of a conclusive amen in a sacred chant, marks the way to to Amarilli's interior world: for the first time, the melody reaches a pitch above the diapente, the E, suggesting erotic rapture. 
7. The Vectors of the Body
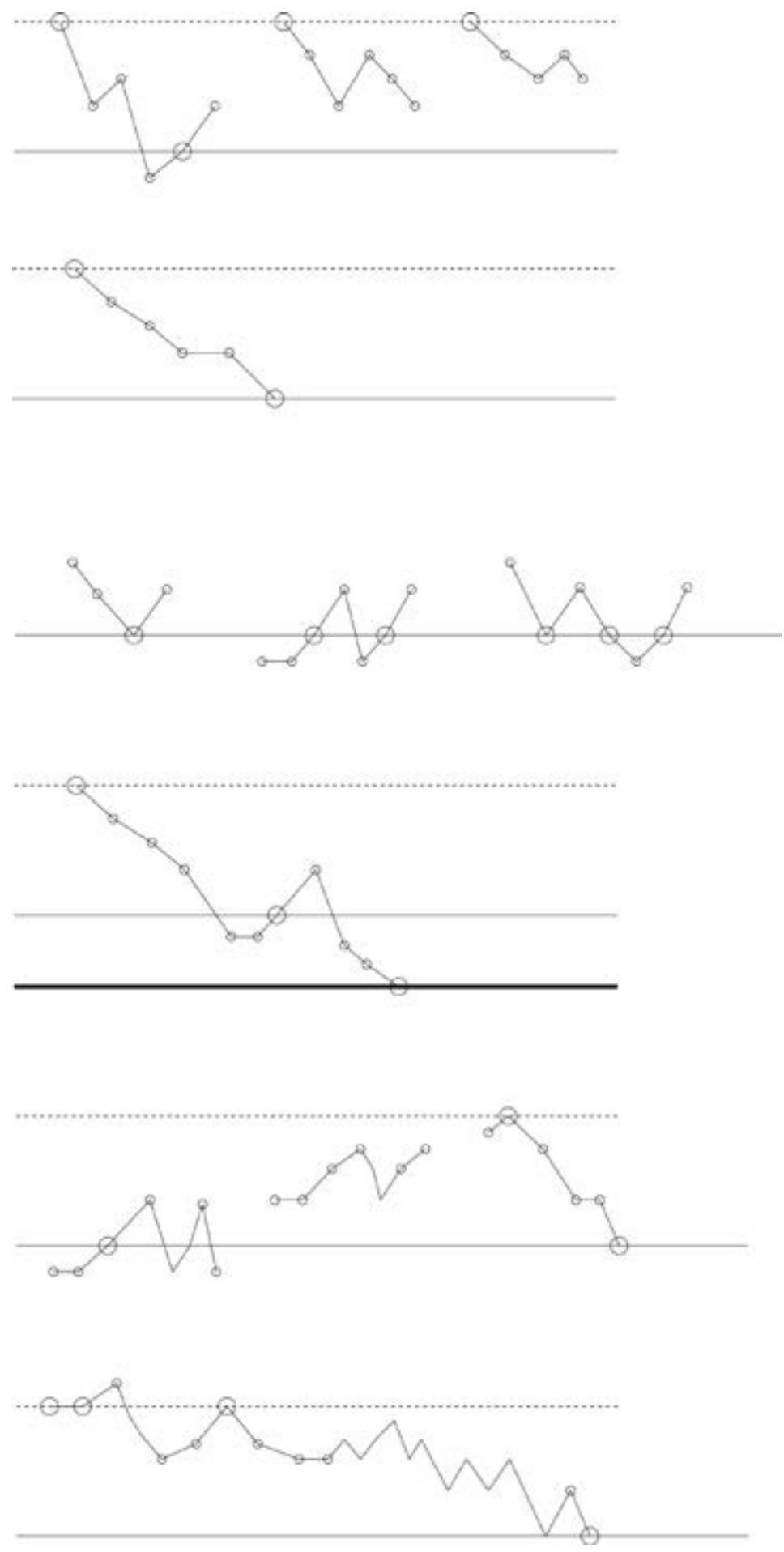

Figure 11.

98

Figure 11. A diagram showing the six vectors in Amarilli mia bella. As in a rhythmic-

diastematic score, the horizontal space represents time and the vertical space represents

frequency. The circles represent pitches. The solid line is the Glover, the dashed line the

$D$-Amarilli, and the bold line the lower D (the lover's visceral inferiority). 
I used this structure to coach a group of five students on the methodologies developed by my research project as part of a musical interpretation course. ${ }^{10}$ Using the diagram shown in figure 11, we worked on the relations between the vectors derived from Caccini's melody and on the physical and sensuous framework of the song's rhetorical structure. Each of the six vectors was used as a starting point for a short composed improvisation. The main elements framing the scenery of bodily states and drives in the song were transposed into different gestures, and were put into relation with one another according to the six vectors. The starting points were the two initial bodily states in Caccini's song, corresponding to the G-singer (the tonic, the bodily interiority) and the D-Amarilli (the dominant, the first element of difference in the harmonic range, revealing the distance of the beloved). The students were invited to find two sounds, or sound sequences, that could suggest these two bodily states. The initial tendency of the students was to develop a compositional arch; I tried to restrain this tendency, inviting the students to use very few actions that would be easily identifiable, functioning as static signals, and to vary the density and pace of their recurrence, rather than adding new elements or evolving them. These sounds, as basic and simple as the proto-tonal framework employed by Caccini, would have to be uncomplicated and clear. The function and state of these musical signals should be similar to Bernini's sculptural figures (see "Derivative VII"), which are not spaces to be occupied by a musical action, but instead are sonic environments immanent to themselves that are able to emanate a space rather than holding onto a place. Most of these environments were therefore static, more concentrated on the evocation of an affect than on a linear development. In some of them, the correspondence between them and the original vector in Caccini's song led the students to develop the fragment internally-especially when the bodily scenario in the song suggested direction and movement.

Table 2 contains a summary of the six vectors, and an explanation of the transpositions that, after the workshop, were chosen to take place in each of them. I would like to emphasise that the contents of the table describe the decisions taken during the workshop; I would not deem them to be valid in the framework of my research to be used as a prescriptive tool by other performers outside the context of the workshop.

10 The students were attending the Advanced Master in Contemporary Music (School of Arts Ghent, Belgium). 
VECTOR ACTION

1. Distance Two planes of sound: the opaque plane of the singing voice (the $G$ ) and the shining but distant plane of Amarilli (the D). Define the ground corresponding to the $\mathrm{G}$ (e.g., a very soft and groaning sound). Sometimes the "star" of Amarilli appears, but as something distant that you try to reach for. Each one of you has to find his or her own "Amarilli" sound. This can appear alone, or you can coordinate with each other and at moments play it in twos or threes.

This section has to "present" the environment. It is thus one of the sections with the least development.

2. Desire Begin by asserting the "Amarilli" sound: now it is no longer distant and vague, but something that we have identified. . . . From that sound, begin a slow descent towards the interior sound. Modulate the timbral morphing as if it was a sort of diatonic scale.

3. Suspicion $\quad \ldots$ begin to agitate... break the membrane of doubt that separates the $\mathrm{D}$ from the G....

Organise this section in waves, leaving a pause between each wave. Create variations in the length, articulation, and shape of the waves.

4. Laceration Begin with a very short "horrific" and violent sound, but straight away this sound should become the Amarilli that by now we can recognise. From this we begin to morph again back to the interior sound.... Stay a bit in the G sound of the interior, then slowly go towards the sound of the heart (low D). Such sound is rich and vibrating, the sound of something concrete and alive that at the same time is beautiful and repellent. All instruments are very static, "inside" the sound, except for the piano, which weaves slow and barely audible patterns on top.

5. Penetration We are now in the opposite direction of morphing: from G to D. This happens not in a line but in three slow waves of sounds, each of which is like a long but consistent breath.... There is silence between each of them. First: start from the interior and then begin to move a little bit out from it. Second: you are already out, trying to reach for Amarilli-D. Amarilli does not yet appear here. Third: reach for Amarilli (produce a kind of "leading tone" movement), let it shine brightly (and now more serenely), and then go quickly back to the interiority.

6. Rapture A moment of bliss: produce simple patterns of very "airy" sound, as if all the bodily affairs that have happened before were sublimated in shadows of sound. Very static and rhythmically defined, simple patterns. 


\title{
Derivative VIII: How to Produce a Phantasm? Part II: Francis Bacon
}

\begin{abstract}
The longer you work, the more the mystery deepens of what appearance is, or how can what is called appearance be made in another medium. And it needs a sort of moment of magic to coagulate colour and form so that it gets the equivalent of appearance, the appearance that you see at any moment, because so-called appearance is only riveted for one moment as that appearance. In a second you may blink your eyes or turn your head slightly, and you look again and the appearance has changed.... appearance is like a continuously floating thing. (Francis Bacon quoted in Sylvester [1975] 1999, 118)
\end{abstract}

What does it mean to produce pure appearance, or as Buci-Glucksmann calls it $(2013,2)$, a phantasm? The phantasm doubles a given shape-therefore retaining a similarity with the object of which it is an image. However, it also occupies a parallel dimension, which does not correspond with, though is inseparable from, the shape it doubles. As painter Francis Bacon underlines, appearance is to be produced in another medium, through the fluid of painting, through the hardness of sculptural materials—or, I add, through the acoustic vibration and the bodily gestures of performance. Through and in these materials the artist tries to evoke, in the moment of their coagulation and contraction, something else. The phantasmic image is therefore the simulacrum of a referent that, through an act of failed representation, is indicated as absent, but whose status and importance as a departure point is fundamental.

Bacon's problem with painting and my own problem with the performance of written music are problems of resemblance. Both practices aim at subverting the Platonic mechanism, according to which what resembles can only differ while trying to be as accurate and faithful as possible to the unparticipated pure idea (see "Derivative IV"). In contrast, in the logic of the simulacrum, "only differences can resemble each other" (Deleuze [1990] 2004, 261). The contrivance of the phantasm is then the production of a difference that retains only an aberrant resemblance to the starting point, which it aporetically negates through a distorted doubling.

In chapter 13 of his book on Bacon's painting, Gilles Deleuze (2003, 11121) proposes two modalities of analogy in visual art. In the first, an analogy is attained when resemblance is "the producer"; that is, when "the relations between the elements of one thing pass directly into the elements of another thing, which then becomes the image of the first" (ibid., 115). In the second modality, resemblance is "the product ... it appears abruptly as the result of relations that are completely different from those it is supposed to reproduce: resemblance then emerges as the brutal product of nonresembling means" (ibid.). The first kind refers, for example, to photography, where the relations 
of light are directly captured and transferred onto the film to produce an image that points to an original referent, despite all the material differences within it. In the second kind, the analogy between the two things is dictated not by a figurative and representational code, but by a sensible and sensual communality. The fundamental difference, paraphrasing Deleuze, is that while in the first kind the relationship of resemblance is an internal one (where faithfulness is an aim, having the clearness of the proportions between the two elements as the guideline for the composition), in the second kind resemblance appears as a sort of third occurrence, a quasi-autonomous after-effect linked to both terms of analogy, but not directly connected to either of them. Resemblance becomes a fundamental variance that at the same time separates the two terms (stating their incompatibility) and unites them (exposing their degree of difference as their inextricable common ground). Instead of following the clear pathway of resemblance as a leading principle-by the repetition that, by its own nature, leads to differentiation, in the Platonic sense of deviation from the unparticipated Idea-resemblance is produced afterwards, as a consequence, as a symptom.

According to Deleuze $(2003,155)$, every time a painter sets him- or herself to work, he or she begins from an unavoidable starting point, the space "preexistent or prefabricated," a figurative given that occupies the canvas even ahead of the first brushstroke. Entering the world of resemblances that crowd the canvas is easy, it is the exiting that is difficult-one needs to become aware of the cliché and to dismantle it. In pursuing the phantasmic doubling of a pre-existing piece of musical repertoire, my practice is faced with a similar problem: entering the cliché, reproducing it faithfully, and being "figurative" are relatively easy. I might compare the skill of a traditional interpreter to that of a figurative painter: the more resemblance he or she is able to produce with the image of a given musical work, the better. The endowing of fluidity, meaning, expression, and "life-likeness" are still the gifts of figuration. In my relationship with the original score, the entrance in the cliché is a preparatory phase, whereby the musical work is observed through an analogy of the first kind (where "resemblance is the producer"). It is then performed in a traditional way, read, analysed, and, where possible, experienced through execution or interpretation of other performers. At that moment, the score's internal relationships pass directly into the sounding inscription to become its relationships. This phase accepts that "there are figurative givens. Figuration exists, it is a fact" (Deleuze 2003, 87), it is present in the mind of the painter and in the culturally shared assumptions about what is seen. As the painter "paints on images that are already there" (ibid., 86), the first angle of relationship with the primary musical work (see $\$ 4$ ) coincides with the preparatory listening and executive phase, during which one detects the identity of the givens to depart from and which relations are to be redefined between the score and the sounding result. 
Derivative VIII: How to Produce a Phantasm? Part II: Francis Bacon

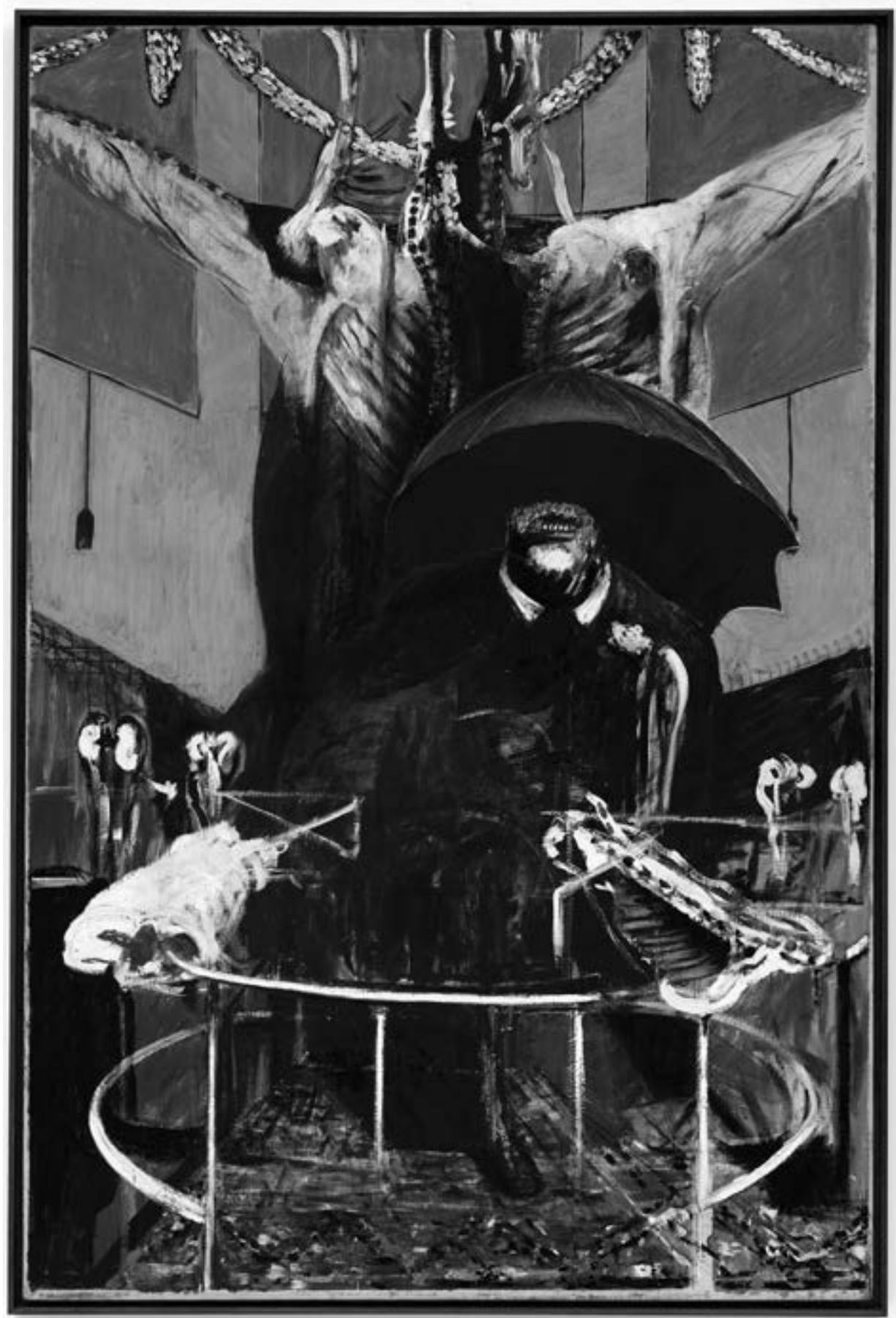

Figure 12. 
Deleuze describes two ways that Bacon accomplishes the production of resemblance through non-resembling means. The first is exemplified by Painting 1946 (figure 12), which started as Bacon's attempt "to make [a painting of] a bird alighting on a field" (Francis Bacon quoted in Sylvester [1975] 1999, 11). Any trace of a figurative intention for the bird has vanished in the final image. The composition is carried out in a completely unpredictable way, where no actual resemblance to a bird can be found. Yet, some traits of "birdness" are still present, even if not univocally traceable in any of the visible elements of the painting. How does the painter pass from the intention of the bird to an image that displays beef carcasses, an umbrella, and the bust of a man with a half-severed head? Deleuze emphasises that one does not pass directly from one form to the other. The relationship between bird and umbrella, for example, is not a one-to-one morphing. The "birdness" is scattered in the background, in the scrambled circular lines in the lower part, in "a series of accidents "mounting on top of another" (Deleuze 2003, 157). It is not something to be traced back, but to be felt. There is not a specific form that substitutes for the bird, "but completely different relations" (ibid.) that produce a final result that, although it bears no likeness, draws an aesthetic analogy to the bird, an analogy in sensation. The bird is suspended on the painting as a submerged shape, yet it is impossible to trace an objective correspondence with it anywhere: do its wings, perhaps, become two beef quarters; does its beak, perhaps, become the mouth of a man; is the black, open umbrella part of the bird's "crowness"? There are no clues from which to backtrack to an original intention, only imaginative suppositions about what and how one can make oneself feel a bird where there actually is no bird to be spotted. The appearance of the bird has thus acquired autonomy from the object that generated it. A phantasm is produced, a resemblance without a real object, a pure appearance. The bird is denied as a figurative referent, but exactly because of that its imaginative presence can be felt in a much stronger, more oblique way.

The second process takes place when the production of resemblance does not happen through the transferral from one form to another, but when it occurs within the same form. In this case, the painter starts with the intentional figurative given, and then "scrambles it from one contour to the other, like a gray that spreads itself everywhere. ... out of which new relations will emerge ... that are completely different from relations of resemblance. And these new relations ... produce a more profound resemblance, a nonfigurative resemblance for the same form; that is, a uniquely figural Image" (Deleuze 2003, 158). Scrambling, rubbing, introducing new distances between the figurative lines, new relations that have nothing to do with the pre-given relations of resemblance. Bacon wants to make "a Sahara of the appearance" (Francis Bacon quoted in Sylvester [1975] 1999, 56), to introduce the distances of a desert within a portrait. The emergence of elements that are apparently unrelated to the original image is sometimes dictated by unpredictable nexuses, the product of a twisted and aberrant relaying, as when, in Figure with Meat (1954), the velvet clothes in Velásquez's Potrait of Pope Innocent $X$ become the sumptuous red of animal meat. The displacement is never logical or geometrical, but is always a way of redefining the relationship between the elements in the original. 
In my musical practice, I have explored both modalities of producing a phantasm enunciated by Deleuze; furthermore, I have combined them with each other to produce resonances between the micro- and macro-levels of intervention on the primary work. In the first case, the relationality between the two terms is produced through the delineation of an underlying formal shape derived from the original score, an assemblage of lines of force that persist in the passage from one sounding result (the one already encompassed by the score) to another. According to this methodology, textual musical facts (including not just pitches, harmonies, and durations, but also lyrics, etc.) cease to have a structural weight preserved in the sonic and gestural enactment, instead acquiring a functional weight. The forces latent in the score are vectorialised and are made elastic and capable of imprinting materials other than those envisioned by the composer him- or herself.

The second modality-where new distances are introduced between the elements of the same image-is the one used most frequently in my musical practice. To describe what happens in this case it is useful to refer to what Deleuze calls the hystericisation of the elements of the first term of analogy. It is important to note that through the use of the clinical category of hysteria Deleuze tries to go critically beyond psychoanalysis and the ways in which psychoanalysis treats such a pathology as the embodied "symbolic expression of a psychic content" (Geyskens 2010, 217). Deleuze is interested in the specific power of art-in particular that of painting - to relate to manifestations of hysteria in a way that is capable of bypassing the narrative and interpretive modalities of psychoanalysis. The clinical and pathological aspect is not the focus of Deleuze's discourse: for him, the bodily sensations of the hysteric, and the way they are conveyed in a primarily aesthetic modality, unleash forces of pure vitality that unsettle the predetermined organisation of the "sane" body, leading to a disorganisation and a rearrangement that happens at an intensive level. This is why Deleuze $(2003,54)$ would like to "speak of a hysterical essence of painting, under the rubric of a purely aesthetic clinic, independent of any psychiatry and psychoanalysis." Painting thus, by staging the struggle between the physical body of sensation and the organised body of representation-the figurative givens, but also the material media through which it takes place-is the hysterical art par excellence.

Hysteria therefore accounts for a particular kind of formal and aesthetic displacement, one that has something in common with both the Freudian notion of Verschiebung (displacement) and the Lacanian linguistic dislodgement provided by metonymy but that radically departs from both. The structural rearrangement that Lacan describes fundamentally happens in language, and cannot escape the symbolic dimension-even at the level of an unconscious "structured in the most radical way like a language" (Lacan 2006a, 179). In contrast, Deleuze rejects the confinement of the expressive and subversive force of both pathology and art to their semantic, signifying dimension, to emphasise how they are means through which the body tries to escape its own organisation. What Deleuze contests, in Lacanian terms, is the vision of the Real as an unattainable limit, in favour of a Real that is produced by the friction between 
the body and its limiting structures-between the body of painting and its figurativeness, its representativeness.

Deleuze (2003) also writes about music's intrinsic power of hystericisation: "Certainly music traverses our bodies in profound ways, putting an ear in the stomach, in the lungs, and so on. It knows all about waves and nervousness" (54). However, it is also different from painting in that "it involves our body, and bodies in general, in another element. It strips bodies of their inertia, of the materiality of their presence: it disembodies bodies" (54). Even if Deleuze states that "music does not have hysteria as its clinical essence" $(55)$, and that "to hystericize music we would have to reintroduce colors, passing through a rudimentary or refined system of correspondence between sounds and colors" (55), we must keep in mind that he is considering sound only as the material inscription specific to music. In contrast to painting, in which the hysteric rhythm struggles to liberate the body from both the materiality of paint and the represented, figurative body, Deleuze considers music to be at a further stage, one where the body is already liberated through its dematerialisation. However, the starting question of my practice addresses the material of music not only as sound but also as a much more constraining and organised body: the body of the musical text, its visual and spatial component. In this respect, what is said about the hystericising power of painting can be applied to the performance of written music, by means of a displacement that, having the text traversed by a force and a rhythm in disconformity with its own structure, convulsively disorganises it and rearranges its parts according to a law of pure affect. Such a law is what Deleuze calls "the logic of sensation," which affects the viewer, listener, or reader before any meaning coagulates.

Bacon is a painter of hysterics because of the coexistence, in his paintings, of "both the sense of strain that bodies are under (the pressure and structure of organisation), and the attempt of these bodies to escape their organisation" (Roffe 2005, 123). Bacon keeps the elements present in Velásquez's original painting of Innocent $\mathrm{X}$, but displaces them according to a deformational force that is neither homothetic nor simply transformational. We are instead dealing with a special case of anamorphosis - in the broad sense, not strictly in the sense of projection. The elements codified in Velásquez's original painting escape their grid of reference to be relocated according to a logic that exceeds geometry, as it does all other extensive visual assumptions. Bacon is a superb baroque painter. Similarly to Bernini, even if through completely different processes and materials, he sets the world as a phantasm and not as an icon; thus, he does not proceed from the real to its codification, but rather creates a real through a proliferation of materials that emanate from a shape, dissipating it at the same time. The images created by Bacon obey "the logic of sensation," characterised by the ability "to pass through different levels owing to the action of forces" (Deleuze 2003, 65). Hystericisation becomes then a practice of rearrangement, of displacement, and most importantly of producing a friction between the body of sensation and its own anatomical, figurative, and structural limits. In my practice, the anatomy of the primary work is not simply twisted (activity that might still belong to an interpretative process): it is negated (e.g., linear 
Derivative VIII: How to Produce a Phantasm? Part II: Francis Bacon

temporality is suspended), dissipated in intensive forces (e.g., textural backgrounds encircle and blur identifiable figures), repeated/varied (e.g., isolated elements return and overlap without development). Again, it is an anamorphosis, not through the clearness of geometry but through the opaque density of body and thought. 


\section{8. \\ The Musical Work as a "Manifold"}

As part of the research team MusicExperiment21 I worked on the artistic project Rasch $^{x}$, a series of performances and lectures based on two main materials: Robert Schumann's Kreisleriana, op. 16 (1838), and Roland Barthes's essays on Schumann's music, particularly focusing on "Rasch" (Barthes 1985b). The aim of the project was to generate "an intricate network of aesthetic-epistemic cross-references, through which the listener has the freedom to focus on different layers of perception" (Assis and D'Errico 2017). It involved live piano playing, visual elements, projection, the reading of texts, playback, and live electronics.

As an element of a wider research project on the production of experimental performance practices, Rasch ${ }^{x}$ questions "what we know" about Kreisleriana, by exposing audiences in concert situations to materials that are not contained in its score but that belong to its wider landscape: Kreisleriana is not only a musical work in its traditional ontological definition, nor does it coincide with a physical object (such as one of its score's editions); rather, it is an "assemblage" (see Assis 2018) of materials, forces, affects, and percepts that exceed the actual moment of its composition. In the project, such a familiar musical and aesthetic object is turned into an object for thought, through a defamiliarisation that happens nonetheless through materials and activities generated within a widened, reshaped image of it as a musical work. ${ }^{11}$

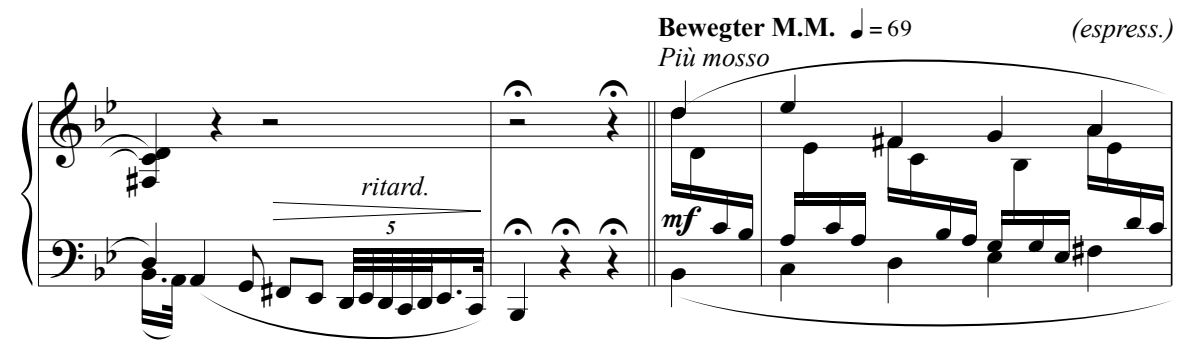

Figure 13

In this context, I worked on a version of Kreisleriana no. 4 for Rasch²3, a live performance that was the twenty-third instantiation of the project. It consisted of a soundtrack to be played alongside a live piano performance, in place of the enigmatic five fermatas in bar 11 of Kreisleriana no. 4 between the end of

11 For a complete overview of the new image of work elaborated within the research project MusicExperiment21, see Assis (2018, chapter 1) 
section A and the beginning of section B or the intermezzo (figure 13). Here, I could experiment with yet another performative function of the sonic image: that is, its direct insertion into the performance of the primary work it departs from, as if it were a crater opening between the piece's two sections, a new and unexpected dimension emanating from the traditional rendition of the piece.

To a certain extent, this work also reflects on some of the concepts underlying the whole Rasch ${ }^{x}$ project, and the methodologies developed and utilised by MusicExperiment21. In turn, these concepts and methodologies exposed me to operations that were active aspects of my previous experiences, but that had not yet emerged so explicitly on a reflective level. Quoting Paulo de Assis, the principal investigator of MusicExperiment21:

\begin{abstract}
I suggest a new "image of work," crucially devised in a post-aesthetic regime of the arts, where works are no longer seen as static entities (the idea, the score, the performance, the recording, the analysis), but rather as highly elaborated manifolds with potentially infinite constitutive parts (sketches, manuscripts, editions, recordings, theoretical reflections, previous works or styles that exerted an influence, future works that shed new light upon them, etc.). In the place of a reiteration of uncritically inherited performance practices, this perspective offers a methodology for unconventional, critical renderings that expose the variety and complexity of the music materials available today. More than repeating what one already knows about a given work, it claims the unknown as the most productive field for artistic practices. Rather than accepting a reproductive tradition, it argues for an experimental, creative attitude. (Assis 2016, 22)
\end{abstract}

If many elements of the new sonic image are taken from the score and its "interpretational" rendition (the preparatory phase as explained in $\$ 4$ ), then other elements are influenced by the wider network of materials constituting the "manifold" of Kreisleriana. In particular, the reading of Barthes's texts became inextricably part of Schumann's piece, adding new dimensions to the preparatory phase. In other words, the glance thrown towards the work by my practice (the new status of the "of") is not just mobile in itself: it also relates to an entity-the musical work-that is not ontologically enclosed, and whose affective potency also depends on its capacity to implicate innumerable materials. Musical works are "assemblages.” They enfold a material dimension, a historical one, and a psychological one.

The second important concept that influenced this particular experience is Barthes's idea of "somathemes," or "figures of the body" (Barthes 1985b, 307). The whole of the essay "Rasch" is based on the idea that a fundamental part of Schumann's music can only be grasped, experienced, and understood through the body of the performer and of the listener. The "figures of the body" provide a sort of second layer of the score, linked to and yet fighting against the musical text constituted by "grammar" and "musical semiology: ... identification and arrangement of 'themes,' 'cells,' 'phrases”' (307). For each of the Kreisleriana, Barthes sketches the respective "somathemes," which are determined by the movements of the hands of the pianist, by the affective impact of the accents on the body of the performer/listener (the "blows" [299]), or by the voice-like character of certain musical gestures. 


\section{The Musical Work as a "Manifold"}

The "somatheme" that Barthes (1985b) associates with part A of Kreisleriana no. 4 is "quasi parlando" (almost speaking) (306), the effort of a voice that cannot speak but that needs and wants to. In this fragment, it is as if the body "puts itself in a state of speech" (306). In the intermezzo (part B), on the contrary, "it speaks, it declares: someone declares himself" (299). The two limits of human utterances suggested by the two somathemes provided a sort of imaginative and physical framework for the whole performance of Rasch ${ }^{23}$ : at one end, an impeded will to speak, at the opposite end, the scream, the violent explosion of inarticulate utterance. Following from this, my own Kreisleriana no. 4 starts with soft prolonged notes, echoing the ending of part A. At a certain point, the "scream" irrupts, through processed siren sounds and heavily distorted textures, to then end in a sort of reprise where the residues of the beginning (fragmented, stuttering and distorted) return, only to fade out again before the piano starts after the five fermatas. 


\section{Derivative IX: \\ How to Produce a Phantasm? Part III: Salvatore Sciarrino}

Starting from the beginning of the twentieth century, various relevant compositional practices have denied the romantic ideas of both the composer-genius as origin and the listening experience as telos. In these ideas, the musical work does not come into being upon dictation of the logos; rather, it stems from the constructional potency of its own material. In particular, compositional activities that expose the autonomous power of a highly parameterised musical language (such as in the various forms of serialism, specifically, integral or total serialism) lay bare the autonomy of the automaton (see "Derivative VI"), the operative dimension of language that marks off the two extremes of origin and telos, without superimposing it onto a delusional vision of sonic reality "as it is." The automaton is exposed as the matrix of the linguistic system, suspended in its independence and arbitrariness and liberating a machinic productivity, now free from the illusion of a correspondence to an absolute referent outside itself. Such music does not represent (emotions, states of mind, imaginative landscapes), nor re-present (already constituted materials in new configurations); it presents itself as a totally new system of relations.

In his introduction to Lohengrin: Azione invisibile (1984), composer Salvatore Sciarrino expresses a completely new vision of composition and music, and a redefinition of the relationality of the listening experience: "The world does not exist. What exists is the consciousness of how we see it" (Sciarrino 2001, 83 , translation mine). The relationship to the world, and to musical composition, happens through a detachment, an increased awareness of the mechanisms of perception and cognition, a duplicity of the listening experience (as consciousness and as illusion). The change operated by Sciarrino decentres the compositional activity towards the physiology and psychology of the listening experience regarded as a field of forces and affections. He concentrates on the material aspects of sound, on its relational quality, and on its capacity to affect the listener, to condition - and in turn to be conditioned by-human perception and cognition. The compositional structures he generates are not merely "perceivable," as were those contrived by serialist practices; rather, they are also perceptional: they implicate the way they are apprehended by the human hearing interface. Sciarrino's music listens to the way that sound is listened to. The fundamental move away from serialist formal processes lies in the object of composition: no longer the autonomous dimension of parameterised musical relations, but the affective power of sonic structures. Sciarrino's vision of music and art is not a representation of reality (as the mimetic notion underlying humanism/Romanticism implies); music does not present itself as a reality either (as serialist composition does). It represents the representation of reality (Bernini). 
The analytic logic underlying the serialist approach is questioned and challenged by this vision. Serialist thought takes the Euclidean dimension of the automaton to its extreme. Its epistemic system is based on the parameterisation of sound according to the Western semiotic approach: sound is dividable and analysable-in other words, serial composition treats sound solely as a mental category. Even when the results of the sonic sequences generated by such an approach are extremely sensuous, expressive, and even viscerally bodily, the fundamental epistemic premise of serialism remains a segmentation of the perceivable whose potency does not depend inherently on the sensible and material phenomenon of sound in order to fully unfold itself. In contrast, Sciarrino starts from the primary element of musical activity-the phonic matter in its vibratory status-as an entity in a continuous movement and becoming, as a continuum that cannot be segmented without losing vitality and energy. His vision of sound is vectorial: "Sciarrino detaches himself from any other composer, since he does not conceive of sonic events as discharged from energy, or in anyway a static manner, but he conceives them always and only as in movement in the mental space, that is, vectorially" (Angius 2007, 22, translation mine). Sound, therefore, is physical, physiological, but in the same way that the mind is physical and physiological. Memory then becomes the paramount space of inscription of music, where the present tense of listening expands, including past and future sonic events, duration, and becoming. Sound prolongs the instant, implicating its before and its after.

On many levels, the compositional experience of Sciarrino can be regarded as a baroque practice. The four principal features of his baroqueness, which I would like to analyse, are:(1) the poetics of the double and its deployment in the musical operational system, (2) the paroxysm generated by the non-conformity between semiotics and materiality, (3) the use of figures, and (4) anamorphic processes.

\section{(1) The poetics of the double}

Sciarrino writes about his own music as "disturbing realism" (realismo inquietante): "A language that one learns under the deadly tree of dreams, and that one perfects with the study of the subtle perceptions that nourish it" (Sciarrino 2001, 83, translation mine). Such realism has nothing to do with descriptivism, or with a naive form of naturalism and mimesis. ${ }^{12}$ It is disturbing because it questions the listener's own representation of reality, doubling it and substituting itself for it-making it shimmer. The strong materialist component of his music cannot be understood if it is detached from the belief that the mental space itself is material and produces the world ("the world does not exist"). A split is thus produced within the composer, who is on the one hand the producer of sonic structures, on the other hand their listener. Yet, such a split is not aimed at an attempt to match the expectations of the audience with their

12 It must be noted that Sciarrino himself utilises the term "naturalism" to describe his approach to music; though, he uses it in a way that does not imply the notion of mimesis. In his own words, "Naturalism does not necessarily mean realism. More than illusion, naturalism means transfiguration" (Sciarrino 1998,54 , translation mine). 
gratification. The contrary is rather the case, where, "since we are conscious of what we would like to perceive, we will not fall therein. Conscious of what the audience hears or would like to, we will not fall therein" (Sciarrino 2001, 59, translation mine). As in Bernini's case, the representation of representation evokes a referent to the lived experience, and it simultaneously destroys it by substituting it with an artificial experience that exhausts imagination by being at the same time incommensurably material and mental (artistic and artificial). Art is not consolatory (pointing to a reassuring "presence" in Derrida's sense), nor does it strip reality of a referent (exposing the structure that defines the limits of language). It is instead a viral art: a form that is empty, and by this virtue it appropriates a body (the body of representation but also the physical body of the listener) in order to constitute a new organism.

(2) The non-conformity between semiotics and materiality.

If on the one hand Sciarrino makes a very conscious use of the structural elements of music, on the other he questions them through their reaction against the incommensurable materiality of sound. Through his use of instruments and of phonic textures, he brings perception and cognition to the limits of dissolution. The clarity of the atomistic semiotic category (the "note") is brought towards it abolition. As in the infinity of folds of Bernini's statues, as in the baroque proliferation of ornaments that blurs the limit between matter and void, sound is brought to the point where the perception of a discrete sequence of notes is dissipated into a material continuum. As an epitome of this gesture, we can take the notational symbol invented by Sciarrino (and by now entered into common usage): ${ }^{\circ}<>\circ$, crescendo e decrescendo dal niente. Matter, as if accompanied by a breathing arch, blends with the point of its dissipation, becoming blurred with the listener's physiology.

In his use of silence, Sciarrino shows a deep communality with, and at the same time a radical difference from, the experience of John Cage. Both composers pay attention, and homage, to the infinite proliferation of sound inhabiting so-called silence. At the same time, for Cage silence is the suspension of intentionality and of sense-making, the infinitely smooth space where the listener wanders, deprived of a foothold and given back to listening to his or her own interiority. In contrast, for Sciarrino silence is the sense "around which each sound hovers, pregnant with allusions and references" (Carratelli 2006, 64, translation mine). Similarly to Francis Bacon, Sciarrino uses music to subtract music, to exit from music. Memory, structure, and semiotics are thus "the givens" that already occupy the mental space of the listener before the first note is played. Sciarrino aims at the dissolution of such givens through the ambiguity of materiality.

\section{(3) The use offigures.}

I have hinted above at the distance Sciarrino puts between himself and the analytic approach implied by serialist musical practices. The vision of musical time as sectionable, as a succession of events in chronological order, is abandoned in favour of a temporal flux organised in figures. "Never in my life have 
I put together pitches, but rather thought through sonic figures" (Sciarrino quoted in Angius 2007, 229, translation mine). As such, the pitch cannot be detached from the other parameters of sound and, in turn, from its being part of a wider force field. A musical thought developed in "figures" is not only a compositional and epistemic approach, it also acquires a critical function when Sciarrino reflects on and writes about other composers, either contemporary or from the past, as is evident in his collection of music lessons Le figure della musica da Beethoven ad oggi (Sciarrino 1998). The figural then becomes also a retrospective conceptual tool for rethinking past music. The problem of the figural as a capture offorces has been common throughout the history of Western music - the examples chosen in Sciarrino's book span from Rossini to Debussy, from Beethoven to Bartók, from Puccini to Stockhausen, and so on. Yet, I would argue that Sciarrino makes the figural the main problem of his composition, leaving aside in his own practice other concerns that, for other composers, either are intermingled with the figural or even overrule it as a compositional question. For example, and fundamentally, the atomistic category of the "note" (an abstract parameter that corresponds to the "being-heard-ness" of sound) is not productive for Sciarrino's thinking. It does not make sense then to rely on combinatory compositional procedures to determine the sequence of notes (the notion of scale or melody, even its extremely pointillistic version that can be found in serialism), nor their superimposition (the notion of counterpoint) or their concordance/discordance (the notion of harmony). The figure is rather the sounding systole of a force that is neither technically musical nor merely sonic.

One of the ways that Sciarrino attains the figural in his music is isolation. "If we isolate even only a single instrumental part, that characteristic pulsating within silence subtracts its own contours, neutralising the sense of succession itself" (Sciarrino quoted in Angius 2007, 228, translation mine). Isolation is a technique through which the interrelation between the elements of musical discourse is suspended. Once severed from a meaningful context, such elements begin to instigate their own autistic, non-narrative, non-developing monologue. This procedure becomes evident when Sciarrino inserts isolated elements from past musical objects in his compositions-for example, the soprano part of a madrigal by Claude Le Jeune opening Luci mie traditrici (1998), or the melody of a Venetian boat song emerging from the phantasmic, underwater sonic world of the Aspern Suite (1979).

As in Bernini's vectorial bodies, Sciarrino's figures are not inserted into a context (melodic, harmonic, tonal, atonal, serial, etc.); rather, they emanate a space, reacting with the mental landscape of the listener and with the complicated network of his or her memory (historical, physiological, instrumental, etc.). They do not occupy the space, nor do they construct one, but they instead point to $a$ space that is at the same time mental, imaginative, and forcefully bodily. 
(4) Anamorphic processes.

In Vanitas (1981) for voice, cello, and piano, Sciarrino developed a musical technique analogous to the visual projectional process of anamorphosis, through temporal stretching of the harmonic structure of Hoagy Carmichael's song Star Dust (1927-29) over a duration of fifty minutes. Setting aside this particular case, the role of anamorphosis in his practice that I would like to focus on is less literal, and more forcefully pervades the compositional operative system itself.

Visual (pictorial) anamorphosis is not only an operation exerted on the represented object but also a modification of the relationality between object and spectator. The perception of the portrayed object changes according to the spectator's point of view, thereby engendering a duration of the viewing experience, which unfolds over time as well as through space. Similarly, anamorphosis takes place in Sciarrino's music through a modification of the sonic "object" (a figure, a pattern, a sound quality) throughout the time of the listening experience. The object is repeated and modified, transformed not so much according to a technically musical "variational" process, but through its own incommensurable materiality. The modification of the mental space over time through the listening experience is "comparable to a relocation of the ear, an accumulation of perspectives on the same landscape" (Carratelli 2006, 68, translation mine). The inconsistency of sound, in contrast with the clarity of its "being-heard-ness," displaces the sonic "object" each time it reappears, leading listeners to question their memories and perceptions and hallucinating them. The spatio-temporal occurrences of what asks to be qualified as "the same" interfere with each other, disrupting the possibility of sameness through the prominence of their physicality. The form of the musical piece is then the singular "point of view," ordering the inapprehensible multiplicity of states of the same object.

Sciarrino weaves these mental relationships in the space of memory. Memory becomes a spatial plane, upon which past events, their presence, and the expectation of their futurity are available simultaneously. Using memory, the directionality of time is suspended, negated, and turned into a dimensional space that can be navigated in any direction:

\footnotetext{
Without the intervention of memory the temporal dimension would produce a present of irrecoverable instants, not relatable to one another. Time would spin freely, and we would not even suspect its existence.

Through our memory we compare successive portions of time, vast portions, as well as minuscule elements. We compare what we are listening with what we have just listened to. This means that we take ourselves out of the temporal dimension, out of the present flux, and we form links and localise ourselves according to a purely spatial logic. (Sciarrino 1998, 60, translation mine)
}

There are many levels on which Sciarrino's music inhabits the space of memory, arresting and reverting the movement of time. The first is an oneiric use of repetition through which a continuum is created, where the return of elements does not mark time but rather suspends time. The listener tries to fix some stable 
reference points in the ambiguity generated by the friction between expecting the return of the same (through the clarity of musical language) and the continuous microvariation and inconsistency of the repeated elements. Repetition then comes as a question - "have I heard correctly?"

The second level on which memory is explored is the cultural memory of instrumental sounds. Sciarrino subtracts instruments from themselves: he carves a violin out of a violin, a flute out of a flute; he creates a void inside them. Using traditional instruments-mostly acoustic ones-Sciarrino explores their sonic peripheries, sometimes through the use of extreme virtuosity, sometimes exploring the extremes of the pitch range, always in a sonic and physical marginal or border zone. The sound descends towards the subhuman (crackles, whistles, puffs, screams, groans, roars, bird-like trills) or evaporates towards the suprahuman (ghosts, phantoms, illusions, doubles).

Third, the role of memory becomes very evident through the use of materials inherited by tradition, whereby Sciarrino questions the collective cultural memory of the listeners. In his own words: "The use of pre-existing materials in a historical perspective has nothing more to do with quotation. Quotation remains a foreign body, between inverted commas that maintains all the authority of its origin. I believe that tradition has to be radically transformed, and I think this is the only condition for one to access the creative energy deposited there throughout the centuries" (Sciarrino quoted in Angius 2007, 232, translation mine). For example, in his 6 capricci for solo violin (1976), Sciarrino points towards the gestural world of Niccolò Paganini's Twenty-Four Caprices without manipulating the musical code of his antecedent in any way: he does not quote Paganini, or insert material derived from Paganini's scores, nor does he try to mimic anything that might be designated Paganini's "style." Sciarrino evokes a memory of the original caprices-but an uncannily inverted one, as if the act of remembrance paradoxically coincided with the erasure of its object-through a language and a sonic world that is entirely his own. To quote Grazia Giacco, "Sciarrino does not become a contemporary of Gesualdo, Schubert, Beethoven, Rossini . . . ; instead, like timeless spirits, the composers from the past become our contemporaries, living with our own time. For Sciarrino, the point is not to seize the sense of origin of a composition ... or to even believe in the unicity of this sense itself. He wants to demonstrate that the works of tradition can produce a sense [emphasis mine] (and not the sense) for the listeners of today" (Giacco 2003, 20, translation mine).

My research project and Sciarrino's aesthetic and epistemic approach share a concern with producing $a$ new sense from past musical experiences. Sciarrino manages to displace himself from the traditional poietic position of the composer, encapsulating the listening experience within his own position and actually starting from it as its main material. The relevance of his approach for my own project therefore lies both in his concrete operations on history (even if it is not his foremost aim, the departure from and distortion of works from the past is very close to the processes of my own practice) and in the general move of detachment from the traditional centre of activity (in his case, composition) to encapsulate other roles in it (crucially, that of the listener). At the same time, 
what is not addressed in his practice is a reshaping of the role of the performer. From this point of view, Sciarrino's position remains strongly rooted in that of the traditional composer, acquiescing to his role in the mediation of the text and its further communication with performers. The performer, for him, still has the role of the interpreter/mediator: "the interpreter... mediates between the creator [ideatore] and that which is impossible or unheard for most people" (Angius 2007, 18, translation mine). In avoiding the backward reflection of musical textuality on the sonic imagination-which generates the supposed anticipated consistency and wholeness of the sounding and gestural performance in relation to the written score that is incommensurable with it-Sciarrino still considers sound as being an origin of the text, not as its combustive and problematising act. In his own words, "in the compositional act therefore, what in olden times was called a note is now specified afterwards; in that the conformation of the figure adds to the physical, technical, or registeral possibilities of the sound chosen to obtain it, generating the relative frequencies" (Sciarrino quoted in Angius 2007, 228, translation mine). Thus the biunivocal relationship between score and performance is rehabilitated anyway, a posteriori. 


\section{9. \\ A Peripheral Instrument}

For the last example of my musical practice, I decided to make a return to my instrument, the classical guitar. After all these experiences with the creation of sonic images and their various forms of interaction with live performance, I wanted to again address instrumental interfaces, how they impose their own physical and semiotic organisation on sound, and how the techniques developed so far would relate to this issue.

In 2011, three years before starting this research project, I developed a "prototype" for my artistic practice: a divergent performance of Athanasius Kircher's (1602-8o) tune known as Antidotum Tarantulae. In this prototype for my artistic practice, I started to address on a purely artistic level some of my current research questions. That experience can now already be seen as a form of "performance as writing," as opposed to a new composition. For practical reasons, I created a graphic guide to serve as a mnemonic aid, which by no means would be able to function as a normative score, nor be of any use to other performers.

The formal aspects of that performance already enacted, at an embryonic level, some of the operations I would develop later during the research. The elements were very simple, and of two kinds: (1) fragments of the melody, isolated and framed by long intervals of silence, each played crescendo and diminuendo dal niente, as if emerging from and returning to an imperceptible background of silence; (2) two- or three-note percussive patterns in triplets played on the sixth string. The whole tension of the performance was generated through the conduct of these two gestures: sometimes juxtaposing them against one another, other times varying or repeating them, interrupting them abruptly, transferring some elements of one into the other (e.g., displacing the triplet rhythm into the upper register). The primary work was, on the one hand, dissipated into sounds and gestures that were alien to the world that created it; on the other hand, it unfolded aspects that were only implicated in the original work but not exposed in it. An example of these aspects are the triplet sounds, which refer to the rhythm of the pizzica, the folk dance that was utilised to cure the bites of tarantulas in the region where Kircher operated (the Antidotum Tarantulae was also employed for this therapeutic treatment).

At an early stage, notions that were to be developed later in my research were already at play, such as the vision of a relationship with a musical work that would include other points of view in it-ones that included not only my subjective treatment of the performance but also other elements that are external to it while still being part of its imaginative, historical, and geographical "assemblage." 


\section{A Peripheral Instrument}

The most relevant reflection upon this experience concerns the use of a musical instrument, and in particular the exploration of the periphery of the "classical paradigm" of the sound of a guitar. Such a paradigm, developed throughout my conservatoire training and professional activity, has been marked by a minimisation of the many instabilities of the instrument-for example, very soft loudness, irregular tuning, high incidence of parasitical noises, short sustain, overly-rich harmonic blend of the timbre. In designing the phantasmic version of Kircher's tune, I concentrated only on extreme registers of the instrument. Almost all the performance was carried out on the first (the highest) and sixth (the lowest) strings. On the first string, I played with an unconventional technique, using the left hand to press the string over the sound hole (a left-hand position that is placed way beyond the limit of the fretboard) while the right hand produced a very fast tremolo. The sonic result emphasised, rather than minimised, the "limits" of the instrument: it created a very soft sound, utterly unstable pitch, noise (the attack of the fingernail on the nylon string is louder than that of the resonance, partly due to the extreme shortness of the vibrating string), very short resonance, and a marked prevalence of high harmonics-including an irregular sound quality, swarming with micro-variations. Regarding the part on the sixth string, this consisted of percussive patterns with two-hand tapping, so that the complementary sounds ${ }^{13}$ were as prominent as the regular ones, which were dampened by both hands. Again, the noise of the tapping and the ambiguity of pitch generated a divergence from the "classical" sound of the instrument.

For my last divergent performance in this project, I chose to work on a duet from L'Incoronazione di Poppea (1642) by Claudio Monteverdi (1567-1643), and to apply to my own performance the technique developed for Variation VIII of the Diabelli Variations (see, $\$_{5}$ ) for a group of musicians. For this, I decided to record a sonic image using only the guitar, while assembling the recorded sounds through a kind of "montage." I wanted to generate a dense sequence of sonic events, and while recording and assembling them I did not pay attention to their technical performability. I was instead interested in the discrepancy and tension between the recorded sound and the live performance, and especially in the impossibility of matching the two. To a certain extent, I wanted not to be able to recognise what I had done during the recording, in preparation for my own future listening experience as a crisis, even if it was me who had produced and recorded those sounds. As in the case of Antidotum Tarantulae, I chose hyper-modulated textures, most of them in a pianissimo dynamic or with uncommon techniques, but also including extreme register ranges, especially in the high part. The sonic image would still be in my own instrumental "voice," but its later listening would be registered as if in someone else's "voice."

13 The complementary sounds in the guitar are those produced on the fretted string by the portion of string that is between the left hand and the nut. They are rather soft, so that music up to the twentieth century ignores them. During the twentieth century, they have been emancipated to become part of the sonic palette of the guitar. 


\section{A Peripheral Instrument}

Initially, I tried to perform this piece by only relying on my memory of the recorded sonic image. Later on I realised that this would have been too demanding. I therefore decided to design a graphic guide, while making sure to avoid the mistakes I had made in devising Variation VIII (see, $\mathbb{S}_{5}$ ). This graphic guide was not made as a mimesis of a rhythmic-diastematic score, but rather as a "cartography" of the instrumental interface, not descriptive of sonic events. I invented symbols for various actions of the palms and fingers on the strings, frets, or body of the guitar, for various uses of objects (e.g., the bottleneck), and for the topology of the natural harmonics. In this way, I was not actually "playing" the guitar; I was "being played" on two levels: on the physical level, my body was "being played" by the automatisms of the gestures on the instruments, unlinked to a sonic result and to any form of musical signification; on the aural level, I was "being played" by my mnemonic navigation of the sonic image, by its fluid arrangement of the musical tempo and of the energetic space of sound. I was creating a bilingualism in my own language: on one side, the inherited language of my professional approach to the instrument and of my interpreter-subject; on the other side, the limping language of another instrument (a sort of anti-guitar) and of another, external, subject. Mine was a monologue, but not declaimed onstage and in front of an audience. It was instead a monologue that one split part of my non-subject would say to another one, in a short circuit. 


\title{
Derivative $\mathrm{X}$ : \\ How to Produce a Phantasm? \\ Part IV: Carmelo Bene
}

The problem of representation and of its relationship to materiality and intensity is common to many art forms-as shown in the experiences that I have described so far in sculpture, architecture, painting, and musical composition. One artistic practice that retains a particular closeness to the performance of written music is theatre staging. The task that music interpreters and theatre performers equally face is the constitution of a correspondence between a codified text and a material act onstage. The fact that theatre practice deals with verbal texts-which have a considerably stronger relation to signification and meaning than musical ones-must not mislead the reader. Theatre is of course strongly representative, in the sense that it portrays characters, circumstances, feelings, and relationships that "are similar" to those found in "real life"; yet, the aspect I would like to focus on is the material action of transferring the symbolic structure of the graphematic codification into the material inscription of the performative situation. Moreover, theatre staging has another very strong commonality with music performance: it is allographic, and therefore entails a relation not only to the semiotics but also to the historicity of texts.

In his writings about Antonin Artaud, Jacques Derrida severely criticises the theatre of representation, the one "dominated by speech, by a will to speech, by the layout of a primary logos which does not belong to the theatrical site and governs it from a distance" (Derrida [1978] 2005, 296). It is not difficult to think of this critique as pertinent to significant aspects of the interpretation of written music:

\begin{abstract}
The stage is theological for as long as its structure, following the entirety of tradition, comports the following elements: an author-creator who, absent and from afar, is armed with a text and keeps watch over, assembles, regulates the time or the meaning of representation, letting this latter represent him as concerns what is called the content of his thoughts, his intentions, his ideas. He lets representation represent him through representatives, directors or actors, enslaved interpreters who represent characters who, primarily through what they say, more or less directly represent the thought of the "creator." Interpretive slaves who faithfully execute the providential designs of the "master." (Derrida [1978] 2005, 296)
\end{abstract}

In this passage Derrida stresses the role of the god-like author; however, non-representational theatre is not, or is at least not primarily, interested in attaining a supposed freedom from authority in performance. The crucial point is that the mechanisms of textuality, inescapably imposing a logocentric and phonocentric vision over the situation of performance, generate a "theological" situation, in which the interpreter is situated in the place of the 
hermeneut, and where the text communicates-and at the same time obliterates-a will preceding it and demanding faithfulness. In this sense, there is no difference between interpretation in theatre and in music, where, as Laurence Dreyfus $(2007,254)$ underlines, "we still assume we are reading someone's thoughts correctly. If only the author (or his emissary) were present, he ... would vouch for the correctness of our actions."

Artaud's project of a theatre of non-representation, in combat with the text and in opposition to interpretation, is continued and deepened by actor and theatre director Carmelo Bene. Bene's work on the theatrical repertoire and its relation to performance has been highly influential on my own practice, both for the similarity of the set of problems that we have been interested in exploring and for the thoroughness and awareness with which he has faced them. The most relevant aspects of his experience for my practice can be summed up in five main points that I explore below: (1) performance as subtraction, (2) the function of the phonè and of rewriting, (3) the multiplication of roles and the actorial machine, (4) the jeopardy of subjectivity, and (5) practice as critique.

\section{(1) Performance as subtraction}

In his stage practice, Bene always relates to the pre-existing theatrical repertoire (Camus, Shakespeare, Wilde, Marlowe, Laforgue, Byron, etc.). Yet, in place of a mise en scène of the primary plays he is addressing, he operates what he calls a togliere di scena, a removal of the play from the scene. He defines his own theatre as a "theatre of absence" (Giacchè 1997, 114, translation mine), where the pursuit of absence permeates every aspect of his practice. On a more apparent level, Bene blatantly eliminates elements from the stage: his Richard III has no male characters; his Hamlet is without a Hamlet. At the same time, his vision of absence in no way corresponds to the void, to silence, or to the physical non-appearance of actors or of the elements onstage. All these operations would remain subtractions within the theatrical discourse, still part of representation, whereas what Bene wants to achieve is the subtraction of the theatrical discourse itself.

The most important method through which Bene pursues this absence is, paradoxically, accumulation. The overwhelming hypersaturation of the semantic and semiotic space combined with an emphasis on the density of materiality pursues a defeat of the whole and of the one. In this action, one can retrace the baroque gesture of a theatre that nullifies itself by means of exposing its own becoming as a fatal assault to its being.

The first target of Bene's practice is faithfulness to the text-what Gilles Deleuze, in "One Less Manifesto," which is wholly dedicated to Bene's theatre, defines as the "magnification/normalisation" (Deleuze 1997, 243) of works and authors from the past. Bene's operation is not oriented towards producing Platonically "good" copies of the primary plays-the line followed by traditional interpretation, the meticulous reproduction of an infinity of details on top of which the subjectivity of the interpreter adds a final coat of self-expression-but instead towards the simulacrum, where the affirmation of the same is warded off through its distorted repetition (reinscription in performance). The 
primary play is therefore present in the performative space, but only insofar as it is an object of negation. Performance is then what remains when the primary play is subtracted: the expression of an afterlife of the work; a life around it, beneath it, and between its fissures. Bene's productions are impossible without a primary play - a primary scene is always already there, similar to the figurative stratification in the work of Francis Bacon, always already present before the activity of the artist begins. At the same time, Bene provokes the play's dissolution in order to trigger its futurity. The primary play becomes then a combustible substance: it contains a latent energy that is intrinsically dependent upon its properties; nevertheless, at the same time, this energy cannot be liberated unless the play is burned and destroyed.

Deleuze $(1997,243)$ defines this subtraction as the "minor treatment" of the primary play. In opposition to ascending to the major (magnification), he proposes a movement of minoration, consisting of subtracting elements of power, both from the representation and from what is represented in the theatrical event. "Magnifying" the play consists of extracting a unifying vision or practice out of disparate and incongruous elements, and for Deleuze amounts to its "normalization" (ibid.), that is, to its insertion into the grid of mapping, codification, institutionalisation, territorialisation - all of which are elements that concur with the mechanism of representation. As a means to break away from representation, Deleuze proposes a becoming-minor of the theatrical play, and of theatre performance itself.

Deleuze uses the concept of "minor" (which appeared for the first time in a collaborative text that he wrote with Félix Guattari, Kafka: Towards a Minor Literature [1986]), detailing this concept with extreme specificity. He explained that minoration has nothing to do with statistic minority, nor with the representation of a conflict between the power of the major and a minority trying to upheave it. Minoration is insoluble from a movement of becoming, while "majority designates the power or weakness of a state, of a situation" (Deleuze 1997,255 ). If the first move is to identify the elements of power in a given mode of representation, then the fundamental approach must consist of mobilising and putting into a state of constant variation all the elements that, whether in a given play or in theatre itself, constitute constant and coded elements.

Deleuze analyses and detects the elements of power that have been "amputated" in Bene's work, with these elements corresponding to the elements of power of theatre itself. First, history is "the temporal marker of Power" (Deleuze 1997, 245). This is seen in the history that has been portrayed in Bene's plays (such as in Richard III), but also in the historicity that the works from the past carry with themselves. Second, structure gets amputated, "the synchronic marker, the totality of relations among invariants," together with stabilised elements "because they belong to major usage" (ibid.). This is seen not only in the structure of language, but also in the constant internal relations that constitute the identity of a given text. Importantly, in Bene's works the text itself is amputated, being a text that is "like the domination of language over speech and still attests to invariance or homogeneity" (ibid.). This implies also that there is a subtraction of dialogue, "because [dialogue] transmits elements of power into 
speech and causes them to spread" (ibid.). And finally, diction and action are amputated, through a "playback [that] is first of all a subtraction" (ibid.).

Importantly, Bene's main subtraction of the text happens through the superabundance of the voice's materiality, more than by means of the-more evident but somehow also more formulaic-removal of elements from the play. This leads to the second main aspect of his practice: the function of the phonè, the term that he uses to describe the materiality of the sounding voice.

\section{(2) The function of the phonè and of rewriting}

The material use of the voice to counter the power of the same-the power of "diction and action"-is central to Bene's theatre of absence. It is the tool through which the "abyss between the written and oral" (Bene 2013, 79, translation mine) is exacerbated, rather than bridged. Bene aims at an upheaval of the "theatre of the text" in favour of a "writing of the scene" (scrittura di scena), through an approach to performance that is irreducibly material and therefore is crucially in friction with the existence of a text and of writing. The materiality of performance is a rebellion to the "already said" of mediation and interpretation, against which Bene hurls the subverting force of the act and of the phonè.

Bene practices the "actorial reading as a non-memory of the pre-written oral dead" (Bene quoted in Giacchè 1997, 64, translation mine). The use of the phonè is not aimed at generating natural harmony and synchrony "between voice and body, between gesture and word, as well as within the word, between sound and meaning" (Giacchè 1997, 141, translation mine). Instead it engenders a break, a split, a disturbance, and therefore a destabilisation of the text that ultimately leads to its dissolution. The materiality of the voice fights against writing, against the text, against the internal concordance of the relations, even fights against itself - as an echo, as a delay.

To emphasise the hiatus between the voice and the voice, the body and the body, the self and the self, Bene not only works on intonation, on the deterritorialisation of speech into music, and on the internal variance of the phonetic quality of his own voice; he also resorts to an extensive use of electronic media and apparatuses. He uses microphones to amplify the voice, to diminish (again, to subtract) the declamatory self of the actor: playback becomes the exposition of a dissociation between voice and presence. As Maurizio Grande phrases it, "the self-moving statue or the body-without-organs of the electronic phonè (automatic pathos) corresponds to the great megaphone of the ancient mask. ... The scene is implanted as an apparition of the automaton and of the simulacrum: the simulacrum as automatic authenticity" (Grande in Giacchè 1997, 61, translation mine).

Such a pervasive form of materiality constitutes the very core of the performative operation, and not merely the concrete enactment through which the abstractness of the text is filled, accomplished, and eventually decorated. This implies a redefinition of the role of the inscription. The onstage materialisation of sounds and gestures thus becomes a form of writing in its own right. Or better yet, a rewriting -immediately lost within the depths of the singularity of the actor-author as soon as it is generated - that cannot be reappropriated and 
perpetuated by other "interpreters." "The rewritings-scores of Bene can ... be reproposed and modified only by the author, since they are no longer plays, but they have been turned into the opposite. Technically, they do not constitute the embankments that regulate the flux of the actors' sayings and doings, but they provide ... operative choices (that remain subjective and even intimate) which take on a body, literally, only through the actor-author" (Giacchè 1997, 78 , translation mine). Bene still relates to the original text of the play, critically, as an interpreter would do, but this operation remains a preparatory phase, left offstage (where the primary play is also left).

(3) The multiplication of roles and the actorial machine.

Reflecting on the break with text and representation attained by Artaud in theatre, Derrida envisions "the absence of an author and his text" to be necessary. This suggests the invention of a different kind of inscription from the performer's side: "a writing and a text whose fabric will no longer resemble the model of classical representation" (Derrida $[1978] 2005,302$ ). This implies first that the performer has to go beyond the role of the interpreter-mediator.

The solution to mediation and to interpretation that Bene implements is the absorption of multiple roles within the same actor-subject. The actor becomes author. And, since the separation of the theatrical action between text and enactment requires dialogue between the two sides (which is communication and by consequence representation), both text and enactment have to be enfolded within the role of actor, in a short-circuit with himself. The actor goes beyond himself. He is voice and body, but he also becomes the text, a new inscription, the playwright from the past, the play itself, or better yet, a locus where both the actuality and the potentiality of the play are implicated. Leaving aside his several extra-theatrical experiences (as film-maker, as poet), Carmelo Bene multiplies his roles onstage, letting them correspond to myriad facets of the fragmentary self required by the collapse of the imaginary "ideal-I": he is a reader, a translator, an actor, and a capocomico (responsible for decisions on lighting, music, amplification, and scenography). The text becomes but one of the infinite elements of proliferation of a non-meaning, which points towards the obliteration of text itself as an origin and a matrix towards which reverence and fidelity are due. In his own words, Bene becomes the operator, or "actorial machine" (macchina attoriale).

The concept of an operator is useful for describing the position that I as a music performer am called to assume in my own practice: it is a site, both imaginative and operational, where the figures of the listener, of the performer, and of the composer (even of the stage manager if required) intersect to the point that they become inextricable from one another. To quote Giacchè, the operator "does not restrict himself to designing, realising, and controlling each of his creations, but poses himself ... as both cause and effect, as both the process and the result of such creation" (Giacchè 1997, 111, translation mine). This situation is completely different from that in which the composer performs his or her own music or where the author doubles as an actor in his or her own play: in this case, the division between roles remains, reproduced even within the same 
person. The mutual validation and endorsement of the roles must continuously be impeded to block the generation of mediation and interpretation even within the same subject. Structure and inscription, writing and materiality, and body and phonè must all be placed in a state of continuity and contemporaneity.

The actorial machine and the phone are linked in the same strategy of subtraction: the actorial machine is what remains of the actor and of the play from their dissolution into the materiality of the phonè. The implementation of an apparatus nourished by so many extra-theatrical devices or experiences (electronic amplification, music, cinema, etc.) does not point towards a multidisciplinarity that tries to enliven the theatre of the past through the actual or the quotidian; it is again a construction of an absence. Absence starts with multiplication and proliferation, with a paroxysm of material density that alone can overwhelm the presence-as-origin of signification and of the logos.

(4) The jeopardy of subjectivity.

The first elements that need to be brought out from the stage are the traditional function of the composer and the score through which he or she "keeps watch" over the performance. At the same time, we have already seen how the mechanism of mediation between composer and interpreter can also be recreated within the same subject (see $\$ 2$ ). On an outward level, there are many traditional ways through which the division between composer/performer (or in Bene's case, author/actor) can be eliminated. For example, by the composer taking on the role of the performer: he or she "performs" sound alongside a formal structure that is presented through media that allow a form of its materiality to be directly inscribed-such as in phonographic recording and processing, electronic sound generation, automatic instruments, sound installations, and so on. Or, to give another example, by the performer taking on the role of the composer: he or she "performs" (in the Latin etymological sense of "forming to completion") a formal structure by means of an improvisatory act that takes place directly through live-produced vocal or instrumental sounds and gestures. However, these operations, while they apparently solve the problem of mediation, actually merely move it somewhere else. They are subsumed within the same subject, whereby the non-conformity between code and materiality is not emphasised and forced to its extremes, but is instead idealistically bridged. In these cases, what is at work is still a sound that "speaks to itself," that "coincides with itself," as the logos claims to be able to do according to Derrida.

Operators therefore do not reassemble or recompose material from past musical repertoire; nor do they "add literature to literature" (Deleuze 1997, 239-40); nor do they pursue the reduction of the caesura of writing by inscribing their own presence into sound through improvisation. The crucial difference between these surface solutions and Bene's approach lies in the latter's uncompromising use of sound and materiality as the emanation from an initial trace and as gravitation towards an unknown and vacant centre, and not as a mirroring and a correspondence to something else (even if it is the something else of subjectivity). 
Through the operator, the actor is continuously displaced. Displaced towards the work and out of him- or herself, no longer a subject acting on the work but subjected (as in the Latin form subiectum) to the work's array of forces- not playing it but being played by it. Displaced towards the spectator, substituting his or her own listening and seeing act, removed from oneself, and as self-reflective as the baroque eye ("an eye that would view itself to infinity" [Buci-Glucksmann $2013, \mathrm{xv}]$ ). As Giacchè phrases it, the actor now is not free to $d o$, but is freed from doing: suspended, "exposed to his own thoughts, that will not belong to him but will possess him ... as visions" (Giacchè 1997, 17, translation mine). This results in the absence of the illusion of freedom from the text that improvisation pursues $-\mathrm{a}$ freedom from the text outside the subject, yet that still mediates and interprets the even more enslaving text embedded in the cultural, biographical, and personal conditioning that the human all too human always carries with him- or herself. The actorial machine thus displaces the actor from the human: the actor is a machine (culture and text exert an automatic action upon him or her), but he or she also goes beyond the cultural automaton, as phantasm and vision.

The jeopardy of subjectivity also undermines the possibility of dialogue in Bene's theatre. This is because where there are no subjects expressing themselves there can no longer be communication. The technique in this case is isolation: "[Carmelo Bene] produces himself in stubborn monologues even when he is apparently not alone, since, alone, he has to occupy all the space, to prevent the social action sliding into the place of the theatrical vision" (Giacchè 1997, 18, translation mine). As in Bernini's sculpted groups that are deprived of a context (but that emanate one); as in Bacon's figures, with their need "to break with representation, to disrupt narration, to escape illustration, to liberate the Figure: to stick to the fact" (Deleuze 2003, 3); as in Sciarrino's musical figures that disrupt the organic discourse of internal "musical" relations; as in all these examples, isolation for Bene is a technique through which the unity of the subject is undermined, and the multiplicity of internal forces of the actoras-locus (as point of view) can now instigate its own autistic, short-circuited discourse.

\section{(5) Practice as critique}

In “One Less Manifesto," Deleuze (1997) goes so far as to state that Bene's plays are "critical essay[s]" (239) on the original plays that they depart from. Bene's is "neither a theater of the author (d'auteur) nor a critique of the author (d'auteur)" but is an activity that "is inseparably creative and critical" (241). Through the act of performance, through a process that is eminently artistic and practical, Bene questions and problematises the traditional function of the actor and the theatre, constituting performance as a theoretical reflection through practice. When Deleuze writes, "this critical theatre is a constitutive theatre. Critique is a constitution" (239), he is proposing a vision of the performance space as the stage for an act of theoretical reflection and active problematisation. By assuming a creative/critical posture, Bene manages both to break free from pre-given codes (the text) and to suspend pre-given territories (theatre as representation 
and as spectacle). The same creative/critical stance can be seen in the function of music performance, as music performance is not a discipline that generates within its own enclosure the epistemic and technological tools for its own analysis and hermeneutics, but is instead a practical activity able to give rise divergently to critique through creativity.

In the Copernican move (even better, a Keplerian decentring) pursued through my own artistic research, a fundamental centre that needs to be displaced is the core from which practice and research on performance are made. A musical practice that comments on itself starts from implements that are generated within its own language and thus remains within the limits imposed by its own discipline, inhabiting them. Musical research that relies on the objectivity of the analysis of a score or of a performance by means of quantifiably extensive (intrinsically divisible) properties, as much as one that scrutinises the performer's or composer's subjectivity, is bound to reinstate the perspectival and logocentric model over and over. In this respect, reflection of practice on practice manages to bypass both the objective and the subjective approach, becoming antidisciplinary: it becomes a reflection that tries to exit something through something (exit music through music, exit theatre through theatre, etc.). Bene's insistence on the following quotation from Tommaso Landolfi can also be read in this light: "one cannot make music with music, painting with painting, literature with literature" (Landolfi 2012, 108, translation mine).

Anti-disciplinarity calls into question several approaches to art, and therefore also approaches to artistic research. First, an anti-disciplinary approach questions the technical fetishism that presents skill, craft, and expertise as being the centres of art. Second, it questions the "comforting" role of art as decoration, beauty, and enjoyment. Finally, an anti-disciplinary approach questions a form of art that addresses what is outside itself while exiting its own discourse by means of an excess of signification — or an excess of actuality, as for example in political "manifesto" art. In the vision of art and of artistic research that I would like to uphold, one that is inspired by Carmelo Bene and by the artistic practices here described, art is able to exceed itself, to propound the existence of an "outside to itself" that constitutes the empty centre of the unceasing renegotiation of the gravitational centre it is departing-from/returning-to. 


\section{Five Glances upon the Unspeakable Body: Third Glance}

In "Rasch," Roland Barthes (1985b) seems to suggest that, as there are two mutually dependent yet non-conformable levels in a musical text, such nonbinary duplicity can also be present in the body. The body-the human body, the body of the performer-must not be naively mistaken for what lies beyond, or before, sign systems. The problem of representation, and of its paradoxical struggle with the non-representational, happens first of all in the body. In other words, Barthes's text seems to hint at the existence of a "first semiology" also of the body: a body that is codified, organised, anatomical.

Barthes's essay provides the starting point for a crucial idea: artistic practice- a practice that incises the body, that forces direct confrontation with the materiality of both the media of art and of one's physical responses to themcan question traditional semiotic categories. Yet, even more importantly, artistic practice can (and must) be in friction with itself, constituting a "struggle" within disciplinary boundaries that attempt to frame its overflowing materiality. Barthes is very clear in his distaste for a kind of artist (including the artist's physical body) too well domesticated by structure: "a mediocre body, trained, streamlined by years of Conservatory or career, or more simply by the interpreter's insignificance, his indifference" (Barthes 1985b, 303).

To inquire into the possibilities of shattering "writing" through dismantling the bodily organism, I would like to refer to an artistic experience that consciously has constituted itself as a struggle against both linguistic and anatomical structure. The life-long quest of Antonin Artaud, the man and artist who invented the "body without organs" (in To Have Done with the Judgement of God, 1947), although disseminated through and constituted by the media and modes of art-theatre, writing, drawing - was fundamentally undertaken as experimentation on the potentialities and limits of the body. Artaud was challenged all his life by the need to convey a non-representable form of expression, with the contradictory necessity of doing it through modes that involveunavoidably-representation. The "body without organs" of artistic media set an ongoing horizon before him. In the pursuit of this limit, he searched for a form of art that would be able to make do with the representational "grid" that in his words constitutes "a terrible moment for sensitivity, for matter" (Artaud quoted in Murray 2014, 20).

Artaud's rejection of representation and his search for a new type of textuality-even if it still needed to rely on representative strategies-is paradoxical and thus endless. Like the "organism" of Deleuze and Guattari, representation can never be fully denied: one has to keep small portions of it, and experiment with the displacement of its boundary. Such a boundary, though, can only be 
defined by the irruption of the real. Consequently, this search must be led by a belief that, although it is impossible to access it directly, the real emits signals, it transmits, allowing it to impinge on the linguistically accessible world by means of mysterious modalities. Artaud's ongoing challenge was to inquire through these modalities, with the possibility of bringing them about as effectively and forcefully as possible.

Every action for Artaud presupposes a non-dialectical and non-oppositional duplicity. The gestural, processual force of the living action is always supported and "revealed" by a delayed, re-presented action (see Cambria 2012, 5). The living action is always presupposed (as it is also in the sense of a "supposed before"), not yet formed; as such, it is not yet actualised and thus is impossible clearly to relate to. It is not an action per se, but the only prerequisite for the re-presented (presented again) action to take place. At the same time, the re-presented action is also not properly an action, because it could not subsist without the living action it refers to.

This non-binary duplicity is part of every action. Yet, theatre seems to be the privileged place for the exploration of the relationship between these two sides of the action, exactly because it stages actions. This is extremely important, because, in an operative sense, the performance of written music presents exactly the same issues. It stages not only sequences of sounds and structures (compositions) but also modes of conveying them, and ways of relating them to a system of language.

Theatrical action for Artaud means rendering this processual force as visible and audible, although by structural definition it is neither visible nor audible. This means incarnating a form of materiality that is not oriented, not extensive, and not dialectically opposed to spirituality. This force is present, but its presence cannot be seen or measured. In this respect, such presence radically differs from the "absent presence" of representation-the presence of metaphysics, which is always denied and deferred by materiality. Artaud's invisible presence is the real, not located in transcendence, and he wants to have its physical materiality felt through theatrical action. The words uttered onstage should physically affect the audience; they ought not to represent a preconceived text. Consequently, spectators ought to be affected without any need to interpret the verbal and visual signs uttered by the actors.

Representation is therefore not rejected; rather, it is used in a functional way. Given the dependency of the action on its re-presented state, representation can be taken as the tyrannical, normative force that to be disrupted must be evoked. In the anatomical counterpart of the process, there must be a normative organism from and against which one can construct a "body without organs." Representation therefore needs to be "problematised to the extent that the very existence of the text becomes contradictory" (Murray 2014, 34).

To liberate an immediate force from the blockage of representation, Artaud proposes a vision of thought - and even of the spirit— that is radically material. Thinking for him is a physical process, which happens in the nervous system. This form of nervous thought requires a different kind of language, as it takes place in the body, in opposition to the mental thought, which is metaphysically 
"present to itself." Thinking must be expressed as a process that acts directly on sensations without being slowed down through the detours of the mind and of communication.

In the renewed approach to the performance of written music proposed in this book, distinguishing between material and mental processes is fundamental; but while doing so one needs not to fall into a dichotomising view of materiality that reinstates the spiritual as metaphysical. The "being-heard-ness" of musical sound (that which can be assimilated to the Saussurean signifier) and its relation to a signifying dimension-be it expressive, subjective, or indexical-are both mental categories. To bypass representational mechanisms, the new musician needs to operate through the materiality of sound and gesture on the materiality of the body, and, vice versa, through the body on sound and gesture. Whenever this process takes a detour through the "mind" and the processes of signifiance and subjectification, representation will inevitably reenter it. Artaud wants to enact a corporeal representation, able to pass directly from one materiality to another. He says "shit to the spirit" (Artaud 1965, 111) not to debase and reject the spiritual dimension but to emphasise how it is in turn matter-of the same matter as the body. Materialism without spirit and abstract spirituality are only the two faces of a binary logic that expresses a partial vision of life. A materialism that does not regard spirit as a form of matter will not be able to produce any form of effective action.

In contrast, Artaud looks for ways to unsettle and shatter his audience's nervous system. He does so by "put[ting] into play a distinctly corporeal notion of representation" (Murray 2014, 32). He treats forms of media as material bodies, such as where the surface of the paper on which he draws and writes is like a skin that is scratched, pierced, burned, or wounded. In performance, the phonic manifestation of the word undergoes a similar process. Intonation is approached in as concrete a manner as possible, in its physical, vibratory form. According to Ros Murray (2014), the phonographic medium and radiophonic diffusion are particularly successful in inscribing the physical imprint of the body. Phonographic recording has an almost phantasmal quality, reporting the most volatile aspects of a body's manifestation-its voice-without keeping the body's physical presence. And yet, "there remains ... a corporeality that is nonetheless very different to the kind present in bodies on screen or stage. In some instances ... bodily presence may even be accentuated rather than diminished by the lack of visible images of bodies" (ibid., 160). Phonographic inscription carries with itself the physiological dimension of the body. Operating in a way that is diametrically opposed to notation - and most evidently, music notation-phonographic inscription captures the body's utterances without regard to their eventual signification. Sound is recorded in its irreconcilable ambiguity, in its infinity that escapes univocal codification-even if perception and consciousness, in their need for univocality, strive to assign to it an a posteriori meaning. Phonographic inscription helps disrupt the Lacanian imaginary integrity of the "I" through the actual, material manifestations of the living body. Moreover, even if the recorded sound might be uttered by a body that believes itself to belong to a self-contained entity (the imaginary "I"), such an 
utterance imprints itself together with its expansion into the ambient along with the background noises, the involuntary fluctuations, and the glitches of the recording medium. The clarity of consciousness is thus threatened and attacked from multiple sides.

The surface on which sound is inscribed becomes in turn a skin on which the pliable limits of the body are explored. The skin, the exteriority of both the human body and of the material inscription of art, conquers a privileged status as the place of experimentation. The deepest place of artistic creation is dislocated towards the spaces that were traditionally relegated to superficiality and ornament: the surface, the limit. Such is the limit between unformed action and re-presented action. It is the hiatus where a negotiation takes place between the chaotic and inconsistent yet alive and vibrant matter of the virtual and the physicality of the body and of artistic material, which threatens to sclerotise but is also able to provide a foundation. No place is left for the metaphysical, mental depth of meaning and signification, or of a spirituality detached from the bodily "scum."

Beyond metaphysics, Artaud's vision and artistic experience posits the real as perceivable and accessible-albeit through paradoxical and contradictory means. Overturning the Platonic vision, the real is not the unreachable world of Forms, but rather is the material world. With Plato, Artaud shares the understanding of the sensible world as a system that prevents and limits one's access to the real. But in Artaud's vision, the sensible world is the one that is constructed culturally, with the system of interpretation that modifies and domesticates the material world forcing it to enter the organised world. The real then is "not inaccessible, but rather requires a change in mentality, and the world-reflecting, in Artaud's work, coincides with the world-creating" (Murray 2014, 30).

Through the insistence on sound's physicality, the mental categories of music are also shattered and put in crisis. The "being-heard-ness" of sound expressed by notational units that always precede and regulate performance; the imaginary unity of the musical composition, be it in metaphysical terms or in historical ones; the narrativity and subjectivity that inhabit musical structure through the performer's self-expression; all these categories cannot but belong to spirit and/or to linguistic structure. An insistence on a materiality imbued with the virtual, with the not-yet-formed, radically surpasses a binary opposition that keeps falling back into the "human." On the one hand, this allows one to surpass the "spirit" as an overriding category, as "an old invariable value, a reminder of that eternal entity back to which all things are brought" (Artaud 1965, 112) that claims to express the height of human nature. On the other hand, this insistence surpasses the false materiality of structure, which superimposes the cultural determination that makes a human what it is-language-onto the overpowering materiality of the real, eclipsing it. 


\section{0. Modes of Exposition}

In 1989, the then director of the Venice Biennale theatre section, Carmelo Bene, decided to take a radical stance: for two editions of the event, the audience would not be allowed to participate. The theatrical experience would take place in the form of a laboratory as a process of research independent from the spectacle and from the "show."

This decision encountered resistance from the press, the public, and from the directorial board of the Biennale itself; eventually, Bene relieved himself of his position as director. However, the polemic that this episode raised, with its economic and legal implications, risks obfuscating the relevance and innovativeness of Bene's approach. That relevance lies in a vision of art as producing knowledge that can and must be independent from its spectacular side, and ultimately even from the need to relate to a traditional audience expecting aesthetic fruition.

The production of artistic output in my own research project was conducted following a similar approach. In this way, the artistic experience is a locus of experimentation and is not only an activity that produces aesthetically valuable or less valuable objects. For this reason, research on and documentation of audience reaction to the artistic output has been left out of this book. Nevertheless, the problem of expositionality has had to be faced, together with the attempt to make explicit, during concert situations, that the aesthetic autonomy of this activity is less relevant than its constitution as critique.

Throughout the research process, I have experimented with various degrees of balance between the artistic and the critical aspects during the expositional moment. I will list them here, explaining how each modality enables or prevents different aesthetic and epistemic experiences.

(1) Presentation of divergent performances as autonomous "pieces" in a concert situation. This modality brings to the fore the compositional and performative qualities of the performances; although, here the whole process of reflection on the resemblance to a primary work is entrusted to the chance that people in the audience will already know such works and will manage to connect them to the new performances. The probability of this is lessened because almost all the primary works I have chosen are not widely popular. This modality of presentation would probably prove more interesting in two cases: either if the primary works chosen were "iconic," or if the audience consisted of specialists in such works.

(2) Performance accompanied by a video projection, or programme notes, displaying captions with the titles, composers, and dates of primary works. In this situation, certain expectations are raised in the audience. If the audience does not know either the pieces or the composers, they can at least project their knowledge about the musical style of the periods indicated by the dates. In this 


\section{Modes of Exposition}

case, a productive friction is created between a preconstructed expectation and a sonic result that has no straightforward connection to such an expectation.

(3) Presentation of divergent performances preceded or followed by a recording or a live performance of an execution/interpretation of the primary work. In this case, auditory proximity to the primary work helps the audience trace the production of resemblance in the new performance. Nevertheless, this mode of presentation risks being schematic and didactic.

(4) Divergent performances can be preceded or followed by a verbal explanation of the process of resemblance production, and of the research methods. In this case, the audience's attitude changes completely, as it is continually being paralleled by an enhanced consciousness that the musical object is part of a wider process, which is not to be considered merely aesthetic. In my experience, this modality of listening has been particularly satisfactory for the audience, who are enriched and guided through the aesthetic and epistemic outcome of the listening encounter.

(5) Exposition through Research Catalogue ${ }^{14}$ or other online platforms. Although this option allows for a productive interaction between verbal explanation and diverse artistic materials, the performative situation is conveyed only in the form of documentation (audio or video). The drawback of this situation is the loss of the performative intensity that a live event alone can convey. Moreover, the visual and sonic realisation of the performances is flattened to the bidimensional/stereophonic user experience provided by computer interfaces. That said, the online medium is a highly valuable tool to expose the mutual affection between theoretical reflection and artistic practice. Such a result is very difficult to achieve either in the live performance situation or in the exposition of the theoretical discourse through traditional textual media (print or ebook formats).

(6) Incorporation of elements of research into the artistic presentation. This modality differs from modality 4 because, whereas the earlier example retains some elements of didacticism, this one creates a perturbation between aesthetic and epistemic modes of fruition. In this case, the two levels are not clearly separated and thus act in parallel, with the verbal level acquiring an artistic status and the musical level becoming slightly displaced from a purely artistic modality. In this option, it is possible to imagine the conveyance of the epistemic dimension not only through verbal language, but also through visual forms of art: video projection, dance, light design, and so on.

14 https://www.researchcatalogue.net. "The Research Catalogue (RC) is a searchable, documentary database of artistic research work and its exposition. With the aim of displaying and documenting practice in a manner that respects artistic modes of presentation, the RC allows the weaving together of text, image, audio and video material. The RC is an inclusive, open-ended, bottom-up research tool that any researcher in the world can use free of charge as a private or collaborative workspace and for the dissemination of their artistic research" (Society for Artistic Research 2018). 


\section{Modes of Exposition}

Modality 6 was experienced in a collaboration with dancer Marlene Monteiro Freitas. Inspired by reflections on the baroque double, on polycentrism, on the difference between body and organism, and on the non-correspondence in artistic production between an extensive level and an intensive level, I decided to design a stage situation where my performing body would be doubled by another body, that of a dancer. Ideally, my own body would appear to the audience without a face. Gilles Deleuze and Félix Guattari $(1987,115)$ explicitly connect semiotics and the face when they write, "The signifier is always facialized. Faciality reigns materially over that whole constellation of signifiances and interpretations.... Conversely, when the face is effaced, when the faciality traits disappear, ... we have entered another regime, other zones infinitely muter and more imperceptible where subterranean becomings-animal occur, becomings-molecular, nocturnal deterritorializations over-spilling the limits of the signifying system." Whereas my (anatomical) performing body would be deprived of significance-and therefore, again, of interpretation - the body of the dancer would function as its intensive double: a face that expresses nothing but non-human affects, not moving according to its anatomy but "moved" by non-human forces.

The work with the dancer also opened a further possibility: creating a divergent performance with no sound, where one only experiences the movements of the dancer. In this last option, which seems to point towards future possibilities for this research project, the divergence from the primary work goes so far as to transgress the disciplinary boundaries completely. For this experience, I again chose Amarilli mia bella by Giulio Caccini to be the primary work. 


\section{Appendix 1: Techniques of Minoration}

This section provides a list of all the elements encountered during my artistic practice that mark a "major usage" (Deleuze 1997, 245) (see "Derivative X") in the interpretation of written music. Their practical implications on performance and a proposal for their "minoration" (ibid.) are accompanied by reflections on the theory articulated so far, and by reference to the four "baroque artists" portrayed in this book (Bernini, Bacon, Sciarrino, Bene).

\section{TRANSHISTORICITY AND ANTIHISTORICISM}

In the second of his Untimely Meditations, Friedrich Nietzsche strongly criticises the dominant cultural attitude of his own century, in particular the tendency to venerate historical knowledge and the progressivist faith in the scientific objectivity of history. If, on the one hand, such a historicising vision has considered true knowledge as something "factual and verifiable, and thus collectable within the individual" (Lundy 2009, 190), on the other hand, it has relegated the cultivated person to the role of a mere epigone of past events and personalities. While still affirming the importance of history's impact on life, Nietzsche warns against the various ways in which such an approach can prove detrimental to living people, paralysing and mummifying their energies. An "admiration for the "power of history" is dangerous not only because it "transforms every moment into a naked admiration for success and leads to an idolatry of the factual" as an immediate consequence, but also because "he who has once learned to bend his back and bow his head before 'the power of history' at last nods 'Yes' ... to every power, whether it be a government or public opinion or a numerical majority" (Nietzsche 2007, 105). The devotion towards historical knowledge would thus be for Nietzsche the basis of an indiscriminate deference towards every form of power.

As a way to liberate oneself from the overwhelming wielding of history, Nietzsche proposes an "antidote ...-the ahistorical[15] and the suprahistorical" (ibid., 120, translation modified). While the "ahistorical" has the power of suspending history, of forgetting, and therefore of momentarily clearing consciousness from the imprint of the past, the "suprahistorical" allows one to regard history as a constant becoming, and thus allows one to "complete ... the world, ascertaining its singular meaning in every individual moment" (Lundy 2009, 193). These two categories, when partially injected into the individual's relationship to history, are capable of mobilising the past towards the creation of the future: "the genuine historian must possess the power to remint the universally known into something never heard of before.... only if you are

15 On the preference for the English translation “ahistorical” over “unhistorical," see Lundy (2009, 194-95). 
an architect of the future and know the present will you understand [the past]. ... Only he who constructs the future has a right to judge the past" (Nietzsche 2007, 94). History's utmost utility therefore lies for Nietzsche in promoting a certain creation of the future. As Henk de Jong phrases it, "To put it in a paradoxical tautology, the past could liberate us from the past because only the past showed us how to liberate ourselves from it" (quoted in Lundy 2009, 201).

In the wake of Nietzsche, Gilles Deleuze and Félix Guattari bring the criticism of history even further. For Nietzsche, history remains essential for life, provided one uses the necessary countermeasures against its poisons; on the contrary, Deleuze and Guattari not only contest some of its particular uses but also the power of history as such. From Nietzsche they retain the emphasis on the necessity of the individual's creativity in liberating him- or herself from the oppression of the past. However, beyond that, Deleuze and Guattari also consider that history is a set of conditions one has to depart from. History is thus necessary for life only insofar as it allows the liberation of a becoming that, without it, would remain undetermined, but that in itself is transhistorical if not openly antihistorical:

\begin{abstract}
History is made only by those who oppose history (not by those who insert themselves into it, or even reshape it). This is not done for provocation but happens because the punctual system they found ready-made, or themselves invented, must have allowed this operation: free the line and the diagonal, draw the line instead of plotting a point, produce an imperceptible diagonal instead of clinging to an even elaborated or reformed vertical or horizontal. When this is done it always goes down in History but never comes from it.... Creations are like mutant abstract lines that have detached themselves from the task of representing a world, precisely because they assemble a new type of reality that history can only recontain or relocate in punctual systems. (Deleuze and Guattari 1987, 295-96, emphasis mine)
\end{abstract}

Countering the power of history and its predetermined chronological grid (the "punctual system") is therefore a reaction to representation in favour of creation; every creative act will be inevitably reinserted into such a grid, but the act of becoming, in itself, is unceasingly resistant to the system of history.

In “One Less Manifesto," Deleuze (1997) goes as far as to deny any interest in the future considered as a goal or arrival, along with the past seen as a departure or origin, in favour of the "middle" as the space of pure becoming. He describes Carmelo Bene's attitude towards theatre plays from the past ("primary plays") as an act of "minoration" of history through an unceasing becoming:

\footnotetext{
the middle does not at all mean to belong to the times, to be of one's time, to be historical. It means just the opposite. It is the means by which very different times communicate. It is neither the historical nor the eternal but the untimely. A minor author is precisely that - without future or past, s/he has only a becoming, a middle ... by which s/he communicates with other times, with other spaces. ... "Antihistoricism," says Carmelo Bene: do you know which men must be seen in their century? Those we call the greatest. ... But truly great authors are the minor ones, the untimely ones. It is the minor author who delivers the true masterpiece. The minor author does not interpret his or her time. (Deleuze 1997, 242)
} 
The minoration operated by Bene-which is also exerted on major authors such as Shakespeare-opens a bridge in time between different historical periods, but is one that does not develop along the cultivated pathways of philology and hermeneutics, that is, of interpretation. In line with Deleuze's rejection of the future as a telos, Bene states that "one has to rewrite because one cannot write ... I rewrite above all because ... I feel untimely. I rewrite because I am ashamed of belonging to my own time" (Bene quoted in Giacchè 1997, 69, translation mine). In other words, he displaces himself from his own time (he is not "timely"), through searching for a communality with other times; and, in doing so, he simultaneously mobilises the time of Shakespeare, Marlowe, or Wilde by activating the latent potentiality in their works and re-actualising it in other times and other places. The minoration of history, therefore, takes place through the "untimely." The artist is disconnected from his or her own time, but the artist also approaches works from the past as somehow disconnected from his or her own time.

A minoritarian approach to historicity in the performance of written music implies first of all the disavowal of reconstructive approaches and historical informedness, not only as artistic practices but also as an expression of a unified vision of history. Furthermore, the dismissal of a historicising approach does not imply the utopian dismantling of previously accumulated knowledge and experience about a given musical work-this would amount to a completely "ahistorical" approach, which according to Nietzsche is as detrimental to life as the suffocating power of history. The knowledge of and about a given piece is retained, but is not made the object of performance. As such, historical knowledge can and must belong only to the preparatory phase, at which time the musician detects which aspects to retain of the "givens" expressed by the primary work. Therefore he or she must subtract from performance all the elements that relate to style, organological accuracy, and philological informedness. In this sense, the process of "rewriting" traces a direction that is completely opposite from that of a postmodernist parody or pastiche that relies on the culturally shared recognisability of the historicity of the material and reshapes it into new combinations. As Sciarrino states about the relationship of his practice towards history, "the use of pre-existing materials in a historical perspective has nothing more to do with quotation. Quotation remains a foreign body, between inverted commas that maintain all the authority of its origin" (Sciarrino quoted in Angius 2007, 232, translation mine).

\section{Displacement AND HYSTERICISATION}

In “One Less Manifesto," Deleuze $(1997,255)$ refers to structure as "the synchronic marker" of power. The internal relation between invariants in a piece of written music prominently takes on the form of a fixed temporal organisation. This is because the linearity of gestural and sonic events according to the chronological sequence of signs in the score is probably the strongest structuring element in the formal organisation of the written musical work. 
In "Derivative VIII" I described some of Bacon's pictorial procedures, and how Deleuze terms them practices of "hystericisation." Hystericisation in painting is at the same time a non-representative and an eminently bodily approach, allowing one to displace elements according to a law of pure affect, which Deleuze termed "the logic of sensation." Hystericisation in the performance of written music can happen through various concrete operations, of which the simplest is the displacement of one or more elements in relation to the temporal structure of the primary work. In the example of Piange Madonna $\left(\right.$ see $\left.\$ 3_{3}\right)$, the closing gesture in the original song is displaced from the end to immediately after the opening figure. Together with this displacement, temporal linearity can also be stretched or shrunk, and at the same time diachronic elements can be superimposed onto each other. In such a process, the change of the temporal duration of one or more elements does not happen through homothetic scaling (which for example could be achieved through the stretching of an audio sample by means of a digital workstation, or by increasing or decreasing the metronomic tempo of a performance). Every operation must be based on the rules of the baroque, such as where tempo stretching or shrinking happens through anamorphic transformations, or where the point of view from which the object is regarded radically contaminates the process of deformation. In other words, deformation does not take place according to a fixed law that is imposed onto the internal relationships between the structural elements, but is instead deformed through an application of forces of divergence and variation. Another method for subtracting the linear temporal structure is a reiteration of elements that occur only once in the primary works, as in the case study on Madonna il poco dolce (see $\mathbb{1}$ ), where the initial semiphrase is both repeated and internally varied. Hystericisation involves not only linear structure but also other parameters such as melody and harmony and the reciprocal internal relations between them. Moreover, hystericisation can also involve elements that are not strictly musical. For example, in Madonna il poco dolce, the sound $/ \mathrm{m} /$ (quite pervasive in the primary work's lyrics) is hystericised in such a way that it spreads over the whole performance in the form of a voice-like background of muted sounds.

\section{IsOlation}

Before it can be displaced, an element of a primary work has to be isolated. Isolation is also the starting gesture through which Francis Bacon manages to break with narrativity and meaning in his paintings, and therefore from representation. This implies severing the relationship between a figure and its environment, blocking the space through which a story might slip in or a narration constructed. Thus disconnected, the space of the figure ceases to be an environment and becomes an "operative field" (Deleuze 2003, 2). Inside the field, the figure is not paralysed, not reduced to stillness and immobility, but on the contrary, it starts its own unevolving movement from its place. Isolation allows a figure to enact a different development than the ones imposed by narrativity and representation. This is also what Carmelo Bene looks for in his mon- 
ologues, because even when-or especially when-he is not alone in a scene, "he has to occupy all the space, to prevent the social action from sliding into the place of the theatrical vision" (Giacchè 1997, 18, translation mine).

In a similar way, the internal relationship between the elements in a primary musical work needs to be broken apart so that their meaningful interrelation through performance is prevented. The simplest way to do this is to isolate a single figure or instrumental part. Sciarrino describes the use of isolation in his compositional practice, by stating that, when a single instrumental part is isolated, "its characteristic pulsation within silence subtracts its own contours, neutralising the sense of succession itself" (Sciarrino quoted in Angius 2007, 228, translation mine). The most evident case of isolation in my own practice happened in the Prelude by Robert de Visée (see $\$$ 6), where six elements, or "traits," of the primary work were singled out and separated—also physicallythroughout space.

Once the isolated element has been released from the task of relating to other elements in the composition and released from adhering to a harmonic function or to a contrapuntal arrangement, it can liberate a potential that was not perceivable when it was inserted in its original environment. Another example of isolation in the Prelude is the extraction of single pitches out of a harmonic progression, which then are stretched and superimposed onto each other so as to form an indeterminate sonic texture. The elements that can be isolated (eventually then to undergo a process of hystericisation) can also be phonemes, parts of words, circumscribed rhetorical units, and so on.

\section{Deformation and saturation}

After isolation, the second main force that Deleuze observes in Bacon's treatment of the figures is the force of deformation. Deformation is very different from transformation, as the second can also be "abstract or dynamic" (Deleuze 2003, 59). Contrary to this, the result of deformation is not an abstract form, nor is it a dynamic combination of forms. Let us take the musical example of a melody. Its transposition, augmentation, diminution, retrogradation, or inversion would amount to transformations, with all these modifications still happening within the structural milieu in which the writing of the melody was conceived. In these cases, transformation still takes place within a Euclidean space and according to its grid. In contrast, deformation subordinates an element-such as a melody - to a force that is external to it, without recourse to any mediating abstract forms. Even if re-inscription cannot be avoided in the procedure of subtraction (for an inscription happens, even if only in sound or in the physical gestures of the performer), it is still incorrect to describe it as "recomposition," because recomposition still takes place at the level of the text. The use of the term therefore implies the performer is conforming to a representation. Deformation thus cannot consist of creating a "secret code" that substitutes it for the original one, where the semiotic units are not transposed or transcoded into a second determined system of signs. Rather, what is created resembles a sort of secret language. According to Deleuze and Guattari 
$(1987,97)$, a secret language is produced when artistic "style" is employed as an "assemblage of enunciation." In this situation, "language becomes intensive, a pure continuum of values and intensities. That is when the whole of language becomes secret, yet has nothing to hide, as opposed to when one carves out a secret subsystem within language" (ibid., 98).

Pitch systems that in the original composition are clear and defined (constituted into discrete unities), are bent and blurred so as to produce "zones of indiscernibility" (ibid., 101), which are internal ambiguities within the musical fragments. Gestural shapes such as glissandos obfuscate the pitch system as a structural element and at the same time saturate the sonic space between the "intervals." If pitches are the perceptual punctuation that determine the semiotic units of the "being-heard-ness" of the sound, and that therefore establish a pre-given relationship between system and sounding result, then the reversal of the phonocentric vision must unsettle this one-to-one relationship by exceeding the gaps between such discrete units.

Besides isolation and deformation, the third main force that acts on Bacon's figures is dissipation. This happens when the outlines of identifiable fragments (melodies, rhythm, harmonies, phonemes, timbres) are partly blurred to lose their identifiability and to merge together with a completely deterritorialised ground. Such is the a-signifying background of silence (the silence of Sciarrino, already swarming with microscopic vibrations that confound the listener's perception), or an indeterminate field of noise, or an array of fluctuating elements.

\section{INSTABILITy OF THE SOUND EMISSION}

A particularly strong marker of identity in the performance of written music is sound emission. In traditional interpretation, quality of sound is usually normalised towards the constitution of specific coordinates of "good" and "bad" sound according to the parameterisation of loudness, the stability of the pitch in relation to a given tuning system, and the interference of accidental noises.

The primacy of this configuration has been largely questioned over the course of the twentieth century, through a variety of practices that have emancipated types of sound previously excluded from the domain of the musical. To provide only a few examples, in 1913, with Luigi Russolo's invention of the intonarumori, noise irrupts onto the musical stage; while, with Pierre Schaeffer, the listener's attention is moved to focus on the "concrete" aspects of sound rather than on its aprioristic and symbolic parameterisations. This emancipation of noise, and the focus on the material and energetic charge of sound, affected Helmut Lachenmann's use of traditional instruments in the compositional horizon that he described as musique concrète instrumentale. The necessity of a break with the polished sonorities of the classical approach to instrumental sound generation is particularly pregnant for Lachenmann, for whom one of the meanings of compositional activity is exactly the building of a new instrument (Lachenmann 2004, 56), even if traditional instruments are still used. Through an approach to sound "as something real and palpable, as a 'natural phenome- 
non' taking place here and now," Lachenmann “evokes a mode of listening previously excluded from the musical medium, or at least neglected in reflections upon it" (ibid., 64). In this respect, the activity of the composer expands to also include the reconfiguration of the possibilities of a given instrument, which, by becoming something other than its historically located definition (becoming, that is, a producer of potentially infinite sounds, comparable to an electronic generator and processor), liberates a new virtuality, carrying with itself even the futurity of its own past.

In "Derivative IX" I have already described Salvatore Sciarrino's research on the sound of traditional instruments. Sciarrino explores the fringes of instruments' dynamic ranges and their technical limits in order to achieve a minimal threshold of the listening experience able to contaminate the inner physiology of the listener. A clear example is Esplorazione del bianco (1986), where the lowering of the dynamics approaches silence, designing patterns of micro-variations that lead to an increased listening effort in the listener, which results in the physiological amplification of the threshold of hearing perception. The sounds produced on traditional instruments become utterances of a world below that which has been consecrated as "art music": they become puffs, crackles, whistles, thumps, and clinks. It is as if the "good" sounds of traditional performance practice were subtracted from an instrument, leaving only its peripheral and accidental noises. To a different end, Fausto Romitelli aims at the inclusion of low-fi, distorted sounds - not only through the extensive use of electric instruments, amplification, and electronic processing, but also by requiring from the performers sonic actions that they are untrained for: for example, singing, whistling, and blowing on kazoos or guitar tuners. Romitelli also includes in his works samples from recordings-such as at the beginning of An Index of Metals (2003), where the opening from Pink Floyd's 1975 studio album Wish You Were Here is reproduced, repeated and distorted, or the ending of Professor Bad Trip (1998-2000), where sounds are played back by a portable cassette player.

All the cited examples aim to produce a minor sonic utterance and a minor instrument inside, between, or besides the major one. Yet, the expansion of the sonic, gestural, and most importantly imaginative possibilities for performers that all the cited examples have opened has very little affect on the way that instrumentalists approach the repertoire external to the contexts in which such expansions were produced. The openings of the sonic horizon described above-and the consequent reconfiguration of what is "allowed" and "not allowed" on instruments and onstage-are restricted to the repertoire for which they are envisioned. For example, it seems possible to use a harmonic trill on a flute where the composer asks for it, yet inappropriate to utilise this kind of emission for music written before this technique was codified. The efforts of composers in reconfiguring "what we know" about classical instruments (a cello can resonate if the bow is scratched on its body instead of on its strings) and about classical performers (almost every performer can sing and whistle, however badly) still leaves performers without the capacity to make use of such reconfigurations unless the composer grants them the right to do so. 
Lachenmann's and Sciarrino's practices propose a reshaping of the function of instruments from that codified by tradition, in simultaneous relationship and friction with the function that instruments have inherited from tradition. A parallel renewal of the approach to the performance of a musical text implies the invention of a new sonic and gestural result, still relating to the one envisioned by the text but at the same time in conflict with it. This means that one has to subtract from performance the kind of sound that-according to the phonocentric vision-one supposes is close to the sonic imagination of the composer who conceived the text. All the compositional practices described above have influenced my practice's approach to sound: the modulation (or, to use Russolo's word, "intonation") of noise, whether generated electronically, produced live, or "found" in pre-recorded samples; the use of classical instruments in a non-canonic way; the exploration of extreme dynamic ranges and of secondary and peripheral sounds; the inclusion of sonic gestures that the performer does not master but can still produce (use of the voice and of imperfect and home-made instruments); the use of electronic distortion, processing, and amplification; the use of low-fidelity pre-recorded sounds.

\section{Provoked amateurism}

The inventions of a new sound horizon and of a set of new sonic gestures go hand in hand with relinquishing instrumental overspecialisation. A direct consequence of the ideal "translation" of sounds into notation that lies at the core of the phonocentric vision of music is the codification of the instrumental interface. The capacity to decode such an interface from the side of the performer runs parallel to the capacity of (re)constructing meaning out of a given score. Instead of specialising in the means through which notational and instrumental code is translated, in my practice the performer works directly with sound. As in the case of Carmelo Bene's phonè, sound does not mirror an imaginary phonic substance that is embedded in the text and is seen as presence. Sound is prominently "delirium" (Bene et al. 1984a, 1984b, my translation), a perverting and deviating force. As such, sound is not dependent on a domesticated instrumental specialisation, but on the production of divergence.

The importance of "deskilling," especially in visual art, has increased since the late nineteenth century (see Burn 1981, 52; Buchloh 2004, 531), in reaction to the bourgeois values associated with artisanal competence. At the same time, relinquishing virtuosity and skill does not mean that one approaches art as an amateur would. Provoking the amateur within the professional musician is something quite different from possessing poor musical skills. The operation that I propose is the renegotiation of the familiar space of skill, approached "as if" from the perspective of an outsider. "To be a stranger, then, in one's own language ... is not to speak 'as' an Irishman or a Romanian speaking French. ... It is to impose on language, as it is spoken perfectly and soberly, this line of variation that will make you a foreigner in your own language or make a foreign language your own or make your language a bilingualism immanent to your foreignness" (Deleuze 1997, 247). Better still, one has "to stammer, but as a stam- 
merer of language itself, not only of speech" (ibid., 246). Academic training and instrumental specialisation are then only preliminary phases, albeit necessary ones: they are yet another means in and through which the musician can detect the commonsensical in his or her own practice-the cliché-in order to relinquish it. As a consequence of such an approach, Bene (quoting Vincent Van Gogh) goes as far as to state that "when one says 'I am not a painter,' that is when one must paint" (Bene 2001, translation mine).

The "provoked amateurism" of the musician can go in at least two directions: The first and more apparent is the proliferation of roles and the partial appropriation of zones of expertise that traditionally belong to different musical personae-the performer becomes a composer or stage director, including in his or her activity practices and instruments that he or she does not fully master. The second and more challenging direction is the creation of obstacles and handicaps that diminish one's expertise, in order to discover in oneself a stranger to one's own field, thus having to "stammer" and "be a stranger" in one's own language.

An example of this in my practice is the search for a distance between oneself and one's self, such as when in the duet from L'Incoronazione di Poppea (see $\mathbb{S}$ ) the proximity between live-produced sound and recorded sound is used as a means of creating ambiguity and distance, even within one's own "voice."

From this provoked amateurism, the performer's experience becomes a solitary one: he or she invents his or her own grammar anew, inaugurating new idioms and significations, instead of being a decipherer of already present significations. It is at this point that, to use one of Bene's terms, music becomes detached from musicistica (musicianship): the production of sound is not the target, but is one of the many means through which the performer enacts the perversion of the musical text. Together with all the other elements of the scene, sound is an emanation in search of a level of aphasia able to contradict the text and its meaning, to make the musical language explode from within. Consequently, the sense of the re-inscription (in the gestures of the body, in sound) is not to remain in continuity with the text and to establish a communication, but is rather the autistic act of listening to oneself in a permanent detachment from one's own voice.

\section{Chance (“the will to lose one's Will”)}

In "Derivative X," I reported Derrida's remarks on the existence of a god-like author as one of the foundations of the "theological" theatre. Whether either physically present or from a remote presence in absence, such a god-like author regulates the time and meaning of a performance and imposes it through his or her will onto the slave-like interpreters. The task of eliminating such god-like figures from the musical stage does not end, however, with the suppression of the role of the composer and of his or her intentions. There is also a god-like force acting on the performer with even more forceful authoritarianism: the performer's own self. The end of "the conflictual petty theatre of the I and of its reprisals" in favour of "the lack one consists of" (Bene 2013, 9, translation 
mine) is one of the main aims of Carmelo Bene's practice. Or, in Bacon's words, "the will to lose one's will" (Sylvester [1975] 1999, 13).

The subtraction of one's self from performance is perhaps the most difficult task to be achieved by a musician, yet it has to be faced, at least from a speculative and exploratory point of view. To do so, it is necessary to briefly discuss two notions that are commonly associated with the subtraction of the regulative self from performance, and to distinguish between the several uses of the notions of improvisation and chance.

(1) Improvisation is often regarded as a practice that is capable of generating the emergence of unpredictable events, brought about by the pressures or influences of contingency. At the same time, the connections between improvisation and freedom from a preconstructed script, or between improvisation and an unfettered flow of spontaneous associations, have relevant pitfalls. First, it should not be assumed that improvisation and textuality are two different modalities of organising performance from an operational point of view: in many instances, improvisation can be the recombination of predetermined possibilities, which constitute a sort of textual database, even if it has not been previously organised according to a fixed rhythmic-diastematic linear structure. A jazz musician improvising on a "standard" is actually performing a set of rules that, even if they exceed the score, are woven throughout a tonal system and an idiomatic set of phrasings that do not differ, operationally, from a form of textuality. Furthermore, even in cases in which improvisation is used as a practice meant to liberate the performer from the constraints of textuality-be it conveyed through a score or through a shared prefigured set of probabilities - the risk is that improvisation expresses a level that has been dictated by cultural or even personal clichés, including those of spontaneity or interiority. As paradoxical as it may sound, discipline and rigour can be considered more productive for the generation of unpredictability than a "freedom of the instant." According to Derrida, this was also the case with the theatre of cruelty of Artaud, where "the absence of an author and his text does not abandon the stage to dereliction. The stage is not forsaken, given over to improvisatory anarchy" (Derrida [1978] 2005, 301). Unless it is already disciplined by a form of unwritten textuality, improvisation, far from unburdening the performer from representation, still involves a high risk of instigating "habits" and the repetition of deeply embedded formal, instrumental, and bodily clichés. Moreover, it reinstates the idea of a proximity to interiority with its primacy over exteriority, potentially locating itself in the "metaphysics of presence" (Derrida 1997, 22).

A semi-improvisatory attitude is used in my performative practice only insofar as it generates a completely different approach to the production of sound and gesture. The "being-heard-ness" of the discrete sonic units prescribed by the score forces the performative act within the brinks of a prefigured mould: the performer is free to vary the performance as long as it remains within the margins that make it recognisable, as if cast from the starting mould (again, the Platonic "good" copy). In contrast, the sonic and gestural quality produced in improvisatory practices lacks the fixed target of the already determined 
"being-heard-ness," and is therefore more apt to be utilised in a practice that withstands the phonocentric vision of music and considers performance as a departure from and a perversion of a given text.

The subtraction of identity from performance is one of the topics that Carmelo Bene repeatedly insists on in his practice. The approach that he advocates is a suppression of the interpretative "I" in favour of a particular vision of the "subject." Bene utilises etymology to explain his use of the word: the soggetto (subject) is to be considered soggetto (subjected) — from the Latin subjectum (brought under) -insofar as it is assoggettato (subjected, subjugated) to an external force. This does not coincide with the affirmation of an acting identity, but with a reacting entity, which is at the same time both passive and active-being active insofar as it reacts. The soggetto of Carmelo Bene does not use language, or interpret a text: it is rather used by language and text, involuntarily twitching under the external force of language, of the primary play. It is precisely this twitch that constitutes the subject's reaction and resistance to the text, its force of minoration. As Deleuze $(1997,249)$ phrases it, the subject becomes subordinated to affect, where "two essential aims of the arts should be the subordination of form to speed, to the variation of speed, and the subordination of the subject to intensity or to affect, to the intense variation of affects. Bene participates fully in this movement that produces the critique of form and subject.... Only affects and no subject, only speeds and not form."

(2) Bacon uses the notion of chance to explain his own attempts to leave behind the clichés generated by the figurative assumptions present in one's imagination. Reflecting on such a notion, Deleuze (2003, 94) distinguishes between two very different domains that are normally intermingled. The first is the domain of "probabilities, which are givens, the objects of a possible science, and which concern the dice before they are thrown"; the second is "chance, which designates, on the contrary, a type of choice, nonscientific and not yet aesthetic." Probabilistic givens are prepictorial: in the empty space of the canvas-or during an open performative temporal span of the music performance-all places are equally probable. At best, their different probabilities are organised, on the one hand, by the prefigured coordinates that regulate the space-the given limits, a given centre-and, on the other hand, by what the painter (or the performer) has in mind as to what he or she wants to do. When John Cage determines the position of events through time, or the duration and pitch of these events, or the positions of the performer's hands on an instrumental interface through aleatory processes such as the I Ching (as in Music of Changes, 1951), or by picking numbers out of a box, he selects from a number of probabilities. The same happens with algorithmic-driven sound generation or processing. But Bacon's problem is different: "at that very moment, once I have begun, how do I proceed so that what I paint does not become a cliché?" (Deleuze 2003, 93). The painter-and the performer-has to "destroy the nascent figuration" (ibid., 93-94) through the insertion of free marks: where free marks have nothing to do with probability, but are rather "the improbable itself... . a type of choice or action without probability" (ibid., 94). Probabilities are yet another prefigured 
given that occupies the canvas before the painter starts his work, and his task is to exit figuration as well as probability. This means that if he is certain about what to do, this would imply a maximum of probability - this is the case with the "perspectival" painter, and is tantamount to the "perspectival" performer. However, free and involuntary marks can be inserted in the painting at each gesture, as in a roulette, to escape the fall into cliché. It is only insofar as it is manipulated and utilised that chance can become pictorial. If it remains prior and external to painting, it amounts to a-yet again-figurative probability.

\section{Selection of "The procedures opposed to SELECTION"}

At each sounding gesture, the performer/operator inserts involuntary and free marks, as they allow the modification or destruction of the figurative cliché in the moment that it threatens to coagulate in the performative space. But how does such an operation take place, given that the performer's practice does not rely on improvisation, unless in very restricted and regulated terms? The operation on chance by which Francis Bacon inserts free marks into figuration is very different from that by, for example, Jackson Pollock. Whereas Pollock's use of chance can be compared to the recording (inscription) of an improvisatory act, where the process is as important as the result and the result unthinkable without the specific process of the painter's “action," Bacon needs the materiality of canvas and paint as a measure of a continuous negotiation between the emergence of the figurative and its defiance through involuntariness. The space of the canvas and the material "body" of the paint guide his involuntary acts in a process that is "always shifting, ... constantly oscillating between a beforehand and an afterward: the hysteria of painting ... the work of the painter is shifted back and only comes later, afterward: manual labor" (Deleuze 2003, 98). The performer/operator thus needs to be able to inscribe sound and to renegotiate it through the insertion of free marks.

The inscription of part of the production of sound onto the phonographic medium is one of the tools that has allowed me to follow this method. Electronic recording, by fixing sound in a medium that is able to carry its materiality alongside its formal elements, on the one hand, consents to the inscription of involuntary traits, and, on the other hand, allows one to filter out the sonic utterances where the representative and the interpretational emerge too obviously. As Deleuze (1990 [2004], 265) comments about the simulacrum in relation to the Platonic copy: "It is still selective, it 'makes a difference,' but ... what is selected are all the procedures opposed to selection; what is excluded, what is made not to return, is that which presupposes the Same and the Similar, that which pretends to correct divergence, to recenter the circles or order the chaos." The performer acts therefore as a particular sort of censor: he or she sifts the sounds produced, and selects only those that escape the grid of representation, to then assemble them in a new sonic result. Performative practice thus resembles painting: the performer works directly on the material he or she is dealing with-the sonic substance-manipulating it in a moment prior to 
onstage performance, as a composer would, but through an act that is itself performative. Phonographic inscription allows the musician to perform with an absent-minded and oblivious attitude that is rarely requested of - if not detrimental to-executants and interpreters (remember the part, be aware of its internal relations, play from memory!); but, at the same time, it gives way to a process of extremely concentrated variation. The medium of electronic recording makes possible the intertwining of ephemerality and durability-of vagueness and precision. In other words, the practice of the performer/operator introduces an ambiguity between the "allographic" nature of music and an "autographic" version of it, where everything becomes an infinitesimal inflection, indissoluble from the imprint and the circumstances of its making.

Again, the task of the performer/operator is eminently subtractive. A traditional musical interpreter is called to give consistency to disparate elements through their mutual interrelation. His or her work resembles that of a restorer: assembling fragmented pieces according to an anticipated image of wholeness, compensating for the eventual missing bits with experience and skill. He or she adds elements to one another, and the interpreter who refrains from objectivity and wants to exceed the mere executant will enamel the product with a final layer of expressivity and subjectivity. In my practice, the contrary happens: the whole is already there, imposing meaning, order, and consistency to the performance. One is then to forestall it in the moment of its emergence, as it pushes to constitute itself, time after time, at each sonic and gestural utterance.

\section{AFFECT}

Relinquishing a vision of music as characterised by a system of internal relations and an apprehensible meaning (either compositionally or historically determined) that can and must be reconstructed through interpretation and brought out during performance also brings about the subtraction of expressivity from the practice of the performer/operator. Expressivity implies the proactive utterance of subjectivity: it is in accordance with the logocentric vision, whereby the interiority of the subject is in dialogue with itself, which the subject can then translate directly into external acts. Consequently, the expressive performer/subject mirrors and incarnates the "ideal-I," anticipated as a whole, as an idealistic control of perceptions and emotions during the moment of performance. In "Derivative II" I described the performer as a fragmented subject, characterised by inconsistency and deficiency. Such a performer is not a "fixed substance"; instead, his or her identity is provisional and reassembled into a new configuration time after time. As Deleuze ([1993] 2006, 21) phrases it, "a subject will be what comes to the point of view, or rather what remains in the point of view," provided that the point of view is a point of view on variation. The formation of the subject depends on the position it takes at a given time and place, a position from which it clearly expresses only one viewpoint on the world, encompassing the rest of it only in an obscure way. Since the subject is in perpetual transformation, it is not possible to speak of one self; the subject is rather "the inclusive disjunction borne from the contraction of all ... selves" 
(Boundas 2005, 269). Subjectivity is thus not given, but is under construction, as a consequence rather than as a cause of external events. As a result, consistent expressivity is impossible.

The concept of expressivity in performance must then be substituted with a concept that is not just able to account for the variation of the fixed material of the score-as traditional interpretation envisions-but is instead one where the variation of the point of view (the series of postures that the subject undergoes throughout his or her own ever-changing "here and now") sweeps up the subject into the variation itself, continuously exciting new subjects out of a variation of the object. The object/work and the subject/performer affect each other when they come into contact. "Affect" can describe this new concept: the third-almost material—state that occurs in the encounter between entities. Affect is the mutual mobilisation and double variation or change that invests bodies through their colliding into one another. It is not active, as expressivity is; yet it is not passive either, in that there is a suspended activity in the unavoidable reaction that affection generates. Affect is a state situated prior to activity and passivity, as in this state subject and object are not yet clearly separated.

In "The Autonomy of Affect" Brian Massumi distinguishes between the level of affect, characterised by the suspension of function, meaning, and subjectivity, and the level of personal, semanticised, and narrativised emotion:

\begin{abstract}
An emotion is a subjective content, the socio-linguistic fixing of the quality of an experience which is from that point onward defined as personal. Emotion is qualified intensity, the conventional, consensual point of insertion of intensity into semantically and semiotically formed progressions, into narrativizable actionreaction circuits, into function and meaning. It is intensity owned and recognized. It is crucial to theorize the difference between affect and emotion. If some have the impression that it has waned, it is because affect is unqualified. As such, it is not ownable or recognizable, and is thus resistant to critique. (Massumi 1995, 88)
\end{abstract}

Affect is "not ownable": the performer is not in control of it, thus it is not a further level of meaning that can be added to the others in the constitution of the interpretative act. It implies a subtraction of meaning and will, allowing the performer to be affected by the work. The performer/operator does not actively play the score, but rather the score plays him or her, in a state of passivity where affection engenders a reactive activity.

\title{
10. Dismembrance
}

The subversion of the relation between phonè and writing-from mirroring and additive to deforming and subtractive-also implies a reversal of the function of memory in relation to the musical work. Carmelo Bene defines "actorial reading" as a "non-memory of the pre-written oral dead" (Bene quoted in Giacchè 1997, 64, translation mine). He does not regard the oral dimension of language as a pristine state of proximity to presence (and thus as being worthier than its degraded written form), but instead regards it as already "pre-written," and therefore "dead." The sonic enactment of a work in performance will thus 
not be a retrieval of the past (remembrance), but the inevitable act of dissolving its image through forgetfulness (dis-membrance).

This particular role of memory connects with what was stated in section 1 ("Transhistoricity and Antihistoricism") about history. As Deleuze and Guattari claim, "Memory has a punctual organisation because every present refers simultaneously to the horizontal line of the flow of time (kinematics), which goes from an old present to the actual present, and the vertical line of the order of time (stratigraphy), which goes from the present to the past, or to the representation of the old present" $\left(1987,294^{-95}\right)$. Remembering a musical work amounts to representing it: transferring the stabilised grid of its internal relationships (eminently its chronologically ordered structure) into the reorganised and meshed space-time of performance. To the punctual organisation of memory, Deleuze and Guattari present the opposing force of becoming, considered as "the movement by which the line frees itself from the point, and renders points indiscernible" (ibid., 294).

In Proust and Signs, Deleuze ([1972] 2000, 57-66) distinguished between voluntary and involuntary memory. The first proceeds from an actual present towards the past considered as once having been an actual present. Therefore, the past of voluntary memory is twice relativised. On the one hand, it is relative to the present it has been; on the other hand, it is relative to the present that now regards it as past. Voluntary memory recomposes the past by substituting it directly with snapshots of the present. But, in doing so, it is not able to encompass one fundamental characteristic of the past: its being past. In other words, by establishing the past as a localisable and reproducible present, and therefore by regarding it as the origin, active remembrance crucially fails to apprehend the irretrievability of the past. On the contrary, involuntary memory "couple[s] together two sensations that exist ... at different levels of the body, and that seize ... each other like two wrestlers, the present sensation and the past sensation, in order to make something appear that [is] irreducible to either of them, irreducible to the past as well as to the present" (Deleuze 2003, 67). Sensation is the bridge that unites two moments in time, but this common sensation is inevitably experienced as having a completely different relationship with the two different moments. The past moment rises in the present sensation by means of an internalisation of its difference from the past sensation. However, this internalisation does not arise through identity, but rather through difference. Involuntary memory thus holds in a common indeterminate zone two moments that are unable to interpenetrate each other, that are characterised by an unbridgeable difference and externality. The past is apprehended as past, and therefore not as a moment in time that can be recalled and recuperated through the good will of voluntary memory. The past coexists in two presents (the present one and the past one) but out of the reach of both, irretrievable by voluntary memory and obscure to the conscious perception of the past moment.

The task of the performer/operator can then be described as an active dis-memberance of past musical works, as the internalisation of a difference between two totally external moments in time: the moment of the inscription 
in the score and the moment of the inscription in performance. Through the act of affective interconnection (see preceding section), the relation between score and performer undergoes recursive causality, where the activity of the performer ("I play the piece, I remember it") is mingled with his or her passivity ("I am played by the piece, I am forgetting it"). This must happen through an irreconcilable externality between the two moments, through the acceptance of the impossibility of approaching the past as presence, and through the intervention of sensation as the capturing agent of the two moments. This inverted role of memory (dis-membrance in the place of remembrance) is serviceable not to the past, but to the present and most of all to the future: the apprehension of the past as pure past (and not as once having been a present) allows the becoming-past of the future, and the becoming-memory of the present.

\section{Playback}

Deleuze $(1997,245)$ states that Carmelo Bene's use of playback is "first of all a subtraction." The use of pre-recorded samples (voice in the case of Bene, sounds and/or voices in that of music performance) is not a merely technical means to obtain a given finished result-or, again, an additive device. Above all, playback is a way whereby ambiguity is generated between vision and listening, between presence (onstage) and absence (offstage, or what Bene through para-etymology names the "obscene" [os-kenè, out of scene]). The use of electronic reproduction of sounds in the scene breaks the synchronicity between the gestural and the sonic acts of the performer, allowing sound to become estranged from the body of the performer onstage, depriving the performer of his or her virtuosity and alienating the act from the sonic result.

The use of playback coupled with electronic amplification goes back to the function that, according to Bene and Maurizio Grande, the apparatus of disguise had in ancient Greek theatre. Actors during the fifth and fourth centuries BCE in Athens used masks, megaphones, and buskins, not simply as a means to compensate for the deficiencies of the hall-to gain visibility and audibility — but to operate a depersonalisation, a deformation, a counterfeiting of the actor's self. Through these devices, the actor would gain a level of pronunciation other than and beyond the human dimension of speaking. The Greek theatre actor would then be the prototype of Bene's "actorial machine," estranged from his self, from his own voice, and at the same time from the image of his own body, and therefore subtracted from himself through the augmentation provided by amplification. The amplified actor does not speak: he or she is spoken by a voice that is inhuman and external to the body, a voice that the actor cannot control, a voice that just passes through him or her. The actor's self vanishes, his or her consciousness fails, but not as if in a trance, in an uncontrolled ecstatic liberation from the self. This can instead be seen as the actor being traversed by another voice, another rhythm that shatters and deforms the vocal, physical, and psychological structure of the self, submitting it to multiple and contradictory speeds. 
The playback allows the dehumanised body of the performer to utter a phonic substance unmediated by the "ideal-I" and by its prefigured structures. In the case of the musician, these prefigured structures include the bodily interfaces, virtuosity, and physical presence itself. The live body of the performer/operator onstage acquires a completely different meaning: one becomes at the same time a surgeon and a patient of the sonic, musical, and physical operation, where his or her role is defined not by the necessities of declamation (or better, of reproduction of the already-said) but by the willingness to undergo the experimental alteration that comes from and points to what is outside the stage-starting from the absent and "ob-scene" primary work and directed towards the unspeakable reality that lies outside the barriers of the linguistic automaton.

As Deleuze underlines, playback is also one of the privileged devices that allow the amplification of the range of the variations of the voice and provides them with order. To pursue minoration, the text has to be set in perpetual variation, as a consequence of the subtraction of the invariants and a counteraction to their rebirth. "Voices, simultaneous or successive, superimposed or transposed, are caught in this spatiotemporal continuity of variation" (Deleuze 1997, 246). Playback manages to deviate the sonic utterance from the fixation that the "I" tends to impose on it, while at the same time constituting a compositional order-so to speak, an ordering point of view-to counter the total dissolution of the form, which is as negative as its complete stratification.

\section{VECTORIALITY}

Writing about Deleuze and Guattari's “concept," Brian Massumi $(1992,6)$ associates it with the vector, describing the latter as "the point of application of a force moving through a space at a given velocity in a given direction.... It is an act." A vector is a mathematical entity individuated by a magnitude and a direction. It relates to a point in space not as a singled out quantity (what is called "scalar"), but rather as one on which a force of some kind is exerted. The concept - the vector-is an abstract relation between abstract points. It creates "a unity that [does] not exist in actuality" (ibid., 14), which does not negate the discreteness of the scalar quantities it connects, but rather inhabits a parallel dimension, non-compliant with the scalar one. A spatial paradigm that distinguishes between the two models of scalar and vectorial quantities is useful for reflecting on the differences between additive practices in music performance-and in particular the additive practice expressed by the "perspective" model or interpretation — and subtractive or minoritising practice. I do this here by comparing the operating ways of raster graphics to those of vectorial graphics.

The term "raster," mainly used in relation to computer or television screens, defines a rectangular pattern of parallel lines scanning images. Rasterisation thus divides images into discrete and quantifiable dots or pixels, each of which is characterised by stable properties (colour, size, position). The most obvious example of the operational modalities of a raster is in the photographic or 
filmic image, where the variation of light in a given interval of time is transferred, through an optical correspondence, onto a bidimensional surface. One of the earliest physical examples of this can be found in the apparatuses devised by Albrecht Dürer and his contemporaries for perspective drawing. Such apparatuses were constituted by grids that allowed the projection of visual relationships in three-dimensional space onto a flat surface. These machines were eminently physical, spatial, and tactile, functioning through a material connection, through wires or sticks-the points in space that define the limits of the represented object to the surface of representation. This physical and spatial action underlines the necessity of a mediational apparatus to put into communication two spaces-the visible and the codifiable.

The starting point for an additive practice (interpretation) can be regarded as a raster, clearly exemplified by the rhythmic-diastematic score. To make the non-sounding score comply with the space of performance-in "Derivative I" I argued that these two spaces have different curvatures, and therefore are incompatible with each other-the performer has to turn the raster into a mesh (again in the graphic sense), a semi-mobile interlaced structure. The points in the mesh allow for a certain flexibility, which the performer determines according to (1) meshes that have already been envisioned by the raster of the score but that might be in partial contrast with it (the mesh of the instrumental interface; the mesh of bodily interfaces) and (2) the eventual interpolation of a potentially infinite number of meshes that are more or less related to the mesh of the score.

The model of the score as a raster can be understood through three very different examples of musical interpretation:

- An early Baroque score, which in its level of detail does not come close to expounding all the information necessary for its transmission into performance, constitutes a very broad raster, providing the performer with very few scalar points. The raster has to be integrated with the interpolation of the meshes of performance practice treatises, organology, historical research, and so on.

- In a modern score (for example from the early twentieth century), the raster is much thicker. It contains indications of tempo, of articulation, of agogics, of expression. Fewer external meshes will be necessary to relate it to the space of performance.

- Extremely virtuosic scores, or scores that encompass the idea of the impossibility of being performed by means of hypercomplex notation (for example a New Complexity score), produce a programmed perturbation of their raster by creating a friction with the meshes of instrumental and bodily interfaces. The raster of rhythmic-diastematic notation will necessarily diverge dramatically from its transmission into performance. 
The paradigm of vector graphics is completely different from raster images: vectorial images comprise so-called paths, which are constituted by points, curves, and angles. Such elements can be modified, displaced, and deformed without affecting the stability of the image. In a vectorial image, therefore, there are no scalar values, no fixed points or pixels that possess a set of stable properties. Vectors define directions in motion, not the fixed dimensions established by a grid. They are singular points upon which a force is exerted, but in their singularity they carry a velocity and a direction. They are the momentary form of a becoming.

A "vectorial" performance is therefore unthinkable without a form of relationality between the "scalar" level of quantifiable elements and the level of forces and directions. In this performance, the virtuality of the relation is actually more important than the actual elements it connects-as in the vectorial image, the actuality is determined only by the combination of the paths at a given time, but is open to change without the singular properties of its points being affected. In the raster performance, excessive deformation would lead to a break in one of the meshes, and therefore would not be "acceptable." On the contrary, performing a score vectorially means to detect in it its forces, directions, and relations, which can be extracted to form a virtual network that can be applied to actual elements totally different from the ones stabilised in the raster/score. The meshes-both those contained in the raster and those interpolated with it-are therefore subtracted, to leave only the watermark of the connectors running across their surfaces. In the example of $n$ (Amarilli-1) (see $\mathbb{S}$ 2 and $\$ 7$ ) I extracted a vectorial network of forces out of the rhetorical structure of the primary work. What remains of the original song are only the relations, whereas the extensive elements have been completely subtracted. The sonic and gestural elements can no longer be thought of in terms of objective "material," that is, as matters-of-fact devoid of any energetic load, or analysable as static entities. Such sonic and gestural elements always move in a space of relationality - even if the movement might be in place, as if suspended. Vectoriality seems to be the way in which Bonnefoy describes Baroque art: "a becoming? yes, but the first instant will determine a second one, instead of causing in it a rebound somewhere else, in the dispersion of the space, and thus this plunge takes place, this spiralling movement, that closes itself 'finally' in the hic et nunc of a destiny" (2000, 36 , translation mine).

\section{Multiple outputs}

Marking off both origin and telos posits the space of performance as closed and suspended. Once the primary work's anticipated and imaginary wholeness is subtracted from performance, the sonic and gestural enactment of the score can no longer appear as "the same again," but emerges as an immanent offspring of a given point of view in time and space. Thus, it is not only the pathway of one-to-one communication between score and performance that is severed; instead, the new sonic and gestural enactment must also be designed in such conditions to be closed in on itself and be irreproducible. 
Such conditions are bound within unavoidable limits. The performance is linked to an existence in inscription - even if in the most volatile and transitory inscription, such as the one that happens as part of the audience's perception and consciousness. The intersection between the performance's event-like status and the chronological time in which the event takes place will inevitably confine and define it. This means that every kind of performance can be "rasterised" (see preceding section) and eventually reproduced. Contrary to this, the (declaredly paradoxical) aim of my practice is to produce events whose fixation and reproduction would amount to a partial loss of their inherent potential—or, better yet, whose potential would problematise the possibility of their fixation and reproduction.

The multiplicity of the artistic outputs is a consequence of the shift from thinking of a performance as the primary work's copy to thinking of it as the primary work's simulacrum. Platonic copies are material bodies over which immaterial Ideas have an effect; simulacra, on the contrary, are bodies that produce an incorporeal effect-such as resemblance. The fundamental difference therefore lies in the order (spatial, temporal, and hierarchical) in which materiality and immateriality relate to each other. In simulacra, material bodies (the physicality of sound, of gesture, of space) have precedence over the Idea, opening and unleashing sense(s). In contrast, the narrowing down of the generating Idea into a material copy is the result of the intersection between two coordinates whose function is to suppress difference and to prevent the proliferation of multiple senses. These two coordinates are common sense and good sense.

Common sense presupposes the existence of the transcendental identity of a knowing subject, which in turn mirrors the identity of the object of knowledge. In its domain, "knowledge is reduced to recognition" (Poxon and Stivale 2005, 66). It is possible to identify a performance of a given Beethoven sonata because we re-cognise it as the one we have already experienced, perceived, or imagined. This sort of identification is based on the ability to reduce all diverging and inconsistent details about a singular performance to the features we recognise as stabilised, and to suppress the elements that would prevent us from identifying it as "that particular work." Even if the listener may not be consciously called to such an identification, and is instead free to relate to an unmediated encounter with the idiosyncrasy of all the elements presented in a performance, from the side of the interpreter it is impossible not to rely on common sense as a means of conveying the recognisability of a given score or work.

Good sense is what lies at the very core of the phonocentric vision of music. Advocating a unidirectional conception of time, good sense sees music performance again as teleological (and theological). Performance is directed towards an origin in transcendence (the Platonic Idea) and therefore its end is to conform its own particularity to the universality of the work seen as whole. The essential function of good sense is "to foresee what is to come" (Poxon and Stivale 2005, 66), again stating the primacy of recognition over difference. The anticipated imaginary "being-heard-ness" of sound that is already embedded within the score allows us to understand its performance as relating to a given work. 
Considering and constructing performance as a simulacrum liberates difference from its status of being a "side effect" of representation and recognisability. A simulacrum is not simply an exception from the same. It is detached from the Idea. Therefore, divergence of output becomes more than the aim of performance. Rather, it is the inevitable consequence of the performance's independence from the supposedly faithful reproduction of the primary work. It becomes the expression of the intersection between work and performerprovided neither are seen as fixed identities but as series: the work is a score and is a set of historical conditions and is a style and is part of the thought of a composer and is a recording, and so on. The performer is an instrumentalist and is a listener and is a reader and is a composer and is bound to a given moment in time and in space, and so on. The ever-changing intersection of these two series gives rise to a potentially ever-changing output as performance. The longer and more differentiated the two series, the less powerful and suppressive will be the identities of both work and performer seen as idealised wholes.

\section{Proliferation of multiple senses}

The idea of good sense (see the preceding section) implies that a musical work possesses an ultimate kernel of truth, whose attainment might also be regarded as utopian in the interpretational tradition, but which nonetheless orients the hermeneutical efforts of its interpreters. As seen before, a linear and unidirectional conception of historical time is one of the most forceful axes along which good sense is oriented in relation to past objects and practices. The pathway of the traditional interpreter is directed towards the recuperation of one single moment from the past, using the optional aids of methodologies or objects generated after that moment, provided they corroborate and facilitate such a recovery. In contrast, the subtraction of history and good sense allows the performer/operator to exit chronological time and communicate with other times and other places by means of their untimely potential; this reverses, so to speak, the chronological good sense, and regards history as a network of relations where the present and the future are able to modify the past as much as the past influences the present and future (which is more often deemed to happen).

The relationship that Sciarrino has with the works of the musical tradition has nothing to do with philological accuracy. As Giacco phrases it, for Sciarrino, "it is not a matter of seizing the original sense of a composition (which would mean negating any kind of further interpretation) and believing in the unicity of sense itself. He wants to demonstrate that the works of tradition can produce a sense (and not the sense) for today's listeners" (Giacco 2003, 20, translation mine). In tradition lies a "creative energy that has been deposited for centuries" (Angius 2007, 232, translation mine), which can be revived only at the cost of transforming tradition radically. To extract this potential one must be willing to produce the inevitable fractures that allow such excavations to happen. The operation is therefore not mimesis of past events, and not even mimicry (the implement of postmodernism), but the mutual and synchronous transformation of past and present by means of their common energetic denominator. 
Authors from the past-whether minor or major-undergo a minor treatment that unleashes their potential becomings, even including those of which the authors themselves might not have been aware.

The renunciation of the good sense and of the univocal sense generates a paradox where the utmost haughtiness is matched with the utmost humbleness. Haughtiness, because this approach entails bringing out one's own singular voice, speaking in one's name, and in consequence not paying "due respect" to the repressive role of a pre-existent knowledge, which keeps saying, "You can't seriously consider saying what you yourself think until you've read this and that, and that on this, and this on that" (Deleuze 1995, 5); humbleness, because in order to speak in one's name, and to have one's voice traverse the objects and practices inherited from tradition (performance as ventriloquism) one has to be able not to see oneself as a single subject, an "I." A new voice arises, not to establish a new authority, nor to reassert the voice of the authorities who preceded it, but to make emerge, from the limitedness of one's point of view, an unprecedented rethinking of tradition and the past. A humble voice, because "what one says comes from the depths of one's ignorance, the depths of one's own underdevelopment" (ibid., 7), from the acceptance that the scope of one's singular point of view is limited and not exhaustive, but at the same time, in its deficiency, is unheard of and infinite.

\section{Antidisciplinarity}

In "Derivative X" I have described the infinite multiplication of Bene's roles, and not only those outside the theatre stage. The actor doubles as author and text; in a similar way, the performer/operator becomes both composer and inscription. The performing subject is at the same time in constant self-negation while also being the object of subtraction. The performer says and is said: "I remove myself, I exist only to be the one who is 'watched' and does not see" (Buci-Glucksmann 2013, 42). The liberation of the subject does not happen through the free flow of subjectivity, but through subjugation, in the total submission to the authority of the text that alone allows one to defy its repressive power. Therefore, Bene's assumption of multiple roles is not oriented towards interdisciplinarity, where an array of techniques and multi-media illustrate, corroborate, or decorate the already-said $\log o s$. The insertion of visual, scenic, and even tactile or olfactive elements is now common in Western music compositional practice. And yet, as long as these elements do not displace the performer from his or her pre-given role-that of constructing meaning, respecting a text, accomplishing a taskthey have no subtractive power whatsoever in the locus of the performance. They maintain the chain of representation intact, transforming the traditional role of the performer while at the same time preserving it.

The performer/operator unsettles the discipline of the performance of written music from the status assigned to it by the tradition of execution and interpretation. I have emphasised how my musical practice proposes to widen the gap between the "performance of-" and the "musical work" by enhancing the creative and productive role of the former. At the same time, the role of 
the "performance of-" is very different from "performance" alone. The importance of the event situation characterising live performance is still central, and yet this does not imply a privileging of the unmediated expression of subjectivity, which supposedly has a closer proximity to life. Therefore, the fictionality and artifice of the stage situation is kept and enhanced. In his stage activity, Carmelo Bene wants to subtract pre-given forms and practices from the scene, but his "subtraction ... can be attained also through an addition," and he violently scorns devices such as "the white painting, the theatre in the theatre, fortuitous music" (Bene 2001, translation mine). The operator moves in a direction opposite to subjectivity and truthfulness, because in the operator's work everything is an artefact. The performer does not become "free to do," but rather "a strange passive protagonist: ... free from doing, ... exposed to his own thoughts, that will not belong to him, but will rather possess him like visions" (Giacchè 1997, 17, translation and emphasis mine). And the performer as artifex (a word that means "maker," but also "counterfeiter") "totalis[es] becoming. He is played in the instant in which he plays" (Bene quoted in Giacchè 1997, 55, translation mine).

The multiplication of the functions of the performer/operator and his or her overflow from the centrality of interpretation and declamation are not means to attain "contaminations," implements able to "modernise" the stage and to make musical works from the past more appealing or understandable to contemporary audiences; rather, they pursue unrepresentability. The expansion into other disciplines, more than being interdisciplinary, is therefore extra- and antidisciplinary, assuring a permanent mobilisation of music towards territories that lie outside the discourse generated within its own boundaries.

The use of other forms of art onstage also has another function: to put the textual element (score) in perspective, and to overload it with elements and forces that are not directly textual but that still emanate from the text. Text is but one of the many ways in which a musical work materialises, and its ability to affect the performer can take on several other forms. Such components contribute to the variation of speeds by which the text is traversed on the way to its deformation and dissipation. And yet, such expansion aims to remain within the field of music. Again, the performer/operator is like the baroque artist eminently embodied in Bernini, who becomes an urban designer even when he stays an architect, an architect even when he stays a sculptor.

\section{IRRUPTION OF UNRELATED ELEMENTS}

I have described how, in order to displace the "perspectival" rendition of the score, the musical markers of stability such as the pitch system, melody, harmony, and internal relations must undergo the forces of isolation, deformation, and dissipation, and how these forces can ensue from an operation of chance from the side of the performer. Such an instability and unpredictability of the process of performance accounts for the fragmentariness and inconsistency of both the musical work and the performing subject, and determines an inscription into sound that, at each turning point, takes unknown paths. According to 
this procedure, it can happen that in some moments of the subtractive process, completely unpredictable sonic and gestural events appear. An unrelated and irrational world emerges in the scraps that exist in the fissures between the identifiable components, isolated between pauses or voids or dissipated into an undifferentiated background.

These unrelated sections are akin to what Deleuze terms "asignifying traits" in the painting of Bacon: "these marks, these traits, are irrational, involuntary, accidental, free, random. They are nonrepresentative, nonillustrative, nonnarrative" (Deleuze 2003, 100). They are produced by a subject that does not claim control over the materials, nor any internal consistency of will or cognition. They are urged by a primary work regarded as an infinite and non-finite entity, open-ended and unable to coagulate into an unambiguous whole. Issuing from a third dimension that hovers above both work/object and performer/subject, the performative output contains elements that derive from the singular experience of the performer/subject as a point of view, through pathways that are not always traceable. The common ground between such unpredictable and irrational elements over a large range of performative outputs is perhaps what best defines the performer's own singular mark, his or her own style.

\section{POSTSCRIPT: THE RISKS OF MINORATION}

The process underlying the techniques of subtraction described above experiments with the radical difference between extensive and intensive levels of the primary work. What are the levels that would persist even if every single extensive determination of the work was effaced, and how would they be expressed? What would the performer be left with if he or she could subtract every pitch, every harmony, every rhythmical pattern, and every instrumental indication in it? Nonetheless, these processes of minoration start from an experience in the performance of written music that is in turn historically, geographically, and culturally determined. It is conceivable that in other times, places, and contexts, some of the "markers" that are considered as major here might not appear as such; or that different markers of stability might emerge, perhaps unimaginable in this particular historical time and cultural context. A practice whose principal aim is to open new modes of thinking, in friction with, or expanding outwards from, an established norm or system, must be led with a high awareness towards the risk of turning it into yet another norm or system. It is dangerous for a process of continuous variation and subtraction to settle into a too well-defined operational methodology. Gilles Deleuze $(1997,254)$ warns about the "great risk that the minority form will restore a majority, remake a measurement [of representation] (when art begins again to become demagoguery ...)." The elements that "make" a majority are always shifting, always adapting to changing environments, circumstances, and needs. Variation has in turn to vary itself, to always look out for the unexpected, and to avoid stratifying into new clichés.

The process of stratification is ongoing, and impossible to forestall. One must therefore insist on the importance of the gesture over the result-or better yet, on the result that cannot be achieved if not through a specific gesture. It is 
this gesture that must be emphasised and perhaps systemised, rather than the appropriation of specific technical operations. The performative and artistic output is the expression of the affection that a musical work and a performer/ subject exert on each other. Some of the work's parts will be necessarily filtered by the experiences, whether musical or not, through which the performer apprehends them. In this respect, if I or others were to carry on with the artistic pathway traced by this research, it would make no sense to imitate its outputs; rather, one should understand its operative ways and pursue them, keeping track of changed and changing circumstances. In other words, the directions in motion are way more relevant than the dimension that the fixing of such directions at a given time might assume.

On this point my artistic activity significantly diverges from musical composition. A composer aims to produce artefacts that have been expressly conceived for the purpose of replication - therefore the need for a score or another kind of inscription to make possible the re-enactment of the first performance, of the first sound in dialogue with the mind of its conceiver. The difference with this kind of attitude is the closure of the communication and of the replication of the performative output. Performance becomes an interrupted system, a dead end, but one that is able, by carrying on with the process and the research leading to it, to reverberate with other, completely different performative experiences. This is also the reason why it is impossible completely to account for the reasons behind certain choices, such as choosing particular instruments and devices, or choosing some of the innumerable parts in the primary musical works over others. In the methodological framework of minoration and subtraction, even for the same performer it might be impossible to produce the same result again, because his or her point of view would have changed along with the changes to time and space. 


\section{Five Glances Upon the Unspeakable Body: Fourth Glance}

In "The Autonomy of Affect" (1995), Brian Massumi reports an experiment on the effects of the reception of images and words. Three versions of the same film were shown to an audience of children: the first film was wordless; the second had a spoken commentary describing the content of the film in a factual way; while the third had a different kind of spoken commentary, which added an emotional qualification to the images. The experiment exposed a physiological split in the audience's bodily reactions between the first two versions: while the insistence on the factuality given by the second version, with the spoken commentary, had the strongest impact on heartbeat and breathing (deep autonomic functions); the first version, which was nonverbal, provoked a higher galvanic skin response.

This experiment highlights two fundamental points. First, there seems to be a receptive gap between "content" and "effect" (Massumi 1995, 84). The two different bodily reactions (heartbeat; breathing and skin) are independent from each other: they can coexist but they are not elicited by the same elements in the film. Second, the content and the verbal communication elicit a reaction related to deep autonomic functions, whereas the level left without the straightforward qualification of words has an effect on the skin. Massumi distinguishes between these two levels, naming the verbal one "quality," and the nonverbal one "intensity" or, significantly, "affect." These two levels do not contrast with each other, yet nor do they correspond with each other either.

The level of intensity, as shown by the audience reporting their reactions to the experiment, is "characterized by a crossing of semantic wires" (Massumi 1995, 85). Its logic is not binary: it does not follow the law of the excluded middle, and "is not semantically or semiotically ordered" (ibid.). The dimension of intensity therefore operates on a level different from that of signification, and it cannot be explained other than through paradoxes (the audience experienced inconsistent sensations: they felt pleasure at the sight of "sad" images, etc.).

This shows how the body is clearly involved in signification. Its response to narrativity, to expectation, to "consciously positioning oneself in a line of narrative continuity" (Massumi 1995, 85), is directly functional. Heartbeat and breathing are therefore autonomic bodily responses to consciousness; or, better yet, are a veritable "conscious-autonomic mix" (ibid.). The body is not a wild and primordial territory outside and before signification, but it participates in it with the depth of its functional organs. A completely different level of the body responds to intensity: "Intensity is ... a nonconscious, never-to-[be]conscious autonomic remainder. It is outside expectation and adaptation, as disconnected from meaningful sequencing, from narration, as it is from vital 


\section{Fourth Glance}

function. It is narratively de-localized, spreading over the generalized body surface, like a lateral backwash from the function-meaning interloops traveling the vertical path between head and heart" (ibid.).

Massumi's view places language in a different light, in seeming contrast with what has been maintained by Barthes and by Artaud. Language, semiotic codification, is not exactly in a struggle with the level of intensity-with the a-linguistic, the side of action that is never going to coincide with its correspondent "oriented" side. For Massumi (1995, 86), "Language, though head-strong, is not simply in opposition to intensity," but operates in a different modality. There are at least two ways in which language can relate to intensity. When it tries to add something to intensity in order to explain it, to instil the sense of meaningful sequence, to add the linearity that presupposes a telos and an origin, to create the expectation that activates the deep autonomic functions, then language blunts intensity. As such, it could be argued that this is the feeling that Barthes has when he writes that music struggles with writing; this is also the way that inscription hinders an expression able to directly affect the nervous system in Artaud's experience. At the same time, there is another modality through which language can relate to intensity: "linguistic expression can resonate with and amplify intensity at the price of making itself functionally redundant" (ibid., emphasis mine). The third version of the film of the experiment reported by Massumi had a verbal commentary that added emotional qualification to the images: in it, words enhanced the level of intensity, breaking the narrative line to re-register at a conscious level an already felt bodily state (this version provoked the most long-lasting memory in the audience). Massumi warns that a language that qualifies emotions is not in itself immune from carrying functional information. On the contrary, it often produces a narrative; it contributes to the development of the action. In this case, it has the same effect as factual language: to dampen and counter intensity.

The example of the film chosen by Massumi might lead one into making the mistake of considering images and verbal language as if they were in a clearcut contrast with each other: where images would produce affects, words would produce factual or emotional qualifications. This is not the case, for it is possible for images to be read factually or emotionally (what Francis Bacon calls "illustration" [Sylvester $(1975) 1999,17])$ and it is possible for words to produce an effect that completely shatters their semantic framework, as in the wildly vocalised radiophonic version of To Have Done with the Judgement of God, or in Antonin Artaud's glossolalic writings.

What does it mean for language to make itself "functionally redundant"? Every form of artistic expression has its own specific "language"; and it can be argued that such language, with its peculiar codifications and structures, its functionality, doubles intensity on another, parallel level. This could be seen as, on the one hand, the level of content/form and, on the other hand, the level of intensity and affects. Language and structure need to make themselves redundant - they need not linearise and narrativise intensity through an excess of signification that imposes a consistent order upon unordered affective action. 


\section{Fourth Glance}

The limits of "the first semiology" (Barthes $1985 \mathrm{~b}, 312$ ) are by now clear, in that what semiotics and semiology fall short of is the dimension of intensity. Being concerned with structure, they cannot but revolve around the selfconsistent centre of pre-established rules. The study object of these disciplines is the set of variables that is already embedded in an invariable framework.

It could be maintained that this problem in performance is tackled by disciplines analysing the performative event from sides that differ from textual analysis. However, most of these disciplines merely shift the problem of text-and of semiotics-elsewhere. Studies on the subjectivity of the performer often concentrate on the emotional level, which, as Massumi clearly states, does not differ much from factual verbalisation as long as it qualifies affects. Emotion becomes one more degree in the mediation of consciousness and language. On the other hand, disciplines that focus on the body of the performer often fail to address the dimension of intensity, concentrating either on the oriented dimension of the body (the measurement and description of exterior gestures based on Euclidean spatial grids) or on its functional level, which participates directly in consciousness and in the creation of meaning. A new mode of thinking about music performance, one that is able to take into account the dimension of intensity, implies a reworking of the approach to musical textuality and semiotics, and an acknowledgement of the incommensurability between mental categories and physical materiality, but also, and fundamentally, a renewal of the modes of thinking about the performing body.

There is a level of the body that feels faster than and differently from the linearisation of consciousness. At this level, the inexplicable is real: an event emerges, accompanied but also countered by the "overdubbing" of the structure. At this level, intensity is felt as tension and tension is felt as tension because in intensity there are inconsistent possibilities that coexist, that are in a fight against the need for orderliness that consciousness imposes. Intensity is experienced as a crowd of potentialities. Crossing the threshold of consciousness and anatomy, only one of these potentialities can be selected and actualised, inserted in a meaningful line of signification and narrativity. But before that happens, the intensive body, Barthes's and Schumann's "body that beats," cannot but feel - without the capacity to verbalise - this tension as existent.

It is important not to mistake this bodily and textual level for a sort of romantically primitive terrain, a pre-verbal, preconscious receptacle out of which the musician would fish for a dimension of instinctual immediacy. Actually, if there is a limit to the resonance between Artaud's project and the one described in this book, it is precisely that, as has emerged in some of his writings, Artaud seems to be after an unmediated dimension that lies ahead of "culture." Such a primitive domain risks ultimately coinciding with a disguised version of the logocentric and phonocentric "metaphysics of presence" (Derrida 1997, 22), the self-founding origin of which the originated cannot but repeat and reproduce imperfectly.

In the first instance, the dimension of intensity does not arise within the body. It has nothing to do with interiority, and spiritual interiority in particular. Intensity is felt-not even experienced-at the intersection between the 


\section{Fourth Glance}

bodily surface and affection. It is always exterior, and it is encountered at the surface of the body. Second, as seen above, the body as a supposedly privileged locus where primitive forces are at play independently from consciousness does participate in consciousness, via its reflux in the autonomic functions.

Although every action is constituted on these two levels-intensity and qualification-art, and performance in particular, can constitute the privileged locus for an investigation on intensity. Similar to Artaud's theatrical staging, the doubling and potential conflict between intensity and qualification becomes the most explicit in the performance of past musical repertoire. On the basis of the three versions of the film in the experiment reported by Massumi, it is possible to delineate three modalities of performance of written music:

(1) Execution: being called to re-produce or to re-present an already formed structure, a music performer can restrict his or her task to bridging the gap between text and sound/gesture. This is the performer whom Igor Stravinsky $(1947,122)$ called an "executant," lending his or her expertise and skill to pronounce as clearly as possible what has already been stated by the composer. The executant accepts and perpetuates the culturally shared assumptions that establish a correspondence between the two incommensurable levels of text and performance. His or her action is structurally impossible without a belief in a transcendental "already said" in dialogue with itself. The clarity of the semiotic system is reflected in the clarity of sound and gesture. The microvariations swarming in the unassimilable and "real" materiality of sound are suppressed in favour of a pre-given sonic paradigm. Arbitrary changes in tempo and dynamics are often regarded as neglectful. Reverence is due either to the composer's intentions (as happens in the mainstream paradigm of classical music) or to history (as happens in historically informed performance).

(2) Interpretation: an interpreter allows him- or herself to add an emotional qualification to the factual text. He or she narrativises, linearises, endows with meaning-even possibly including meanings that differ from the ones allegedly attributed to the piece by the composer. But he or she also disrupts the linear factuality of the score through an emotional level of meaning. The interpreter enacts the dialectic dialogue between subjectivity and objectivity. $\mathrm{He}$ or she is alert to the body's functional autonomic responses to the narrative expectations raised by the text. The interpreter "breathes" with the musical work; he or she gives a pounding "heart" to the text. At the same time, the task of the interpreter fails to address intensity: he or she is unaware of a level of the body - and of the body of the text - that acts and reacts too fast for consciousness to readdress it into coherence, and for the functional body to be moved by it. An interpreter must interiorise a text. Being assimilated, the text finds a place alongside the coordinates of anatomy (Euclidean bodily interfaces) and the axis of autonomic functions (heartbeat and breathing, expectation and emotion).

(3) Intensive performance: a musical practice that accepts the role of accounting for the dimension of intensity must be able to displace the positions of text and 


\section{Fourth Glance}

body from those inherited from executional and interpretational traditions. We have seen how the inconsistency of unactualised potentials that are excited by affective reception and the pressing of those potentials to be actualised are felt on the skin: it is the outer bodily interface that reacts, contaminating the visceral interiority too quickly for the anatomic body to orient the received impulses alongside the "organised" axis anatomy/mind (function/meaning). The musical work, in its integrity and self-containment, must be left outside the body. Physically, the relationship between the body of the performer and the text is an external one. The performer does not wish to assimilate the text, to fuse with it into a superior harmony. Work and performer must remain outside each other for the body to be affected in its outer interface - the skin - by means of a total, unbridgeable exteriority. There is no possibility of assimilation-for, as Massumi $(1995,88)$ phrases it, "Intensity is the unassimilable." The mind of the performer and the mind of the composer are not regarded as instruments of self-expression, infusing life and meaning to the inert matter of the text. They are excluded as active principles. The body of the performer and the body of the text are not raw matter, dumb and passive fabrics upon which the mind-the Artaudian "spirit"-bestows life. Everything happens on the surface, in the infinitesimal gap where the inconsistent potentialities contained in the text affect the body, eliciting an action before a response can be drawn from the organised anatomy/mind.

The performer is then affected by the externality of the work-in its textuality that already encompasses both sound and body, provided they are the qualified levels of both sound and body. The gestures and sounds that the performer releases are out of control, out of consciousness, since they are felt and produced in the epidermic zone that acts too quickly for consciousness to appropriate them. There is no more outside - an outside that mirrors and reflects the anatomic and oriented body. There is no more inside-the inside of self-expression that acts on a matter seen as dead and meaningless. The inside of the body is turned inside out, reacting to external affections only with its skin-deep limit. In this zone of mutual affection, the past constituted by the musical work is "reactivated, but not accomplished; begun, but not completed" (Massumi 1995, 91).

The semiotic system used by its composer to convey the intensive level of the text determines what one makes of the musical work as something that is past and objective. Such an intensive level of the text is what Barthes calls the "beats," the "sole structural elements of the musical text-which constitute music's transhistorical continuity" (Barthes 1985b, 310). Thus, the semiotic system has to make itself "functionally redundant." The price to be paid for the unleashing of intensity in music performance goes as far as effacing, mutilating, and subtracting the semiotic level. If it is actually redundant, a performer can experiment with how many of its units can be twisted and eliminated for the level of intensity to remain. In its mutual affection with the performer, the musical work inevitably becomes contaminated with sounding and gestural experiences that its composer and its historical context have not seen or imagined. The past affects the present, and the present sweeps up the past into a becoming-something-else than it was meant to be. At the skin level of 


\section{Fourth Glance}

affection, craters are opened up at the point where the tension of inconsistent virtualities affects the body. Instead of selecting from the restricted range that the clarity of semiotic communication allows, consciousness opens up to register elements from other ranges of this infinite inconsistency. What is then fixed-for it is impossible, as Artaud knew, to make do with inscription-bears the trace of this divergent, twisted, and anomalous affection. 


\section{Appendix 2: List of Musical Examples}

Antidotum Tarantulae (after Athanasius Kircher's homonymous tune): for solo acoustic guitar

Madonna il poco dolce (after Nicola Vicentino's homonymous madrigal):

- version 1 for electronic soundtrack, viola, and electric guitar

- version 2 for electronic soundtrack and electric guitar

Piange Madonna (after Sigismondo d'India's homonymous song):

— version 1.1 for electronic soundtrack

- version 1.2 for live electronic performance

- version 2.1 for electronic soundtrack

- version 2.2 for live electronic performance

- version 3.1 for electronic soundtrack

- version 3.2 for live electronic performance and electric guitar

Prelude (after Robert de Visée's Prelude from the Suite in D Minor for guitar):

- version 1 (installation)

- version 2 for live electronic performance

Variation VIII (after Ludwig van Beethoven's Diabelli Variations no. VIII): for flutes, bass clarinet, violin, cello, piano, and percussion

$n$ (Amarilli-1) (after Giulio Caccini's song Amarilli mia bella):

$-1\left(\text { Amarilli-1 }^{1}\right)^{1}$ for electronic soundtrack

$-2\left(\right.$ Amarilli-1 $^{1}$ for electronic soundtrack and electric guitar

$-n(\text { Amarilli-1 })^{2}$ for flute, alto flute, clarinets, cello, and piano

$-n(\text { Amarilli-1 })^{3}$ for electronic soundtrack

$-n\left(\right.$ Amarilli-1 $^{4}$ for solo dancer

"Sento un certo non so che" (after Claudio Monteverdi's homonymous duet in L'Incoronazione di Poppea): for solo acoustic guitar

$\operatorname{Rasch}_{4}^{23}$ (after Robert Schumann's Intermezzo in Kreisleriana, op. 16, no. 4): for electronic soundtrack

Other artists involved in the performances or design of the sonic objects were:

Paulo de Assis $\left(\right.$ Rasch $\left.^{23}{ }_{4}\right)$, Sara Baldini (flute, $n\left(\right.$ Amarilli-1 $\left.^{2}\right)$, Marieke Berendsen (violin, Variation VIII), Bettina Berger (flutes, Variation VIII), Anna D'Errico (piano, Variation VIII), Niels Hap (bass clarinet, Variation VIII), Hanna Kölbel (cello, $n\left(\right.$ Amarilli-1) $\left.^{2}\right)$, Agnieszka Koprowska (percussion, Variation VIII), Johan Liekens (architect, Prelude version 1), Benjamin Maneyrol (clarinets, $n\left(\right.$ Amarilli-1 $\left.^{2}\right)$, Christophe Mathias (cello, Variation VIII), Marlene Monteiro Freitas $\left(n(\text { Amarilli-1 })^{4}\right)$, Andrea Nagy (bass clarinet, Variation VIII), Carlo Prampolini (piano, $n\left(\right.$ Amarilli-1 $\left.^{2}\right)$, Hannah Reardon-Smith (alto flute $\left.n(\text { Amarilli-1 })^{2}\right)$, Elisabeth Smalt (viola, Madonna il poco dolce version 1). 


\section{Prototype: Antidotum Tarantulae, after Athanasius KIRCHER'S HOMONYMOUS TUNE}

Composer: Athanasius Kircher (1602-8o)

Primary work: Antidotum Tarantulae

Published in Magnes sive de arte magnetica (1643)

This divergent performance is constituted by two main gestures: (1) some proto-melodic lines, played as a pianissimo tremolo on the first string of the acoustic guitar, with the left hand pressing the string over the sound hole; (2) percussive patterns of one to three pitches, played with two hands tapping on the sixth string.

The main technique of the performance is isolation. Melodic lines extracted from the primary work (1) are played without their harmonic foundation, and are separated from one another in fragments that correspond to a durational length of approximately a semi-phrase. These fragments are articulated as if they emerge from and return to silence. Furthermore, they are not always played in their original sequence, but are repeated or slightly varied.

The technique of isolation is reinforced by deformation. Each melodic line, pulsating between intervals of silence, is also internally deformed. The diatonic relationship between the pitches is deprived of clarity (glissando-like figures); the density of the texture of the tremolo and the imprecision of the intonation caused by the unconventional left-hand technique generate a sound quality that is suffocated, blurred, and swarming with internal microscopic irregularities.

The continuity of the semi-phrases is further broken by the irruption of the fragments of rhythmical patterns (2), produced by the percussive actions of the fingertips of both hands on the fingerboard, in configuration of pitches and figures - a set of triplets played without metrical rigour - that distantly recalls the basic rhythmic unit of the pizzica, a dance from the Salento region of Puglia (southern Italy) by which the phenomenon of tarantism has been used as a cure until recently, and where Kircher himself travelled and worked.

The gestures of this performance were conceived without fixed durations. They were guided by the memory of the primary work, and assisted by a diagram that provided an aide-memoire for its structure.

\section{MADONNA IL POCO DOLCE, AFTER THE HOMONYMOUS MADRIGAL BY NiCOLA ViCENTINO}

Composer: Nicola Vicentino (1511-72)

Primary work: Madonna il poco dolce

Published in L'antica musica ridotta alla moderna prattica (1555)

This divergent performance was developed as part of a project led by Bob Gilmore, in which composers and performers were invited to revive Nicola Vicentino's innovative attempt to reintroduce the three Greek ancient genera (diatonic, chromatic, and enharmonic) into contemporary musical practice. 
Composers and performers were encouraged to relate their own imaginative world to the idiosyncratic harmonies generated by Vicentino's system.

The first part of the primary work is characterised by several repetitions of the word "Madonna" (my lady) and of the sound $/ \mathrm{m} /$, associated with accents that prolong it before the vowel sounds (as in the words "molto" [much] and "amaro" [bitterness]). The lyrics are about unfulfilled love and prolonged torment. The divergent performance is characterised by a vector of unvented passion and mourning, suggested in the soundtrack by a muted choir of humanlike voices, where a sound close to the phoneme $/ \mathrm{m} /$ is occasionally pierced by vowel-like sounds, especially in the few moments of climax. Such a suffocated sound contains variations of the harmonic blend, which suggest vowel changes.

The clash of Vicentino's enharmonic chords against the modern ear's expectation for just or tempered intonation is evoked by a blurry and unsettling pseudoharmonic environment. The sounds in the soundtrack follow the profile of the initial chord progression, bending it using glissandos; the initial chords are repeated and hybridised with other parts of the melody from later sections. The first climax recalls the cadenza at bar 10 (see Vicentino 1990), where also the "a" of "amaro" emerges. The next three bars in the primary work- "il breve riso" (the short joy), imitating a swift laugh in the original-are suppressed in the divergent performance (although the hint of laughter will surface later on); in their place an unrelated section opens. This section, a sequence of harmonics merged with percussive and whistling sounds, is in its turn a recapitulation of the preceding part, echoing the variation of the harmonic spectrum of the muted sounds.

The next part corresponds in the primary work to the chromatic ascent that begins at bar 14 and culminates at bar 18. In the chromatic progression, the lyrics describe a prolonged weeping. In the divergent performance, the harmonic profile of the progression is kept, but dilated and blurred in glissandos, and the culmination, mimicking the downbeat of bar 18 and dissolving into the following short chromatic descent, is agitated by a sense of impatience and distress. A second unrelated section follows, a variation on the first one reassembling similar sounds in new patterns. From the background, some other recognisable elements surface: the "breve riso" of bars 11-13, rendered through the imitation of a laughing sound made mechanical and artificial through looping; the profile of the soprano phrases "il troppo lungo pianto" (the too long weeping), bars 19-22, and "che "l pianger sempre" (that weeping all the time), bars 22-24, results in a whistling sound quality. Most of the remaining part is omitted, except for the final cadenza, which is encapsulated in one single wavering F\#.

The gestures-both physical and sonic - of the performers onstage recapitulate the elements of the soundtrack. At the beginning, the guitar produces a rattling sound that reacts with the harmonic environment, and that opens up into feedback after the first climax - the performer is facing the amplifier and draws the pickups close to it, modulating the feedback intensity and pitch by regulating distance and by selecting the harmonic range through a wah-wah pedal. These gestures further re-elaborate the elements of the soundtrack. The muffled sound $/ \mathrm{m} /$ at the beginning, characterised by internal harmonic mobility, is doubled by the rattling sound of the guitar strings whose free vibra- 
tion is stopped by the insertion of a metal object; the vowel explosion is doubled by the open sound of the feedback. In the version for electronic sample, guitar, and viola, the latter intervenes only in the two unrelated sections, by underlining their lack of direction and development. The indications given to the player concerned only the pitch range (high harmonics of the D string) and the performative energy. Such energy should happen with the least possible effort, as if the performer were "played" by an external agent. In the final section, the guitar produces small agglomeration of bell-like sounds, processed through wah-wah and reverse delay.

\section{N(Amarilli-1), After Giulio Caccini's song Amarilli $M I A B E L L A$}

Composer: Giulio Caccini (1550-1618)

Primary work: Amarilli mia bella

Published in Le nuove musiche (1602)

$n$ (Amarilli-1) is a series of performances after Giulio Caccini's song Amarilli mia bella. The starting point for each performance is the forceful rhetorical structure of the song (see $\mathbb{7}$, figure 11). The score of the primary work was first transcribed into a graph, where three lines stand for the extremes of the melodic range: the solid line is the body singing voice ( $G$ note), the dashed line the body of Amarilli (high D note), and the bold line corresponds to the visceral interiority of the singing voice (low D note). Vertical space represents frequency, while horizontal space represents time, as in a standard notated score. Pitches are represented by rings, connected to one another to emphasise the profile of the melodic line. A bigger ring is used whenever the melody hits one of the lines that represent the three main pitches. The graph is divided into six vectors, each corresponding to a rhetorical situation and to a bodily scenario of the song. The six vectors provided the subtext for the transcoding of Caccini's song into each divergent performance.

$N(A M A R I L L I-1)^{1}$

In $n(\text { Amarilli-1 })^{2}$, the scenery of distance conveyed by vector 1 was rendered by the superimposition of two layers of sounds. The G, referring to the opaque interiority of the singing voice, was turned into the sound produced by rubbing a gum mallet against the body of an electric bass. The $\mathrm{D}$ became breathy sounds-bottles used as wind instruments and processed through pitch alteration and delay. The breathy sounds follow the profile of the initial fragments of each phrase. Vector 2 was transferred into an intensification of events and amplification of the timbral range by the introduction of sounds produced by scratching a cello bow against the steel strings of a chitarra battente. The last " $G$ " in the vector, the approach of the interior world of the singing voice, corresponds to a thump (gum mallet on bass guitar strings, dampened), followed by an "air" sound (airy sound produced with a cello bow lightly press- 
ing on the dampened bass guitar strings). The third vector is rendered through two superimposed layers of scratching sounds, again produced with a cello bow on two strings of the chitarra battente. The two strings were tuned in $\mathrm{B} b$ and $\mathrm{A}$ (as the main pitches in the corresponding section of the primary work), and the sound attack recalls the harsh texture produced by the consonants in the lyrics of the song. The violence of vector 4 appears in a sudden increase in the volume and in the gestural intensity, followed by a fade out into silence. Vector 5 , the movement of ascent of the melodic line in the original is rendered through a very slow crescendo of the airy sound of the cello bow on the music stand. Vector 6 is omitted in this rendition.

$$
N(A M A R I L L I-1)^{2}
$$

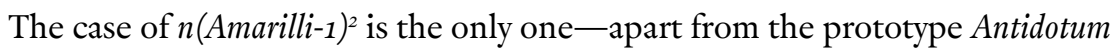
Tarantulae-in which the construction of the sonic image (phase b), was substituted with a process other than phonographic fixation. This case followed up the attempts to transform the score into graphs that could then be used as a track for live improvisation (see $\$ 2$ ). The rhetorical structure of the song and the six vectors individuated were used to coach a group of students on the Advanced Master in Contemporary Music (School of Arts Ghent, Belgium) about the possibilities for performance opened by my research project.

\section{Piange Madonna, After Sigismondo D'INDIA'S HOMONYMOUS SONG}

Composer: Sigismondo d'India (c.1582-1629)

Primary work: Piange Madonna

Published in Le musiche da cantar solo (1609)

Of the three divergent performances derived from this primary work, I consider rendition no. 1 to be the most satisfactory in terms of attaining a divergent resemblance to the primary work. However, when analysed more closely, it is hardly possible to detect recognisable shapes. The most clearly detectable aspect of the primary work is the pace, the punctuation, the plaintive mood of the melodic shapes and of the lyrics. Such a very faint traceable correspondence with the extensive elements of the primary work might also be because this version started not from a score but from various recordings of the work.

The sonic image begins with a gesture recalling the harmonic shift opening the song (word "piange" [weeps]), and is followed by a descending line that refers to the successive figure, which in the primary work seems to imitate a sobbing (words "Madonna ed io" [my lady and I]). Another descending line follows, a hybridisation of the descending line "madonna ed io" with another one (words "come del mio" [as much as in mine]). The next melodic "whistled" fragment recalls the melody of the last phrase (words "anima al pianto avvezza" [soul accustomed to tears]), suddenly compressing the compositional arch of the primary work by bringing the beginning close to the ending. This section is 
concluded by a short descending fragment, resembling the "mio" (mine) at the end of the first period in the primary work.

After this, the opening fragment returns, hinting towards the repeat in the primary work; nevertheless, it is soon lost in the more undifferentiated background. The final section corresponds to the final period of the song (from "anima al pianto avvezza" on), except that the melodic scraps suggest more the profile of the fragment "come del mio."

The harmonisation that sometimes hits the voice-like lines in the divergent performance is not produced by the actual playing of chords, but by adding a resonator filter to the recorded sample at certain moments. This effect, perforating the melodic space through an opening of the harmonic spectrum, recalls the presence of an accompanying instrument (such as a theorbo), underscoring the vocal line at specific points in the primary work.

In this example, several elements emerge that do not bear a traceable correspondence to d'India's song. These sections or elements recur in all the divergent performances produced for this project, yet in this case they are particularly pervasive, at times almost taking over the entire structure and almost overwhelming the recognisable figures. This might be due to the structure of the original song, which is organised around clearly separated phrases, and is steadily punctuated at the end by a cadence with a small fermata. In this divergent performance, the silences and fermatas have grown to almost take over the sounding space.

Rendition no. 2 concentrates on two elements: (1) the melodic lines, which are slurred over and blurred (the contour of the melodic line of the singing voice is partly preserved); (2) the plaintive mood that both the lyrics and their musical setting convey. Lamentation is the general theme of the lyrics, in the primary work this is conveyed by fitful melodic lines-enhanced by the singers through extensive use of ornamentation - and by the semitonic relationships between chords, in an almost onomatopoeic imitation of weeping.

In this divergent performance, the vocal quality of the lament is liberated in its pure timbral state. I have used a voice-like klaxon horn, whose harmonic amplitude is modulated using the hand as a trumpet mute and through electronic processing. Choked and sobbing, the klaxon horn produces fragments of melody as if it were a larynx deformed by fits of weeping. The initial recording was elaborated electronically through pitch modulation-since the horn allows for too small a melodic range-vaguely contouring the melody of the original song. Afterwards it was split and delayed through granular synthesis, which created a sort of polyphonic-harmonic layer on top of it, recalling the function of the continuo underlying and accompanying the singing voice.

Rendition no. 3 is presented here as an example in which the resemblance to the primary work failed to be produced. This version was designed following an attempt to anamorphise the word "Madonna" (my lady), and the melodic profile of one of the segments of the song in which this word is pronounced. However, anamorphosis in this case too closely followed the internal relationship of the elements contained in the first term of the analogy. I detected some sounds that could relate to the single phonemes of the word, and I stretched the 
tempo. The result, rather than being an anamorphosis, was a combination of a homothetic projection (or scaling) and the devising of a sort of new code into which to translate the old one (pitches and phonemes). If, on the one hand, the correspondence remains highly traceable, on the other hand, its resemblance does not take place through the modalities and goals inherent to the project.

\section{VARIATION VIII, AFTER LudWig VAN BeEthoven's Diabelli} VARIATIONS NO. VIII

Composer: Ludwig van Beethoven (1770-1827)

Primary work: Diabelli Variations no. VIII

Published in 33 Variations on a Waltz by Anton Diabelli, op. 120 (1823)

Variation VIII was the first instance in my musical practice of taking a piece from the nineteenth century as a primary work. In all the previous examples, I related to music from the early Baroque, for a number of reasons. First, I was searching for a vicinity between the visual principles I wanted to apply to the interaction between text and performance - the "baroque paradigm," see "Derivative I"in an initial line of research that investigated whether such principles were also active in early Baroque music (a line that was eventually abandoned). Second, the distance between my own musical background (interpretation of classical and contemporary music) and seventeenth-century music practice generated a difference of potential that allowed me to concentrate on the relationship between my own experience as a performer and the primary work. Third, and most importantly, the music produced in the cultural and aesthetic framework seconda prattica is often characterised by radical experimentation in terms of clashing harmonies, expressive melodic lines, and forceful rhetorical structures, all of which provided an intricate net of musical materials and relations that facilitated their transposition into vectors and forces.

In contrast, Beethoven's Diabelli Variations no. VIII is built around a rigorous rhythmic and formal structure. The transformational power of each of the Diabelli Variations in relation to the theme is less noticeable when one of them is taken on its own as a self-standing instance. My decision was to treat Variation VIII as an autonomous object, not necessarily linked to the larger construction of the work as a whole, and therefore to partly deprive it of the transfiguring potentiality that it has when reacting to the rest of the composition. There was another option: starting from the "anamorphic" nature that the Diabelli Variations conveys, which is considerable as it contains thirty-three anamorphic glances on the original waltz object. However, as Beethoven reacted to a circumscribed piece of music - the original waltz by Anton Diabelli-I wanted to try to relate to one particular variation, treating it as a delimited departure point as much as possible.

The rigidity of the structure organised in four-bar phrases imposed itself before and upon other properties. The divergent performance follows the linear structure of the original variation almost literally, with few irruptions of completely unrelated elements and no chronological displacements, making 
Variation VIII the only example in my practice of the use of a technique similar to a palimpsest. One of the unrelated elements was semi-conscious: when playing from the score at the piano, the arpeggiated figures at the bass with the leading-note on the downbeat of each bar as if piercing the tonal space suggested a gestural and sonic link with the first lied in Schumann's Dichterliebe, "Im wunderschönen Monat Mai." Various melodic fragments from the melody and accompaniment of the lied were inserted into the divergent performance. This is the only example where elements from a piece of music different from the primary work become part of the preparatory materials.

Differently from other instances of my practice, Variation VIII follows almost linearly the temporal distribution of the elements of Diabelli Variations no. VIII. The description below follows the bar divisions in Beethoven's piece (see Beethoven 1862-65) and how each section relates to the divergent performance.

Bars 1-8

The beginning of each four-bar group is marked by a beat of the bass drum and the piano, a gesture at the same time violent and rigid. These breaks are followed by two parallel actions: the piano gesture diluting into an ascending four-note pattern (reminiscent of the piano's incipit in Schumann's lied); and the flute, violin, and cello recalling the descending melodic line in the original variation's right hand. Such a gesture is produced with an airy sound and wavy and imprecise pitches. The only liveliness in this part comes from the bass clarinet, whose pianissimo muttering derives from the figures of the left hand in the primary work; the prominent role of the leading tone in the left-hand part is transferred into intervals of a semitone and major seventh. The same features apply to the second set of four bars.

In this example, almost every quantifiable element in the primary work has found its precise correlative in the divergent performance, except for the upbeat, quite relevant in Beethoven, which is removed. The choice of pitches for the piano and the bass clarinet was made not according to a homotetic transformation but by a process of deformation of the relationships of tension in the original harmony.

Bars 9-10:

The downbeat of these two bars is marked by a slamming gesture on the piano and bass drum, similar to the ones underscoring the first section but this time softened, assisted by the puffing sound of the flute. Also here the bass clarinet figures suggest the repeated left-hand patterns in the primary work. The violin and cello introduce elements of Schumann's lied - the first three pitches in the melody, $\mathrm{C} \sharp, \mathrm{B}$, and $\mathrm{D}$, which correspond to the sung words "Im wunderschönen" in bar 5 (see Schumann 1879-1912). 
Bars 11-12:

The response to bars 9 and 10, which in the primary work return to the tonic in the second inversion after a short passage in the subdominant, is assigned to a figure of the bass clarinet, overshadowed by the piano playing in a very soft and condensed chord in the low register.

Bars 13-15:

A similar process continues; the flute, violin, and cello proceed with fragments of the melody of the lied ( $F \sharp, G \sharp, A$ for the first figure- the words "Monat Mai," bars $5^{-6}$ - then $B, C \#$, and $\mathrm{E}$ to finish-the words "ist in meinem Herz"-bars 9-10).

Bar 16:

This bar concludes the first half of the variation. In the original, the right hand leaves the chordal modality and expands into a melodic figure in quavers; in the divergent performance this is suggested by the piano, which plays as if suspended in a zone of fast and soft trills on four notes. For the first time, the tempo in the new performance is significantly dilated.

The next short section, cutting off the piano trill and developing out of a thumping pattern on the bass drum and piano, has no clearly traceable relation to the primary work. It is like an opening between the two parts of the variation, out of which the second part emerges.

Bars 17-24:

The second part, reprising various elements from the first (the slamming gesture at the beginning; the flute, clarinet, and cello outlining the three-voice melody, this time ascending), superimposes itself onto the preceding undefined zone. The pattern of bass drum and piano, punctuating silence and returning at regular but not rhythmic intervals, inserts the new fragments into a space of more concentrated listening. This time the bass clarinet does not produce the muttering figures as before, but pierces and expands the sound environment through long multiphonics.

Bars 25-31:

This part is symmetrical to bars $9-15$. The violin and cello play fragments of the melody from Schumann's lied, transposed from the pitches of the original.

Bar 32:

This bar is similar to bar 16, but elements irrupt that have no correspondence with the score, such as the coupled melody of violin and flute and the gestures of the cello.

The ending section - four impulses with similar character-is a sort of recapitulation. Each of the impulses corresponds to one segment from 8 bars of the primary work, again recalling the rigid structure organised around the number four. The sound spectre is constructed as if a starting impulse - the tam-tam- 
was sustained, expanded, and diluted by the other instruments (bass clarinet and cello with long notes; flute and bass drum with a percussive pattern). The violin on top repeats a rhythmic pattern of four notes.

The end is in turn a recapitulation of the four previous impulses, with the piano reprising the pattern of the bass drum and the clarinet and the flute thinning out the listening space into silence.

\section{The Cabinet of Sonic Gazes, after Robert de Visée's Prelude from the Suite in D Minor for guitar}

Composer: Robert de Visée (c.1655-c.1733)

Primary work: Prelude from the Suite in D Minor

Published in Livre de Pieces pour la Guitarre (1686)

As opposed to the other examples in my practice, the Prelude from the Suite in D Minor by Visée was written for an instrument very close to my own: the Baroque guitar. Therefore, in the preparatory phase, it was possible for me to perform it both on classical guitar and on an instrument that has the same string system, tuning, and fretboard as the one used by Visée, namely the chitarra battente. This affected the relationship between the score and performer (me), since the idiomatic gestural instrumental elements came to the fore much more than in other examples.

Initially conceived as an ongoing audio installation, this divergent performance was organised in seven fragments, each constituted by an electronic soundtrack played in a loop with variable volume envelopes. Each fragment can be regarded as expressing one single "trait" of the primary work. This divergent performance does not entail a temporal continuity, since the fragments were played back as independently automated soundtracks. Thus, the temporal succession was not predecided, but was determined by the autonomous conduct of the fragments (live version) and by their spatial disposition in relation to the position of the listeners (in the case of the installation).

The first fragment refers to the dotted articulation (typical of French music in the late seventeenth and early eighteenth centuries when Visée worked as a composer and performer), assigning it to a percussive pattern (gum mallet on the body of the chitarra battente).

The second fragment follows the same pattern, adding to it certain traces of melody, played by hitting the strings of the chitarra battente with a cello bow.

The third fragment isolates the melody through a whistling tone.

The fourth fragment deterritorialises the harmonic progression: the pitches of the chord progression in bars $5^{-6}$ are prolonged and superimposed on each other.

The fifth fragment isolates and reiterates ornaments.

The sixth fragment condenses the initial harmonic progression into two descending lines (processed sound of fretless bass guitar) that are bended and "liquefied."

The seventh fragment isolates the bass line and transposes it to a lower register. 
$\operatorname{RASCH}_{4}{ }_{4}$, AFTER ROBERT SCHumann's KREISLERIANA NO. 4

Composer: Robert Schumann (1810-56)

Primary work: Kreisleriana no. 4

Published in Kreisleriana, op. 16 (1838)

The particular case of $\operatorname{Rasch}_{4}{ }_{4}$ was designed as part of the performance of a wider project, Rasch $^{23}$, which was based on materials related to Kreisleriana, op. 16, by Schumann, and Roland Barthes's essay “Rasch” (1985b). The piece's electronic soundtrack was produced utilising some of the methodologies developed within this research project, although now with a more specific performative function-namely, that it was played back in place of the enigmatic five fermatas in bar 11 of the score of Kreisleriana no. 4 (see Schumann 1885), during its live piano performance.

The initial long pitch around which the whole soundtrack is constructed, a processed sound of a singing bell, refers to the starting and ending pitches of the melodic phrases at bars 11-13 (and similar). In the background are noises, patterns of husky sounds with a faltering articulation. These were probably suggested by the hesitating pace with which Vladimir Horowitz (in one of the recordings listened to during the preparatory phase) articulates some of the arpeggio formulas in the intermezzo, lingering on the crotchet notes of the melody. The irruption of siren sounds and of heavily distorted backgrounds is like a violent utterance. It reflects the contrast between Barthes's commentaries on the first part of the piece and on the intermezzo after the five fermatas. The first part, which for Barthes is "quasi parlando" (1985b, 306), expresses the effort of one who cannot speak but who needs and wants to. In the intermezzo, on the contrary, "it speaks, it declares: someone declares himself" (ibid., 299).

After evoking the four initial pitches of the melody (D, E, F\#, G), the piece goes back to the initial noisy patterns, where some of the pitches already enunciated return in crescendo waves.

\section{“Sento un certo non so che," after Claudio MONTEVERDi's HOMONYMOUS DUET (FROM L'incoronazione di Poppea)}

Composer: Claudio Monteverdi (1567-1643)

Primary work: duet "Sento un certo non so che"

Published in Lincoronazione di Poppea (c.1651)

The main technique in this divergent performance is variation. This performance is divided into three parts, each subdivided into "phrases" where fragments derived from the primary work are recombined, repeated, and varied.

In the first part, almost all the "phrases" open with a rhythmical pattern derived from the ritornello (bars $377^{-80}$, see Monteverdi 1931). The patterns played in tremolo with the left-hand finger pressing the first string over the sound hole refer to the diatonic oscillation characterising the vocal conduct in bars $339^{-44}$ and 360-68. The use of the voice, mostly whistling and with an 
airy quality, matches and hybridises the sonic texture of the tremolo patterns. This texture is further interpolated with the same figuration played with the bottleneck on high positions on the first and second strings.

A series of single pitches punctuates the otherwise misty and unclear sonic space. They refer to pitches that belong either to the melodic line in the primary work or to the bass and its harmonisation. Such pitches are not played in consistent lines, but are sprayed over different registers and produced with irregular sound emissions (harmonics, especially very high ones; left- and righthand tapping; complementary sounds).

The use of the voice becomes increasingly more pervasive, up to and including a micro-fragment of singing (with the brief appearance of the words "vivo 1-," from bar 366).

The second section is organised around long descending slurs with the left hand scratching the wound strings. These figures reflect the descending movement characterising bars $381-84$ and similar figurations, compressing and outlining them. Each slur is preceded by patterns derived from the melody in bars 404-6, played with tremolo on the three higher strings. At its end, rhythmic patterns recall the opening of each gesture of the first section.

Section three refers mainly to bars $381-87$ and $397-400$. The melodic profile of the primary work is kept almost faithfully here, but it is made unrecognisable through the use of ambiguous sound emissions, the spraying of the registers and octaves, and the uneven, non-metrical temporal scansion. The gestures are repeated and varied (each time a slightly different section of the primary work is referred to) and progressively rarefy, ending in a general diminuendo. 


\section{Closing Remarks}

After three years of research, the writing of this book, and the establishment of a new artistic practice (new for me as well as for others), the questions I have opened outnumber those I have answered. This research started in the awareness of its own paradoxical nature: not only that the answer to the initial questions was unknown but also that the very existence of an answer was uncertain. Looking back at the work done, the main result seems to be the framing of a new field, whose interest and potential for exploration is perhaps more promising than any quantifiable result. From the very limited scope announced at the start-exploring the nature of the "of" that both separates and unites "performance" from "written music"-I observed a variety of disciplines and practices: semiotics, philosophy, media theory, music composition, music interpretation, visual arts, theatre, and so on. If my research could not master such a wide horizon, nonetheless this very limited perspective could provide a unique point of view on it. I would regard the capacity for expressing a singular and unprecedented point of view on a variety of disciplines as perhaps the biggest potential of artistic research, which in its instability and lack of definition benefits from unfinished thinking more than from the production of objects of concluded knowledge.

During the last year of my artistic activity, I experienced directly the effects of an expansion of the disciplinary boundaries on my starting field of expertise, which was the interpretation and execution of written music in the Western tradition. During my research years I radically modified my everyday practice: from deepening my expertise with tools generated within the confines of my discipline (muscular training, reading practice, music analytical skills, expansion of the repertoire, organological competence, knowledge of music history, ear training, notions of acoustics, etc.), to a displacement of my musical practice towards the above mentioned wide range of fields and practices. Returning to my previous activity after this long trans-, extra-, and anti-disciplinary detour was surprising: the imaginative tools I had refined affected the performative result in a way that $I$ had not experienced during my earlier multi-decade activity in training and professional performance. A whole new field of possibilities was disclosed; a reconfiguration of the thinkable in music performance was achieved. The focus on the relation between the matter of sound and gesture and the semiotic clarity of the score, the widening of awareness about it, and the experience of its radicalisation and problematisation allowed me to inhabit the old disciplinary boundaries with an increased creativity, energy, and understanding.

This opening of horizons did have its downsides. The friction between the wideness of the discourses and the limits of time and expertise led to technical limitations that give some of the outputs an unfinished or "work-in-progress" quality. The artistic output of this project proved on many occasions to have an aesthetic and affective impact on audiences coming from diverse contexts 


\section{Closing Remarks}

and levels of expertise; though, under closer scrutiny, various limitations are present from a specifically technical point of view, in particular at the level of recording techniques.

This project benefited from a thriving multi-disciplinary environment, from an insight into teamwork and collective thinking, and from a confrontation with many experts in various fields; nonetheless, it might have profited from a wider network of steady collaborators (such as semioticians, assistants in acoustics and recording, and philosophers), whereas it was mostly conducted as a solitary process. Solitary work allowed for the necessary concentration, but the further pursuit of this research might benefit from the inclusion of experts from other fields on a more regular basis.

Finally, I would like to list the new concepts that have emerged during the project, concepts that might be explored further in an eventual future research activity: (1) the definition of a "baroque paradigm" in the performance of written music, in confrontation and opposition to the "perspectival" and "reverse perspective" paradigms, also individuated by this research; (2) the invention and definition of the practice of "divergent performances" as a concrete proposition for going beyond traditional notions of interpretation and execution in the performance of written music; (3) the notions of the "anamorphic glance" and of "simulacrum" as new modalities for relating music performance to written music; (4) the redefinition-especially together with and with thanks to Paulo de Assis and the team of MusicExperiment21—of the musical work as an "assemblage" and of the music performer as an "operator"; (5) the application of the Deleuzian concept of "minoration" to the elements of stability in the performance of written music; (6) the formulation of a "phonocentric vision of music," and a proposition to move beyond it. 


\section{Five Glances upon the Unspeakable Body: Fifth and Last Glance}

The baroque is the regulating of the soul by corporal radioscopy.

In San Francesco a Ripa, on the left end, there is a niche, on the bottom there is porphyry and on top there is this "beyond-the-masterpiece" by Bernini, Blessed Ludovica Albertoni, with the carved little window by Bernini that is never crossed by the sun, whether rising or setting. There is this frozen thingthe limbs seem disjointed. This goes beyond the baroque, not only beyond polycentrism; it is a beyond, Bernini is going beyond himself. It is before and after words, it does not belong to discourse anymore. "Here art misses"; here really "earth and fate breathe": I know nothing else that is not, all the rest is art. The marble clothes of Blessed Ludovica do not envelop the body of the saint. There is simply no body: there is only this infinitely folded surface. There is no longer depth or height. What is most deep is the skin: in the skin the heights of meaning, the depths of function, are equally bypassed by the non-conscious, non-subjective, non-objective, affective layer of intensity. The body - the centre-is empty; anatomy fails. Brain and skin form a resonating vessel. Stimulation turns inward, is folded into the body, except that there is no inside for it to be in, because the body is radically open, and because the entire vibratory event is unconscious, out of mind. To belong to interiority does not mean only to "be inside," but to be on the "in-side" of the limit. The entire content of internal space is topologically in contact with the content of external space at the limits of the living. The subject lives and re-enacts its own embryonic development as a play of folds (endo-, meso-, and ectoderm) rather than as a battleground that pits the self against the world (like Michelangelo's David, contemplating an accomplished deed from the central position of the human, humanistic body). The subject does not "find a place" in the meaningful mesh of the culturally already-oriented space. Like Bernini's David, the body makes of itself an event of space, it creates a space by tentatively, riskily swirling away from its centre, towards the unknown: from world-reflecting to world-creating. A body on the run. Escaping, but without a new homeland to head to. Its escape is what shapes, time after time, the conditions for its existence. It does not anatomise the reality it brings in by projecting its perspectival, autopsic glance upon it. The outer world does not simply reflect the image of man as the centre of the universe. It does not reflect the imaginary, transcendental unity of the Platonic origin, but nor is it even limited within the boundaries of the human linguistic interface. Away with the height of the Platonic origin, of the self-originating Idea. But, also away with the depth of interiority, mind, heart. Away with a body that is understood as the deep and wild territory of instinct. Depth is a digestive illusion that complements the 
ideal optical illusion. Everything happens on the surface. The skin-faster than consciousness-is what gets hit, pricked, bruised by the external stimuli. The body becomes a hollow receiver of affections, transceiver of signals that, coming into contact with their own singularity, are transformed into a new materiality-the Real. The non-representational becomes then a possibility of production of the Real. The Real is no more thought of as the unrepresentable limit, but as that which unsettles and questions representation, exposing its redundancy, welcoming the excess and the paradox of intensity. This liberation of folds that are no longer merely reproducing the finite body is easily explained: a go-between — or go-betweens - are placed between clothing and the body. And when the folds of clothing spill out of painting, it is Bernini who endows them with sublime form in sculpture, when marble seizes and bears towards infinity folds that cannot be explained by the body, but by a spiritual adventure that can set the body ablaze. His is not an art of structures but of textures, as seen in the twenty marble forms he fashions. The body is as immediately abstract as it is concrete; its activity and expressivity extend, as on their underside, into an incorporeal, yet perfectly real, dimension of pressing potential. Although the realm of intensity is transcendental in the sense that it is not directly accessible to experience, it is not transcendent and it is not exactly outside experience either. It is immanent to it-always in it but not of it. Intensity and experience accompany one another, like two mutually presupposing dimensions, or like two sides of a coin. These could be seen not as binary oppositions or contradictions but as resonating levels. Affect is their point of emergence, in their actual specificity; and it is their vanishing point, in singularity, in their virtual coexistence and interconnection-that critical point shadowing every image/expression-event. The body, unlike the organisms of Leonardo da Vinci, is not made up of anatomical layers. Professional music analysis risks bypassing the body: the compositional treatises are ideological objects, whose sense consists in the nullification of the body. When asked to signify itself, bodily intensity can only do so in a paradox. There is disconnection of signifying order from intensity. Intensity is embodied in purely autonomic reactions most directly manifested in the skin - at the surface of the body. Depth reactions belong more to the form/content level; they are associated with expectation, which depends on consciously positioning oneself in a line of narrative continuity. Intensity is narratively de-localised, spreading over the generalised bodily surface. It is qualifiable as an emotional state, and that state is static. It is temporal and narrative noise. It is a state of suspense, potentially of disruption. It's like a temporal sink, a hole in time. Intensity can be called affect: a suspension of action-reaction circuits and linear temporality in a sink of what might be called "passion," to distinguish it both from passivity and activity. A new harmony, enslaved by the rhetorical rhythm of words, not regulated by actions and reactions of dissonance and consonance; where each chord functions as a moment of suspense, where dissonance is let loose and is bound only to the emergence of an intensity, of an affect. Matter equals energy. The production of the real is an intensive magnitude that starts at zero. If the body without organs is a limit, if one is forever 
attaining it, it is because behind each stratum, encasted in it, there is always another stratum. This is because many a stratum, and not only an organism, is necessary to make the judgement of God. A perpetual and violent combat occurs between the plane of consistency, which frees the body without organs cutting across and dismantling all the strata, and the surfaces of stratification that block it or make it recoil. The centrifugal forces do not flee the centre forever, but approach it once again, only to retreat from it yet again: such is the nature of the violent oscillations that overwhelm an individual so long as he seeks only his own centre and is incapable of seeing the circle of which he himself is a part. For, if these oscillations overwhelm him, it is because each one of them corresponds to an individual other than the one he believes himself to be, from the point of view of the unbeatable centre: it turns. That fact still has a great deal of value for us, as reduced as it may be in the final analysis, motivated only by the fact that the earth turns and that it therefore seems to us that it is the celestial sphere that turns. The earth continues to turn and that has all sorts of effects, for example, the fact that you count your age in years. The subversion, if it existed somewhere, at some time, was not that of having changed the point around which it circles-it is that of having replaced "it turns" with "it falls."

This text has been assembled with quotations from Jacques Lacan (1998), Carmelo Bene (1994, my translation), Gilles Deleuze ([1990] 2004, [1993] 2006), Gilles Deleuze and Félix Guattari (1987), Brian Massumi (1995), Pierre Klossowski (from Nietzsche et le cercle vicieux, as quoted in Deleuze and Guattari [1977] 1983), Roland Barthes (1985b), Ian Buchanan (2008), and myself. 


\section{References}

Adorno, Theodor W. 2006. Towards a Theory of Musical Reproduction: Notes, a Draft and Two Schemata. Edited by Henri Lonitz. Translated by Wieland Hoban. Cambridge: Polity. First published 2001 as $Z u$ einer Theorie der musikalischen Reproduktion: Aufzeichnungen, ein Entwurf und zwei Schemata (Frankfurt am Main: Suhrkamp).

Angius, Marco. 2007. Come avvicinare il silenzio: La musica di Salvatore Sciarrino. Rome: Rai-ERI.

Argan, Carlo Giulio. 2003. "Vita e opere de Gian Lorenzo Bernini.” Tesori di Roma. Accessed 24 February 2016. http:// www.tesoridiroma.net/pittori_scultori/ bernini_roma.html.

Artaud, Antonin. 1965. Anthology. Edited by Jack Hirschman. San Francisco: City Light Books.

- (1976) 1988. "To Have Done with the Judgment of God." In Antonin Artaud: Selected Writings, edited by Susan Sontag, translated by Helen Weaver, $555^{-71}$. Berkeley: University of California Press. Written as a radio play in $1947-48$. This edition first published 1976 (New York: Farrar, Strauss and Giroux).

Assis, Paulo de. 2012. "Experimentation versus Interpretation. Exploring New Paths in Music Performance in the Twenty-First Century: 1. On Interpretation. Music as Text." MusicExperiment21. Accessed 3 January 2018. https://musicexperiment21. eu/programme/1-on-interpretationmusic-as-text/.

_- - 2016. Abstract of the paper "Virtual Works-Actual Things.” In Virtual Works-Actual Things: International Orpheus Academy for Music and Theory 2016, 22. Accessed 18 January 2018. https:// issuu.com/me21collective/docs/orpheus_ international_academy_2016_. - 2017. "Rasch24: The Somatheme." In Artistic Research in Music: Discipline and Resistance; Artists and Researchers at the Orpheus Institute, edited by Jonathan Impett, 15-42. Orpheus Institute Series. Leuven: Leuven University Press. . 2018. Logic of Experimentation: Rethinking Music Performance through
Artistic Research. Orpheus Institute Series. Leuven: Leuven University Press.

Assis, Paulo de, and Lucia D'Errico. 2017. Rasch $^{X}$. Accessed 18 January 2018. https://www.researchcatalogue.net/ view/64319/64320.

Baltrušaitis, Jurgis. 1977. Anamorphic Art. Translated by W. J. Strachan. New York: Harry N. Abrams. First published 1969 as Anamorphoses; ou, Magie artificielle des effets merveilleux (Paris: Olivier Perrin).

Barthes, Roland. 1985a. "Loving Schumann." In Barthes 1985c, 293-98. First published 1979 as "Aimer Schumann," preface to $L a$ musique pour piano de Schumann by Marcel Beaufils (Paris: Phébus), 9-16.

- - 1985b. "Rasch." In Barthes 1985c, 299-312. First published 1975 as "Rasch," in Langue, discours, société: Pour Émile Benveniste, edited by Julia Kristeva, JeanClaude Milner, and Nicolas Ruwet (Paris: Seuil).

.1985 c. The Responsibility of Forms: Critical Essays on Music, Art, and Representation. Translated by Richard Howard. Berkeley: University of California Press. First published 1982 as L'obvie et l'obtus: Essais critiques III, edited by F.W. (Paris: Seuil).

Bene, Carmelo. 1994. "Uno contro tutti: Carmelo Bene.” Maurizio Costanzo Show, Canale 5, 27 June 1994.

——_. 2001. "Quarto momento: Arte." Episode 4 of Quattro momenti su tutto il nulla, broadcast by RAI, May 2001. YouTube video, 20:45. Accessed 25 January 2016. https://www.youtube.com/ watch? $\mathrm{v}=\mathrm{aJoEjAiD} 2 \mathrm{ao}$.

__- . 2013. Sono apparso alla Madonna. $4^{\text {th }}$ ed. Milan: Bompiani.

Bene, Carmelo, Maurizio Grande, Giancarlo Dotto, and Cosimo Cinieri. 1984a. Phoné e delirio. Seminar at Università "La Sapienza" Rome. YouTube video, 69:47. Accessed 23 January 2018. https://www. youtube.com/watch? v=zhcnHRMXZ94. .1984b. Phoné e immagine. Seminar at Università "La Sapienza" Rome. YouTube video, 72:34. Accessed 23 January 2018. https://www.youtube.com/ watch? $\mathrm{v}=\mathrm{iXHjNhpgbDY}$. 


\section{References}

Benjamin, Walter. 2008. The Work of Art in the Age of Its Technological Reproducibility, and Other Writings on Media. Edited by Michael W. Jennings, Brigid Doherty, and Thomas Y. Levin. Cambridge, MA: Harvard University Press. Essay first published 1936 as "L'œuvre d'art à l'époque de sa reproduction mécanisée" (Zeitschrift für Sozialforschung 5 [1]: 40-68).

Bonnefoy, Yves. 2000. Rome 1630: L'horizon du premier baroque. Nouvelle éd. Paris: Flammarion.

Boucquet, Kristof. 2009. “'Die Uninterpretierbarkeit der Musik': Adorno's Theory of Musical Reproduction." Dutch Journal of Music Theory 14 (1): 42-50.

Boundas, Constantin V. 2005. "Subjectivity." In The Deleuze Dictionary, edited by Adrian Parr, 268-70. Edinburgh: Edinburgh University Press.

Buchanan, Ian. 2008. Deleuze and Guattari's Anti-Oedipus: A Reader's Guide. London: Continuum.

Buchloh, Benjamin H. D. 2004. "Deskilling." In Art Since 190o: Modernism, Antimodernism, Postmodernism, edited by Hal Foster, Rosalind Krauss, Yves-Alain Bois, and Benjamin H. D. Buchloh, 531. London: Thames \& Hudson.

Buci-Glucksmann, Christine. 1994. Baroque Reason: The Aesthetics of Modernity. Translated by Patrick Camiller. London: Sage. First published 1984 as La raison baroque: De Baudelaire à Benjamin (Paris: Galilée).

—_- 2013. The Madness of Vision: On Baroque Aesthetics. Translated by Dorothy Z. Baker. Athens: Ohio University Press. First published 1986 as La folie du voir: De l'esthétique baroque (Paris: Galilée).

Burn, Ian. 1981. "The Sixties: Crisis and Aftermath (Or The Memoirs of an ExConceptual Artist)." Art and Text, Autumn: 49-65.

Cage, John. 1961. Silence: Lectures and Writings. Middletown, CT: Wesleyan University Press.

Cambria, Florinda. 2012. "Dramma e materia: Sul 'materialismo assoluto' di Antonin Artaud." Noéma 3. Accessed 19 January 2018. https://riviste. unimi.it/index.php/noema/article/ view/2521/2761.

Caporaletti, Vincenzo. 2014. Swing e Groove: Sui fondamenti estetici delle musiche audiotattili. Rev. ed. Lucca: LIM.

Carratelli, Carlo. 2006. "L'integrazione dell'estesico nel poietico nella poetica musicale post-strutturalista: Il caso di Salvatore Sciarrino, una "composizione dell'ascolto.” PhD thesis, Università degli studi di Trento and Université de Paris IV-Sorbonne.

Danuser, Hermann. 2015. "ExecutionInterpretation-Performance: The History of a Terminological Conflict." In Experimental Affinities in Music, edited by Paulo de Assis, 177-96. Orpheus Institute Series. Leuven: Leuven University Press.

Deleuze, Gilles. (1972) 200o. Proust and Signs. Translated by Richard Howard. London: Athlone Press. First published 1964 as Proust et les signes (Paris: Presses universitaires de France). Translation first published 1972 (New York: G. Braziller). . (1990) 2004. The Logic of Sense.

Translated by Mark Lester with Charles Stivale. Edited by Constantin V. Boundas. London: Continuum. First published 1969 as Logique du sens (Paris: Minuit). This translation first published 1990 (New York: Columbia University Press). - (1993) 2006. The Fold: Leibniz and the Baroque. Translated by Tom Conley. London: Continuum. First published 1988 as Le Pli: Leibniz et le Baroque (Paris: Minuit). This translation first published 1993 (London: Athlone Press).

_—_. 1995. "Letter to a Harsh Critic." In Negotiations, 1972-1990, translated by Martin Joughin, $3^{-12}$. New York: Columbia University Press. Essay first published 1973 in Michel Cressole, Deleuze (Paris: Éditions universitaires). Book first published 1990 as Pourparlers: 1972-1990 (Paris: Minuit). - 1997. "One Less Manifesto." Translated by Eliane dal Molin and Timothy Murray. In Mimesis, Masochism, and Mime: The Politics of Theatricality in Contemporary French Thought, edited by Timothy Murray, 239-58. Ann Arbor: University of Michigan Press. First published 1979 as "Un manifeste de moins" in Superpositions by Carmelo Bene and Gilles Deleuze (Paris: Minuit), $85^{-131 .}$

\footnotetext{
- - 2003. Francis Bacon: The Logic of Sensation. Translated by Daniel W. Smith. London: Continuum. First published
} 


\section{References}

1981 as Francis Bacon: Logique de la sensation (Paris: Éditions de la Différence).

Deleuze, Gilles, and Félix Guattari. (1977) 1983. Anti-Oedipus: Capitalism and Schizophrenia. Translated by Robert Hurley, Mark Seem, and Helen R. Lane. Minneapolis: University of Minnesota Press. First published 1972 as Capitalisme et schizophrénie: L'anti-CEdipe (Paris: Minuit). Translation first published 1977 (New York: Viking Press). 1986. Kafka: Toward a Minor

Literature. Translated by Dana Polan. Minneapolis: University of Minnesota Press. First published 1975 as Kafka: Pour une littérature mineure (Paris: Minuit).

-1987. A Thousand Plateaus: Capitalism and Schizophrenia. Translated by Brian Massumi. Minneapolis: University of Minnesota Press. First published 1980 as Capitalisme et schizophrénie: Mille plateaux (Paris: Minuit).

Derrida, Jacques. (1978) 2005. "The Theater of Cruelty and the Closure of Representation." In Writing and Difference, translated by Alan Bass, 292-316. London: Routledge. Essay first published 1966 as "Le théâtre de la cruauté et la clôture de la représentation” (Critique 230). Book first published 1967 as L'écriture et la différence (Paris: Seuil). This translation first published 1978 (Chicago: University of Chicago Press; London: Routledge and Kegan Paul).

- - 1997. Of Grammatology. Translated by Gayatri Chakravorty Spivak. Corrected ed. Baltimore: Johns Hopkins University Press. First published 1967 as De la grammatologie (Paris: Minuit).

Di Ciaccia, Antonio, and Massimo Recalcati. 200o. Jacques Lacan: Un insegnamento sul sapere dell'inconscio. Milan: Bruno Mondadori.

Dreyfus, Laurence. 2007. "Beyond the Interpretation of Music." Dutch Journal of Music Theory 12 (3): 253-72.

Ernst, Wolfgang. 2013. Digital Memory and the Archive. Edited by Jussi Parikka. Minneapolis: University of Minnesota Press.

Florensky, Pavel. 2002. "Reverse Perspective." In Beyond Vision: Essays on the Perception of Art, edited by Nicoletta Misler, translated by Wendy Salmond, 197-272. London: Reaktion Books. Essay first delivered as the lecture "Obratnaia perspektiva" in 1920.

Geyskens, Tomas. 2010. "Painting as Hysteria-Deleuze on Bacon.” In Sexuality and Psychoanalysis: Philosophical Criticism, edited by Jens De Vleminck and Eran Dorfman, 215-30. Leuven: Leuven University Press.

Giacchè, Piergiorgio. 1997. Carmelo Bene: Antropologia di una macchina attoriale. Milan: Bompiani.

Giacco, Grazia. 2003. La notion de figure chez Salvatore Sciarrino. Paris: L'harmattan.

Goodman, Nelson. (1968) 1976. Languages of Art: An Approach to a Theory of Symbols. Indianapolis: Hackett. First published 1968 (Indianapolis: Bobbs-Merrill).

Grant, Morag Josephine. 2003. "Experimental Music Semiotics." International Review of the Aesthetics and Sociology of Music 34 (2): 173-91.

Hurst, Andrea. 2008. Derrida vis-à-vis Lacan: Interweaving Deconstruction and Psychoanalysis. New York: Fordham University Press.

Isidore of Seville. (c.635) 1472. Etymologiarum sive Originum libri xx. Augsburg: Günther Zainer. Written c.635. Translated by Stephen A. Barney et al. as Isidore of Seville 2006. . 2006. The Etymologies of Isidore of Seville. Translated by Stephen A. Barney, W. J. Lewis, J. A. Beach, and Oliver Berghof. Cambridge: Cambridge University Press. For further bibliographic details, see Isidore of Seville (c.632) 1472.

Lacan, Jacques. (1977) 1998. The Seminar of Jacques Lacan; Book XI: The Four Fundamental Concepts of Psychoanalysis. Edited by Jacques-Alain Miller. Translated by Alan Sheridan. New York: W. W. Norton. First published 1973 as Le séminaire de Jacques Lacan, Livre XI: Les quatre concepts fondamentaux de la psychanalyse (Paris: Seuil). This translation first published 1977 (London: Hogarth Press).

- 1998. The Seminar of Jacques Lacan; Book XX: Encore 1972-1973; On Feminine Sexuality, the Limits of Love and Knowledge. Edited by Jacques-Alain Miller. Translated by Bruce Fink. New York: W. W. Norton. First published 1975 as Le séminaire de Jacques Lacan: Livre XX, Encore 1972-1973 


\section{References}

(Paris: Seuil).

. 2006a. "The Direction of the

Treatment and the Principles of its Power." In Ècrits, translated by Bruce Fink, 489-542. New York: Norton. Essay first delivered as a paper in 1958. Book first published 1966 as Écrits (Paris: Seuil). - 2006b. "The Mirror Stage as Formative of the $I$ Function as Revealed in Psychoanalytic Experience." In Ėcrits, translated by Bruce Fink, $75^{-81}$. New York: Norton. Essay first delivered as a paper in 1949. Book first published 1966 as Écrits (Paris: Seuil).

Lachenmann, Helmut. 2004. "Philosophy of Composition-Is There Such a Thing?" In Identity and Difference: Essays on Music, Language and Time, edited by Frank Agsteribbe, Sylvester Beelaert, Peter Dejans, and Jeroen D'hoe, 55-70. Collected Writings of the Orpheus Institute. Leuven: Leuven University Press.

Landolfi, Tommaso. 2012. Rien va. 2nd ed. Milan: Adelphi.

Lundy, Craig. 2009. "Deleuze's Untimely: Uses and Abuses in the Appropriation of Nietzsche." In Deleuze and History, edited by Jeffrey A. Bell and Claire Colebrook, 188-205. Edinburgh: Edinburgh University Press.

Massumi, Brian. 1992. A User's Guide to Capitalism and Schizophrenia: Deviations from Deleuze and Guattari. Cambridge, MA: MIT Press.

- 1995. "The Autonomy of Affect."

In "The Politics of Systems and Environments, Part II," special issue, Cultural Critique 31: 83-110.

McClary, Susan. 2007. "Towards a History of Harmonic Tonality." In Towards Tonality: Aspects of Baroque Music Theory, edited by Peter Dejans, 91-117. Collected Writings of the Orpheus Institute. Leuven: Leuven University Press.

Murray, Ros. 2014. Antonin Artaud: The Scum of the Soul. New York: Palgrave MacMillan.

Nattiez, Jean-Jacques. 1990. Music and Discourse: Toward a Semiology of Music. Translated by Carolyn Abbate. Princeton, NJ: Princeton University Press. First published 1987 as Musicologie générale et sémiologie (Paris: Christian Bourgois).

Nietzsche, Friedrich. 1997. "On the Uses and Disadvantages of History for Life."
In Untimely Meditations, edited by Daniel Breazeale, translated by R. J. Hollingdale, 60-123. Cambridge: Cambridge University Press. Essay first published 1874 as "Vom Nutzen und Nachteil der Historie für das Leben," 2nd part of Unzeitgemässe Betrachtungen (Leipzig: Fritzsch, 1873-76).

Poxon, Judith L., and Charles J. Stivale. 2005. "Sense, Series." In Gilles Deleuze: Key Concepts, edited by Charles J. Stivale, 65-76. Montreal and Kingston: McGillQueen's University Press.

Recalcati, Massimo. 2011. "Arte e tradizione: Quella tela bianca nel processo creativo.” La Repubblica, 27 November 2011. Accessed 3 January 2018. http://ricerca. repubblica.it/repubblica/archivio/ repubblica/2011/11/27/arte-tradizionequella-tela-bianca-nel-processo.html.

Roffe, Jonathan. 2005. "Hysteria." In The Deleuze Dictionary, edited by Adrian Parr, 122-23. Edinburgh: Edinburgh University Press.

Saussure, Ferdinand de. (1983) 2013. Course in General Linguistics. Translated and edited by Roy Harris. London: Bloomsbury. First published 1916 as Cours de linguistique génrale (Paris: Payot). This translation first published 1983 (London: Duckworth).

Sciarrino, Salvatore. 1984. Lohengrin: Azione invisibile. Milan: Ricordi.

___ 1998. Le figure della musica $d a$ Beethoven a oggi. Milan: Ricordi.

___. 2001. Carte da suono: 1981-2001. Palermo: Comitato Nazionale Italiano Musica.

Sini, Carlo. 2014. "La materia del soggetto." Noéma 6 (1). Accessed 14 February 2018. https://riviste.unimi.it/index.php/ noema/issue/view/627.

Society for Artistic Research. 2018. "Research Catalogue.” Accessed 14 February 2018. http://www.societyforartisticresearch. org/rc/research-catalogue/.

Spivak, Gayatri Chakravorty. 1997. “Translator's Preface.” In Derrida 1997, ix-lxxxvii.

Stravinsky, Igor. 1947. Poetics of Music in the Form of Six Lessons. Translated by Arthur Knodel and Ingolf Dahl. Cambridge, MA: Harvard University Press. First published 1942 as Poétique musicale sous forme de six leçons (Cambridge, MA: Harvard University Press). 


\section{References}

Sylvester, David. (1975) 1999. Interviews with Francis Bacon: The Brutality of Fact. New York: Thames and Hudson. First published 1975 (London: Thames and Hudson).

\section{Musical Works}

Beethoven, Ludwig van. 1862-65. Diabelli Variations, op. 120. In Ludwig van Beethovens Werke, Serie 17: Variationen für das Pianoforte, No. 165, 37-70. Leipzig: Breitkopf und Härtel.

Caccini, Giulio. 1602. Le nuove musiche. Florence: Giorgio Marescotti.

Cage, John. 1951. Music of Changes. Frankfurt: Peters.

. 1990. cComposed Improvisation No. 1. Frankfurt: Peters.

D'India, Sigismondo. 1609. Le musiche di Sigismondo D'India, nobile palermitano: da cantar solo nel clavicordo, chitarone, arpa doppia et altri istromenti simili. Milan: Appresso l'herede di Simon Tini, \& Filippo Lomazzo.

Kircher, Athanasius. 1643. Magnes sive de arte magnetica. Rome: apud Iodocum Kalcoven.

Monteverdi, Claudio. 1931. Lincoronazione di Poppea. Edited by G. Francesco Malipiero. Vienna: Universal Edition.

Romitelli, Fausto. 1998-200o. Professor Bad Trip. Milan: Ricordi.

- 2003. An Index of Metals. Milan: Ricordi.
Tarasti, Eero. 1994. A Theory of Musical Semiotics. Bloomington: Indiana University Press. - 2015. Sein und Schein: Explorations in Existential Semiotics. Berlin: De Gruyter.

Schumann, Robert. 1879-1912. Dichterliebe, op. 48. In Robert Schumanns Werke, Serie XIII: Für eine Singstimme, mit Begleitung des Pianoforte. Leipzig: Breitkopf \& Härtel. - 1885. Kreisleriana, op. 16. In Robert Schumanns Werke, Serie VII: Für Pianoforte zu zwei Händen. Leipzig: Breitkopf \& Härtel.

Sciarrino, Salvatore. 1976. 6 capricci, per violino. Milan: Ricordi.

___ 1979. Aspern Suite. Milan: Ricordi. -1984. Lohengrin: Azione invisibile. Milan: Ricordi.

__- 1986. Esplorazione del bianco II. Milan: Ricordi.

——_. 1987. Vanitas: Natura morta in un atto, per voce [mezzosoprano], violoncello e pianoforte. Milan: Ricordi.

. 1998. Luci mie traditrici. Milan: Ricordi.

Vicentino, Nicola. 1990. Four Enharmonic Madrigals. Edited by Alexander Silbiger. Utrecht: Diapason Press.

Visée, Robert de. 1944. Suite in D Minor. Edited by Karl Scheit. Vienna: Universal Edition. 
Multimedia Link

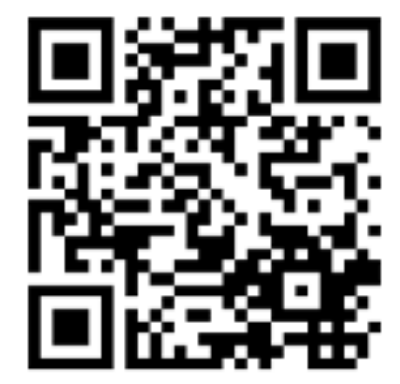

As further illustration to this publication, an online repository of audio and video examples, scores, and images has been created. These examples, which should be viewed in connection with a reading of the relevant material in this book, may all be accessed under the URL www.orpheusinstituut.be/en/ powersofdivergence. 



\section{Biographical Note}

Lucia D'Errico is a musician and artistic researcher. She performs on guitar and other plucked-stringed instruments, with a particular focus on Western notated art music of the twentieth and twenty-first centuries. A research fellow at the Orpheus Institute (Ghent, Belgium), from 2014 to 2018 she was part of the research project MusicExperiment21, with which she explored notions of experimentation in the performance of notated music in the Western tradition as an expansion of/in opposition to traditional practices of musical interpretation. She holds a PhD from KU Leuven (docARTES programme) and a master's degree in English literature, and is also active as a graphic artist and video performer. 

Adorno, Theodor W., 26, 51-53, 59, 81, 184-85 affect, $31,63,72,99,106,108,135,139,146,148-49$, $161-63,182$

Affektenlehre, 67

aleatoric music, 74

anamorphosis, 22-23, 27-29, 44, 58-59, 62-63, 69, 87, $106-7,112,115,139,172-73,180$

Angius, Marco, 112, 114, 116-17, 138, 140, 156, 184

aphasia, 56, 90, 144

architecture, 84, 89, 121

Argan, Giulio Carlo, 88, 184

Aristotle, 79

Artaud, Antonin, 24, 27-28, 31, 55, 121-22, 125, 129-32, $145,162-64,166,184-85,187$

artistic research, 13-14, 28, 34, 128, 134, 179

assemblage, 19, 21, 29, 105, 108, 118, 141, 180

Assis, Paulo de, 7, 14, 19, 93, 108-9, 167, 180, 184-85

authority, 16, 18, 42, 48, 116, 121, 138, 157

automaton, $55^{-56}, 79-82,111-12,124,127,151$

Babbitt, Milton, 71

Bacon, Francis, 22, 27, 30, 33-34, 6o, 82, 101, 103-4, $106,113,123,127,136,140-41,145^{-} 47,159,162$, $185^{-86,188}$

Baltrušaitis, Jurgis, 22, 28, 44, 184

baroque, 16, 21-22, 24-28, 30, 43-46, 59, 61-64, $66-67,82-84,88,90,96,106,112-13,122,127$, $135-36,139,153-54,158,173,176,180-81,185,187$

Barthes, Roland, 24, 28, 31, 90, 93-94, 108-10, 129, $162-63,165,177,183-84$

Bartók, Béla, 114

becoming, 27, 92, 94, 112, 122-23, 135-37, 150-51, 154 $157-58,165$

Beethoven, Ludwig van, 29, 58, 74, 114, 116, 155, 167, $173-74,187-88$

being-heard-ness, 11, 74-76, 78, 114-15, 131-32, 141 , $145-46,155$

Bene, Carmelo, 22, 27-28, 30, 121-28, 133, 136-40, $143^{-46,149,151,157-58,183-86}$

Benjamin, Walter, 75,185

Bernini, Gian Lorenzo, 21-22, 27, 30-31, 61, 88-92, 99, $106,111,113^{-14}, 127,136,158,181-82,184$

body without organs, $24,28,31,56-57,94^{-95}, 129-30$, 182

Bonnefoy, Yves, 28, 43, 62, 89, 154, 185

Boucquet, Kristof, 51, 185

Boulez, Pierre, 71

Boundas, Constantin V., 149, 185

Brunelleschi, Filippo, 20, 37-39, 41, 53, 61-62, 75, 81

Buchanan, Ian, 183,185

Buchloh, Benjamin H. D., 143, 185

Buci-Glucksmann, Christine, 22, 28, 61-62, 88, 90-91, $101,127,157,185$

Buonarroti, Michelangelo. See Michelangelo

Burn, Ian, 143, 185

Byron, George Gordon, Lord, 122

Byzantine art, 39, 43, 45, 61, 89

C

Caccini, Giulio, 29, 47, 96, 99, 135, 167, 170, 188

Cage, John, 26, 72-73, 113, 146, 185, 188

Cambria, Florinda, 130,185

Camus, Albert, 122

Caporaletti, Vincenzo, 26, 75, 185

Caravaggio, 88-89
Carmichael, Hoagy, 115

Carratelli, Carlo, 113, 115, 185

chance, $69,144-47,158$

codification, 7, 15-17, 20-21, 26, 29-30, 35, 39, 45, 47, $59,73,75^{-76}, 106,121,123,131,143,162$

cognition, $111,113,158$

composition, 7, 15-16, 20-21, 28, 35, 48, 67-69, 70, $73^{-74}, 81,84,104,108,111-12,114,116,118,121$, $132,140-41,156-57,160,173,179$

consciousness, $47,54^{-}-55,61,76,111,131^{-}-32,136,151$, $154,161,163-66,182$

Copernican revolution, $24,45^{-46,53,88,128}$

D

Danuser, Hermann, 15, 18, 185

Debussy, Claude, 114

deconstruction, 55

deformation, 62, 67, 69, 139-41, 151, 154, 158, 168, 174 de Jong, Henk, 137

Deleuze, Gilles, 18, 21, 24, 27-28, 31, 56-57, 62-63, $65-66,80,82-83,89,91,94-95,101-2,104-6$, $122-23,126-27,129,135^{-}-40,143,146-52,157,159$, $180,183,185^{-87}$

Derrida, Jacques, 17, 21, 27, 30, 49, 50-51, 53-55,

$80-81,83,113,121,125-26,144-45,163,186-87$

Diabelli, Anton, 173

Di Ciaccia, Antonio, 50, 186

d'India, Sigismondo, 29, 59, 167, 171-72

dissipation, $113,141,15^{8}$

divergence, $7,21,24,27,45,56,64,66,83,119,135$,

$139,143,147,156$

divergent performance, $11,15,25^{-26}, 28,36,67,69,74$, $87,118-19,133-35,168-72,173-77,180$

Dreyfus, Laurence, 15, 18, 71, 122, 186

Dürer, Albrecht, 153

E

episteme, 18, 24, 88

Ernst, Wolfgang, 26, 75, 186

Euclid, 37

Euclidean space, 44, 53, 61-63, 66, 79, 81, 92, 112, $140,163,164$

execution, $7,11,19-20,35,68-69,81,102,134,157$,

$179-80$

executants, $7,53,57,148,164$

experimental music, 16

experimentation, $7,14,25,36,56,58,69,95,129$, $132-33,173,184$

expressivity, 7, 34, 57, 148-49, 182

extensive, $24,28,44,61-63,66,86,93,106,124,128$, 130, 135, 142, 154, 159, 171

$\mathbf{F}$

Ferneyhough, Brian, 26, 72-73

figuration, $33,82,102,146-47,178$

Florensky, Pavel, 28, 37, 39, 73, 79-81, 186

Freud, Sigmund,

Freudianism, 8o, 105

Galileo Galilei, 92

Gesualdo, Carlo, 116

Geyskens, Tomas, 105, 186

Giacchè, Piergiorgio, 122, 124-25, 127, 138, 140, 149 , 158, 186

Giacco, Grazia, 116, 156, 186

Gilmore, Bob, 168 
Giotto, 20

Goodman, Nelson, 51, 186

Gould, Glenn, 66

Grande, Maurizio, 124, 151, 184

Grant, Morag J., 16, 186

Guattari, Félix, 18, 24, 27-28, 31, 56-57, 94-95, 123 , $129,135,137,140,149^{-}-50,15^{2}, 183,185^{-87}$ guitar, 29, 47, 84, 118-20, 167-71, 176

hermeneutics, $25,128,138$

history, 22, 28, 116, 123, 136-38, 149, 156, 164, 179

Holbein, Hans, 23

Horowitz, Vladimir, 177

Hurst, Andrea, 79-80, 186

hysteria, $105^{-6}, 147,186-87$

hystericisation, $105^{-6}, 13^{-4}-40$

I

identity, $7,35,37,41^{-43}, 47^{-} 50,53^{-54}, 61,66,68$, $73^{-74}, 79,86,89,102,123,141,145^{-46}, 148,15$, $155^{-56}$

illustration, 33-34, 40, 127, 162

improvisation, $16,29,42,47-48,58,73,77,96,99$, $126-27,145,147,171$

inscription, $13-15,34,36,43,55,67-68,71,73,80,86$, $89,102,106,112,121,124-26,132,140,144,147$, $150-51,155,157-58,160,162,166$

intensity, 19, 56-57, 62, 66, 93, 121, 141, 146, 149, $161-65,171,181-82$

intensive, 24, 31, 61-62, 93, 105, 107, 135, 140, 159, 163, 165,182

interpretation, $7,11,13-15,18-21,24-27,34-35,41$, $48,55,57,59,63,66,68-69,71-73,76,78,81,96$ 99, 102, 109, 121-22, 124-26, 132, 134-36, 138 , $141,146-49,15^{2-} 53,15^{6}-58,164-65,173,179-80$, $184-86$

interpreters, $7,17-18,25^{-26}, 33^{-35}, 48,57,60,66$, $70-73,78,94,102,117,120-22,125^{-26}, 129,144$, $147-48,155^{-5} 6,164$

Isidore of Seville, 76, 186

isolation, $86,114,127,139-41,158,168$

jazz, 145

$\mathbf{K}$

Kant, Immanuel,

Kantianism, 79

Keplerian revolution, 24, 27, 45-46, 128

Kepler, Johannes, 24, 88

Kircher, Athanasius, 29, 118-19, 167-68, 188

Klossowski, Pierre, 183

L

Lacan, Jacques, 17, 22, 27, 30, 45, 49-51, 53, 61, 66, $79-81,88,105,131,183,186$ mirror stage, $27,49,61$

Lachenmann, Helmut, 141-43, 187

Laforgue, Jules, 122

Landolfi, Tommaso, 128, 187

language, $17,19-20,26-28,30,50,51,55,61,71,81-82$, $90,94,105,111,113,123,130,132,134,140-41$, $143-44,146,149,162-63$

Le Jeune, Claude, 114

Liekens, Johan, 84-86, 167

linear perspective, $20-21,28,37-38,79-80$ logocentrism, 49, 8o, 82, 121, 128, 148, 163

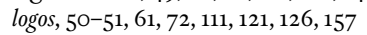

Lundy, Craig, 136-37, 187

M

manifold, 29, 109

Marlowe, Christopher, 122, 138

Massumi, Brian, 28, 31, 149, 152, 161-65, 183, 186-87

materiality, $7,13,15^{-16}, 20-21,24,26,28,33-36,47$,

$53,56-57,60-61,63,66-67,69,71-72,78,83-84$,

$88-89,92,96,106,112-13,115,121-22,124,126$,

$129-32,147,155,163-64,182$

McClary, Susan, 96-97, 187

media theory, 26, 29, 179

memory, $36,5^{8-59}, 67,76,84,87,91,114-16,120,124$, $148-51,162,168$

metaphysics of presence, $27,55,80,145,163$

Michelangelo, 21, 92, 181

minoration, 26-27, 123, 136-38, 146, 152, 159-60, 180

Molino, Jean, 70

Monteiro Freitas, Marlene, 135, 167

Monteverdi, Claudio, 29, 119, 167, 177, 188

Murray, Ros, 129-32, 187

musical work, 7, 11, 14-16, 19-20, 25-26, 28-29, 34-35,

$42,53,58,66,73,80,85,96,102,108-9,111,118$,

$138,140,149^{-} 50,156-60,164-65,180$

music analysis, 16, 24, 26, 52, 66, 109, 128, 163, 182

MusicExperiment21, 7, 14-15, 19, 58, 108-9, 180, 184

musicology, 14, 18, 24, 26, $5^{2}$

\section{$\mathbf{N}$}

narrativity, 132, 139, 161, 163

Nattiez, Jean-Jacques, 26, 42, 51, 70-71, 73, 187

New Complexity, 153

Nietzsche, Friedrich, 136-38, 183, 187

notation, $14^{-15}, 17-19,21,26,33,35,43,47^{-54}, 5^{8-59}$ $63,68,71-77,81,84,131,143,153$

O

objectivity, 7, 34-35, 48, 57, 69, 128, 136, 148, 164 operators, $125,127,147-50,152,156-58,180$

organisms, 16, 24, 50, 53, 56-57, 70, 86, 94-95, 113 , 129-30, 135, 182-83

origins, $7,55^{-5} 6,63,72,80,83,88,111,116-17,125^{-26}$, $137-38,150,154-55,162-63,181$

Orpheus Institute, 7, 184-85, 187, 196

Orthodox art, 39, 61

$\mathbf{P}$

Paganini, Niccolò, 116

painting, $23,33-34,39,41,53,58-59,73,79-80,82$, $101,103-6,121,128,139,144,146-47,158,182$

Palladio, Andrea,

Palladian style, 89

perception, $30,33,47,55,58,71,73,75^{-76}, 81,87$, $89-90,111,113,115,131,141-42,150,155$

performance studies, 14, 26

phenomenology, 26-27, 81

phonocentrism, 21, 26-27, 30, 49-50, 52-53, 72-74, $76,121,141,143,146,155,163,180$

phonographic inscription, $29,35^{-}-36,58,71,75,131$, 148

photography, 20, 79, 101

Pink Floyd, 142

Plato,

Platonism, 7, 27, 56, 65-66, 89, 101-2, 132, 145, 147, 155,181 


\section{Index}

Pollock, Jackson, 147

post-structural philosophy, 27

Poxon, Judith, 155,187

primary work, $11,34-36,47-48,58-60,66-69,86-87$, $105^{-6}, 109,118,133^{-} 35,13^{-4}-40,151,154^{-55}$, $158-59,168-78$

psychoanalysis, 105

Ptolemaic system, 52

Puccini, Giacomo, 114

Recalcati, Massimo, 13, 50, 186-87

Renaissance, 21, 37, 74

repertoire, 16, 102, 122, 126, 142, 164, 179

representation, $13,17,20^{-21}, 25^{-27}, 30^{-}-31,33^{-34}$,

$37,41,43-45,49^{-5}$ O, 53, 55-58, 61-62, 68, 73 ,

$75,79-82,88,101-2,105,111-13,121-23,125,127$,

129-31, 137, 139-40, $145,147,150,153,155,157$,

159,182

Research Catalogue, 134, 187

resemblance, $7,13,16,34,36,47-48,56,59,62,65-68$

$80,88-89,101-2,104,133-34,155,171-73$

reverse perspective, $39-43,45,63,73,79,82,180$

Roffe, Jonathan, 106, 187

Romitelli, Fausto, 142, 188

Rossini, Gioacchino, 114, 116

Rousseau, Jean-Jacques, 50

Rublev, Andrei, 40

Russolo, Luigi, 141, 143

Saussure, Ferdinand de, 17, 19, 50, 131, 187

Schaeffer, Pierre, 42, 71, 141

Schubert, Franz, 116

Schumann, Robert, 24, 28-29, 31, 58, 93-94, 108-9, $163,167,174-75,177,184,188$

Sciarrino, Salvatore, 22, 26, 30, 111-17, 127, 136, 138, $140-43,156-59,184-88$

sculpture, $58,121,182$

seconda prattica, 173

semiology, 18, 24, 93, 109, 129, 163

semiotics, $13,16-18,24,26,28,5^{2}, 55,5^{8}, 112-13,121$, $135,163,179$

sensation, $36,59,104-6,139,15^{0-51}$ serialism, 71-72, 74, 111-14

Shakespeare, William, 122, 138

Sheredega, Natalya, 40

simulacrum, 7, 27, 30, 56, 62, 65-66, 83-84, 86, 89-91, $101,122,124,147,155^{-} 56,180$

Sini, Carlo, 79, 187

somathemes, 31, 93, 109, 110

sonic image, 7, 11, 67-68, 74-75, 77, 109, 119-20, 171

soundtrack, $11,35,42,47,60,67-68,74-76,108,167$,

$$
169,176-77
$$

Spivak, Gayatri Chakravorty, 54, 187

Stivale, Charles J., 155, 185, 187

Stockhausen, Karlheinz, 71, 114

Stravinsky, Igor, 17, 53, 164, 187

structuralism, 27, 55, 93

subjectivity, $7,34-35,48,57,94,122,126-28,132$,

$$
48-49,157-58,163-64
$$

Sylvester, Daniel, 33-34, 6o, 101, 104, 145, 162, 188

Tarasti, Eero, 17, 26, 52, 188

telos, $7,80,111,138,154,162$

theatre, $22,27-28,30,121-3 \mathrm{O}, 133,137,144-45,151$, 157,179

tradition, 11, 13, 16, 18-19, 24, 34, 109, 116, 121, 142, $156-57,165$

$\mathbf{U}$

Urtext, 14

Van Gogh, Vincent, 144

vectoriality, 69 , 112, 114, 152-54

vectors, 92, 96-100, 152-53, 169-71, 173

Vedova, Emilio, 13

Velásquez, Diego Rodríguez de Silva, 33, 104, 106

Venice Biennale, 133

Vicentino, Nicola, 29, 35, 47, 6o, 167-69, 188

virtual, 91, 132, 154, 166, 182

Visée, Robert de, 29, 84, 140, 167, 176, 188

visual arts, 17, 20-21, 28, 37, 58, 61, 101, 143, 179

W

Werktreue, 14

Wilde, Oscar, 122, 138 
Author

Lucia D’Errico

Production manager

Heike Vermeire

Managing editor

Edward Crooks

Series editor

William Brooks

Lay-out

Studio Luc Derycke

Cover design

Lucia D’Errico

Cover image

Lucia D’Errico

Typesetting

Friedemann bvba

(C) 2018 by Leuven University Press /

Universitaire Pers Leuven /

Presses Universitaires de Louvain.

Minderbroedersstraat 4

B-30oo Leuven (Belgium)

ISBN 9789462701397

e-ISBN 9789461662514

$\mathrm{D} / 2018 / 1869 / 18$

NUR: 663

The research leading to these results has received funding from the

European Union Seventh Framework

Programme ([FP $7 / 2007-2013]$

[FP7/2007-2011]) under grant agreement

$\mathrm{n}^{\circ} 313419$.
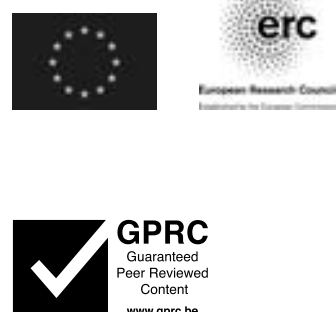

GPRC

Guaranted

Peer Review
Content
nat

This work is licensed under a Creative Commons Attribution-NonCommercialNoDerivatives 4.o International License (CC-BY-NC-ND). For more information, please visit creativecommons.org.

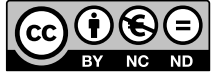

This book is published in the Orpheus Institute Series.

DOI https://doi.org/10.11116/9789461662514 
The Orpheus Institute Series encompasses monographs by fellows and associates of the Orpheus Institute, compilations of lectures and texts from seminars and study days, and edited volumes on topics arising from work at the institute. Research can be presented in digital media as well as printed texts. As a whole, the series is meant to enhance and advance discourse in the field of artistic research in music and to generate future work in this emerging and vital area of study.

\section{RECENT TITLES IN THIS SERIES:}

- Logic of Experimentation:

Rethinking Music Performance through Artistic Research

Paulo de Assis

2018, ISBN 978946270138 o

- Transpositions: Aesthetico-Epistemic Operators in Artistic Research

Michael Schwab (ed.)

2018, ISBN 978946270141 o

- Virtual Works-Actual Things: Essays in Music Ontology

Paulo de Assis (ed.)

2018, ISBN 9789462701403

- Experimental Encounters in Music and Beyond

Kathleen Coessens (ed.)

2017, ISBN 9789462701106

- Artistic Research in Music: Discipline and Resistance

Jonathan Impett (ed.)

2017, ISBN 9789462700901

- The Dark Precursor: Deleuze and Artistic Research

Paulo de Assis and Paolo Giudici (eds)

2017, ISBN 9789462701182

- Experimental Affinities in Music

Paulo de Assis (ed.)

2015, ISBN 9789462700611

O R P H E U S Orpheus Institute

$$
\begin{array}{ll}
\text { Instituet } & \text { Korte Meer } 12 \\
& \mathrm{~B}-9000 \text { Ghent } \\
& \text { Belgium } \\
& +32(0) 93304081 \\
& \text { www.orpheusinstituut.be }
\end{array}
$$


The Orpheus Institute has been providing postgraduate education for musicians since 1996 and introduced the first doctoral programme for music practitioners in Flanders (2004). Acting as an umbrella institution for Flanders, it is co-governed by the music and dramatic arts departments of all four Flemish colleges, which are strongly involved in its operation.

Throughout the Institute's various activities (seminars, conferences, workshops, and associated events) there is a clear focus on the development of a new research discipline in the arts, one that addresses questions and topics that are at the heart of musical practice, building on the unique expertise and perspectives of musicians and maintaining a constant dialogue with more established research disciplines.

Within this context, the Orpheus Institute launched an international Research Centre in 2007 that acts as a stable constituent within an ever-growing field of enquiry. The Orpheus Research Centre is a place where musical artists can fruitfully conduct individual and collaborative research on issues that are of concern to all involved in artistic practice. Its core mission is the development of a discipline-specific discourse in the field of artistic research in music. 

What does it mean to produce resemblance in the performance of written music? Starting from how this question is commonly answered by the practice of interpretation in Western notated art music, this book proposes a move beyond commonly accepted codes, conventions, and territories of music performance. Appropriating reflections from post-structural philosophy, visual arts, and semiotics, and crucially based upon an artistic research project with a strong creative and practical component, it proposes a new approach to music performance. This approach is based on divergence, on the difference produced by intensifying the chasm between the symbolic aspect of music notation and the irreducible materiality of performance. Instead of regarding performance as reiteration, reconstruction, and reproduction of past musical works, Powers of Divergence emphasises its potential for the emergence of the new and for the problematisation of the limits of musical semiotics.

Lucia D'Errico is a musician and artistic researcher. A research fellow at the Orpheus Institute (Ghent, Belgium), she has been part of the research project MusicExperiment21, exploring notions of experimentation in the performance of Western notated art music. She holds a PhD from KU Leuven (docARTES programme) and a master's degree in English literature, and is also active as a guitarist, graphic artist, and video performer.

"'Woe to those who do not have a problem,' Gilles Deleuze exhorts his audience during one of his seminars. And a 'problem' in this philosophical sense is not something to dispense with, a difficulty to resolve, an obstacle to eliminate; nor is it something one inherits ready-made. Just as a 'concept' in the paradigmatic repertoire of Deleuze's philosophy is a creation, a 'problem' must be invented; it needs to be developed, its strength measured by the force of the path it breaches across an already established field -reconstructing it, reorganising it. The principal virtue of Lucia D'Errico's book is that it constructs precisely such a problem."

-Zsuzsa Baross, Trent University Durham, CA

"An original and valuable contribution to the field of artistic research, integrating theory and practice and charting a clear pathway through the work of a great number of artists, philosophers, and composers by way of philosophy, art and media theory, semiotics, and musical composition."

-Edward Campbell, University of Aberdeen, UK

O R P H E U S

INSTITUUT

LeUven University PRess

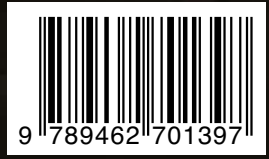

